\title{
A Critical Assessment on the Resources and Extraction of Rare Earth Elements from Acid Mine Drainage
}

Christopher R. Vass

crvass@mail.wvu.edu

Follow this and additional works at: https://researchrepository.wvu.edu/etd

Part of the Mining Engineering Commons

\section{Recommended Citation}

Vass, Christopher R., "A Critical Assessment on the Resources and Extraction of Rare Earth Elements from Acid Mine Drainage" (2019). Graduate Theses, Dissertations, and Problem Reports. 4046.

https://researchrepository.wvu.edu/etd/4046

This Dissertation is protected by copyright and/or related rights. It has been brought to you by the The Research Repository @ WVU with permission from the rights-holder(s). You are free to use this Dissertation in any way that is permitted by the copyright and related rights legislation that applies to your use. For other uses you must obtain permission from the rights-holder(s) directly, unless additional rights are indicated by a Creative Commons license in the record and/ or on the work itself. This Dissertation has been accepted for inclusion in WVU Graduate Theses, Dissertations, and Problem Reports collection by an authorized administrator of The Research Repository @ WVU.

For more information, please contact researchrepository@mail.wvu.edu. 


\title{
A Critical Assessment on the Resources and Extraction of Rare Earth Elements from Acid Mine Drainage
}

\author{
Christopher R. Vass \\ Dissertation submitted \\ to the Benjamin M. Statler College of Engineering and Mineral Resources \\ at West Virginia University \\ in partial fulfillment of the requirements for the degree of \\ Doctor of Philosophy in Mining Engineering
}

\author{
Aaron Noble, Ph.D., Chair \\ Mark Sindelar, Ph.D. \\ Qingqing Huang. Ph.D. \\ Xingbo Liu, Ph.D. \\ Paul Ziemkiewicz, Ph.D. \\ Department of Mining Engineering
}

Morgantown, West Virginia

2019

Keywords: Acid Mine Drainage, Rare Earth Elements, AMD, Solvent Extraction, Acid Leaching

Copyright 2019 Christopher R. Vass 


\begin{abstract}
A Critical Assessment on the Resources and Extraction of Rare Earth Elements from Acid Mine Drainage
\end{abstract}

Christopher R. Vass

Rare earth elements (REEs) are crucial to many modern products used in both civilian and defense applications. Currently, a reliable supply of these elements is uncertain with the clear majority of REE production and refining occurring predominately in China. Furthermore, domestic ore deposits with commercially attractive concentrations of REEs are uncommon in the United States. As a result, the identification of a domestic supply of these technology metals is essential not only for manufacturing consumer merchandise but also for national security.

Recently, one promising source of REEs has been identified: coal and coal-byproducts. One of those is acid mine drainage (AMD), the most prevalent water quality impediment in the Appalachian coal mining region. This research found that AMD concentrates REEs through an autogenous process where the presence of sulfide material in an oxidizing environment results in a general lowering of water $\mathrm{pH}$. This acidic water in turn leaches metals, including REEs, from the surrounding geologic strata. Accordingly, this degraded water holds potential value as a REE source. Furthermore, identification of this environmental burden as a reliable supply of REEs could incentivize additional treatment efforts, while providing an additional revenue stream to those responsible for mitigating this substantial source of water pollution. However, current scientific literature lacks systemic studies that describe the content, distribution, and processing amenability of this resource.

Therefore, this research details a study that: (1) characterized the REEs contained in AMD and its byproducts; (2) classified the REEs inherent to AMD and identified the size of the resource; (3) designed a process to recover REEs from AMD byproducts; and (4) demonstrated the feasibility of the beneficiation process by generating a concentrated REE product from AMD. This was accomplished by conducting a broad sampling campaign where 185 raw AMD and 623 AMD precipitate (AMDp) samples were collected across the Northern and Central Appalachian coal basins. Next, a series of laboratory experiments were conducted to determine a hydrometallurgical processing route to recover the REEs from AMDp. The results of the laboratory-scale studies were utilized to design a bench-scale plant capable of producing a concentrated REE product. Finally, an acid leaching and solvent extraction demonstration plant was constructed and operated which produced a rare earth oxide product with a purity greater than $60 \%$. 


\section{ACKNOWLEDGMENTS}

I would first like to express my sincere gratitude to my committee chair, Dr. Aaron Noble, for his expert guidance, understanding, support, and encouragement. Dr. Nobles charisma, wisdom, and astute analytical reasoning have guided me throughout graduate school. I will be eternally grateful for everything you have taught me.

Next, I would like to thank my committee members Dr. Paul Ziemkiewicz, Dr. Qingqing Huang, Dr. Mark Sindelar, and Dr. Xingbo Liu for their time, advice, and insightful comments. They have provided a wealth of knowledge and steadfast guidance, which I will never forget.

I am very appreciative to all the members of the ETD 30, 39, and 50 team members. Their hard work and painstaking effort helped to make these projects successful.

Finally, I would like to thank my father Casey. Dad has taught me the value of a sturdy work ethic and provided an example of the achievements that are possible given enough determination and hard work.

This dissertation is based upon work supported by the U.S. Department of Energy under Award Numbers DE-FE0026927 and DE-FE0026444. 


\section{Contents}

1 Background 1

1.1 Introduction . . . . . . . . . . . . . . . . . . 1

1.2 Rare Earth Elements . . . . . . . . . . . . . . . . . . . . . . . 2

1.2.1 Applications for REEs . . . . . . . . . . . . . . 3

1.2.2 Production of REEs . . . . . . . . . . . . . . . 3

1.2.3 Strategic Importance . . . . . . . . . . . . . . . . . 5

1.3 Origins of REEs in Coal and Coal Byproducts . . . . . . . . . . . . 6

1.4 Acid Mine Drainage . . . . . . . . . . . . . . . . . . 9

1.4.1 Effects of AMD on the Environment . . . . . . . . . . . 12

1.5 Treatment of AMD . . . . . . . . . . . . . . . . . . 12

1.5.1 Passive AMD Treatment . . . . . . . . . . . . . 13

1.5.2 Active AMD Treatment .................. 14

Chemical Treatment . . . . . . . . . . . . . . 14

1.6 Rare Earth Element Extraction . . . . . . . . . . . . . . . . . . . . . 15

1.6.1 REE Processing Routes .................. 16

Leaching . . . . . . . . . . . . . . . . . . . 18

Solvent Extraction . . . . . . . . . . . . . . . 19

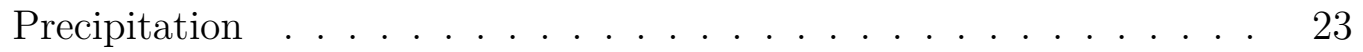

1.7 Summary . . . . . . . . . . . . . . . . . . . . 24

1.8 Research Objectives . . . . . . . . . . . . . . . . . . . 25

1.9 Dissertation Outline . . . . . . . . . . . . . . . 25

2 Prospectivity of Rare Earth Elements - Northern Appalachian Basin 26 
3.1 Introduction . . . . . . . . . . . . . . . . . . . . . . . 41

3.2 Materials and Methods . . . . . . . . . . . . . . . . . . . 44

3.2 .1 Overall Experimental Objectives and Approach . . . . . . . . . . 44

3.2 .2 Site Selection and Sampling Locations . . . . . . . . . . . . . . 44

3.2 .3 Site Sampling Protocols _ . . . . . . . . . . . . . . . . . . . 45

3.2.4 Sample Analysis and Characterization . . . . . . . . . . . . 47

3.2 .5 Data Analysis and Modeling . . . . . . . . . . . . . . . . 47

3.3 Results and Discussion . . . . . . . . . . . . . . . . . . . . 49

3.3.1 Concentration of REEs in AMD . . . . . . . . . . . . . . . . 49

3.3 .2 AMD Modeling and Analysis _ . . . . . . . . . . . . . 52

3.3.3 Concentration of REEs in AMDp . . . . . . . . . . . . . 55

3.3 .4 Resource Assessment . . . . . . . . . . . . . . . . . . . 58

3.3.5 Resource Outlook and Criticality . . . . . . . . . . . . . . 63

3.4 Conclusions . . . . . . . . . . . . . . . . . . . . . . 64

4 Bench-Scale System Design $\quad 73$

4.1 Introduction . . . . . . . . . . . . . . . . . . 73

4.2 Process Overview . . . . . . . . . . . . . . . . . . . . 75

4.3 Leaching and Precipitation . . . . . . . . . . . . 75

4.3 .1 Parametric Leaching Studies . . . . . . . . . . . . . . . 77

Feedstock Characterization . . . . . . . . . . . . . . 79

Effect of Acid Type . . . . . . . . . . . . . . . . . . 81

Kinetic Effects of Leaching _ . . . . . . . . . . . . . 82

Effect of Leaching $\mathrm{pH}$ Value . . . . . . . . . . . . . . . 83

Sensitivity of Results to Moisture Measurement . . . . . . . . . 84

Results and Discussion . . . . . . . . . . . . . . 86

4.4 Laboratory-Scale Solvent Extraction _. . . . . . . . . . . . . . 87

4.5 Design Approach and Commissioning . . . . . . . . . . . . . . 87

4.5 .1 Design Objectives . . . . . . . . . . . . . . . . . . . . 87 
4.5.2 Design Constraints and Criteria . . . . . . . . . . . . . 88

4.5 .3 Design Assumptions . . . . . . . . . . . . . . . . . . . . . 90

4.6 System Design . . . . . . . . . . . . . . . . . . . . . . . . . . . 91

4.6 .1 Overall Design Approach . . . . . . . . . . . . . . . . . . . . 91

$4.6 .2 \quad$ Design Flowsheet . . . . . . . . . . . . . . . . . . . . . . . 92

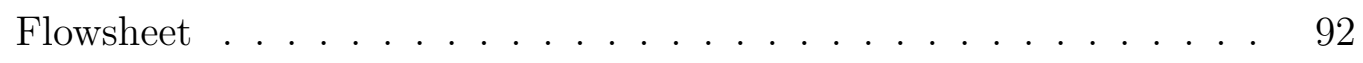

4.6 .3 Design Table . . . . . . . . . . . . . . . . . . . . . 97

4.6 .4 Piping and Instrumentation $\ldots \ldots \ldots$

4.7 Facility Layout . . . . . . . . . . . . . . . . . . . 100

4.8 Testing Plan for the Bench-Scale System . . . . . . . . . . . . . . . 100

4.9 Summary . . . . . . . . . . . . . . . . . . . . . 103

5 Bench-Scale Plant Operation $\quad 104$

5.1 Introduction . . . . . . . . . . . . . . . . . . . . . . . 104

5.2 Feedstock Acquisition and Material Handling . . . . . . . . . . . . . . 105

5.3 Acid Leaching Module . . . . . . . . . . . . . . . . . . . . . 107

5.3.1 Acid Leaching Shakedown Testing . . . . . . . . . . . . . . . 107

Gel Formation of PLS . . . . . . . . . . . . . . . 108

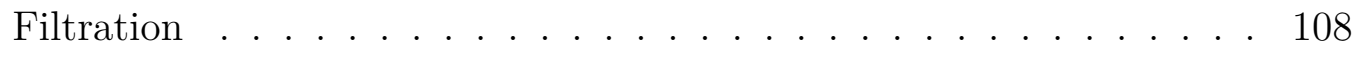

5.3 .2 Acid Leaching Procedure and Results . . . . . . . . . . . . . . 111

5.4 Solvent Extraction Module . . . . . . . . . . . . . . . . . . . . . . . . 114

5.4.1 Solvent Extraction Shakedown Testing . . . . . . . . . . . . . 115

Third-Phase Crud Formation . . . . . . . . . . . . . . 116

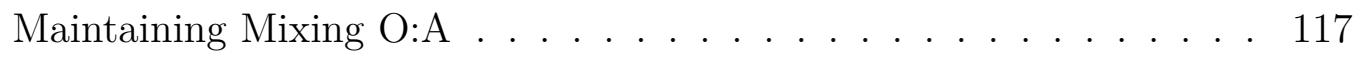

Organic Loss During Saponification . . . . . . . . . . . . . . 119

5.4 .2 SX Procedure and Results . . . . . . . . . . . . . . . . . . . . . . . 119

5.5 Precipitation Module . . . . . . . . . . . . . . . . 126

5.5.1 Precipitation Procedure . . . . . . . . . . . . . . . . . 127

5.6 Solid Waste Stream Characterization . . . . . . . . . . . . . . 130

5.7 Summary . . . . . . . . . . . . . . . . . . . . . . . 133 
6 Summary and Conclusions 135

6.1 Summary . . . . . . . . . . . . . . . . . . . . 135

6.2 Conclusions . . . . . . . . . . . . . . . . . . . . . 138

6.3 Future Work . . . . . . . . . . . . . . . . . . . . . . . . 138

$\begin{array}{lr}\text { Appendix A } & 153\end{array}$

$\begin{array}{lr}\text { Appendix B } & 157\end{array}$

$\begin{array}{lr}\text { Appendix C } & 161\end{array}$ 


\section{List of Figures}

1.1 United States and worlds REE production over the last sixty years after USGS

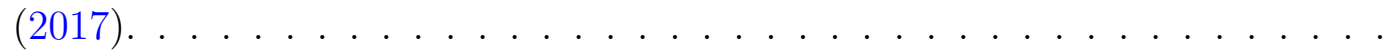

1.2 Distribution of REEs in NAPP raw AMD water after Crovotta (2008b) and Stewart (2016) . . . . . . . . . . . . . . . . . . . . 9

1.3 Streams with orange staining from the iron oxide precipitate "yellow boy." . 11

1.4 Small clarifier used for treatment of AMD. The foreground shows the area where alkaline material and aeration is used to raise the $\mathrm{pH}$. The clarifier structure is located in the middle while the lime storage silo is located in the background. . . . . . . . . . . . . . . . . . . 15

1.5 Schematic drawing of mixer settler with the capability to recirculate the two liquid phases. . . . . . . . . . . . . . . . . 20

1.6 Block flow diagram showing major processes of solvent extraction operations. 20

3.1 County-level map showing number of AMD sites sampled per county and Northern vs. Central Appalachian boundary . . . . . . . . . . . . . . 45

3.2 Distribution of total REEs in NAPP and CAPP raw AMD samples . . . . 51

3.3 Chondrite normalized REE distribution in raw AMD; with Chondrite normalization after Korotev $[41] \ldots \ldots \ldots$

3.4 Total REE concentration in AMD as a function of outflow rate . . . . . . 53

3.5 Relationship between $\mathrm{pH}$ of raw AMD and the concentration of TREE in the

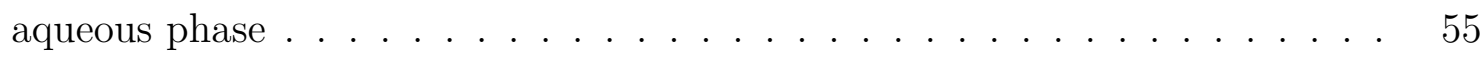

3.6 Results of a multiple linear regression predicting TREE concentrations raw AMD using $\mathrm{pH}$ and major metal concentrations . . . . . . . . . . 56

3.7 Distribution of total REEs in NAPP and CAPP AMDp samples . . . . . . 58 
3.8 Chondrite normalized REE distribution in AMDp; with Chondrite normalization after Korotev $[41] \ldots \ldots \ldots$. . . . . . . . . . . . . 59

3.9 Distribution of REEs between the NAPP and CAPP basins . . . . . . . 60

3.10 Grade-tonnage curves indicating resource mass and average grade given a processing cut-off level . . . . . . . . . . . . . . . . . 62

3.11 Indication of total REE resource available based on an aqueous REE grade . 63

3.12 Arrangement of AMDp in relation to conventional REE deposits based on the outlook coefficient after Seredin and Dai $[7] \ldots \ldots . \ldots . \ldots . . . . . . .65$

4.1 Simplified process flow diagram . . . . . . . . . . . . . . . 75

4.2 Leaching study results for DLM feedstock subjected to $\mathrm{H}_{2} \mathrm{SO}_{4}$ acid. . . . . . 77

4.3 Leaching set up and filtration manifold used for parametric testing. . . . . . 79

4.4 Distribution of major metals within the selected feedstocks. . . . . . . . . . 80

4.5 Distribution of REEs between AMD precipitates from tested sites. . . . . . . 81

4.6 Total REE elemental recovery versus time for parametric leaching experiments. 82

4.7 Total REE elemental recovery versus leach $\mathrm{pH}$ for parametric leaching experiments. . . . . . . . . . . . . . . . . . . . . 85

4.8 Agitated leach tank . . . . . . . . . . . . . . . . . . . 93

4.9 Example of ten stage mixer-settler frame. . . . . . . . . . . . . . 96

5.1 Various pictures from collection of AMDp feedstock. . . . . . . . . . . . 106

5.255 -gallon drums stored at the ALSX facility. . . . . . . . . . . . 106

5.3 Acid leaching module of bench-scale plant . . . . . . . . . . . . . 107

5.4 PLS gel formation on pan filter at $\mathrm{pH}$ 3.0. . . . . . . . . . . . . . . . 109

5.5 Lab-scale 150mm filter press (left) and 420-mm filter press (right). . . . . . . 110

5.6 PLS after filtration in the plate and frame filter and filter cake from clean-out of the 2 cubic-foot filter press. . . . . . . . . . . . . . . 110

5.7 Acid leaching process flow diagram showing PLS generation procedure. . . . 112

5.8 Overview of solvent extraction module . . . . . . . . . . . . . . . . . 115

5.9 Crud formation in an extraction settler during DLM shakedown testing. . . . 117

5.10 Process flow diagram for the solvent extraction module . . . . . . . . . . 123 
5.11 Major Ions and REE concentrations in the extractant raffinate. . . . . . . . 124

5.12 Major Ions and REE concentrations in scrubbing raffinate . . . . . . . . . 124

5.13 Major ions and REE concentration in stripping raffinate. . . . . . . . . . 125

5.14 Major ions and REE concentrations in the saponification raffinate. . . . . . 126

5.15 Precipitation module used to recover REEs from stripped raffinate. . . . . . 127

5.16 Precipitation process diagram . . . . . . . . . . . . . . . . 128

5.17 MREO product with $61.8 \%$ grade . . . . . . . . . . . . . 130 


\section{List of Tables}

1.1 Summary of the uses of REEs their primary applications, critical status and market condition after Binnemans (2018) and Haque (2014). . . . . . . . 4

1.2 Extractants used in the SX process and their common names after Ritcey (1984).

3.1 AMD sites and sampling quantities by basin. Note some sites contained multiple AMDp storage cells serving a given AMD discharge point. (CAPP, $\mathrm{NAPP}=$ Central and Northern Appalachian Coal Basins respectively). . . . . 45

3.2 REE concentrations for raw aqueous AMD influent in Appalachian basin study 50

3.3 REE concentrations for AMDp at 141 sites across the CAPP and NAPP basins 57

3.4 AMDp and TREE resources by coal basin . . . . . . . . . . . . 60

3.5 Implication of cut-off grade on processable AMDp and TREEs . . . . . . . 61

4.1 ICP-MS analysis of the three AMDp feedstocks. . . . . . . . . . . 76

4.2 Experimental parameters for parametric leaching tests $\ldots \ldots \ldots 78$

4.3 Results of solvent extraction laboratory-scale tests for the DLM feedstock after $($ Ren and Liu 2019) _ . . . . . . . . . . . . . . . . 87

4.4 Technical and economic considerations influencing scale-up of the bench-scale system . . . . . . . . . . . . . . . . . . . . . . . . . . . . 89

4.5 Master design table . . . . . . . . . . . . . . . . . . . . 98

4.6 Proposed parameters used for technical success factors _ . . . . . . . . . 102

4.7 Proposed economic success factors for bench-scale SX plant. . . . . . . . . . 103

5.1 Royal Scot acid leaching parameters used to create PLS. . . . . . . . . . . 113

5.2 Royal Scot acid leaching assay and mass balance. . . . . . . . . . . . . . 113 
5.3 Comparison of PLS from the three feedstocks. . . . . . . . . . . . . 118

5.4 Solvent extraction circuit parameters used during baseline testing. . . . . . 121

5.5 Initial Royal Scot strip solution, oxalate precipitation, and mass balance steps. 129

5.6 Assay of precipitation cleaning process . . . . . . . . . . . . . . 131

5.7 TCLP testing on AMDp filter cake after leaching. . . . . . . . . . . . . 133 


\section{Nomenclature}

$\begin{array}{ll}\text { ALSX } & \text { Acid Leaching - Solvent Extraction } \\ \text { AMD } & \text { Acid Mine Drainage } \\ \text { AMDp } & \text { Acid Mine Drainage Percipitates } \\ \text { BCOD } & \text { Baseline Case Operational Decision } \\ \text { CAPP } & \text { Central Appalachian } \\ \text { CREE } & \text { Critical Rare Earth Elements } \\ \text { HREE } & \text { Heavy Rare Earth Elements } \\ \text { ICP-MS } & \text { Inductively Coupled Plasms Mass Spectrometry } \\ \text { ICP-OES } & \text { Inductively Coupled Plasma - Optical Emission Spectrometry } \\ \text { LOC } & \text { Limiting Organic Concentration } \\ \text { LREE } & \text { Light Rare Earth Elements } \\ \text { NAPP } & \text { Northern Appalachia } \\ \text { NPDES } & \text { National Pollution Discharge Elimination System } \\ \text { P\&ID } & \text { Piping and Instrumentation Drawing } \\ \text { PDD } & \text { Permenant Design Decision } \\ & \text { xiii }\end{array}$


ppm

REEs

REO

SEM

SX

TREE

TRL
Parts Per Million

Rare Earth Elements

Rare Earth Oxides

Scanning Electron Microscope

Solvent Extraction

Total Rare Earth Elements

Technology Readiness Level 


\section{Chapter 1}

\section{Background}

\section{$1.1 \quad$ Introduction}

The rare earth elements (REEs) consist of seventeen elements that include the lanthanide series, scandium, and yttrium. While promethium (Pm) is a member of the lanthanides it is not readily found in the natural environment as it has no stable isotopes; for this reason is it commonly disregarded in literature. Also, these elements were awkwardly named so because they were initially discovered in the form of oxides within relatively rare minerals (Moeller 1963). As a result, the presence of "rare" in the name commonly leads to the assumption that the occurance of these minerals is uncommon; when in fact, many of the REEs are more abundant than other commonly used elements on a crustal basis. For example, research by Taylor (1964), indicates that commonly used elements like Fe (5.63 ppm) and $\mathrm{Al}$ (8.23 ppm) are found in much lower crustal concentrations than the REEs La (30 ppm), Nd (28 ppm), and Y (33 ppm).

Additionally, rare earth elements can hold various classifications based on organization or author. For this research, the following classifications will be used:

- Heavy REEs (HREE) - Sc, Y, Gd, Tb, Dy, Ho, Er, Tm, Yb, Lu

- Light REEs (LREE) - La, Ce, Pr, Nd, Sm, Eu 
- Total REEs (TREE) - HREE + LREE

- Critical REEs (CREE) - Y, Nd, Eu, Tb, Dy

Historically, the REE industry has sought deposits where natural hydro-thermal processes resulted in commercially attractive REE concentrations. These deposits are extremely uncommon, particularly in the United States. As a result, the current research seeks to capitalize on an autogenous process occurring as a byproduct of coal mining, which concentrates REEs. Prior data has shown that elevated REE concentrations exist in the low $\mathrm{pH}$ influent to AMD treatment systems. However, REEs were nearly absent in the respective discharge water. This mass reduction indicates that REEs precipitate with other metals in the form of metal hydroxides. Following this observation, an initial prospecting campaign and later detailed sampling campaign were undertaken to directly measure the REE concentration in AMD precipitates. This sampling effort showed the REE concentrations are significantly higher in the AMD precipitates (AMDp) than that of the associated bulk Northern Appalachian (NAPP) coal material.

Finally, efficient processing routes for the REEs have been established for traditional ores since 1950. These processes typically rely on energy intensive comminution and high temperature leaching methods. As a result, these traditional hydrometallurgical processes often make the beneficiation of REEs from traditional ores economically prohibitive. Fortunately, AMDp does not rely on the more costly processing routes and has the potential to provide a lower cost REE feedstock for the current market.

\section{$1.2 \quad$ Rare Earth Elements}

Rare earth elements occur in a wide variety of geologic formations. However, these occurrences rarely meet the necessary minimum cut-off limits to facilitate profitable extraction and refining. When REE concentrations do exceed the required cut-off grade for mining, there are often detrimental environmental consequences because the byproducts from processing often contain high concentrations of uranium and thorium (Fernandez 2017). Consequently, 
more than $90 \%$ of REE production occurs in one country, China (2017). This near-monopoly creates a potential disadvantage for the United States in regard to a dependable supply chain of these strategically important elements.

Currently, the United States consumes approximately 12,000 metric tons of REEs per year (U.S. Geological Survey 2018). Of that, the Department of Defense uses less than five percent, or approximately 600 metric tons (Humphries 2012). Future demand for the REEs are difficult to predict due the number of elements involved and variety of uses. However, given the increasing forecast for "green technologies", such as batteries for electric cars, magnets for windmill turbines, and electronic devices it would be logical to conclude that demand for REEs will also increase (Campbell 2014; Goodenough, Wall, and Merriman 2017).

\subsubsection{Applications for REEs}

Many industrial processes rely on REEs for their products including: catalysts, metallurgy, petroleum refinement, catalytic converters, ceramics, phosphors, magnets, and electronics (Alonso et al. 2012). Table 1.1 is a non-exhaustive list itemizing several of the major uses for each of the rare earth elements. More importantly, is the understanding that each of these applications requires a different grade and distribution of the REEs to meet product specifications (Long et al. 2010). In other words, the REEs are not a single product but differ in quality and quantity based on their host mineral (Jordens, Cheng, and Waters 2013).

\subsubsection{Production of REEs}

Overall, worldwide production and use of REEs has generally increased year over year. One significant deviation from this trend was observed during the 2009 to 2012 time-period as shown in Figure 1.1. During this time, material shortages caused by restrictive Chinese quotas and high prices adversely affected the supply of REEs. Additionally, beginning in the early 1980s the world production of REEs started to outpace the capacity of U.S. production. Likewise, as new production was brought online from China, lower realized prices ultimately 
Table 1.1 - Summary of the uses of REEs their primary applications, critical status and market condition after Binnemans (2018) and Haque (2014).

\begin{tabular}{|c|c|c|c|c|}
\hline Element & Symbol & Applications & $\begin{array}{l}\text { Critical } \\
\text { REE }\end{array}$ & $\begin{array}{l}2014-2018 \\
\text { Market } \\
\text { Balance }\end{array}$ \\
\hline Scandium & $\mathrm{Sc}$ & Aluminum alloys, defense industry & No & $\begin{array}{l}\text { Possible large } \\
\text { supply from } \\
\text { bauxite residue }\end{array}$ \\
\hline Yttrium & $\mathrm{Y}$ & $\begin{array}{l}\text { Red lamp phosphor, yttria-stabalized } \\
\text { zirconium, ceramics, florescent lamps }\end{array}$ & Yes & $\begin{array}{l}\text { In balance but } \\
\text { could potential } \\
\text { for oversupply }\end{array}$ \\
\hline Lanthanum & $\mathrm{La}$ & $\begin{array}{l}\text { NiMH batteries, optical glass, green lamp } \\
\text { phosphor, catalysts, mischmetal, carbon arc } \\
\text { lamps, hybrid engines }\end{array}$ & No & Oversupply \\
\hline Cerium & $\mathrm{Ce}$ & $\begin{array}{l}\text { Polishing compound, decolorization agent, } \\
\text { Ce-doped glass, catalyst, mischmetal, } \\
\text { petroleum refining }\end{array}$ & No & Oversupply \\
\hline Praseodymium & $\operatorname{Pr}$ & $\begin{array}{l}\text { Green colorant for glass, ceramic pigment, } \\
\text { magnets, optical fibers }\end{array}$ & No & In balance \\
\hline Neodymium & $\mathrm{Nd}$ & $\begin{array}{l}\text { Nd-Fe-B permanent magnets, petroleum } \\
\text { refining, hybrid engines }\end{array}$ & Yes & In balance \\
\hline Samarium & $\mathrm{Sm}$ & Sm-Co permanent magnets, glass additive & No & In balance \\
\hline Europium & $\mathrm{Eu}$ & Y2O3:Eu3+ lamp phosphor & Yes & $\begin{array}{l}\text { Slight } \\
\text { oversupply }\end{array}$ \\
\hline Gadolinium & Gd & $\begin{array}{l}\text { Contrast agents magnetic resonance } \\
\text { imaging (MRI), additive in some Nd } \\
\text { magnets, green lamp phosphor }\end{array}$ & No & In balance \\
\hline Terbium & $\mathrm{Tb}$ & Green lamp phosphor, magnets & Yes & In balance \\
\hline Dysprosium & Dy & Additive in $\mathrm{Nd}$ magnets, hybrid engines, & Yes & In balance \\
\hline Holmium & Ho & Glass additive, lasers & No & In balance \\
\hline Erbium & Er & $\begin{array}{l}\text { red and green phosphors, optical fibers, } \\
\text { sunglasses }\end{array}$ & No & In balance \\
\hline Thulium & $\mathrm{Th}$ & Medical X-Ray units & No & In balance \\
\hline Ytterbium & $\mathrm{Yb}$ & Phosphors, florescent lamps, ceramics & No & In balance \\
\hline Lutetium & $\mathrm{Lu}$ & $\begin{array}{l}\text { Scintillator phosphors in PET medical } \\
\text { scanners }\end{array}$ & No & In balance \\
\hline
\end{tabular}

led to the closure of U.S. based production facilities. For example, the United States market share decreased from $31 \%$ in 1985 to $6 \%$ in 2000 (Fernandez 2017). 


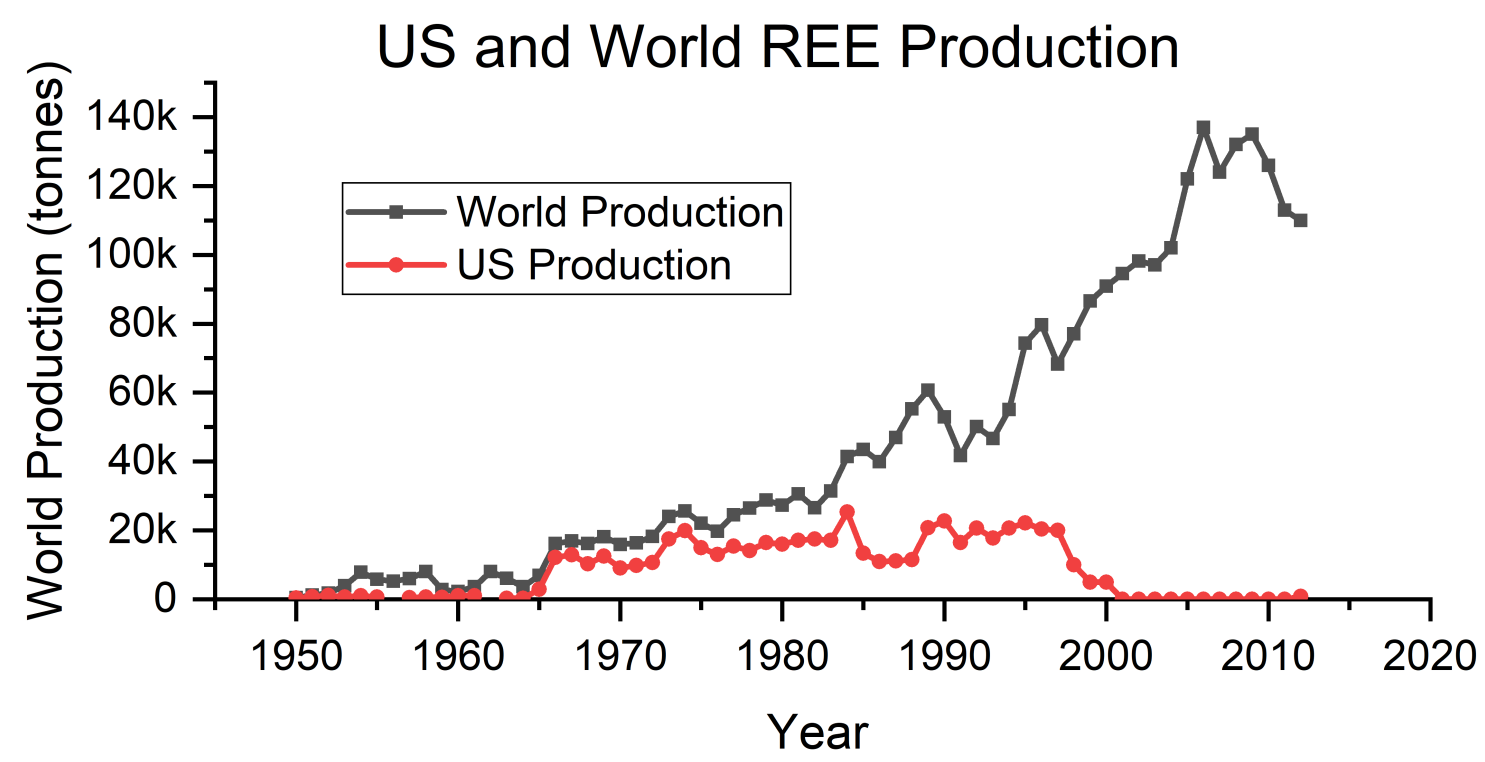

Figure 1.1 - United States and worlds REE production over the last sixty years after USGS (2017).

To this end, United States production of rare earths was drastically reduced in the 1990s as a result of two main factors. First, increased regulatory scrutiny and environmental compliance detrimentally affected the parent corporation of the only U.S. producing REE mine (Ali 2014). These issues originated from the radioactive tailings created by processing the actinide laden bastnasite ore. Second, increased operating costs placed the lone U.S. mine, Mountain Pass, at a disadvantage when competing against Chinese operations with much lower operating costs. Since the closure, the mine has tried to reopen; however, the parent company, Molycorp, was forced into bankruptcy in 2015 (Phadke 2018). More recently, the Moutain Pass mine reopened in 2018 under new ownership and as of 2019 is producing a bastnasite concentrate (Van Gosen, Verplanck, and Emsbo 2019). However, as noted by Seredin and Dai (2012) production from this type of deposit will likely only satisfy the demand for LREEs (Laudal et al. 2019).

\subsubsection{Strategic Importance}

The REEs are not interchangeable and each have their own market requirements. Additionally, the classification of REEs as critical minerals by the United States has brought an increased interest in creating a domestic REE supply. Military use of REEs on a large scale 
are essential for the production of aircraft, submarines, and destroyers (Mulller, Schweizer, and Seiler 2016). More specifically, the military utilizes REEs for fin actuators in missile guidance, disk drive motors used in military vehicles and command centers, lasers for underwater mine detection, satellite communication, radar, sonar, and optical equipment(Grasso 2013). Therefore, any disturbance to the availability of these materials would adversely impact the national security of the United States.

\subsection{Origins of REEs in Coal and Coal Byproducts}

The presence of REEs in coal has long been established by many researchers. One of the earliest references to the occurrence of REEs in coal was published by Goldschmidt (1935) that found REEs are concentrated in coal ash products. Furthermore, it was proposed that REEs were concentrated during the formation of coals from their parent material. Alternatively, it was later proposed that increased scandium concentrations in Australian coals was the result of adsorption from solutions that originated in source geology (Swaine 1964). These two alternate theories have historically been investigated extensively by multiple researchers.

In 1964, Schofield et al. (1964) evaluated eight different terrestrial materials for the relative abundance of REEs. Within these eight materials were two samples of coal, one from western Pennsylvania and one from southern Illinois. Results of this research indicated that REEs existed in these two coal samples at a concentration of $35 \mathrm{mg} / \mathrm{kg}$ each. In regard to the mechanisms of enrichment, Schofield concluded that plant material is primarily responsible for the REEs contained in coals, supporting the findings of Goldschmidt. Furthermore, Haskin (1966) extensively reviewed the occurrence of REEs in coal and other materials. From this research it was determined that little is understood about the occurrence of REEs in coal and that the plant material from which coal is generated is a probable source.

Finkleman and Stanton (1978) explored the occurrence of accessory minerals in Waynseburg coals. This research indicated that the increased REE content in coal is directly attributed to the mineral inclusions in the coal seam. Allanite, monazite, and xenotime were all observed with the aid of a scanning electron microscope (SEM). Therefore, elevated REE concentra- 
tions were attributed to the deposition of these minerals in the coal swamps. Again, in 1980, Finlkeman further confirmed the presence of REEs in coal material. These REEs were found to occur in phosphates, monazite, and xenotime (Finkelman 1980). Additionally, Finkleman showed that the REE distributions in the Waynesburg and Freeport seams were similar to those of the surrounding shale beds with the exception of two elements, lanthanum and europium. The depletion of europium was attributed to a reduction of the element to the plus two valence state while the cause of lanthanum enrichment of was inconclusive.

Similarly, Eskenazy (1987) explored the occurrence of REEs in Bulgarian coal. Like Finkleman, the chondrite normalized distributions of REEs showed a depletion of Eu which is likely attributed to a reduction mechanism as the coal is developed in a peat bog environment. Additionally, Eskenazy showed that the REE content in coals was positively correlated to the ash content. More importantly, this research indicated that coals were more enriched in the HREEs. Of particular note was the enrichment of Lu. This upgrade appeared excessive and alternative research indicated the high values were later questioned by the original author (Birk and White 1990).

Further research surveyed the content of REE in coal from Nova Scotia using both SEM and inductively coupled plasma mass spectrometry (ICP-MS) (Birk and White 1991). In addition to coal, the surrounding roof and floor materials were also evaluated. Results from this research indicated that the roof and floor clay contained the same order of magnitude of REEs as the surrounding coal ash. More significant findings from this research indicated that coal seams in the Sydney coalfield could not be characterized by a single distribution pattern. Additionally, Birk concluded that clay-sized phosphates were the cause of local REE enrichment.

Seredin (1996) explored the occurrence of REEs in eastern Russian coals. Notably, some of these seams contained high concentrations of REEs, varying from $300-1000$ ppm. This research was able to categorize coals and the modes of REE occurrence based on the REE concentrations. In the enriched coal seams, the REEs mainly occurred as fine grained authigenic minerals. Conversely, in coals with more moderate concentrations, the REEs were contained in the REE bearing minerals, as observed by Finkleman (1978). Moreover, Seredin's 
research indicated that the moderately concentrated REE coals tended to posess a positive correlation between ash and REE content as shown by others (Eskenazy 1987), while the highly enriched coals did not exhibit the same correlation.

Schatzel and Stewart (2003) further explored the nature of occurrence between coal and REEs. This research concluded that the mineral matter in Lower Kittanning coals originated from clastic material that was similar in nature to the surrounding shale beds. Furthermore, it was found that while the mineral matter in coal contained a significant portion of the REE distribution, the coal also carried increased concentrations of the HREEs that was not indicative of the surrounding shale materials. This indicated that multiple processes controlled the REEs incorporated in the coal seam.

Recently, Huang et al. (2019) characterized REEs in coals from various Colombian coal fields. This research showed that the average abundance of REEs in the Colombian coals was $45 \mathrm{ppm}$ within the coal and $222 \mathrm{ppm}$ for the associated non-coal lithologies. In addition, Huang et al. showed that a strong positive correlation between the REE content and coal ash content, indicating the REEs were predominantly associated with the mineral fraction of the coal seam. Furthermore, it was shown that the HREE/LREE ratio typically decreased with an increase in the ash yield pointing to an increased presence of HREEs in the organic mineral matrices.

Given the presence of REEs in coal and coal-ash, it was logical to survey other coal products for REEs. Previously, several researchers have looked at ways of generating value from metals contained in AMD (Cheney and Swinehart 1998; Hedin 2002). In that manner, Cravotta (2008a) analyzed the dissolved trace metals in AMD and its byproducts from multiple sites in Pennsylvania. This research showed that significant concentrations of REEs were observed in AMD waters and more so in the precipitates; indicating that REEs were concentrated in the AMD precipitates after treatment. Further research by Ziemkiewicz et al. (2016) demonstrated the presence of REEs in AMD and Stewart (2016) confirmed this finding with additional research that evaluated eighteen raw AMD discharges and twenty-two AMDp samples in the NAPP region. Consequentially, the researchers were able to estimate that a potential resource of 538 tonnes per year of REEs were generated in the Appalachian region. 


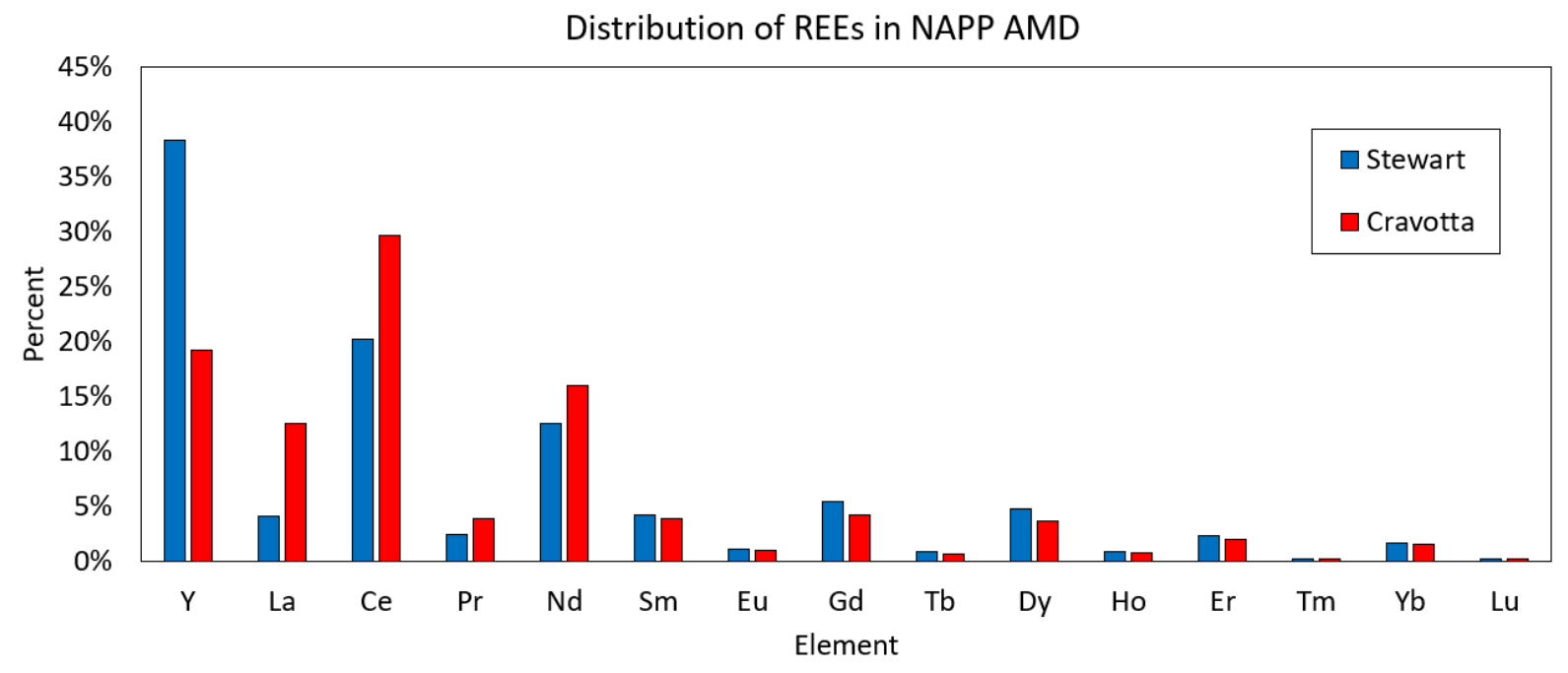

Figure 1.2 - Distribution of REEs in NAPP raw AMD water after Crovotta (2008b) and Stewart (2016).

Finally, Figure 1.2 shows the approximate REE distribution for raw water in the Central Appalachian (CAPP) and NAPP basins according to Cravotta and Stewart.

\subsection{Acid Mine Drainage}

In Appalachia, AMD constitutes one of the most significant and widespread water quality challenges that must be treated per National Pollution Discharge and Elimination (NPDES) guidelines, as defined by the Clean Water Act (Gaba 2007). AMD forms from a general lowering of water $\mathrm{pH}$ that occurs when sulfide minerals are exposed o oxidizing conditions through the mining process. This liberation increases the quantity of exposed sulfide mineral surface area leading to an elevated reaction rate. For example, blasting operations liberate these minerals and increase the contact area resulting in enhanced exposure to the oxidizing agents air and water. Likewise, underground mining operations create voids that fill with air and water, which increases reaction rates at the hydraulic perimeter of the openings. In undisturbed deposits, generation of acidic material is minimal and is a function of natural erosion via weathering. Given the slow generation rate, this minimal release from in-situ deposits does not cause irreparable harm to the subsequent receiving streams. The mining conditions responsible for the generation of AMD prompted substantial research over the last 
40 years, with investigators studying various causal mechanisms and treatment strategies (Hill 1969; USEPA 1994; Skousen and Ziemkiewicz 1995; Gazea, Adam, and Kontopoulos 1996; Ziemkiewicz 1998; Kleinmann 2001; Johnson and Hallberg 2003; Akcil and Koldas 2006; Kalin, Fyson, and Wheeler 2006). This research produced several pragmatic results, which provided numerous methods to predict, prevent, and treat AMD.

Within the Appalachian basin, pyrite and marcasite (both forms of $\mathrm{FeS}_{2}$ ) are the predominant sulfides that cause AMD (Hill 1969; Hoehn and Sizemore 1977; Skousen and Ziemkiewicz 1995; Ziemkiewicz 1998; Agency 2000; Kleinmann 2001; Johnson and Hallberg 2003). Reaction 1.1 is indicative of this oxidation process:

$$
2 \mathrm{FeS}_{2}+7 \mathrm{O}_{2}+2 \mathrm{H}_{2} \mathrm{O} \Rightarrow 2 \mathrm{Fe}^{2+}+4 \mathrm{SO}_{4}^{2-}+4 \mathrm{H}^{+}
$$

where either molecular oxygen or ferric iron acts as the oxidant in the reaction (USEPA 1994). Here, the sulfur is oxidized to form hydrogen ions and sulfate, which are the products required for sulfuric acid.

Additionally, the soluble iron byproduct $\left(\mathrm{Fe}^{2+}\right)$ is left in solution and has the capability to react further as described in Reaction 1.2:

$$
4 \mathrm{Fe}^{2+}+\mathrm{O}_{2}+4 \mathrm{H}^{+} \Rightarrow 4 \mathrm{Fe}^{3+}+2 \mathrm{H}_{2} \mathrm{O}
$$

where ferrous iron materials are converted to ferric ions slowly at low pH values (USEPA 1994).

The presence of certain types of bacteria also plays an important role in the generation of AMD. For example, at $\mathrm{pH}$ values less than 3.5 when in the presence of the iron bacterium Thiobacillus ferrooxidans, Reaction 1.3 may occur:

$$
2 \mathrm{FeS}_{2}+14 \mathrm{Fe}^{3+}+8 \mathrm{H}_{2} \mathrm{O} \Rightarrow 15 \mathrm{Fe}^{2+}+2 \mathrm{SO}_{4}^{2-}+16 \mathrm{H}^{+}
$$

where the presence of the aforementioned bacteria will allow the pyrite to be dissolved if it is in contact with the ferric ion (USEPA 1994). 


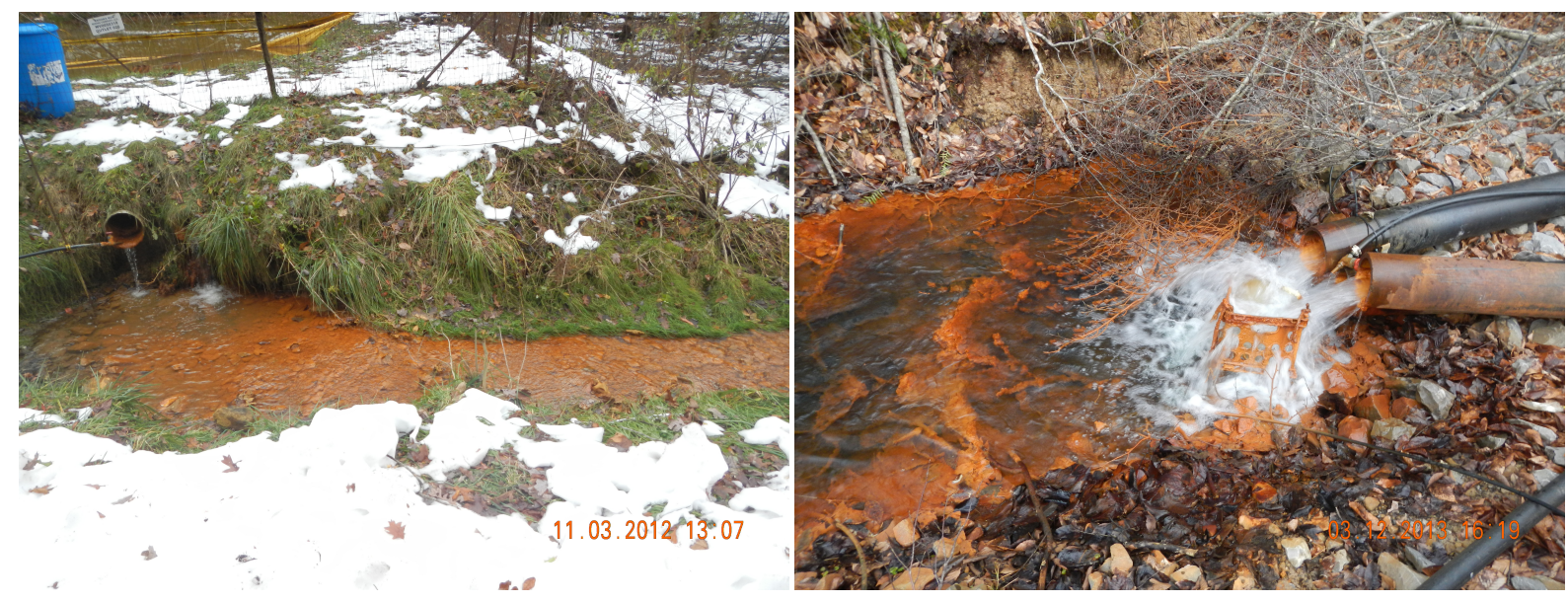

Figure 1.3 - Streams with orange staining from the iron oxide precipitate "yellow boy."

Finally, the ferric iron precipitates from the AMD as hydrated iron oxide as shown in Reaction 1.4:

$$
\mathrm{Fe}^{3+}+3 \mathrm{H}_{2} \mathrm{O} \Rightarrow \mathrm{Fe}(\mathrm{OH})_{3}(s)+3 \mathrm{H}^{+}
$$

where the hydrated iron oxide precipitates into an orange deposit on stream bottoms, commonly referred to as "yellow boy" (USEPA 1994). This hydrated iron oxide precipitate is commonly seen in Appalachian streams with high flows of acidic mine water and is indicative of AMD pollution. Figure 1.3 shows water features, which were impaired by the precipitation of iron oxides.

Akcil and Koldas (2006) investigated the primary factors that determine the rate of AMD generation. This study as well as others concluded that numerous parameters including water temperature, water $\mathrm{pH}$, oxygen concentration, degree of saturation, bacteria content, and the presence of alkaline material in the host rock, all significantly influence AMD generation. Since these parameters can vary considerably from site-to-site and even within the same site, the ability to apply a comprehensive treatment solution is severely limited. As a result, AMD treatment must be carried out using site-specific plans.

Alternatively, mines located below drainage may exhibit a different type of water quality that is less acidic than traditional AMD criteria. When recently abandoned, these mines exhibit 
the aforementioned qualities and produce sulfuric acid. However, once the below-drainage voids become filled with water, pyrite oxidation stops and complex processes including ion exchange, carbonate dissolution, and silica weathering result in net alkaline AMD (Capo et al. 2001). As a result, these mines typically present high iron contents in the form of $\mathrm{Fe}^{2+}$ verses the $\mathrm{Fe}^{3+}$ found in acidic AMD. Furthermore, these net-alkaline waters require a treatment routine that differs from typically acidic AMD discharges.

\subsubsection{Effects of AMD on the Environment}

Acid mine drainage is described by many researchers as a severe environmental problem facing the Appalachian coal mining regions (Hoehn and Sizemore 1977; USEPA 1994; Akcil and Koldas 2006; Kalin, Fyson, and Wheeler 2006). Left untreated, this longstanding problem can cause detrimental effects to steams adjacent to the mines as well as underlying water tables and downstream tributaries accepting inflows of AMD. Regrettably, the mechanisms causing AMD can perpetuate the generation of acidic water many years after a mine is reclaimed and underground workings are sealed (Hill 1969). The environmental problems caused by AMD are well documented and include impairment in growth and reproduction rates for aquatic plant and animal life. Additionally, AMD can infiltrate into the water table, and in extreme cases, contaminate drinking water supplies for residents who depend on wells for potable water (Jimenez et al. 2009). Due to the severe and persisting impacts of AMD, new technologies and methods as well as enhanced treatment regimes with the proper financial incentive are needed.

\subsection{Treatment of AMD}

Despite the availability of various treatment options, the responsible parties often face significant constraints that limit the number of effective options to mitigate AMD. While a typical treatment system includes the addition of an alkaline material and flocculants, various complicating factors, such as retention time, geographic location, topography, hydrology, and water chemistry limit the application of a standardized approach to water treatment (Akcil 
and Koldas 2006). Treatment time-scales vary in length from a few months to indefinitely. Additionally, the topography of the area, can limit the types of treatment available (Gazea, Adam, and Kontopoulos 1996; Johnson and Hallberg 2003). For example, an on-bench sediment structure with an NPDES outfall will typically have less working area than a large pond at the base of a valley fill. Finally, the mine water chemistry drives the treatment process available to mine operators. Net-alkaline AMD discharges are treated in a dramatically different way than the traditional acidic water. Given the aforementioned constraints, the overall AMD treatment system design must consider all of these factors simultaneously. Finally, water treatment at coal operations can be classified as active or passive. Passive treatment systems utilize man-made structures to enhance the quality of water based on the contents of the structure. Alternatively, active treatment requires the addition of chemicals or treatment plants to bring effluent water within permitted limits.

\subsubsection{Passive AMD Treatment}

Passive treatment systems improve the quality of AMD through the use of naturally occurring geochemical and biological processes (Gazea, Adam, and Kontopoulos 1996; Skousen, Hilton, and Faulkner 1997). These systems were first proposed by Huntsman (1978), as well as, Weidner and Lang (1982) observing improved AMD water quality after it passed through natural sphagnum bogs in Ohio and West Virginia. Today, passive treatment systems consist of man-made structures that can reproduce conditions in these natural wetlands. These structures are similar to sediment ponds; however, they are usually shallow and contain features similar to a marshland. Often, passive treatment systems are preferred due to their low cost and ease of maintenance (Gazea, Adam, and Kontopoulos 1996; Skousen, Hilton, and Faulkner 1997). Unfortunately, these systems are not applicable to all AMD flows due to a number of limiting constraints. Because of this, different passive treatment systems are often implemented in series. Various options for passive treatment include: aerobic wetlands, anaerobic wetlands, and anoxic limestone drains. 


\subsubsection{Active AMD Treatment}

Active treatment refers to the direct addition of chemicals to the impaired water to cause reactions that will render the water compliant. While it is normally more costly and labor intensive than passive treatment, those responsible for the AMD are compelled to use active treatment when conditions for passive treatment are unfavorable, such as: limited area, high flow rates, short time periods where impaired water is present, and tighter regulatory effluent limits. In addition to the usage of chemicals, the presence of oxygen in the water is also an important factor for designing a treatment system. Dissolved oxygen in AMD facilitates $\mathrm{Fe}^{2+}$ oxidation and the precipitation of metal hydroxides. This is especially true for the netalkaline type AMD discharges. For this reason, additional chemicals or mechanical aerators are sometimes used to increase the oxygen content of the water.

\section{Chemical Treatment}

The chemical treatment of AMD is primarily governed by $\mathrm{pH}$ control where neutral to alkaline $\mathrm{pH}$ values are required to precipitate dissolved metals. Low $\mathrm{pH}$ mine water typically contains iron, manganese, and aluminum ions. Metal solubility is a function of $\mathrm{pH}$, and the metal concentration can be readily controlled by manipulating the $\mathrm{pH}$ (often by increasing) until the metals precipitate. Given the large flow volumes and relatively slow reaction rates of AMD, standard treatment systems utilize a series of ponds or discrete cells within a single large pond as reactor vessels. These earthen structures are oriented so that runoff from the site must flow successively through the ponds to reach the NPDES permitted outlet.

Chemical treatment is added at the inflow to the system to provide maximum retention time for the neutralization reactions to occur. Pond curtains or baffles may be added to the system to prevent short-circuiting and insufficient reaction time. As water flows through the ponds, the $\mathrm{pH}$ adjustments and chemical reactions force metals to precipitate and fall out of suspension before exiting the system (Skousen and Ziemkiewicz 1995; Jimenez et al. 2009). Alkaline chemicals are used in $\mathrm{pH}$ control of AMD to facilitate the precipitation of metals from the water. According to Skousen (1997), six primary alkaline chemicals are used to 


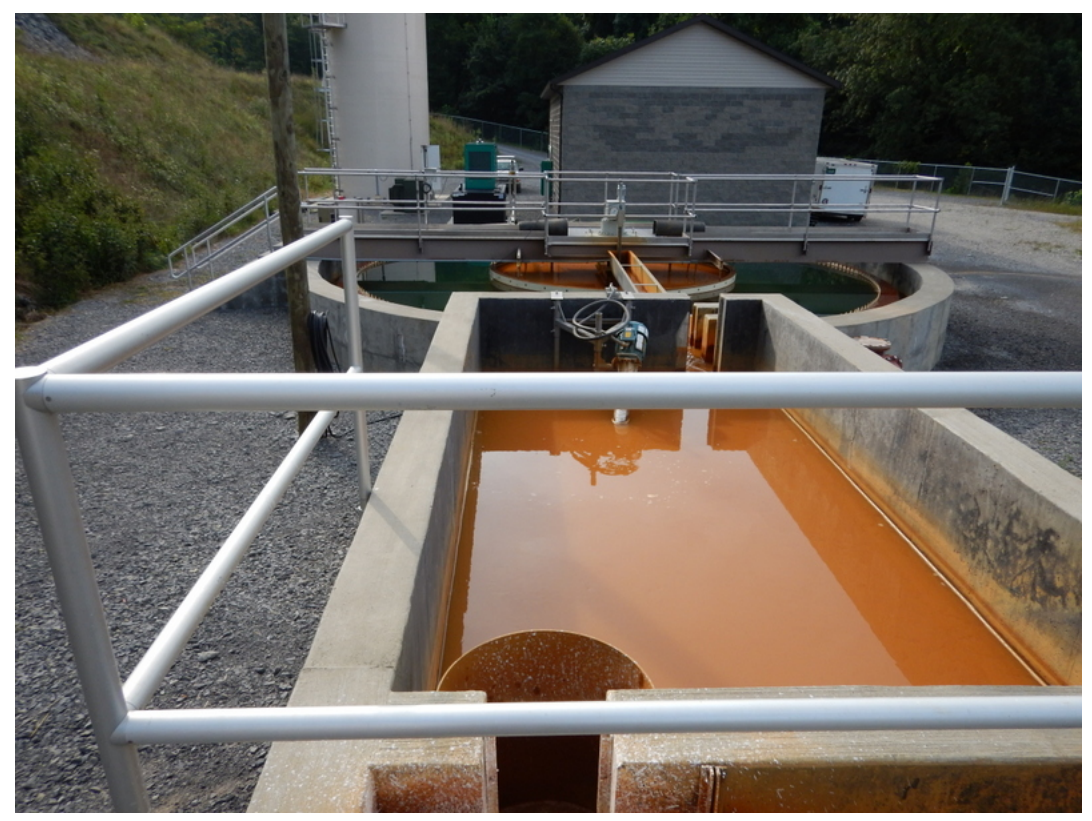

Figure 1.4 - Small clarifier used for treatment of AMD. The foreground shows the area where alkaline material and aeration is used to raise the $\mathrm{pH}$. The clarifier structure is located in the middle while the lime storage silo is located in the background.

treat AMD: (1) limestone, (2) hydrated lime, (3) pebble quick lime, (4) soda ash, (5) caustic soda, and (6) ammonia. Additional chemicals such as flocculants, coagulants, and oxidizing agents may also be utilized to enhance the performance of the treatment system.

Alternatively, where space is limited and the flux of the AMD discharge is high, the use of mechanical clarifiers can be utilized to treat the AMD. These units are common in Northern Appalachia (NAPP) for treating both acidic and net-alkaline waters. The clarifiers allow for a higher throughput of treated AMD where traditional gravity flow pond systems are not feasible due to limited area. Figure 1.4 shows a mine using a clarifier for AMD treatment. Finally, a more detailed characterization of AMD and the requisite treatment processes was described by Vass (2016).

\subsection{Rare Earth Element Extraction}

Rare earth elements have been processed in the United States on an industrial scale since the 1950s-chiefly, from the Mountain Pass mine located in California. In the 1960s, this mine became the largest worldwide producer of REEs due to the invention of color televi- 
sions and their reliance on Eu (Zepf 2013). Unfortunately, adverse environmental discharges forced Mountain Pass into bankruptcy and temporary closure in 2015 (Phadke 2018). These circumstances were indicative of a mining process that was energy intensive and environmentally detrimental.

At the open pit Mountain Pass mine, the REEs were principally contained in the mineral bastnasite. To process bastnasite, it must first be liberated from the host material through crushing, grinding and flotation (Hurst 2010). This initial processing stage is essential to the extraction route of REEs from the mineral matrix. Additionally, the processing route for bastnasite ore used in REE beneficiation is extremely difficult. As a result, the permitting and development of this type of orebody demands high capital commitment and adjustments to many regulatory requirements.

\subsubsection{REE Processing Routes}

Traditional mining methods are commonly used to extract REE ores. Many proposed REE mining projects often employ surface mining methods that include drilling, blasting, loading, and hauling (Hulse, Newton, and Malhotra 2013; Saucier et al. 2013; Dhalberg et al. 2014). Alternatively, underground methods were also suggested for proposed REE mines in cases where the geology dictates these extraction methods (Cox et al. 2010; Workman, Breede, and Goode 2013; Belzile, Marchand, and Bouajila 2015). While common in hard-rock metal mines, underground mining can result in a higher costing structure over the established operations used by the largest exporter of REEs, China, which produces REEs from both conventional ore-bodies and ion-adsorption clays.

In 1992, Chinese production of REEs broadly originated from three main locations (Jones, Wall, and Williams 1996):

- Bayan Obo (60\%)

- Maoniuping Mine (18\%)

- Ion Adsorbed Clays (14\%) 
These three mines were essential to producing the necessary distribution of REEs required to meet demand. For example, the Bayan Obo mine largely produces the LREEs while the ion adsorbed clays produce greater HREEs. Given the importance and reduced availability of the HREEs, mining practices have grown to include both legal and illegal operators (Sprecher et al. 2015). Because of this, it has become necessary for China to implement changes due to the environmental impacts at some of these mining operations.

For example, the large surface mines and in-situ leaching practices resulted in extensive environmental harm (Zhang et al. 2016). Consequently, in 2010 surface mining was banned in this area in favor of the in-situ leaching methods (Yang et al. 2013). Still, the in-situ leaching methods posed detrimental environmental effects including land slides, ammonium sulfate contamination, and other water quality issues (Packey and Kingsnorth 2016).

Alternatively, the Bayan Obo deposit exhibits difficult processing qualities similar to those at Mountain Pass (Huang et al. 2015). Here, the REEs are contained in a complex mineral matrix including monazite and bastnaesite (Ling and Yang 2014). Another problem with this matrix of minerals was the presence of unwanted gangue materials. Deleterious elements such as thorium further increased the complexity of refining due to the need to introduce additional separation circuits to isolate the valuable REEs from the radioactive elements (Zhu, Pranolo, and Cheng 2015).

Processing routes for REEs are largely dictated by the orebody from which they are extracted. In the aforementioned Chinese mines, initial processing routes were presented that are disparate from one another. As an example, in addition to the intensive comminution processes to liberate the minerals, Bayan Obo also preformed alkaline roasting, acid leaching, and finally solvent extraction Huang et al. (2015). In contrast, the ion-adsorbed clays located in south China were more readily delivered to the solvent extraction process through heap or in-situ leaching. As a result, this body of text will review the REE processing routes starting with leaching. 


\section{Leaching}

The REE ore mineralogy dictates the specific leaching process utilized to convert the REEs into an aqueous form. For example, ion-adsorbed types of REEs are typically leached using an ammonium sulfate based lixiviant (Xiao et al. 2015). Alternatively, Bastnaestite and Monazite are commonly digested using complex leaching processes employing both alkaline roasting and acid leaching (Peelman et al. 2014). These processes were designed to selectively dissolve and precipitate the metals of interest (Jha et al. 2016). These leaching mechanisms constitute both reagent and energy intensive processes. For example, a site that conducts alkaline roasting then acid leaching has a significantly higher reagent consumption rate than one that preformed acid leaching alone.

The primary goal of the leaching process is to extract the metal contents of the ore into an aqueous solution, frequently referred to as pregnant leach solution (PLS) (Galvez et al. 2004). This PLS is then used as a feed material to the solvent extraction (SX) process. Several variables can affect the efficiency of the leaching process including:

- Reagent Type

- Reagent Concentration

- Temperature

- Time

- Pressure

- Physical Agitation

- Solid to Liquid Ratio

The measure of efficiency in the leaching process is defined by the mass transfer of the metals of interest from the initial phase to that of the PLS. This is calculated using standard mass balancing procedures as presented by Wills (2006). Additionally, this efficiency can be compared to the aforementioned variables to show their effect on the overall process. For 
example, when evaluating the leaching of REEs from a phosphoric acid byproduct Preston (1996) evaluated different acid media, concentrations, solid to liquid ratios, temperatures, additives, and the effect of time in order to determine the optimum leaching flowsheet for the ore. Since this is commonly the first hydrometallurgical processes of a REE recovery circuit, a high recovery from the leaching circuit is essential to ensuring the overall efficiency of the REE processing circuit.

\section{Solvent Extraction}

After the PLS is created, solvent extraction (SX) is commonly employed for further separation of the REEs. Solvent extraction is a counter-current liquid-liquid separation process where metals ions are transferred from an aqueous solution to an organic solution. This organic solution is often commonly referred to a kerosene. However, the actual organic reagents used in industry tend to be highly refined forms of kerosene that contain low levels of aromatics compounds. This process can occur in a wide array of vessels; however, mixer-settlers are a common unit used during SX. Figure 1.5 represents of one type of mixer-settler. This unit provides one vessel for the thorough mixing of the two liquids allowing the exchange of metal ions. The larger vessel allows the two immiscible liquids to separate before advancing to the next respective unit.

Furthermore, a series of multiple mixer-settler vessels perform four main processes influencing the concentration of the metal ions in the two liquid phases. Figure 1.6 shows a block flow diagram of a streamlined SX process where the individual vessels have been reduced into singular primary functions. During the SX process, the organic phase travels in a closed loop throughout the unit operations while separate aqueous streams are introduced at each individual process of the system to generate desired outcomes in relation to the concentration of metals in the organic phase. These four main processes include:

- Extraction

- Scrubbing

- Stripping 


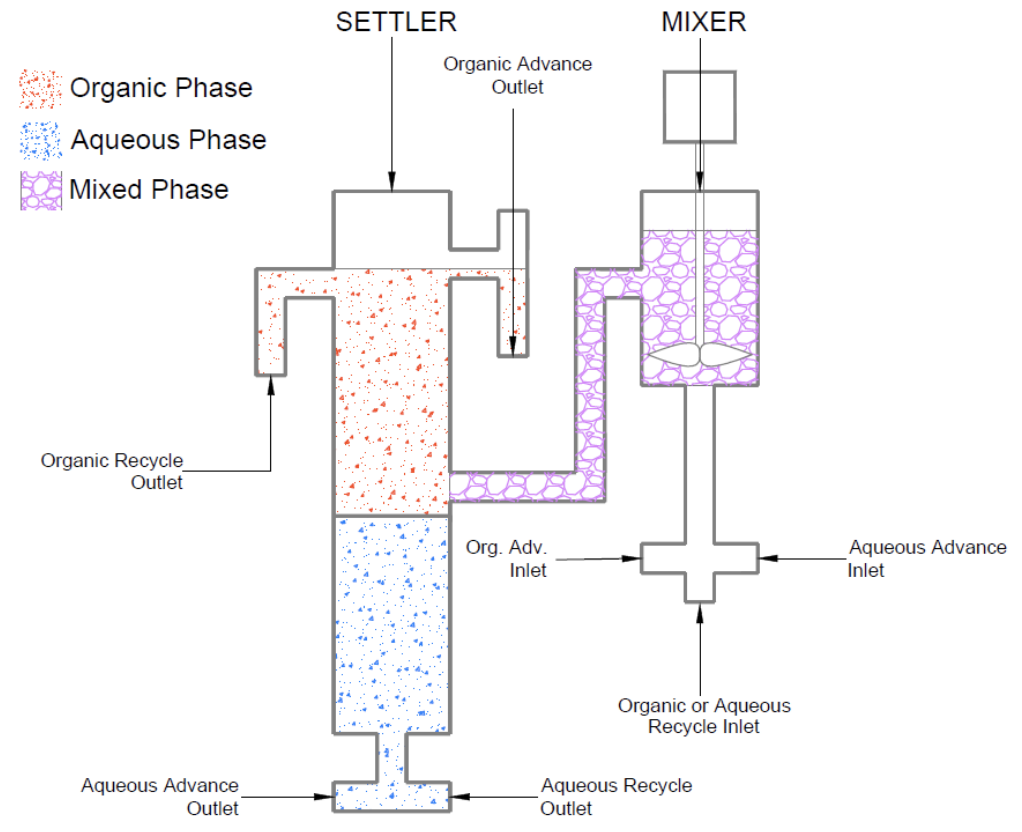

Figure 1.5 - Schematic drawing of mixer settler with the capability to recirculate the two liquid phases.

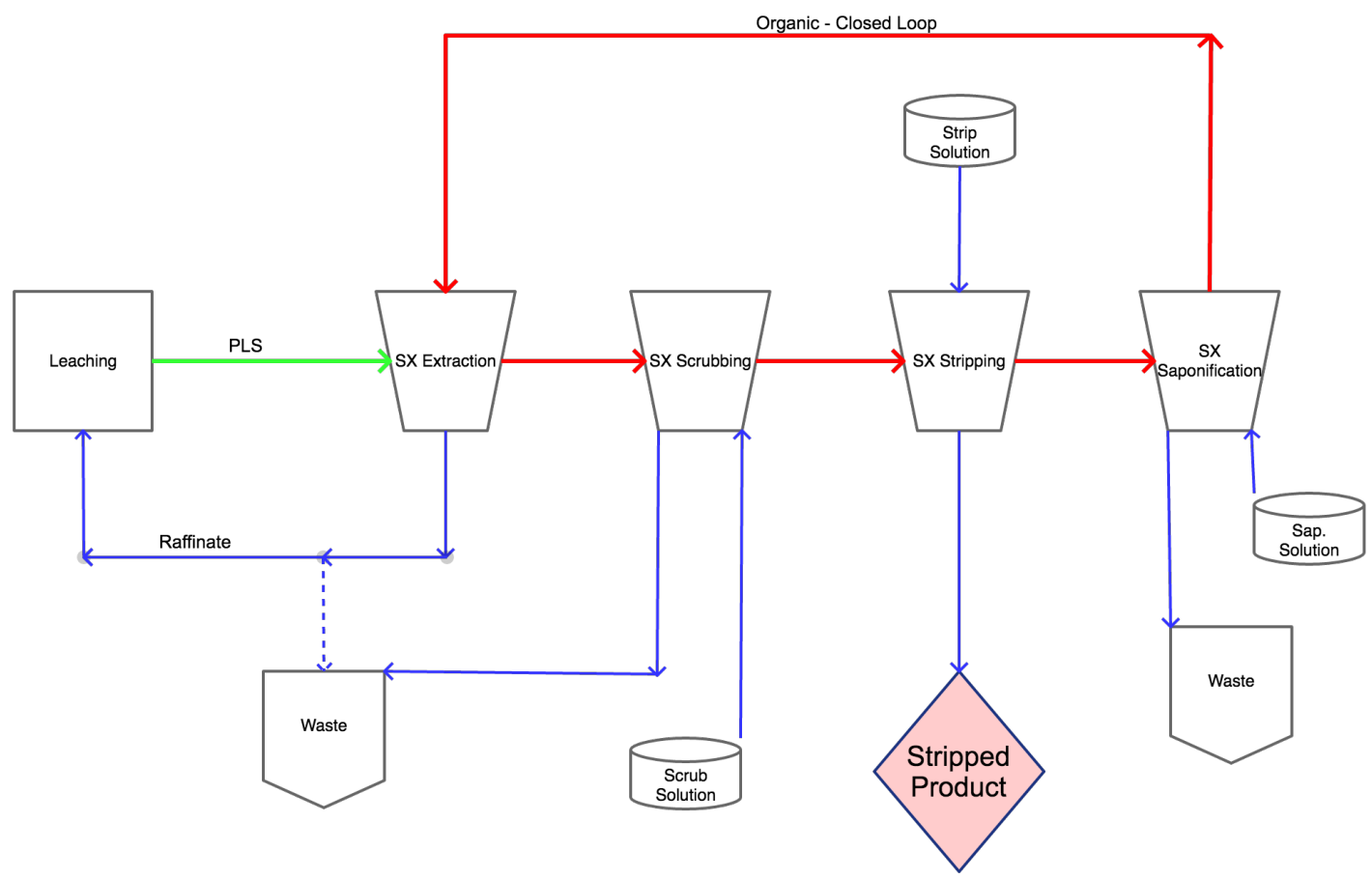

Figure 1.6 - Block flow diagram showing major processes of solvent extraction operations. 
Table 1.2 - Extractants used in the SX process and their common names after Ritcey (1984).

\begin{tabular}{ccc}
\hline Extractant Type & Reagent Class & Industrial Names \\
\hline & Versatic Acid & Versatic 10, Versatic 911 \\
Cation Exchange & Phospohoric Acid & D2EHPA, EHEHPA, P507 \\
& Phosphinic Acid & P229, Cyanex 272 \\
Chelating Extractants & $\beta-$ diketones & Lix 54 \\
Solvating Extractants & Phosphorous Ester & TBP, DBBP. Cyanex 921 \\
Anion Exchanger & Primary Amines & N1923, Aliquat 336 \\
\hline
\end{tabular}

- Saponification or Regeneration

Extraction During the first stage, extraction, metal ions are transferred from the PLS to the organic phase with the aid of an extractant placed into the organic phase. Extractants fall into four main types: cation exchange, chelating exchange, solvating extractants, and anion exchangers (Xie et al. 2014). Table 1.2 shows the four main types of extractants used in the SX process, their reagent class, and common names used in industrial processes.

Previous research indicated that the phosphoric acid extractants are amenable to the extraction of REEs (Antico et al. 1996; Gergoric et al. 2017). The general chemical process that allows the transfer of REE ions from the aqueous phase to the organic phase can be described as follows:

$$
R E E^{3+}+\overline{3(H A)_{2}} \Longleftrightarrow \overline{R E E(A)_{3}(H A)_{3}}+3 H^{+}
$$

where A denotes the organic anion and the over-lined terms indicate the species is in the organic phase (Xie et al. 2014; Bourricaudy et al. 2016). As seen from the above equation, as the REE ions move to the organic phase, $\mathrm{H}^{+}$ions are released, increasing the acidity of the aqueous solution. As the aqueous phase leaves the extraction phase, it is termed raffinate and can be recirculated into the leaching stage as a means to recover the acid and reduce reagent costs (Galvez et al. 2004). Alternatively, when the organic phase exits the extraction process, it is referred to as loaded organic.

Solvent extraction efficiency is measured by the distribution ratio D and extraction efficiency E as follows: 


$$
\begin{gathered}
D=\frac{(M i-M a) * \frac{V a}{V o}}{M a} \\
E=\frac{D}{D+\frac{V a}{V o}} * 100
\end{gathered}
$$

where Mi and Ma represent the initial and final REE concentrations respectively and Va and Vo are the volumes of aqueous and organic phases (Ritcey and Ashbrook 1984). Furthermore, the ability to separate two metals can be determined by the separation factor $(\beta)$ which is calculated as follows:

$$
\beta=\frac{D_{M 1}}{D_{M 2}}
$$

where $\mathrm{D}_{\mathrm{M} \#}$ is the distribution ratio of one metal to the other. Larger values of $\beta$ are indicative of the relative ease of separating two different metals using SX.

Additionally, modifiers may be used as additives or chemical modifiers to combat unwanted physical processes that can occur between the two phases (Ritcey and Ashbrook 1984). One such unwanted process is defined as "crud" in the SX industry. This crud is typically the formation of stable emulsions within the SX vessels. As such, crud can have several deleterious effects on the overall process including extractant loss, organic loss, and lower extraction efficiency (Ritcey 1980). Ritcey further indicated that one common modifier used to combat the formation of crud is TBP, which also works as an extractant itself.

Scrubbing The next unit operation, scrubbing, is used to clean unwanted metals from the organic phase that co-extract with the metals of interest. The scrubbing stage is combined with extraction when similar elements are transferred to the organic phase during the extraction process (Xing et al. 2018). As a result, the similar unwanted metals are removed from the organic solution, thereby increasing the purity of the metals of interest in the organic phase. In order to perform scrubbing a separate aqueous phase is introduced to the loaded organic phase. This scrub solution often consists of water or mildly acidic solutions depend- 
ing on the gangue elements that need to be removed (Tsakiridis and Agatzini-Leonardou 2004; Li et al. 2007).

Stripping Stripping refers to the removal of the metal ions from the organic phase and transferring them back to the aqueous phase. Typically, once a desired purity of metals is attained in the organic solution, the metal ions are transferred back into an aqueous phase in the stripping circuit using strong acidic solutions at high O:A ratios. These acids strip the REEs from the extractant while the high O:A ratio increases the concentration of metals back into the aqueous phase. As with extraction, the number of stripping units required is dependent on the kinetics of mass transfer and stripping efficiency (Galvez et al. 2004).

Saponification Before the organic can return to the extraction phase the extractant often needs to be completely cleaned of any additional metal ions that may still be attached to the extractant. This process is referred to as saponification, equilibration, or regeneration of the extractant (Ritcey and Ashbrook 1984; Bourricaudy et al. 2016). Research from Bourricaudy (Bourricaudy et al. 2016)indicated the saponification with concentrated sodium hydroxide was necessary to regenerate the extractant before it returned to the extraction stage.

\section{Precipitation}

After stripping, the REEs require removal from the concentrated stripped solution. To accomplish this, precipitation with oxalic acid produces REE oxalates (Chi and Xu 1999; Xie et al. 2014; Honaker et al. 2017). Typically this precipitation is efficiently conducted through the addition of oxalic at a ratio of two to three moles of oxalic acid per mole of REEs (Chi and Xu 1999; Abreu and Morais 2010). After precipitation, these oxalates are converted to oxides through calcination using high temperatures in excess of 750 degrees Celsius to form REE oxides (REO)(Preston et al. 1996; Sato et al. 2009). 


\subsection{Summary}

Rare earths elements are commonly found at higher concentrations in regard to crustal abundance than many commonly used metals. Nevertheless, it is quite difficult to to find deposits of REEs in a sufficient concentration that permits profitable extraction. Additionally, these 16 elements are essential to many civilian and military products that require them for advanced technologies. Due to increased demand, a monopolistic supply chain, and recent price volatility, the interest in finding alternative resources has been prioritized by many industrialized nations.

Historically, REEs were identified as trace metals in coal and coal byproducts since the early 1900s. Still, only recently has the motivation been established for researchers to evaluate alternative feedstocks from coal byproducts. Specifically, initial studies indicated the precipitates from the treatment of coal min AMD shows promising concentrations of these rare earth elements. Notwithstanding, the current technical literature is deficient regarding fundamental studies that characterize and quantify the presence of REEs in AMD and AMDp.

In addition, AMD is a autogenous process resulting from coal mining that leaches REEs from the surrounding strata as it migrates through mine spoils and abandoned works. While considered an environmental liability, the ability to extract valuable elements may provide incentive and financial relief for the treatment and processing of AMD. Incidentally, the Appalachian coal basin has significant AMD impairment. Therefore, this region is an ideal location for evaluating the extraction of REEs from AMD byproducts.

Finally, REEs are processed using standard hydrometallurgical processes. These techniques, include leaching, SX, and precipitation to separate REE oxides from other gangue metals. Given the relative abundance of AMD in Appalachia, there exists an opportunity to manufacture REEs in this region by adapting these proven techniques to a novel feedstock. Hence, additional research is required to demonstrate the feasibility of such an endeavor. 


\subsection{Research Objectives}

Given the aforementioned opportunities, a research program was established to describe the content and distribution of REEs in AMD and develop a bench-scale system to demonstrate the feasibility of extracting REEs from AMDp using a hydrometallurgical processing route. The primary objectives of this research include:

- Identify and characterize the occurrence of REEs in acid mine drainage and its byproducts.

- Create a processing flowsheet design from laboratory data, which defines a bench-scale system that will recover REEs from AMD byproducts.

- Construct and operate the bench-scale plant to test the feasibility of REE recovery from AMDp.

- Generate a MREO product that exceeds $2 \%$ REEs on a dry weight basis using the bench-scale plant.

\subsection{Dissertation Outline}

This dissertation consists of five chapters. After the introductory chapter, Chapter 2 and Chapter 3 discuss the prospectivity of both AMD and AMDp and evaluates the overall AMDp resource based on an extensive field sampling study. Next, Chapter 4 contains he laboratory work and methodology used in designing a bench-scale REE extraction plant. Finally, Chapter 5 presents the results of operating the bench-scale plant, and as a result, demonstrating the effectiveness of utilizing a hydrometallurgical processes to extract REEs from AMDp. 


\section{Chapter 2}

\section{Prospectivity of Rare Earth Elements - Northern Appalachian Basin}

This chapter has been published as:

C. R. Vass, A. Noble, and P. F. Ziemkiewicz, "The Occurrence and Concentration of Rare Earth Elements in Acid Mine Drainage and Treatment By-products : Part 1 - Initial Survey of the Northern Appalachian Coal Basin," 2019. https://doi.org/10.1007/s42461-019-0097-z Contributions:

- C.V. - main author, processing and interpretation of data

- A.N. - supervisory author, critically revised manuscript, contributed to the thermodynamic considerations of the behavior of $\mathrm{U}$ and $\mathrm{Th}$

- P.Z. - principal investigator, supervisory author, contributed the basin production estimate 


\title{
The Occurrence and Concentration of Rare Earth Elements in Acid Mine Drainage and Treatment By-products: Part 1—Initial Survey of the Northern Appalachian Coal Basin
}

\author{
Christopher R. Vass ${ }^{1}$ (D) Aaron Noble ${ }^{2} \cdot$ Paul F. Ziemkiewicz $^{1}$
}

Received: 25 February 2019 / Accepted: 6 June 2019

(C) Society for Mining, Metallurgy \& Exploration Inc. 2019

\begin{abstract}
The conventional rare earth element (REE) industry has historically sought to develop ore deposits where geologic processes have produced mineralized zones with commercially attractive REE concentrations. These deposits are extremely uncommon, particularly in the USA. Given the criticality of these materials and the need for sustainable domestic supply, the current research seeks to leverage other autogenous processes that lead to concentrated REE resources. One such process is the generation of acid mine drainage (AMD). AMD is very common in many coal mining districts and results from the exposure and oxidation of pyrite during mining. During the generation and migration of AMD, liberated sulfuric acid mobilizes several metal ions including REEs. Treatment of AMD is required under U.S.C $\$ 1251$, the Clean Water Act, and often consists of neutralization, oxidation, and metal hydroxide precipitation. To investigate the deportment of REEs during this process, a field sampling campaign was undertaken, whereby the concentration of REEs in AMD and AMD precipitates was measured directly. In the nine sites evaluated in this study, the REE concentrations of the precipitates varied from 29 to $1286 \mathrm{ppm}$ with an average of $517 \mathrm{ppm}$ among the sampled sites. The individual elements were enriched compared with the associated bulk Northern Appalachian (NAPP) coal material by factors ranging from 3 to 15 . Furthermore, the distribution of REEs in all precipitate samples favored the heavy REEs (HREEs) when compared with traditional REE ores. This research represents the first part of multi-part research endeavor to characterize, classify, and determine the practicality of refining REEs from AMD and its by-products.
\end{abstract}

Keywords Acid mine drainage $\cdot$ Rare earth elements $\cdot$ Coal by-products

\section{Introduction}

Rare earth elements (REEs) occur in a wide variety of geologic formations; however, these occurrences rarely meet the necessary minimum cutoff limits to facilitate profitable extraction and refining. In cases where the ores do meet cutoff grade limits, the mineralization often contains significant concentrations of the actinides thorium and uranium. The mining and processing of these deposits often entail detrimental environmental consequences and higher operating costs owing to waste disposal and handling [1]. Given the scarcity of

Christopher R. Vass

chris.vass@gmail.com

1 West Virginia Water Research Institute, PO Box 6064, Morgantown, WV 26506, USA

2 Virginia Tech Mining and Minerals Engineering, Holden Hall 100, Virginia Tech, 445 Old Turner Street, Blacksburg, VA 24061, USA geologic settings that lead to enriched REE deposits, more than $90 \%$ of REE production occurs in one country: China [2]. This near-monopoly creates a potential impairment for the USA and other countries where REEs are not readily produced. For example, during 2010 to 2012 rare earth crisis, China imposed reduced export quotas during a period of increased demand. This constrained market caused prices for many REEs to increase more than 100 -fold, leading to shortages in downstream markets [3]. As the demand peaked during this period, almost $\$ 6,000,000,000$ of investment capital was raised by junior mining companies to secure additional REE resources outside of China. Unfortunately, by 2015, many of these companies entered bankruptcy or lost interest in REEs due to the lower prices. This event indicates the overall importance of REE supply on a local and global basis as well as the need to consider alternative resources [4].

Despite the increased investment, only two REE mines recently started production outside of China [5]. The Mount Weld deposit in Australia began production in 2013. The ore from Mt. Weld is processed in Malaysia by Lynas 
Corporation, whose operating permit has recently come under controversy concerning the disposal of radioactive waste [6]. The second operation, Mountain Pass located in the USA, has experienced instability in reaching full-scale production due to lower REE prices and the high distribution of light REEs (LREE) in the orebody [7].

Many industrial processes rely on REEs for their products including catalysts, metallurgy, petroleum refining, catalytic converters, ceramics, phosphors, magnets, and electronics. Currently, the USA consumes approximately 12,000 metric tons of REEs per year [8]. Of that, the Department of Defense uses less than $5 \%$, or approximately 600 metric tons [9]. Future demand for individual REEs is difficult to predict due to the number of elements involved and variety of uses; however, given the increasing forecasted demand for green technologies and electronic devices, many researchers believe that demand for REEs will also increase [10,11]. Specifically, supply concerns regarding the heavy REEs (HREE) are of primary concern because identifying economically feasible HREE-enriched deposits outside of China has been unsuccessful [12].

Given the disparity between current REE supply and future REE demand, many stakeholders including researchers, national governments, and private companies have attempted to identify alternative and unconventional REE resources. For example, by-products of phosphoric acid production have been identified as a potential alternative source of REE production [13-16]. Also, there has been an increased interest in recycling of REEs, further indicating the need for alternative REE supplies [17]. While the overall production volume of REEs may alleviate some criticality concerns of the REE supply, it will not successfully compensate for the projected increase in demand over the next several years [18].

The presence of REEs in coal has long been established by many researchers [19-22]. More recently, the classification of REEs as critical minerals by the USA has brought an increased interest in the availability of a domestic REE supply. Since 2014, the US Department of Energy has analyzed the economic feasibility of recovering rare earth elements from coal and coal by-products [23]. Most initial studies focused on the recovery of REEs from coal tailings (refuse) and coal fly ash [24].

In June 2015, researchers at West Virginia University found significant concentrations of REE in precipitates formed during acid mine drainage (AMD) treatment [25]. These findings formed the basis for a detailed study of REE occurrence in the northern (NAPP) and central (CAPP) Appalachian Coal Basin AMD and its by-products. Consequently, this research was developed to identify the grade and potential recovery of REEs from AMD and its byproducts.

In the Appalachian Coal Basin, AMD constitutes one of the most significant and widespread water quality challenges.
AMD occurs when pyrite-bearing mine spoil oxidizes after mining. It consists of acidity and a varied suite of metals such as iron, aluminum, and manganese as well as the dominant anion, sulfate. Mining exposes these sulfide minerals to weathering, and the increased mineral surface area then leads to elevated oxidation and leaching, resulting in AMD formation as follows [26]:

$$
\begin{aligned}
& \mathrm{FeS}_{2}+\frac{7}{2} \mathrm{O}_{2}+\mathrm{H}_{2} \mathrm{O}=\mathrm{Fe}^{2+}+2 \mathrm{SO}_{4}^{2-}+2 \mathrm{H}^{+} \\
& \mathrm{Fe}^{2+}+\frac{1}{4} \mathrm{O}_{2}+\mathrm{H}^{+}=\mathrm{Fe}^{3+}+\frac{1}{2} \mathrm{H}_{2} \mathrm{O} \\
& \mathrm{Fe}^{3+}+3 \mathrm{H}_{2} \mathrm{O}=\mathrm{Fe}(\mathrm{OH})_{3}+3 \mathrm{H}^{+} \\
& \mathrm{FeS}_{2}+14 \mathrm{Fe}^{3+}+8 \mathrm{H}_{2} \mathrm{O}= 15 \mathrm{Fe}^{2+}+2 \mathrm{SO}_{4}^{2-} \\
&+16 \mathrm{H}^{+}
\end{aligned}
$$

The detrimental effects of AMD are well-documented and include adverse impacts on nearby streams [27-30]. Over the last 50 years, researchers have extensively studied the factors controlling AMD and developed methods that predict the severity and extent of AMD based on mining practices and geological properties [28, 31].

Per Section 402 of the Clean Water Act, mine operators are obliged to treat AMD prior to discharge. This treatment often incorporates alkaline addition and oxidation to increase the $\mathrm{pH}$ and remove metal ions from solution [26, 30, 32, 33]. This method of treatment can be incorporated through the use of different processing systems, both active and passive, to maximize treatment efficiency, minimize cost, and ensure environmental compliance [29, 34].

As AMD is treated by alkaline addition, the dissolved metal ions precipitate as hydroxides (denoted AMD sludge, AMD precipitate, or AMDp) while clean water is discharged into the receiving stream as follows (when using $\mathrm{CaCO}_{3}$ as the neutralizing agent) [35]:

$$
\begin{aligned}
& \mathrm{CaCO}_{3}+\mathrm{H}_{2} \mathrm{SO}_{4}=\mathrm{CaSO}_{4}+\mathrm{H}_{2} \mathrm{CO}_{3} \\
& 3 \mathrm{CaCO}_{3}+\mathrm{Fe}_{2}\left(\mathrm{SO}_{4}\right)_{3}+6 \mathrm{H}_{2} \mathrm{O} \\
& \quad=3 \mathrm{CaSO}_{4}+2 \mathrm{Fe}(\mathrm{OH})_{3}+3 \mathrm{H}_{2} \mathrm{CO}_{3} \\
& 3 \mathrm{CaCO}_{3}+\mathrm{Al}_{2}\left(\mathrm{SO}_{4}\right)_{3}+6 \mathrm{H}_{2} \mathrm{O} \\
& \quad=3 \mathrm{CaSO}_{4}+2 \mathrm{Al}(\mathrm{OH})_{3}+3 \mathrm{H}_{2} \mathrm{CO}_{3}
\end{aligned}
$$

The chemical and morphological characteristics of AMDp are unique to each treatment site and are a function of the composition of the AMD, type of neutralization chemical used, the amount of aeration, the extent of carbon dioxide release, and the configuration of the treatment system incorporated [26, 36]. Typically, AMDp is composed of an ironrich sludge that can contain other metals and vary from granular to gelatinous in consistency [36]. Moreover, the AMDp 
can contain fine to amorphous flocs that are greatly dependent on the treatment chemical used [37]. As a result, the AMDp from each mine site will vary as to the exact makeup of hydroxides, carbonates, and composition of metals. Lastly, this bulky and often moisture-rich sludge is difficult to handle and dispose of effectively. Alternative applications for this material could prove beneficial to the public and private entities liable for the treatment and disposal of AMD [38].

AMD chemistry represents the integration of reactions that occur on much smaller scales such as the pore water surrounding pyritic versus non-pyritic rock grains and localized oxidizing versus reducing environments. This integration occurs over the scale of mines that range in extent from hundreds of acres to 20 square miles or more as is the case of large, underground mines. AMD precipitate further integrates these variations in discharge chemistry by aggregating the dissolved metal loads over periods of months or years. The volume of mine drainage, either derived from surface or underground sources, changes seasonally according to the volume of infiltrating water; but, ionic composition fluctuates within narrow bounds at a given source. Thus, loads and concentrations vary inversely between the wet winter months and the dry latesummer to fall seasons.

While several prior studies have evaluated the partitioning and concentration of major AMD metals such as iron, aluminum, and manganese, few studies to date have evaluated the quality and quantity of REEs in AMD and AMD treatment by-products. Moreover, the lack of technical data on REEs in AMD limits the ability to answer key questions on the prospectivity (a predictive tool for choosing the location for further exploration efforts) of a potential REE resource derived from AMD. These questions include but are not limited to:

- What are the typical REE concentrations in AMD and what factors influence those concentrations?

- What is the size of the REE resource that can be realized from AMD in the Appalachian coal basin?

- What is the contained value of REEs in AMD and AMDp, and is this contained value sufficient to merit further study?

- What is the conceptual framework for the extraction and processing of these resources?

- What environmental, social, legal, and other intangible considerations must be resolved prior to resource development?

The objective of this manuscript is to evaluate the prospectivity of AMDp as an alternative source of REEs. The current technical literature lacks data from systemic studies that describe the content and quality of REEs in AMD and AMDp, and, as a result, few researchers have critically analyzed the value chain that can be derived from this current waste stream. This manuscript will describe a prospecting study where nine AMD treatment sites were extensively sampled and analyzed to determine the variation among and within sites as well as the partitioning of REEs among the AMD, AMDp, and treated water streams. Following this initial characterization, a regional production model was developed and used to estimate the resource size and potential value of REEs from AMD. Lastly, the paper investigates the technical, environmental, and civil considerations that would accompany REE extraction from AMD.

\section{Materials and Methods}

To assist in assessing the prospectivity of REEs in AMD, nine Northern Appalachian coal mine sites with AMD outflows were chosen for detailed sampling that encompassed a variety of coal seams and mine types. Each of these sites employs active chemical treatment of the AMD to meet effluent limits. As a result, both AMD and AMDp were available for sampling. Figure 1 shows the location of these sites within the NAPP basin on a county level, while Table 1 shows the unique characteristics of each site.

Several classes of AMD were represented in the population of sampling sites. The two primary mine categories included underground and surface. The surface category included refuse storage areas and impoundments. Next, the mines were classified as either above or below drainage (a.k.a. flooded). Flooded mines that are located below drainage typically contained net-alkaline water in contrast to the net-acidic water commonly associated with AMD $[39,40]$. This difference is caused by the restriction of pyrite oxidation under anoxic, flooded conditions and the gradual accumulation of the alkaline, bicarbonate ion buffer [41]. Under unflooded, oxidizing conditions, pyrite oxidation is unrestricted and acid generation may be controlled by either neutralizing minerals in the spoil or the eventual exhaustion of pyrite $[42,43]$. This distinction is significant as the extent of acid generation is anticipated to influence REE loading.

Both aqueous AMD and solid AMDp samples were collected over periods of between four and 17 months, depending on the sampling site. Typically, both the influent and effluent aqueous streams were collected at the AMD treatment plant. Additionally, three AMDp samples were collected at the site during each visit.

The sampling interval was chosen based on the inherent variability, quality, or quantity of the AMDp produced at each site. For example, site AMD_7 was sampled frequently even though it had a low REE concentration in the AMDp because it had a high flux of AMD and was therefore a potentially high-volume producer of REEs. Likewise, site AMD_3 had the highest concentration of total rare earth elements (TREEs) in the population and was therefore intensively sampled. 


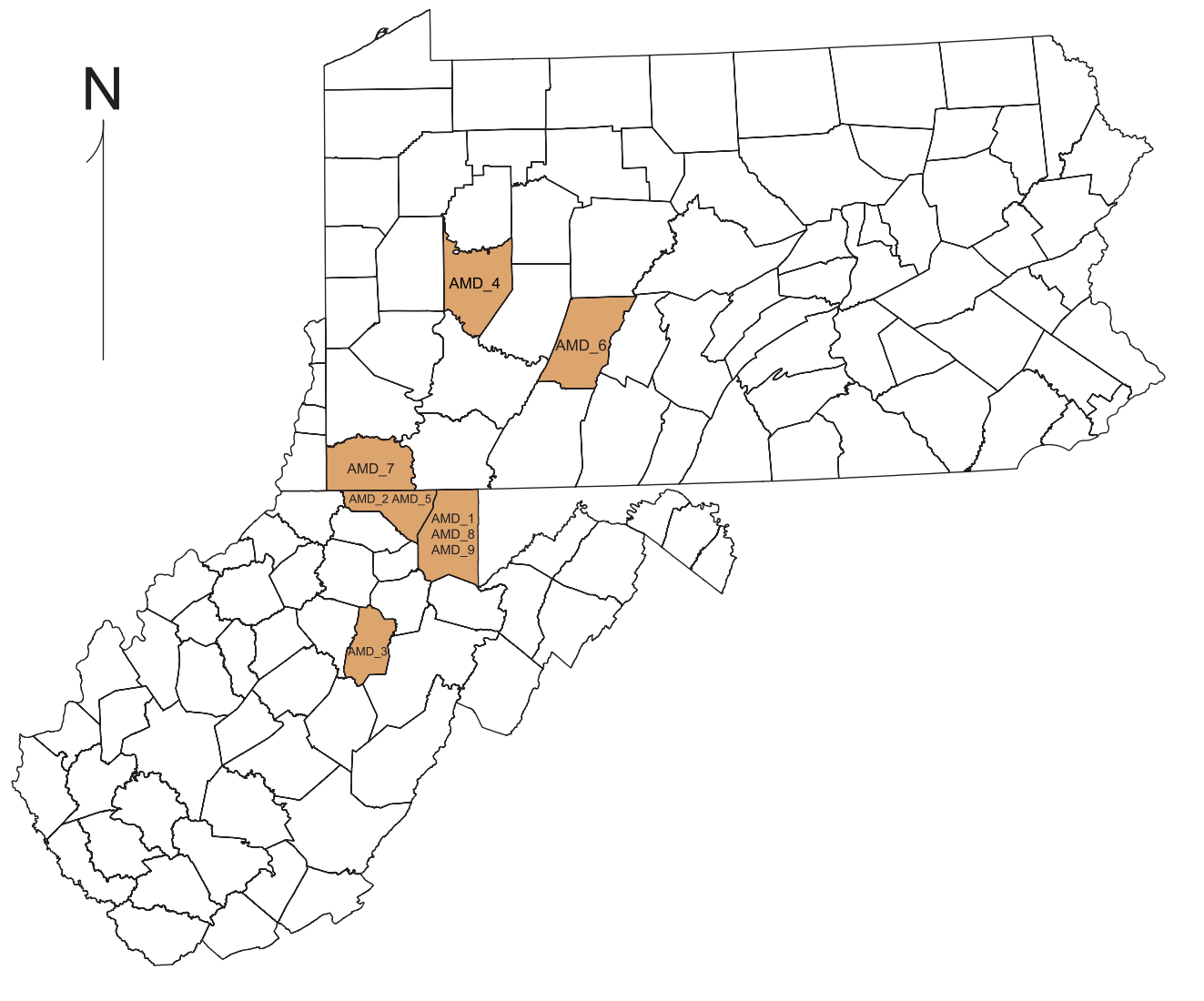

Fig. 1 County level location of the AMD sites evaluated

The collected aqueous and precipitate samples were then analyzed using ICP-MS for the REEs by TestAmerica Laboratories, Inc. and SGS Canada Inc., respectively. Both laboratories are certified by their respective state/provincial agencies to undertake both aqueous and solid REE analysis. Additionally, West Virginia University's National Research
Table 1 AMD site topographic settings and characteristics

\begin{tabular}{|c|c|c|c|c|c|c|c|}
\hline Site ID & State & County & $\begin{array}{l}\text { Influent } \\
\mathrm{pH}\end{array}$ & $\begin{array}{l}\text { Treatment } \\
\text { chemical }\end{array}$ & Seam & $\begin{array}{l}\text { Mine } \\
\text { type }\end{array}$ & $\begin{array}{l}\text { Flooded/above } \\
\text { drainage }\end{array}$ \\
\hline $\mathrm{AMD}_{1}$ & WV & Preston & 2.73 & Lime & Freeport & UG & Above drainage \\
\hline $\mathrm{AMD}_{2}$ & WV & Monongahela & 6.91 & Lime & Pittsburgh & UG & Flooded \\
\hline $\mathrm{AMD}_{3}$ & WV & Upshur & 3.46 & $\mathrm{NaOH}$ & Kittanning & SM & Above drainage \\
\hline $\mathrm{AMD}_{4}$ & PA & Armstrong & 3.17 & Lime & Kittanning & $\mathrm{SM} / \mathrm{UG}$ & Above drainage \\
\hline$\underset{5}{\mathrm{AMD}}-$ & WV & Monongahela & 2.88 & Lime & Freeport & UG & Above drainage \\
\hline$\underset{6}{\mathrm{AMD}}$ & PA & Cambria & 5.38 & Lime & Kittanning & UG & Flooded \\
\hline$\underset{7}{\mathrm{AMD}}$ & PA & Greene & 6.58 & Lime & Pittsburgh & UG & Flooded \\
\hline$\underset{8}{\mathrm{AMD}_{-}}$ & WV & Preston & 2.69 & Ammonia & Freeport & UG & Above drainage \\
\hline$\underset{9}{\mathrm{AMD}}$ & WV & Preston & 2.70 & Lime & Freeport & UG & Above drainage \\
\hline
\end{tabular}

$U G$, underground mine; $S M$, surface mine 
Center for Coal and Energy Analytical Laboratory (NRCCE) used an ICP-OES to analyze the other major ions. AMDp was digested using a sodium peroxide $\left(\mathrm{Na}_{2} \mathrm{O}_{2}\right)$ fusion and redissolved in hydrochloric acid. This method appears to be comparable with the United States Environmental Protection Agency's total digestion method 3052 for REEs. Method detection limits (MDL) for the aqueous rare earths were typically in the 0.02 ppb range, while the solid REE analysis had MDL ranging from 5 to $0.5 \mathrm{ppm}$. Major metal ions were measured in aqueous samples with MDL similar to those of the aqueous REEs.

Aqueous samples were collected in a clean $1000-\mathrm{mL}$ HDPE sample bottle. Next, this sample was then split into two separate containers (one preserved and one raw) for further analysis. Dilute nitric acid (2\%) was added to the preserved sample bottle to prevent precipitation or adsorption of the target analytes during shipping. Afterwards, the raw water samples were stored at $4{ }^{\circ} \mathrm{C}$, until it was ultimately delivered to the NRCCE laboratory for major ion analysis. Finally, the aqueous REE samples were shipped to the TestAmerica laboratory in their preserved state.

Precipitates were collected by hand using a shovel or posthole digger at or near the edge of the drying cell. These samples were placed in new 1-gallon HDPE sample buckets. Later, the AMDp samples were split into 50-mL representative aliquots for the ICP analysis in a laboratory setting. These sub-samples were then placed in $50-\mathrm{mL}$ digestion tubes for transport to SGS Canada Inc. for analysis.

Representative samples of entire AMDp cells were often difficult to impossible to safely obtain due to the depth and semi-liquid consistency of the precipitate. Therefore, many of the collected samples were located near the edge of drying cell ponds. Due to this sampling procedure, bias may have been introduced into some of the results. For example, the AMDp may stratify within the settling pond with varying qualities dependent upon depth. Alternatively, where allowed, various AMDp samples were collected at differing depths across a drying cell for select sites. Figure 2 shows a typical AMDp drying cell where representative samples were difficult to obtain. Finally, at sites that pump an AMDp product to abandoned underground mine works, the samples were collected from the clarifier underflow.

Several authors, including Seredin and Dai [44], Moldoveanu [45], and Gupta [46], have used different classifications methods to assist in analyzing potential REE resources. These classifications can be based on supply-demand relationships (critical REE versus excessive REE) or simple atomic number (heavy REE vs. light REE). For this paper, the following classifications will be observed:

- Heavy REEs (HREE): Sc, Y, Gd, Tb, Dy, Ho, Er, Tm, Yb, $\mathrm{Lu}$

- Light REEs (LREE): La, Ce, Pr, Nd, Sm, Eu

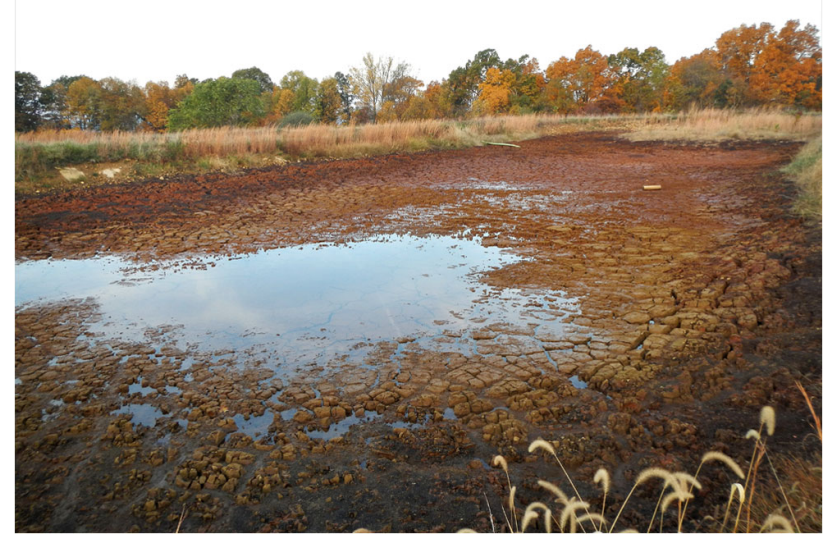

Fig. 2 Typical AMDp drying pond found in NAPP

- Total REEs (TREE): HREE + LREE

- Critical REEs (CREE): Y, Nd, Eu, Tb, Dy

\section{Results and Discussion}

The data from the field sampling campaign was used to assess the prospectivity of the REE resource in AMD. Key questions include the concentration of REEs in AMD and the factors that influence concentration, the overall size of the potential resource, the market value, conceptual framework for extraction and processing, and environmental and civil considerations. Each question is addressed in further detail below.

\subsection{Concentration of REEs in AMD and AMDp}

Tables 2 and 3 show the analytical results of the sampling campaign for AMD and AMDp respectively. TREE concentration averaged $258 \mu \mathrm{g} / \mathrm{L}$ for the aqueous AMD influent. This low REE concentration may seem to preclude AMD as a viable REE feedstock; however, the high enrichment factor after treatment of AMD is significant. Of the samples tested, the average concentration of REEs in AMDp was $517 \mathrm{~g} / \mathrm{t}$ : a concentration factor of 2000 times, with individual REE concentration factors varying from 1300 to 8400 times. These data show that the process of AMD migration through coal strata and the subsequent treatment of AMD produce a net enrichment, because the average TREE concentration in $\operatorname{AMDp}(517 \mathrm{ppm})$ is considerably higher than that of US coal (66 ppm) or the crustal abundance (206 ppm) [19, 47]. Also, REE concentrations in AMD treatment plant effluent was extremely low, often below detection limits, indicating the REEs exited the treatment plant as a precipitate. 
Table 2 Average REE concentrations for aqueous AMD influent at nine treatment facilitates in PA and WV

\begin{tabular}{|c|c|c|c|c|c|c|c|c|c|c|c|c|}
\hline Site & $(t x t)$ & AMD_1 & AMD_2 & AMD_3 & AMD_4 & AMD_5 & AMD_6 & AMD_7 & AMD_8 & AMD_9 & Mean & $\%$ TREE \\
\hline Mine type & $(t x t)$ & UG & UG & SM & UG & UG & UG & UG & UG & UG & - & - \\
\hline Horizon & $(t x t)$ & $\mathrm{AD}$ & $\mathrm{BD}$ & $\mathrm{AD}$ & $\mathrm{AD}$ & $\mathrm{AD}$ & $\mathrm{BD}$ & $\mathrm{BD}$ & $\mathrm{AD}$ & $\mathrm{AD}$ & - & - \\
\hline Seam(s) & (txt) & UFP & PITT & KITT & KITT & UFP & KITT & PITT & UFP & UFP & - & - \\
\hline AMD samples & (\#) & 4 & 12 & 17 & 4 & 17 & 4 & 13 & 6 & 4 & 9 & - \\
\hline $\mathrm{Sc}$ & (ug/L) & 2.63 & 0.83 & 6.11 & 38.70 & 46.50 & 3.16 & 3.82 & 8.05 & 11.38 & 13.46 & $5.2 \%$ \\
\hline $\mathrm{Y}$ & (ug/L) & 18.38 & 2.15 & 41.51 & 355.03 & 72.84 & 16.70 & 13.27 & 42.42 & 66.78 & 69.90 & $27.1 \%$ \\
\hline $\mathrm{La}$ & (ug/L) & 10.48 & 0.42 & 11.55 & 34.65 & 12.75 & 2.53 & 0.32 & 10.08 & 20.08 & 11.43 & $4.4 \%$ \\
\hline $\mathrm{Ce}$ & (ug/L) & 31.23 & 1.41 & 35.69 & 137.60 & 48.81 & 7.73 & 1.49 & 37.33 & 72.88 & 41.57 & $16.1 \%$ \\
\hline $\operatorname{Pr}$ & (ug/L) & 4.83 & 0.22 & 4.34 & 27.18 & 7.86 & 1.07 & 0.35 & 6.08 & 11.40 & 7.04 & $2.7 \%$ \\
\hline $\mathrm{Nd}$ & (ug/L) & 23.00 & 1.14 & 20.06 & 172.15 & 40.39 & 5.70 & 2.55 & 31.10 & 56.35 & 39.16 & $15.2 \%$ \\
\hline $\mathrm{Sm}$ & (ug/L) & 6.35 & 0.27 & 5.34 & 72.05 & 12.27 & 1.73 & 0.92 & 9.25 & 16.98 & 13.90 & $5.4 \%$ \\
\hline $\mathrm{Eu}$ & (ug/L) & 1.40 & 0.06 & 1.40 & 19.78 & 3.22 & 2.83 & 0.29 & 2.27 & 4.15 & 3.93 & $1.5 \%$ \\
\hline $\mathrm{Gd}$ & (ug/L) & 6.98 & 0.43 & 7.72 & 103.08 & 17.80 & 3.13 & 1.83 & 11.60 & 20.90 & 19.27 & $7.5 \%$ \\
\hline $\mathrm{Tb}$ & (ug/L) & 0.96 & 0.05 & 1.31 & 15.80 & 3.35 & 0.51 & 0.28 & 1.80 & 3.25 & 3.03 & $1.2 \%$ \\
\hline Dy & (ug/L) & 5.05 & 0.36 & 7.95 & 82.30 & 20.82 & 3.15 & 1.78 & 10.32 & 17.40 & 16.57 & $6.4 \%$ \\
\hline Ho & (ug/L) & 0.86 & 0.05 & 1.51 & 14.40 & 4.04 & 0.61 & 0.42 & 1.82 & 3.08 & 2.98 & $1.2 \%$ \\
\hline $\mathrm{Er}$ & (ug/L) & 2.18 & 0.20 & 4.26 & 34.95 & 11.79 & 1.60 & 1.21 & 4.95 & 8.15 & 7.70 & $3.0 \%$ \\
\hline $\mathrm{Tm}$ & (ug/L) & 0.28 & 0.01 & 0.53 & 4.33 & 1.49 & 2.64 & 0.15 & 0.62 & 1.03 & 1.23 & $0.5 \%$ \\
\hline $\mathrm{Yb}$ & (ug/L) & 1.58 & 0.13 & 3.12 & 23.53 & 9.14 & 1.05 & 0.81 & 3.88 & 6.50 & 5.52 & $2.1 \%$ \\
\hline $\mathrm{Lu}$ & (ug/L) & 0.23 & 0.01 & 0.45 & 3.43 & 1.30 & 2.62 & 0.13 & 0.55 & 0.88 & 1.06 & $0.4 \%$ \\
\hline $\mathrm{pH}$ & $(\mathrm{pH})$ & 2.73 & 6.91 & 3.46 & 3.17 & 2.88 & 5.38 & 6.71 & 3.92 & 2.70 & 4.20 & - \\
\hline TREE & (ug/L) & 116 & 8 & 153 & 1139 & 314 & 57 & 30 & 182 & 321 & 258 & $100.0 \%$ \\
\hline HREE & (ug/L) & 39 & 4 & 74 & 676 & 189 & 35 & 24 & 86 & 139 & 141 & $54.6 \%$ \\
\hline LREE & (ug/L) & 77 & 4 & 78 & 463 & 125 & 22 & 6 & 96 & 182 & 117 & $45.4 \%$ \\
\hline CREE & (ug/L) & 49 & 4 & 72 & 645 & 141 & 29 & 18 & 88 & 148 & 133 & $51.4 \%$ \\
\hline
\end{tabular}

$S M$, surface mine; $U G$, underground mine; $A D$, above drainage; $B D$, below drainage; UFP, Upper Freeport; KITT, Kittanning; PITT, Pittsburgh

\subsubsection{TREE in Pre and Post Water Treatment}

Further evaluation of the influent and effluent streams at each site confirmed that the bulk of the REEs were recovered into the AMDp. Figure 3 compared these influent and effluent streams from the nine sites. From these data, it was shown that the AMD treatment process reduced the REEs in the effluent by an average of $78 \%$. Likewise, the major polluting metals (Al, Fe, $\mathrm{Mn}, \mathrm{Mg}$ ) were also reduced by an average of $57 \%$. As a result, an economic method for recovering REEs from AMDp could further incentivize operators to meet or even exceed the governing effluent limits.

Results from this characterization of REEs in AMD byproducts indicated that on average, AMDp contained 517 ppm of REEs on a dry weight basis, as seen in Table 3. In addition, Table 4 shows the $95 \%$ upper and lower confidence intervals for repeat samples taken from the same site. In many cases, samples from a given site showed very little variability with respect to REE concentration and distribution. This finding is likely due to the large time scales and spatial scales that govern AMD production and migration. Thus, the concentration of REEs in AMD represents the integration over several decades and large volumes of rock.

\subsubsection{Factors Controlling REE in AMD and AMDp}

Each coal mine has unique geochemical features even among those that are in relatively close geographic proximity and coal seam. Furthermore, the elevation of the mine works, whether above or below drainage, also has a clear effect on the quantity of REEs in the aqueous AMD discharging from the mine. Treatment chemistry further influences the REE concentration in AMDp based on the type of treatment required at the mine. As shown in Tables 2 and 3, the sites AMD_2, AMD_6, and AMD_7 have significantly lower TREE concentrations, in both the AMD and AMDp, than the other mines. These three mines are all below-drainage flooded mine complexes. The water chemistry of these flooded AMD mines differs significantly from above-drainage mines. Typically, the $\mathrm{pH}$ of AMD discharged from these mines are of higher value (as seen in Table 2) since the oxidizing conditions that produce AMD are not present. 
Table 3 Average REE concentrations for AMDp at nine treatment facilitates in PA and WV

\begin{tabular}{|c|c|c|c|c|c|c|c|c|c|c|c|c|}
\hline Site & $(\mathrm{txt})$ & AMD_1 & AMD_2 & AMD_3 & AMD_4 & AMD_5 & AMD_6 & AMD_7 & AMD_8 & AMD_9 & Mean & $\%$ TREE \\
\hline Mine type & $(t x t)$ & UG & $\mathrm{UG}$ & UG & UG & SM & UG & UG & UG & UG & - & - \\
\hline Horizon & $(\mathrm{txt})$ & $\mathrm{AD}$ & $\mathrm{AD}$ & $\mathrm{AD}$ & $\mathrm{AD}$ & $\mathrm{AD}$ & $\mathrm{AD}$ & $\mathrm{BD}$ & $\mathrm{BD}$ & $\mathrm{BD}$ & - & - \\
\hline Seam(s) & $(\mathrm{txt})$ & KITT & UFP & UFP & UFP & KITT & UFP & KITT & PITT & PITT & - & - \\
\hline AMDp samples & (\#) & 14 & 12 & 52 & 12 & 52 & 12 & 13 & 40 & 36 & 27 & - \\
\hline $\mathrm{Sc}$ & $(\mathrm{g} / \mathrm{t})$ & 13.25 & 14.54 & 54.87 & 14.54 & 15.56 & 13.71 & 9.85 & 3.88 & 1.32 & 15.72 & $3.0 \%$ \\
\hline $\mathrm{Y}$ & $(\mathrm{g} / \mathrm{t})$ & 198.21 & 141.42 & 98.33 & 129.01 & 396.74 & 96.37 & 52.40 & 8.31 & 6.67 & 125.27 & $24.2 \%$ \\
\hline $\mathrm{La}$ & $(\mathrm{g} / \mathrm{t})$ & 44.94 & 94.03 & 20.39 & 126.75 & 110.31 & 149.96 & 8.85 & 2.98 & 3.11 & 62.37 & $12.1 \%$ \\
\hline $\mathrm{Ce}$ & $(\mathrm{g} / \mathrm{t})$ & 138.14 & 127.42 & 72.07 & 130.31 & 296.27 & 169.00 & 24.60 & 8.13 & 7.22 & 108.13 & $20.9 \%$ \\
\hline $\operatorname{Pr}$ & $(\mathrm{g} / \mathrm{t})$ & 21.72 & 20.05 & 11.43 & 19.89 & 37.21 & 23.28 & 3.71 & 1.16 & 0.90 & 15.48 & $3.0 \%$ \\
\hline $\mathrm{Nd}$ & $(\mathrm{g} / \mathrm{t})$ & 114.07 & 96.42 & 55.58 & 95.92 & 163.92 & 111.92 & 17.38 & 5.48 & 4.36 & 73.89 & $14.3 \%$ \\
\hline $\mathrm{Sm}$ & $(\mathrm{g} / \mathrm{t})$ & 37.48 & 29.29 & 16.74 & 28.38 & 41.36 & 30.18 & 4.73 & 1.93 & 0.82 & 21.21 & $4.1 \%$ \\
\hline Gd & $(\mathrm{g} / \mathrm{t})$ & 49.36 & 35.69 & 24.17 & 34.98 & 61.18 & 35.33 & 8.52 & 2.25 & 1.18 & 28.07 & $5.4 \%$ \\
\hline $\mathrm{Tb}$ & $(\mathrm{g} / \mathrm{t})$ & 6.92 & 5.80 & 4.43 & 5.62 & 10.22 & 5.53 & 1.43 & 0.55 & 0.30 & 4.53 & $0.9 \%$ \\
\hline Dy & $(\mathrm{g} / \mathrm{t})$ & 37.10 & 31.15 & 26.11 & 32.47 & 61.72 & 31.13 & 8.05 & 1.94 & 0.78 & 25.61 & $5.0 \%$ \\
\hline Ho & $(\mathrm{g} / \mathrm{t})$ & 6.86 & 5.96 & 5.18 & 6.25 & 12.64 & 6.04 & 1.84 & 0.46 & 0.20 & 5.05 & $1.0 \%$ \\
\hline $\mathrm{Er}$ & $(\mathrm{g} / \mathrm{t})$ & 17.38 & 15.48 & 14.01 & 16.45 & 34.18 & 16.05 & 4.72 & 1.07 & 0.46 & 13.31 & $2.6 \%$ \\
\hline $\mathrm{Tm}$ & $(\mathrm{g} / \mathrm{t})$ & 2.12 & 2.16 & 1.95 & 2.21 & 4.48 & 2.06 & 0.68 & 0.47 & 0.40 & 1.83 & $0.4 \%$ \\
\hline $\mathrm{Yb}$ & $(\mathrm{g} / \mathrm{t})$ & 11.72 & 12.12 & 11.15 & 12.54 & 25.38 & 11.61 & 3.19 & 0.70 & 0.37 & 9.87 & $1.9 \%$ \\
\hline $\mathrm{Lu}$ & $(\mathrm{g} / \mathrm{t})$ & 1.76 & 1.80 & 1.68 & 1.86 & 3.70 & 1.72 & 0.57 & 0.35 & 0.30 & 1.53 & $0.3 \%$ \\
\hline $\mathrm{U}$ & $(\mathrm{g} / \mathrm{t})$ & 7.41 & 6.83 & 5.38 & 8.19 & 5.22 & 4.83 & 0.58 & 0.75 & 0.94 & 4.46 & $0.9 \%$ \\
\hline $\mathrm{Th}$ & $(\mathrm{g} / \mathrm{t})$ & 4.91 & 14.37 & 9.64 & 7.39 & 3.96 & 8.98 & 0.38 & 0.82 & 0.64 & 5.67 & $1.1 \%$ \\
\hline TREE & $(\mathrm{g} / \mathrm{t})$ & 710 & 641 & 422 & 664 & 1286 & 711 & 152 & 40 & 29 & 517 & $100.0 \%$ \\
\hline CREE & $(\mathrm{g} / \mathrm{t})$ & 366 & 282 & 189 & 270 & 643 & 252 & 81 & 17 & 12 & 235 & $45.4 \%$ \\
\hline TREE Enrichment & $(-)$ & 624 & 1995 & 1344 & 3647 & 8412 & 6111 & 2675 & 1360 & 3712 & 2007 & - \\
\hline
\end{tabular}

$S M$, surface mine; $U G$, underground mine; $A D$, above drainage; $B D$, below drainage; UFP, Upper Freeport; KITT, Kittanning; PITT, Pittsburgh

The current data generally shows that increased $\mathrm{pH}$ in raw AMD corresponds to a lower TREE concentration. The quantity of free hydrogen ions available for leaching is a major factor in liberating REEs from the surrounding strata. A correlation of influent water $\mathrm{pH}$ and TREE concentration in AMD was derived from the dataset. Figure 4 shows this relationship. Of interest is the lack of data between the $\mathrm{pH}$ values 4 and 5 labeled as an "un-buffered zone," where $\mathrm{Fe}$ and $\mathrm{Al}$ buffering in AMD results in areas of $\mathrm{pH}$ stability in the regions above and below the $\mathrm{pH}$ range of 4 to 5 , respectively. This bimodal behavior is likely due to the carbonate buffering in the upper $\mathrm{pH}$ range and pyrite oxidation at the lower $\mathrm{pH}$ range as described by Cravotta et al. [48]. Indeed, this bimodal distribution is a result of the differences in geochemistry between the flooded underground and above-drainage mines. This differentiation may indicate that different processing paths will be required for the different influent geochemistry profiles.

When compared with the average crustal abundance and the average content of REEs in coal, the AMDp contained a significantly higher abundance of REEs as shown in Fig. 5. Except for Sc, all the REEs in AMDp were found in higher concentrations than in those of either the crustal abundance or native coal material. On average, the REEs in AMDp were 3.5 times more concentrated than the crustal abundance and more than 10 times more concentrated than typical REEs found in coal $[19,47]$. More important is the interaction between AMD and the mineralogy of the coal seam. AMD typically seeps through not just the coal seam but the surrounding strata as well. As indicated by Zhang et al. [49], the REEs typically are associated with the gangue materials within the coal seam and not the coal itself.

\subsection{Basin Production Estimate}

The results from the sampling campaign are analogous to an initial prospecting survey and may be used to approximate the overall regional production at a high level. Unfortunately, comprehensive AMD flowrate datasets are practically 


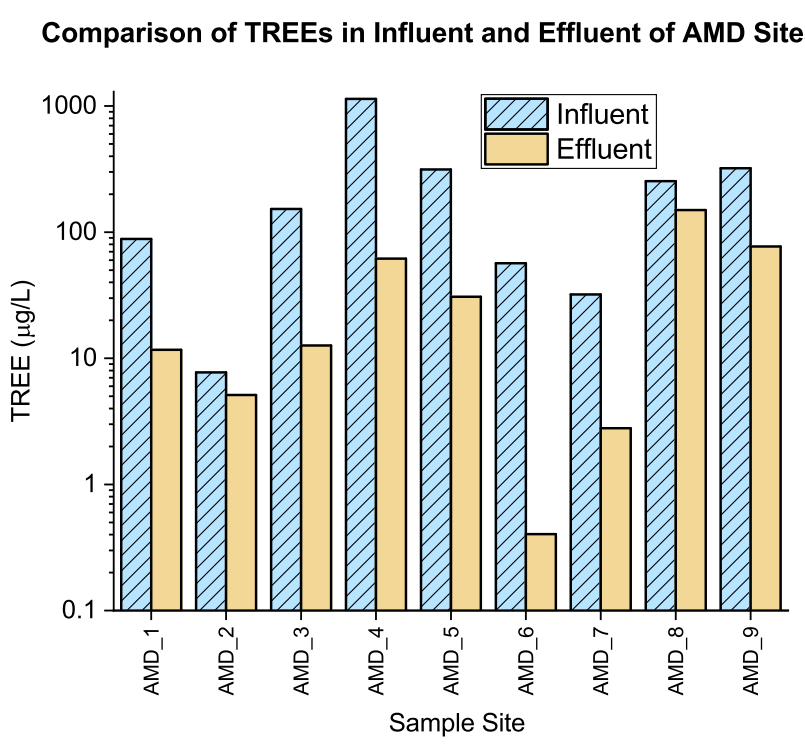

Fig. 3 Difference in the influent and effluent TREE values for nine NAPP AMD sites

nonexistent due to the complexity of flow interactions, large seasonal variations, and the temporal nature of the effluent constituents. As a result, multiple AMD outfall datasets were compiled to estimate the regional AMD flow rate estimate by the authors. These data are composed of projects completed by the West Virginia Water Research Institute, Pennsylvania Abandoned Mine Land Department, West Virginia Department of Environmental Protection, and various studies from others [50-52].

In all, this regional estimate encompasses over 1100 unique AMD outlets, predominately in the NAPP region and indicated that the regional AMD flow rate is approximately $94,700 \mathrm{~L} / \mathrm{s}$. Consequently, this estimate may be considered conservative in relation to the actual flow rate. Previously, Stewart et al. provided a regional flow estimate of 417,448 L/s [53]. By comparison, the methods used by Stewart could lead to overestimation of the true quantity of AMD due to the incorrect assumption that all coal mining leads to the generation of AMD and neglecting the spatial reduction of multi-seam extraction, which is common in Central Appalachia (CAPP). Given these complexities, an accurate and precise determination of AMD flowrate for the Appalachian basin would require a more extensive study well beyond the scope of this research. Nevertheless, for the

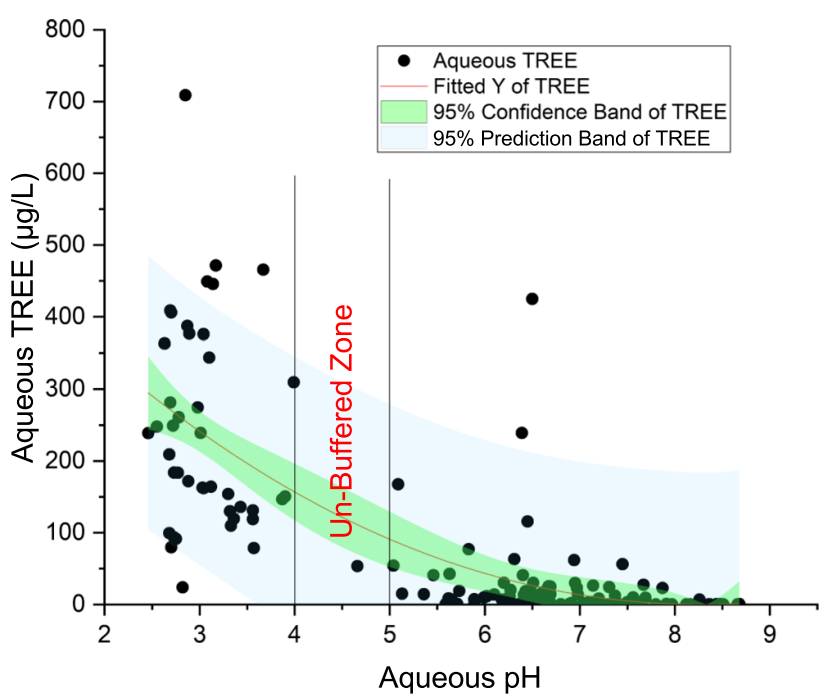

Fig. 4 Relationship between $\mathrm{pH}$ and aqueous TREE concentrations

purpose of the current study, both Stewart's methodology and the authors' methodology were used to estimate the high and low AMD flow rate values, respectively. In addition, the REE content of this AMD was assumed to be the average for the NAPP values shown in Table 5. Given these inputs, the estimated REE production from AMD was determined to be between 771 to $3400 \mathrm{t}$ of REEs per year. The high variance in the two estimated production rates indicates that further exploration of the resource is required to identify an economically feasible process to extract REEs from AMD.

\subsection{Valuation}

To estimate the contained value of REEs in AMD, an average price deck for the REEs was compiled for the lanthanide series plus yttrium from 2008 through 2015 using the USGS Mineral Yearbooks [54-61]. These 8 years contain the global REE peak prices observed during 2011 as well as the preceding and post market minimums. A similar process for economic valuation has been used in similar coal-based REE deposits $[62,63]$. Scandium was not included in this analysis, as the unit high price tends to grossly distort the final values. Additionally, the current global production of scandium is very small, and a large influx of Sc to the market could drastically change the supply and demand relationship [64].

Table 4 AMDp 95\% upper and lower confidence intervals for mean TREE values

\begin{tabular}{lllllllllll}
\hline Site & $(\mathrm{txt})$ & AMD_1 & AMD_2 & AMD_3 & AMD_4 & AMD_5 & AMD_6 & AMD_7 & AMD_8 & AMD_9 \\
\hline Mean TREE & $(\mathrm{g} / \mathrm{t})$ & 711 & 29 & 1286 & 710 & 422 & 152 & 40 & 664 \\
95\% UCL & $(\mathrm{g} / \mathrm{t})$ & 507 & 24 & 1202 & 585 & 406 & 131 & 17 & 504 & 575 \\
95\% LCL & $(\mathrm{g} / \mathrm{t})$ & 916 & 33 & 1369 & 836 & 439 & 173 & 64 & 825 & 707 \\
\hline
\end{tabular}

$U C L$, upper confidence level; $L C L$, lower confidence level 
Fig. 5 Comparison of mean AMDp REE concentrations to that of crustal and US coal abundance values $[19,47]$
Comparison of Mean AMDp REEs to Crustal and US Coal Abundance

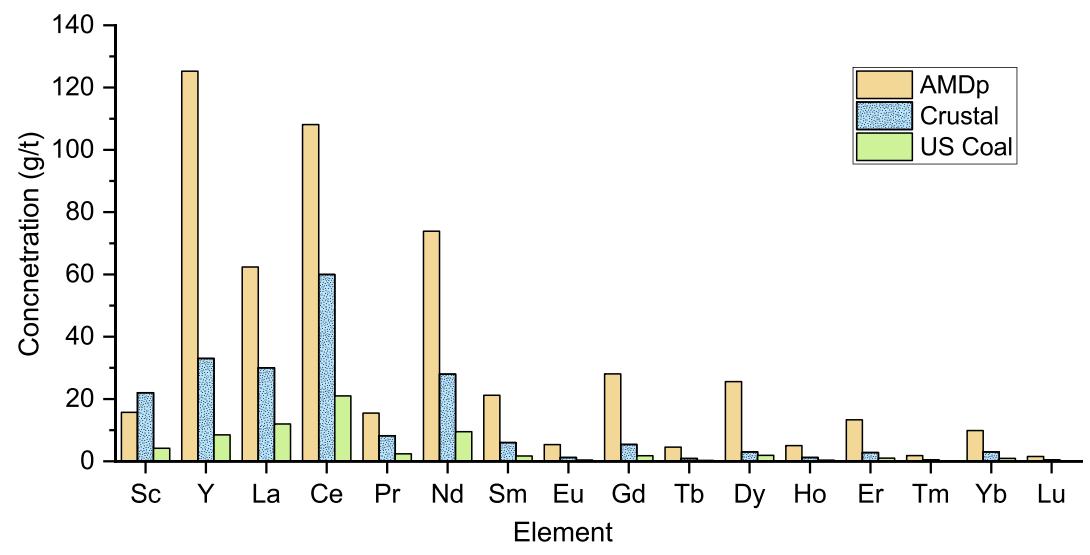

The referenced prices were provided on an oxide basis and were averaged across the 8-year span for the present data. Next, the oxide prices were converted to metal equivalents using standard metal to oxide ratios. Table 6 shows the price deck used for this preliminary valuation.

From these prices, two different economic indicators were evaluated for the mean AMDp REE concentration (minus Sc). First, the basket price was determined by weighting the elemental price by the elemental distribution within the AMDp. This indicator was representative of a what $1 \mathrm{~kg}$ of final REE metal product would command on the open market, assuming a representative distribution of REEs were produced from the mean AMDp values. This could also be viewed as the gross average selling price for the AMDp product before fixed and variable mining costs are deducted. Additional assumptions in the generation of this metric assume that all elements have demand in the market and all were equally recoverable in the refining process. Overall, the basket price would be a poor indicator when choosing between two projects; however, it does provide a good comparison of an ore's potential value when identical elemental prices were used between projects.

The second indicator evaluated was the in situ price. This value represents the unitized value of $1 \mathrm{t}$ of the resource in the ground. In relation to $\mathrm{AMDp}$, this metric would correspond to

Table 5 Low and high regional flow rate estimates

\begin{tabular}{llll}
\hline Regional AMD flow estimate & Units & Low & High $^{2}$ \\
\hline PA & $(\mathrm{L} / \mathrm{s})$ & 51,401 & - \\
WV & $(\mathrm{L} / \mathrm{s})$ & 24,095 & - \\
OH & $(\mathrm{L} / \mathrm{s})$ & 18,900 & - \\
MD & $(\mathrm{L} / \mathrm{s})$ & 317 & - \\
Total & $(\mathrm{L} / \mathrm{s})$ & 94,712 & 417,448 \\
TREE concentration $(\mathrm{mg} / \mathrm{L})$ & $(\mathrm{mg} / \mathrm{L})$ & 0.258 & 0.258 \\
TREE load & $(\mathrm{t} / \mathrm{year})$ & 771 & 3400 \\
\hline
\end{tabular}

${ }^{1}$ Regional flow estimates based on proprietary AMD studies

${ }^{2}$ Regional flow estimate by Stewart et.al. [53]
$1 \mathrm{t}$ of AMDp, on a dry weight basis, located in a storage pond. This price was also exclusive of mining, processing, and milling costs; therefore, it was not an indicator of economic viability. Furthermore, this price assumed all elements were fully recovered and salable. Nevertheless, this benchmark may be used to compare the gross unitized value of reserves and resources between multiple projects. When the in situ price of $\$ 89.08 / \mathrm{kg}$ TREE was applied to the REE production models

Table 6 Price deck used for economic evaluation consisting of average pricing from USGS Mineral Yearbooks (2008-2015)

\begin{tabular}{llllll}
\hline $\begin{array}{l}\text { Element } \\
\text { (txt) }\end{array}$ & $\begin{array}{l}\text { Mean } \\
\text { Concentration }\end{array}$ & $\begin{array}{l}\% \text { TREE } \\
(\%)\end{array}$ & $\begin{array}{l}\text { Elemental } \\
\text { Value } \\
(\$ / \mathrm{kg})\end{array}$ & $\begin{array}{l}\text { Basket } \\
\text { Price } \\
(\$ / \mathrm{kg})\end{array}$ & $\begin{array}{l}\text { In situ } \\
\text { Price } \\
(\$ / \mathrm{ton})\end{array}$ \\
\hline $\mathrm{Sc} *$ & 15.72 & - & $\$ 5628.83$ & - & - \\
$\mathrm{Y}$ & 125.27 & $25.0 \%$ & $\$ 85.53$ & $\$ 21.36$ & $\$ 10.72$ \\
$\mathrm{La}$ & 62.37 & $12.4 \%$ & $\$ 32.73$ & $\$ 4.07$ & $\$ 2.04$ \\
$\mathrm{Ce}$ & 108.13 & $21.6 \%$ & $\$ 35.23$ & $\$ 7.60$ & $\$ 3.81$ \\
$\mathrm{Pr}$ & 15.48 & $3.1 \%$ & $\$ 123.96$ & $\$ 3.83$ & $\$ 1.92$ \\
$\mathrm{Nd}$ & 73.89 & $14.7 \%$ & $\$ 109.10$ & $\$ 16.07$ & $\$ 8.06$ \\
$\mathrm{Sm}$ & 21.21 & $4.2 \%$ & $\$ 158.86$ & $\$ 6.72$ & $\$ 3.37$ \\
$\mathrm{Eu}$ & 5.37 & $1.1 \%$ & $\$ 1817.44$ & $\$ 19.47$ & $\$ 9.77$ \\
$\mathrm{Gd}$ & 28.07 & $5.6 \%$ & $\$ 183.49$ & $\$ 10.27$ & $\$ 5.15$ \\
$\mathrm{~Tb}$ & 4.53 & $0.9 \%$ & $\$ 1438.75$ & $\$ 13.00$ & $\$ 6.52$ \\
$\mathrm{Dy}$ & 25.61 & $5.1 \%$ & $\$ 681.84$ & $\$ 34.81$ & $\$ 17.46$ \\
$\mathrm{Ho}$ & 5.05 & $1.0 \%$ & $\$ 859.11$ & $\$ 8.65$ & $\$ 4.34$ \\
$\mathrm{Er}$ & 13.31 & $2.7 \%$ & $\$ 195.83$ & $\$ 5.20$ & $\$ 2.61$ \\
$\mathrm{Tm}$ & 1.83 & $0.4 \%$ & $\$ 2093.80$ & $\$ 7.66$ & $\$ 3.84$ \\
$\mathrm{Yb}$ & 9.87 & $2.0 \%$ & $\$ 455.48$ & $\$ 8.96$ & $\$ 4.49$ \\
$\mathrm{Lu}$ & 1.53 & $0.3 \%$ & $\$ 3269.27$ & $\$ 9.95$ & $\$ 4.99$ \\
$\mathrm{TREE}$ & 502 & $100.0 \%$ & - & $\$ 177.62$ & $\$ 89.08$ \\
$\mathrm{HREE}$ & 215 & $44.6 \%$ & - & $\$ 119.87$ & $\$ 60.12$ \\
$\mathrm{LREE}$ & 286 & $55.4 \%$ & - & $\$ 57.76$ & $\$ 28.97$ \\
$\mathrm{CREE}$ & 235 & $45.4 \%$ & - & $\$ 104.73$ & $\$ 52.52$ \\
\hline
\end{tabular}

*Sc Excluded from evaluation due to the inherent volatility 
in Table 5 at the mean aqueous inflow concentration, a value of approximately $\$ 69 \mathrm{M} /$ year to $\$ 303 \mathrm{M} /$ year was observed.

To compare the viability of AMDp as a reasonable REE feedstock, the two aforementioned price indexes were applied to 58 different REE resources. The assays for these projects were compiled from NI 43-101, JORC, or SAMREC statements [65]. As a means of comparison, the in situ price for each resource was plotted against that resource's basket price, as shown in Fig. 6.

The AMDp ranks reasonably well among the other resources, indicating that it has a moderate potential as a feasible resource. While AMDp does have a lower in situ price than many other reserves, it also has several unique qualities that are more amenable to processing than traditional hard-rock ores. For example, AMDp does not rely on traditional extraction, comminution, or physical separation as part of the processing flowsheet. AMDp processing to recover REEs would likely occur on brownfield sites that are already permitted for waste disposal. Furthermore, AMDp possesses a significant basket price when compared to other resources.

While this research shows that the production potential of REEs through AMD is below that of the current US demand, AMD is still significant as a steady and reliable domestic source. AMD typically loses acidity over time; however, new mining works are constantly being added that could create the oxidizing environment necessary for future AMD production. Additionally, the generation of REEs through AMD flows is stable over long periods of time; as a result, this resource could be used to supplement other US-based REE sources.

Lastly, AMDp is viewed by the industry as an impediment and the treatment, storage, and removal are conducted in a manner that minimizes cost. As a result, many of the AMDp resources are currently pumped underground or disposed of in impoundments. These practices do not allow for the recovery of REEs from the AMD treatment waste streams. Furthermore, there are many potential positive environmental impacts that could be achieved with the beneficiation of AMDp.

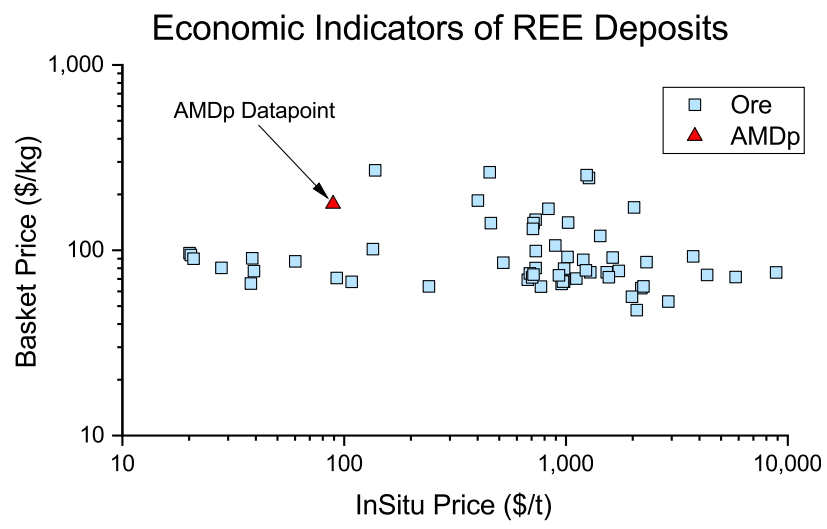

Fig. 6 Comparison of the basket and in situ price index for NAPP AMDp and 58 other REE resources. Ore-based project data after Lifton [65]

\subsection{Conceptual Framework for Extraction and Processing}

Currently, REEs are processed from a large variety of feedstocks that utilize a multitude of mineral processing and hydrometallurgical technologies [66]. By emulating these proven mining and hydrometallurgical processes in the REE industry, a high-level conceptual framework can be applied to AMDp. Figure 7 shows this theoretical flowsheet that could be used in the production of REEs from AMDp.

Initially, the AMDp would need to be extracted from the current in situ location. This material handling process could involve several mining practices from loading and hauling to pumping to transporting the feedstock to a processing facility. Once at the facility, several costly steps that are used in hardrock ore processing could be bypassed due to the amorphous consistency of the precipitate. For example, extensive sizing processes like crushing and grinding as well as physical concentration such as flotation would not be necessary to classify and concentrate the feed material.

Next, the hydrometallurgical process used in the REE industry typically requires the REEs to be in an aqueous form. Likewise, the AMDp would need to be converted from the current oxide form into a soluble feedstock. Multiple leaching routes are available to accomplish this solubilization.

Separation of the REEs from other gangue metals in the AMDp could be accomplished using a variety of techniques. Currently, ion exchange, solvent extraction, or selective precipitation are used to recover REEs in an oxide form. Once separated, the REE oxides could be packaged and transported

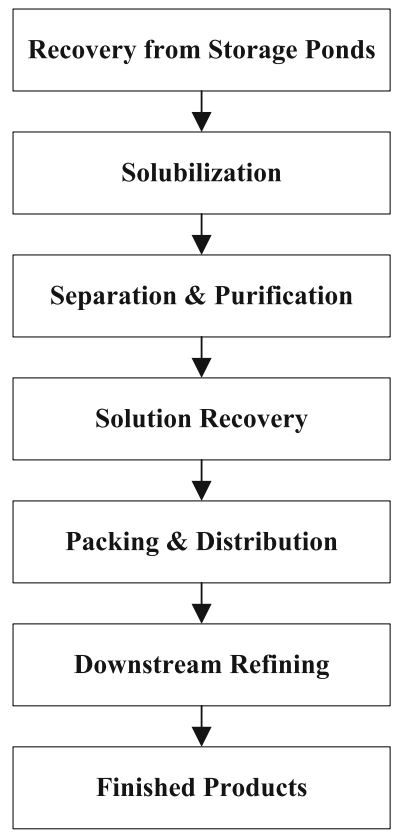

Fig. 7 Conceptual framework for extraction and recovery of REEs from AMDp 

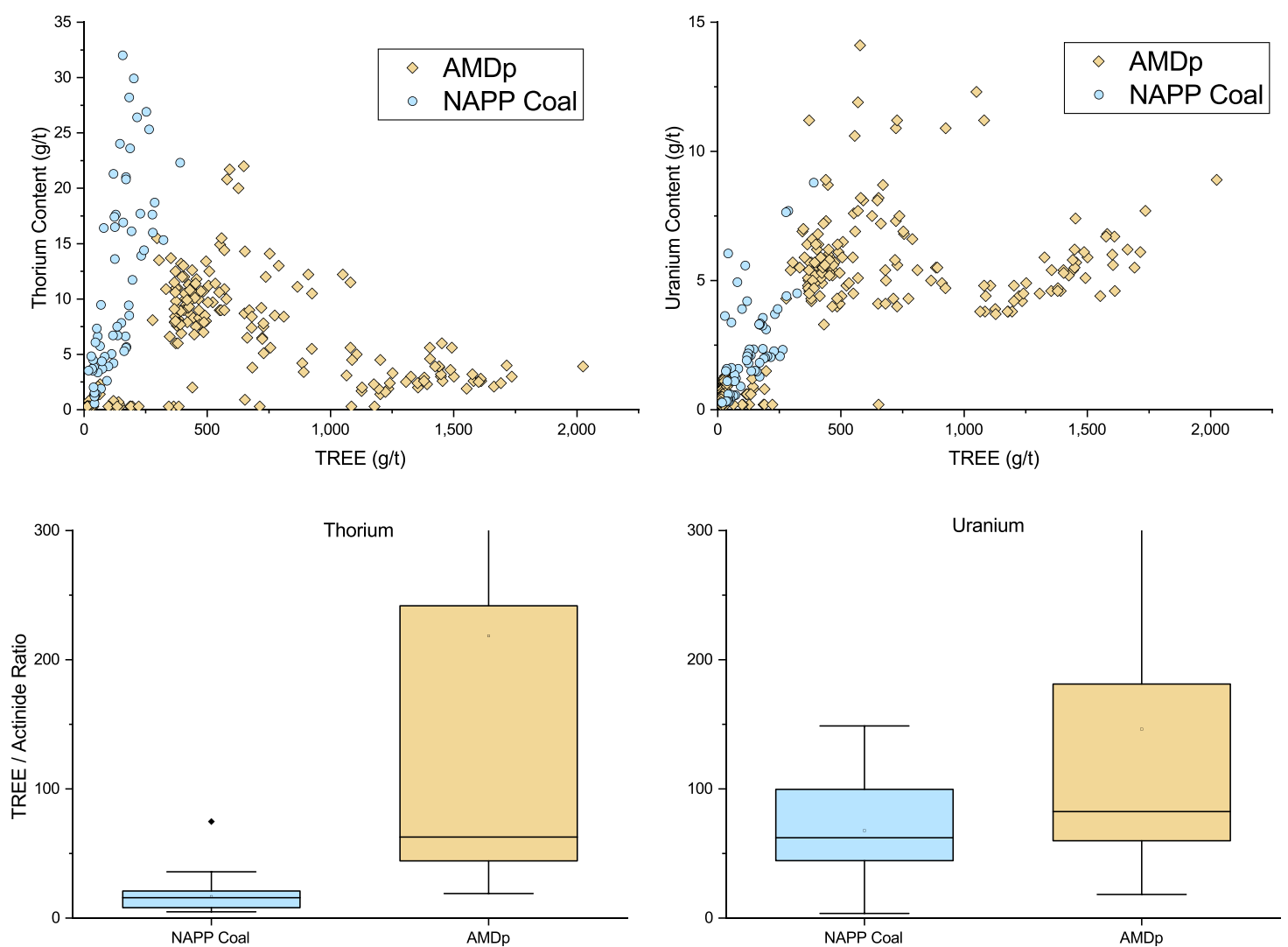

Fig. 8 Comparison of U and Th between NAPP coal and AMDp

to a toll refiner with advanced capabilities to turn the oxides into metal. Typically, these processes utilize a type of smelting or electrolysis to isolate REE metals. Finally, these metals would constitute a finished product that can be sold on the open market.

\subsection{Environmental and Civil Considerations}

AMD treatment within the coal industry currently focuses on simply meeting effluent limits. In meeting these limits, the AMD treatment process does not maximize the removal of metals and REEs. This compliance-based practice thus creates opportunities to increase treatment of the influent to further remove metals before the effluent is discharged into the environment. Should REEs become a revenue stream for AMD plant operators, the overall process could incentivize private or governmental organizations to purchase and treat additional AMD streams that are currently polluting waterways.

Incidentally, the REE revenue could even change mining practices within the Appalachian region. Currently, AMDproducing material is separated using specific material handling plans that result in this material being stored in nonoxidizing conditions or acid-producing overburden is mitigated with alkaline amendments. Alternatively, lined, spoil containment areas could be created in the form of heap-leaching structures. These leach beds would intentionally channel AMD to treatment plants where processing would subsequently follow. As a result, the pyritic AMD-producing spoil would not have an opportunity to adversely affect external waterways.

For most hard-rock REE deposits, uranium and thorium are common contaminants that require specialized handling and disposal during the treatment process. Notably, AMDp has very low concentrations of these elements relative to similar grade REE deposits. This decreased occurrence of the actinides is common among coal and coal byproduct REEs feedstocks; however, AMDp is also significantly lower in these actinides than NAPP coal sources, as shown in Fig. 8 [67].

Thermodynamic considerations (e.g., $\mathrm{pH}-\mathrm{EH}$ diagrams) show that uranium and thorium typically do not mobilize in solution at $\mathrm{pH}$ values greater than 1 [68]. Since typical AMD does not reach these low $\mathrm{pH}$ values, AMDp samples often contain very low concentrations. The AMDp samples in this study exhibited an average uranium and thorium concentration of 4.46 and $5.67 \mathrm{~g} / \mathrm{t}$, respectively. Conversely, monazite (a typical REE-bearing mineral) ores routinely contain 4 to $12 \%$ thorium along with uranium [69]. REE deposits with high concentrations of these actinides need to be evaluated with particular attention to these elements as demonstrated by the 2002 closure of the Mountain Pass mine [5]. 


\section{Conclusions}

In all, nine AMD sites were evaluated for REE content in both raw water and AMDp. This research has verified that REEs concentrate in the by-products of AMD treatment. These concentrated REEs in AMDp may also possess the qualities needed to justify their use as a viable feedstock resulting in a USbased REE supply. Additionally, a conceptual framework was presented to show different unit operations that could be implemented for the beneficiation of REEs from AMD. Finally, by utilizing these precipitates to refine the REEs, certain environmental incentives may mitigate additional AMD pollution.

The following key findings were developed during this research:

- Data from 81 samples showed that the REE concentration in AMD inflows was a strong function of $\mathrm{pH}$.

- For AMD influent samples with a $\mathrm{pH}<4$, the average TREE concentration was $371 \mu \mathrm{g} / \mathrm{L}$.

- For AMD influent samples with a $\mathrm{pH}>4$, the average TREE concentration was $88 \mu \mathrm{g} / \mathrm{L}$.

- Typically, the data showed that net-alkaline flooded underground mines had significantly lower TREE flux than net-acidic aboveground and surface mines.

- Traditional AMD treatment captured approximately $78 \%$ of the TREEs, leaving a precipitate with an average concentration of $517 \mathrm{~g} / \mathrm{t}$.

- A regional flow rate estimate showed that the total amount of REEs produced from AMD can vary between 771 and 3400 t per annum.

- The AMDp data indicated that the precipitate contains concentrations of thorium and uranium that are less than $6 \mathrm{~g} / \mathrm{t}$.

Acknowledgments This material is based upon work supported by the U.S. Department of Energy under Award Number DE-FE0026927.

\section{Compliance with Ethical Standards}

Disclaimer This report was prepared as an account of work sponsored by an agency of the United States Government. Neither the US Government nor any agency thereof, nor any of their employees, makes any warranty, express or implied, or assumes any legal liability or responsibility for the accuracy, completeness, or usefulness of any information, apparatus, product, or process disclosed, or represents that its use would not infringe privately owned rights. Reference herein to any specific commercial product, process, or service by trade name, trademark, manufacturer, or otherwise does not necessarily constitute or imply its endorsement, recommendation, or favoring by the US Government or any agency thereof. The views and opinions of authors expressed herein do not necessarily state or reflect those of the US Government or any agency thereof

Conflict of Interest The authors declare that they have no conflict of interest.

\section{References}

1. Fernandez V (2017) Rare-earth elements market: a historical and financial perspective. Resour Policy 53:26-45. https://doi.org/10. 1016/j.resourpol.2017.05.010

2. Schulz KJ, DeYoung JH, Seal RR, Bradley DC (2017) Critical mineral resources of the United States - economic and environmental geology and prospects for future supply Professional Paper 1802

3. Jordens A, Cheng YP, Waters KE (2013) A review of the beneficiation of rare earth element bearing minerals. Miner Eng 41:97-114. https://doi.org/10.1016/j.mineng.2012.10.017

4. Cox C, Kynicky J (2018) The rapid evolution of speculative investment in the REE market before, during, and after the rare earth crisis of 2010-2012. Extr Ind Soc 5:8-17. https://doi.org/10.1016/j.exis. 2017.09.002

5. Hellman PL, Duncan RK (2014) Evaluation of rare earth element deposits. Appl Earth Sci 123:107-117. https://doi.org/10.1179/ 1743275814Y.0000000054

6. Smyth J (2018) Lynas eyes legal action after Malaysia rare- earths blow. Financ Times London 18

7. Imholte DD, Nguyen RT, Vedantam A, Brown M, Iyer A, Smith BJ, Collins JW, Anderson CG, O'Kelley B (2018) An assessment of U.S. rare earth availability for supporting U.S. wind energy growth targets. Energy Policy 113:294-305. https://doi.org/10.1016/j. enpol.2017.11.001

8. U.S. Geological Survey (2018) Mineral Commodity Summaries 2018: US Geological Survey

9. Humphries M (2012) Rare earth elements: the global supply chain

10. Campbell GA (2014) Rare earth metals: a strategic concern. Miner Econ 27:21-31. https://doi.org/10.1007/s13563-014-0043-y

11. Goodenough KM, Wall F, Merriman D (2017) The rare earth elements: demand, global resources, and challenges for resourcing future generations. Nat Resour Res 27:1-16. https://doi.org/10. 1007/s11053-017-9336-5

12. Van Gosen B, Verplanck PL, Emsbo P (2019) Rare earth element mineral deposits in the United States

13. Preston JS, Cole PM, Craig WM, Feather AM (1996) The recovery of rare earth oxides from a phosphoric acid by-product. Part 1: leaching of rare earth values and recovery of a mixed rare earth oxide by solvent extraction. Hydrometallurgy 41:1-19. https://doi. org/10.1016/0304-386X(95)00051-H

14. Preston JS, Cole PM, Du Preez AC, Fox MH, Fleming AM (1996) The recovery of rare earth oxides from a phosphoric acid by-product. Part 2: the preparation of high-purity cerium dioxide and recovery of a heavy rare earth oxide concentrate. Hydrometallurgy 41:21-44. https://doi.org/10.1016/0304-386X(95)00067-Q

15. Preston JS, Du Preez AC, Cole PM, Fox MH (1996) The recovery of rare earth oxides from a phosphoric acid by-product. Part 3. The separation of the middle and light rare earth fractions and the preparation of pure europium oxide. Hydrometallurgy 42:131-149. https://doi.org/10.1016/0304-386X(95)00079-V

16. Preston JS (1996) The recovery of rare earth oxides from a phosphoric acid byproduct. Part 4 . The preparation of magnet-grade neodymium oxide from the light rare earth fraction. Hydrometallurgy 42:151-167. https://doi.org/10.1016/0304386X(95)00082-R

17. Binnemans K, Jones PT, Blanpain B, Van Gerven T, Yang Y, Walton A et al (2013) Recycling of rare earths: a critical review. J Clean Prod 51:1-22. https://doi.org/10.1016/j.jclepro.2012.12.037

18. Rademaker JH, Kleijn R, Yang Y (2013) Recycling as a strategy against rare earth element criticality: a systemic evaluation of the potential yield of NdFeB magnet recycling. Environ Sci Technol 47:10129-10136. https://doi.org/10.1021/es305007w

19. Finkleman RB (1993) Trace and minor elements in coal. In: Engel MH, Macko SA (eds) Org. Geochem. Springer, Boston, p 594 
20. Schofield A, Haskin L (1964) Rare-earth distribution patterns in eight terrestrial materials. Geochim Cosmochim Acta 28:437446. https://doi.org/10.1016/0016-7037(64)90117-6

21. Zubovic P, Stadnichenko T, Sheffey NB Distribution of minor elements in coals of the Appalachian region, Washington, D.C, p 1966

22. Cravotta CA (2008) Dissolved metals and associated constituents in abandoned coal-mine discharges, Pennsylvania, USA. Part 1: Constituent quantities and correlations 23:166-202. https://doi. org/10.1016/j.apgeochem.2007.10.011.

23. United States Department of Energy (2017) Rare earth elements from coal and coal byproducts

24. Hower J, Granite E, Mayfield D, Lewis A, Finkelman R (2016) Notes on contributions to the science of rare earth element enrichment in coal and coal combustion byproducts. Minerals 6:32. https://doi.org/10.3390/min6020032

25. Ziemkiewicz PF, He T, Noble A, Liu X (2016) Recovery of rare earth elements (REEs) from coal mine drainage. West Virginia Mine Drain. Task Force Symp., Morgantown, WV

26. Skousen JG, Sexstone A, Ziemkiewicz PF (2000) Acid mine drainage control and treatment. Reclam Drastically Disturb Lands, pp 1-42

27. Hoehn RC, Sizemore DR (1977) Acid mine drainage (AMD) and its impact on a Virginia stream. Water Resour Bull 13:153-160. https://doi.org/10.1111/j.1752-1688.1977.tb02000.x

28. Acid Mine Drainage Prediction (1994) Washington, D.C. EPA 530R-94-036

29. Akcil A, Koldas S (2006) Acid mine drainage (AMD): causes, treatment and case studies. J Clean Prod 14:1139-1145. https:// doi.org/10.1016/j.jclepro.2004.09.006

30. Kalin M, Fyson A, Wheeler WN (2006) The chemistry of conventional and alternative treatment systems for the neutralization of acid mine drainage. Sci Total Environ 366:395-408. https://doi. org/10.1016/j.scitotenv.2005.11.015

31. Kleinmann RLP (2001) Prediction of water quality at surface coal mines. Natl Mine L Reclam Cent Located West Virginia Univ Morgantown, West Virginia 239:247

32. Hill DW (1969) Neutralization of acid mine drainage. Ater Pollut Control Fed 41:1702-15.

33. Ziemkiewicz PF (1998) Steel slag : applications for AMD control. Proc 1998 Confrence Hazard Waste Res, p 44-62.

34. Gazea B, Adam K, Kontopoulos A (1996) A review of passive systems for the treatment of acid mine drainage. Miner Eng 9:2342. https://doi.org/10.1016/0892-6875(95)00129-8.

35. USEPA (1983) Design manual: neutralization of acid mine drainage. Cincinnati, $\mathrm{OH}$

36. Ackman TE (1982) Sludge disposal from acid mine drainage treatment. Avondale, MD

37. Payette C, Lam W, Angle C, Mikula R (1991) Evaluation of improved lime neutralization proccesses. Proc. Second Int. Confrence Abat. Acidic Drain., Monreal, Can

38. Johnson DB, Hallberg KB (2005) Acid mine drainage remediation options: a review. Sci Total Environ 338:3-14. https://doi.org/10. 1016/j.scitotenv.2004.09.002

39. Demchak J, Skousen J, McDonald LM (2013) Longevity of acid discharges from underground mines located above the regional water table. J Environ Qual 33:656. https://doi.org/10.2134/jeq2004.6560

40. Light DDM, Donovan JJ (2015) Mine-water flow between contiguous flooded underground coal mines with hydraulically compromised barriers. Environ Eng Geosci 21:147-164. https://doi.org/10. 2113/gseegeosci.21.2.147

41. Capo RC, Winters WR, Weaver TJ, Stafford SL, Hedin RS, Stewart BW (2001) Hydrogeologic and geochemical evolution of deep mine discharges, Irwin Syncline, Pennsylvania. Proc. - West Virginia Surf. Mine Drain. Task Force Symp., vol 22, p 144-53

42. Skousen J, Simmons J, McDonald LM, Ziemkiewicz P (2002) Acidbase accounting to predict post-mining drainage quality on surface mines. J Environ Qual 31:2034. https://doi.org/10.2134/jeq2002.2034
43. Mack B, McDonald LM, Skousen J (2010) Acidity decay of abovedrainage underground mines in West Virginia. J Environ Qual 39: 1043. https://doi.org/10.2134/jeq2009.0229

44. Seredin VV, Dai S (2012) Coal deposits as potential alternative sources for lanthanides and yttrium. Int J Coal Geol 94:67-93. https://doi.org/10.1016/j.coal.2011.11.001

45. Papangelakis VG, Moldoveanu G. Recovery of rare earth elements from clay minerals. 1st Eur Rare Earth Resour Conf 2014:191-202

46. Gupta T, Ghosh T, Akdogan G, Srivastava VK (2017) Characterizing rare earth elements in Alaskan coal and ash. Miner Metall Process 34: 138-145. https://doi.org/10.19150/mmp.7614

47. Taylor SR (1964) Abundance of elements in the crust: a new table. Geochim Cosmochim Acta 28:1273-1285. https://doi.org/10.1016/ 0016-7037(64)90129-2

48. Cravotta CA, Brady KB., Rose AW, Douds JB (1999) Frequency distribution of the $\mathrm{pH}$ of coal-mine drainage in pennsylvania. US Geol Surv Water-Resources Investig Report 99-4018A, pp 313-24

49. Zhang W, Rezaee M, Bhagavatula A, Li Y, Groppo J, Honaker R (2015) A review of the occurrence and promising recovery methods of rare earth elements from coal and coal by-products. Int J Coal Prep Util 35:295-330. https://doi.org/10.1080/19392699.2015. 1033097

50. Cravotta CA (2008) Dissolved metals and associated constituents in abandoned coal-mine discharges, Pennsylvania, USA. Part 2: geochemical controls on constituent concentrations. Appl Geochem 23: 203-226. https://doi.org/10.1016/j.apgeochem.2007.10.003

51. Goode DJ, Cravotta CA, Hornberger RJ, Hewitt MA, Hughes RE, Koury DJ, et al (2013) Water budgets and groundwater volumes for abandoned underground mines in the Western Middle Anthracite Coalfield, Schuylkill, Columbia, and Northumberland Counties, Pennsylvania - preliminary estimates with identification of data needs. Reston, VA

52. Denicola TA, Donovan JJ, Leavitt BR, Sharma S (2013) Geochemistry of mine pool discharges in the Pittsburgh Coal Basin Thesis Submitted to: The Eberly College of Arts and Sciences at West Virginia University in partial fulfillment of the requirements for the degree of Masters of Science In Geology Departme

53. Stewart BW, Capo RC, Hedin BC, Hedin RS (2016) Rare earth element resources in coal mine drainage and treatment precipitates in the Appalachian Basin, USA. Int J Coal Geol 169:28-39. https:// doi.org/10.1016/j.coal.2016.11.002

54. Cordier DJ, Hedrick JB (2010) 2008 Minerals yearbook - rare earths

55. Cordier DJ (2011) 2009 Minerals yearbook

56. Gambogi BJ, Cordier DJ (2012) 2010 Minerals yearbook

57. Gambogi J (2013) 2011 Minerals yearbook

58. Gambogi J (2013) 2012 Minerals yearbook - rare earths

59. Gambogi J (2016) 2013 Minerals yearbook - rare earths

60. Gambogi J (2014) 2014 Minerals yearbook - rare earths

61. Gambogi J (2018) 2015 Minerals yearbook

62. Honaker RQ, Groppo J, Yoon R-H, Luttrell GH, Noble A, Herbst JA (2017) Process evaluation and flowsheet development for the recovery of rare earth elements from coal and associated byproducts. Miner Metall Process 34:107-115. https://doi.org/10. 19150/mmp.7610

63. Noble A, Luttrell GH (2016) Micro-pricing: the value of trace rare earth elements in coal and coal byproducts. 2016 SME Annu Confrence Expo; Preprint N:1-6

64. Binnemans K, Jones PT, Müller T, Yurramendi L (2018) Rare earths and the balance problem: how to deal with changing markets? J Sustain Metall 8:126-146. https://doi.org/10.1007/s40831-018-0162-8

65. Lifton J, Hatch G (2016) Technology Metals Research. http://www. techmetalsresearch.com/metrics-indices/tmr-advanced-rare-earthprojects-index/. Accessed 10/09/2017 
66. Verbaan N, Bradley K, Brown J, Mackie S (2015) A review of hydrometallurgical flowsheets considered in current REE projects

67. National Energy Technology Laboratory UD of E (2018) Rare earth element database. https://edx.netl.doe.gov/ree/?page_id=1587. Accessed 12/14/2018

68. Kim E, Osseo-Asare K (2012) Aqueous stability of thorium and rare earth metals in monazite hydrometallurgy: Eh-pH diagrams for the systems Th-, Ce-, La-, Nd- (PO4)-(SO4)-H2O at $25^{\circ} \mathrm{c}$. Hydrometallurgy 113-114:67-78. https://doi.org/10.1016/j. hydromet.2011.12.007
69. Gupta CKK, Krishnamurthy N (1992) Extractive metallurgy of rare earths. vol 37. https://doi.org/10.1179/imr.1992.37.1.197.

Publisher's Note Springer Nature remains neutral with regard to jurisdictional claims in published maps and institutional affiliations. 


\section{Chapter 3}

\section{Regional Survey of Rare Earth}

\section{Elements in Acid Mine Drainage}

This chapter contains an author approved manuscript that will be published as:

C. R. Vass, A. Noble, and P. F. Ziemkiewicz, "The occurrence and concentration of rare earth elements in acid mine drainage and treatment byproducts. Part 2: Regional survey of Northern and Central Appalachian coal basins," 2019. https://doi.org/10.1007/s42461-01900112-9

Contributions:

- C.V. - main author, field sampling, processing of data, data interpretation, manuscript composition

- A.N. - supervisory author, critically revised manuscript and, provided statistical

- P.Z. - principal investigator, supervisory author, revised final manuscript

\subsection{Introduction}

Rare earth elements (REEs) are essential for many industrial processes and high-tech end use applications, including: catalysts, metallurgy, petroleum refining, catalytic converters, 
ceramics, glass additives, phosphors, magnets, and electronics [2]. From 2015 to 2018, the United States consumed between 9,500 and 10,500 metric tons of REEs per year and was heavily reliant on imports from China over that period [3]. Given the variety of end use applications for REEs, future demand projections for specific REEs are difficult to predict; however, the exponential growth in electronic devices as well as the lack of suitable REE substitutes in these products, suggest that REEs will continue to be a significant and strategic mineral resource for the foreseeable future $[4,5]$. In particular, several researchers have noted a strong future demand for Yttrium, Neodymium, Europium, Terbium, and Dysprosium, all of which are often denoted critical REEs by the US Department of Energy $[6,7]$.

Given risks associated with REE supply shortages, a multitude of stakeholders including researchers, national governments, and private companies have attempted to identify alternative and unconventional REE resources. For example, in the mid-1990s, research in South Africa investigated the feasibility of recovering rare earth oxides from byproducts of the phosphoric acid production process [8-11]. These studies showed that process is technically feasible, and the researchers were ultimately able to produce high-grade Nd-Pr oxide products. In addition, other researchers recently reviewed recycling of REEs from electronic scrap [12]. Unfortunately, this study showed that up to 2011, most of the efforts in this area were restricted to laboratory-scale research and the end-of-life recycling rate of REEs was less than 1\%. According to the U.S. Geological Survey, recycling and alternative sources of REE still only account for limited quantities, and no large-scale commercial efforts have been initiated [3,13]. Even if successful, these efforts will not fully compensate for the projected increase in demand over the next several years [14].

Another potential source of REEs that has received recent attention is geologic material associated with coal and coal byproducts. While the presence of REEs in coal has long been established by many researchers, dating back to at least the 1960s and 1970s [15-17], efforts to extract and concentrate these elements are fairly recent. In 2015, the U.S. Department of Energy - National Energy Technology Laboratory initiated 10 projects representing $\$ 10.6$ million in funds to investigate the technical and economic feasibility of recovering REEs from coal and coal byproducts $[13,18]$. Many of these initial studies focused on solid-phase feed- 
stocks, including coal tailings (refuse) and coal fly ash [19-36]; however, another potential resource is the aqueous-phase acid mine drainage (AMD) generated through coal mining. Successfully developing this resource has the potential to remediate past environmental disturbances, while addressing the issue of resource scarcity.

The first paper in this series identified the presence of REEs in AMD and assessed the general prospectivity of this potential resource [1]. This preliminary work surveyed nine Northern Appalachian (NAPP) AMD sites and identified higher occurrences of REEs in the more acidic AMD flows. Additionally, the initial prospecting study indicated that over $75 \%$ of the REE flux is captured and enriched in the AMD treatment byproducts, often called AMD sludge or AMD precipitate (AMDp). This traditional treatment was shown to concentrate REEs by a factor of 2,000 when comparing the initial aqueous inflows to the solid byproducts. Overall, this study confirmed the prospectivity of the resource but also identified additional questions that must be addressed to better understand the quantity and quality of the resource. Most notably, the limited number (nine) and geographic region (NAPP) of sample sites precluded generic conclusions applicable to the larger coal mining district.

The current technical literature lacks data from systemic studies that describe the content and distribution of REEs in AMD and AMDp. As a result, few researchers have critically analyzed the value chain that can be derived from this current waste stream. Given the promising findings in the initial survey, the authors pursued a comprehensive sampling program to characterize the AMD-based REE resource in two important Eastern U.S. coal fields. The program included 141 AMD treatment sites in the Northern and Central Appalachian coal basins. The sites were extensively sampled to determine regional production, storage, elemental distributions of REEs and critical minerals within the AMD based resource. Lastly, the study investigated the effects that different cut-off grades would have on the overall size of the sampled resource. 


\subsection{Materials and Methods}

\subsubsection{Overall Experimental Objectives and Approach}

The current study employed a large-scale regional sampling campaign to evaluate the concentration and quantity of REEs in AMD and AMDp across the Northern Appalachian and Central Appalachian (CAPP) coal basins. The NAPP and CAPP coal basins vary significantly in regard to coal seam quality and geologic lithology [17]. The NAPP basin coal is associated with younger deposits and the coals typically contain a higher sulfur concentration that is more suitable for use in steam generation. Alternatively, the CAPP basin contains both metallurgical and steam coal with a generally lower overall sulfur content $[18,19]$. Because of these differences, the two basins were recognized as separate sample populations.

Following the sampling campaign, individual solid phase (AMDp) and aqueous (AMD) sample splits were characterized for REE and major metal content. The data was then analyzed to determine: (1) the typical aqueous and AMDp REE concentrations and the factors that influence those concentrations; (2) any differences between the two basins with respect to concentration or distribution of REEs; (3) the potential size of the REE resource that can be realized from AMD; and (4) the effect that process cutoff grade may have on the overall AMD-based REE resource in the Appalachian basin.

\subsubsection{Site Selection and Sampling Locations}

Throughout the study, 141 coal-based AMD treatment site outflows were sampled in the NAPP and CAPP coal basins. Each of these sites employs active chemical treatment of AMD to meet regulatory effluent discharge limits. As a result, both AMD and AMDp were available for sampling. Figure 1 shows the location and number of sampling sites within each county and coal basin. Table 1 shows the general sampling characteristics of sites within each basin. 


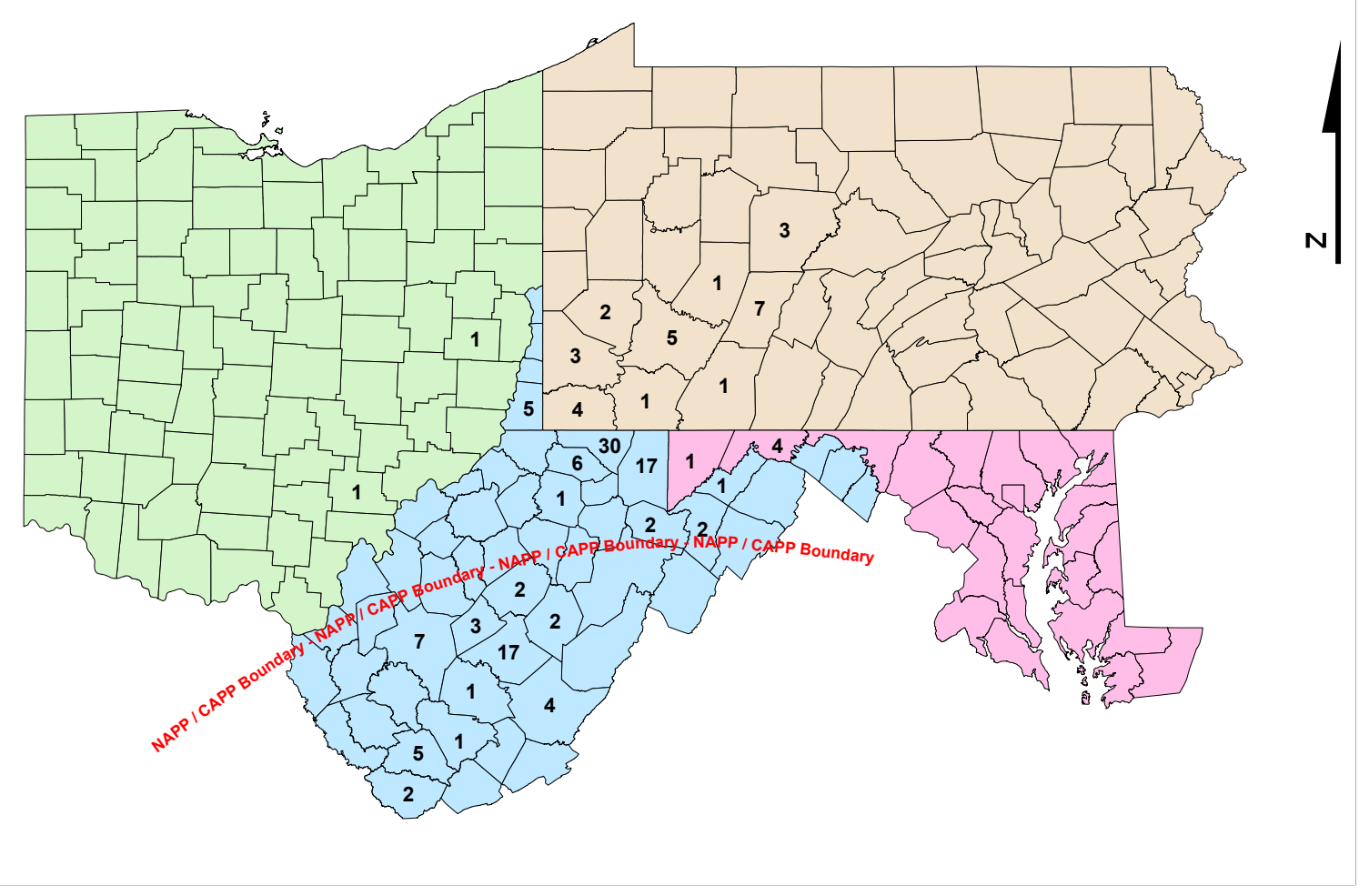

Figure 3.1 - County-level map showing number of AMD sites sampled per county and Northern vs. Central Appalachian boundary

Table 3.1 - AMD sites and sampling quantities by basin. Note some sites contained multiple AMDp storage cells serving a given AMD discharge point. (CAPP, NAPP $=$ Central and Northern Appalachian Coal Basins respectively).

\begin{tabular}{ccccc}
\hline Basin & \multicolumn{2}{c}{ Treatment Sites } & \multicolumn{2}{c}{ Number of Samples } \\
AMD & AMDp & AMD & AMDp \\
\hline CAPP & 44 & 56 & 51 & 141 \\
NAPP & 97 & 96 & 134 & 482 \\
\hline TOTAL & 141 & 152 & 185 & 623
\end{tabular}

\subsubsection{Site Sampling Protocols}

Sampling was conducted in two campaigns. The initial sampling consisted of a regional survey of 141 AMD discharges and formed the basis for estimating the REE resource available in surface AMDp storage cells and the annual REE production rate (flux) based on AMD generation regardless the disposition of AMDp. For example, AMDp might be stored in surface cells, buried in surface mining operations, or injected into deep mine voids. Only the former was available for sampling. A subsequent, intensive sampling campaign focused on 
potentially attractive sites based on either surface sludge resource or REE flux. A maximum of ten AMDp samples were taken on each site. Thus, between one and ten samples were collected and analyzed for each of the 141 sites shown in Figure 1. Statistical analysis was conducted on those sites with multiple samples to assess variation within a single site.

The detailed sampling and analytical procedures have been described in our prior study [1], and the pertinent details are repeated here for convenience. Aqueous samples were collected in a clean 1,000 ml HDPE sample bottle. Next, this sample was split into two separate containers (one preserved and one raw) for further analysis. Nitric acid (2\%) was added to the preserved sample bottle for REE analysis, whereas the raw sample was evaluated for major ions. Afterwards, the raw water sample was stored at $4^{\circ} \mathrm{C}$, until it was ultimately delivered to the National Research Center for Coal and Energy (NRCCE) analytical laboratory at West Virginia University, for analysis. Finally, the aqueous phase REE concentrations were determined by TestAmerica, Inc. While on site, raw (untreated) AMD was characterized with respect to flow rate, temperature, electrical conductivity, and $\mathrm{pH}$.

AMDp samples were collected by hand using a shovel or post-hole digger at or near the edge of the drying cell. For intensive sampling, up to nine samples were taken across each drying cell or from multiple cells if present. Samples were placed in new one-gallon HDPE sample buckets. Later, the AMDp samples were split into $50 \mathrm{ml}$ representative aliquots for ICP analysis in a controlled environment. These sub-samples were then placed in $50 \mathrm{ml}$ digestion tubes for transport to SGS Canada Inc. for determination of REE and major ions.

While efforts were made to ensure the integrity of the sampling process, representative samples of entire AMDp cells were often difficult to obtain in a safe manner due to the depth and semi-liquid consistency of the precipitate. Typical AMDp drying/storage cells are up to $3 \mathrm{~m}$ in depth. As a result, the degree to which the samples are representative of the entire cell is unknown. For example, AMDp often stratifies vertically as operating conditions at the AMD treatment plant vary. We attempted to minimize this effect by sampling from the surface to maximum practical depth. Where practical, multiple AMDp samples were collected at differing depths across a drying cell. Also, some locations used clarifiers for solid/liquid separation and pump the underflow directly to abandoned underground mine 
works, these samples were collected directly from the clarifier underflow. In either case, the sampling methods used in this study were deemed appropriate for the study objectives and scope of work, which seek to address large scale variation across the entire basin. Detailed geospatial resolution on single AMDp storage sites is beyond the scope of this current work but is recommended for future studies.

\subsubsection{Sample Analysis and Characterization}

The collected aqueous and precipitate samples were analyzed using ICP-MS for the REEs by TestAmerica Laboratories, Inc. and SGS Canada Inc., respectively. Additionally, West Virginia University's NRCCE Analytical Laboratory used an ICP-OES to analyze the other

major ions. All of these laboratories are certified by their respective state/provincial agencies to assay the respective analytes. AMDp was digested using a sodium peroxide (Na2O2) fusion and re-dissolved in hydrochloric acid. This method is comparable with the United States Environmental Protection Agency's total digestion method 3052 for TREEs as well as U.S. Geologic Survey's Method 20 for ICP-OES-MS analysis. Minimum detection limits for the aqueous rare earths were typically in the $0.02 \mathrm{ppb}$ range, while the solid REE analysis had MDL's ranging from 5 to $0.5 \mathrm{ppm}$. Major metal ions were measured in aqueous samples with MDL's similar to those of the aqueous REEs. Finally, all solid samples are reported on a dry basis.

\subsubsection{Data Analysis and Modeling}

The mass of REEs in a given storage cell was calculated using the cell volume, the measured REE concentration on a dry-weight basis, the measured moisture content sample, and the measured AMDp density according to:

$$
\text { REEMass }=\text { Area } * \text { Depth } *(1-\text { MoistureContent }) * \text { REEContent }_{D W B} * \text { Density }
$$


For the volumetric calculations, additional geographic data was collected on the location, size, and depth of each AMDp storage cell during the on-site sampling campaign. Afterwards, where applicable, these dimensions were confirmed using geospatial software and satellite imagery. In cases where depth data was not available, it was estimated based on the observable height of the drying cell above grade, not to exceed 10 feet. The moisture content of each AMDp sample was determined by full desiccation and reported with the REE analysis by SGS Canada Inc. Lastly, an average sludge density was determined to be $2.20 \mathrm{~g} / \mathrm{cc}(95 \%$ confidence interval $=2.16$ to 2.23$)$ based on gravimetric analysis of 9 random samples from the population. This value was used in calculations for all sites.

With the large quantity of data gathered through both field sampling and analytical analysis, modeling methods were employed to determine the most influential factors controlling REE content in AMD and AMDp. A partial least squares analysis was conducted to determine the most significant variables in predicting the AMD REE content based on the field and analytical variables. Next, multiple linear regression was used to model the REE concentration based on the significant variables.

A similar analysis was attempted for AMDp; however, results were unsuccessful. While AMD REE concentrations can be predicted using the identified independent variables, additional and unmeasured process variables interfered with the prediction models. Model correlation coefficients never exceed 0.55 indicating poor precision. It is likely that the wide array of treatment methods and operating conditions inhibited the successful completion of the modeling of AMDp concentrations based on AMD qualities.

To assess the resource, AMDp was analyzed using a grade-tonnage model. To apply this method to the AMDp resource, each site was considered as an individual block. This methodology was used to then calculate the cumulative tonnage of REEs and the average grade of all the sites (blocks) inclusive of the cut-off grade. Grade-tonnage models are used to graphically show how different processing cut-off grades will impact the overall size of a resource.

Different classifications have been used by several authors including Seredin and Dai [37], Cox and Kynicky [38], and Binnemans et al. [39] to analyze the occurrence of REEs. These designations may be defined by an organization based on simple atomic numbers (light REE 
vs. heavy REE) or can be based on other relationships, such as supply and demand (critical REE vs. excessive REE). For this paper, the following classifications will be observed:

- Heavy REEs (HREE) - Sc, Y, Gd, Tb, Dy, Ho, Er, Tm, Yb, Lu

- Light REEs (LREE) - La, Ce, Pr, Nd, Sm, Eu

- Total REEs (TREE) - HREE + LREE

- Critical REEs (CREE) - Y, Nd, Eu, Tb, Dy

\subsection{Results and Discussion}

\subsubsection{Concentration of REEs in AMD}

Table 2 shows the average concentrations of REEs and major metals in the raw AMD for both CAPP and NAPP samples. The average TREE concentrations in raw AMD varied by $75 \mathrm{\mu g} / \mathrm{L}$ between the two basins; however, a two-tailed t-test failed to reject the null hypothesis $(\mathrm{p}=0.32)$, indicating that the observed difference in REE content between the two basins is not significant. The element-by-element comparisons show that Sc was the only REE that produced a p value (0.01) less than the critical level $(\alpha=0.05)$, indicating that the NAPP AMD samples are significantly enriched in Sc when compared to the CAPP AMD samples. Alternatively, the major metal data does show a significant difference for many of the metals evaluated in this study. The t-tests indicate that the NAPP samples were significantly enriched in $\mathrm{Al}, \mathrm{Fe}, \mathrm{Mg}, \mathrm{Na}, \mathrm{Si}$, and $\mathrm{SO} 4$. In addition, the average $\mathrm{Cl}$ content was very high in the NAPP samples; however, the t-test failed to reject the null hypothesis due to the high variance in $\mathrm{Cl}$ values measured in the NAPP AMD samples (range: 0.02 to 14,501 $\mathrm{mg} / \mathrm{L}$ ). The high $\mathrm{Na}$ and $\mathrm{Cl}$ values in NAPP AMD can be explained by the depositional setting, as the NAPP coal formed in this basin is associated with a marine environment [17]. Likewise, Fe was also more prevalent in the NAPP basin which is consistent with higher pyritic sulfur. 
Table 3.2 - REE concentrations for raw aqueous AMD influent in Appalachian basin study

\begin{tabular}{|c|c|c|c|c|c|c|c|c|}
\hline \multirow[b]{2}{*}{ Element } & \multicolumn{3}{|c|}{ CAPP AMD $(n=52)$} & \multicolumn{3}{|c|}{ NAPP AMD $(n=133)$} & \multirow[b]{2}{*}{$\begin{array}{l}\text { CAPP vs. } \\
\text { p value }\end{array}$} & \multirow[b]{2}{*}{$\begin{array}{l}\text { NAPP }^{1} \\
<\alpha ?\end{array}$} \\
\hline & Mean & $\begin{array}{c}\text { Confidence } \\
\text { Interval }\end{array}$ & $\begin{array}{l}\text { CI:Mean } \\
\text { Ratio }\end{array}$ & Mean & $\begin{array}{c}\text { Confidence } \\
\text { Interval }\end{array}$ & $\begin{array}{c}\text { CI:Mean } \\
\text { Ratio }\end{array}$ & & \\
\hline \multicolumn{9}{|l|}{ REE $(\mu \mathrm{g} / \mathrm{L})$} \\
\hline $\mathrm{Sc}$ & 3.09 & 1.11 & 0.36 & 6.38 & 1.56 & 0.25 & 0.01 & yes \\
\hline $\mathbf{Y}$ & 49.69 & 20.38 & 0.41 & 81.08 & 24.17 & 0.30 & 0.13 & \\
\hline $\mathbf{L a}$ & 26.82 & 15.08 & 0.56 & 21.21 & 6.76 & 0.32 & 0.44 & \\
\hline $\mathrm{Ce}$ & 53.66 & 27.43 & 0.51 & 63.57 & 19.29 & 0.30 & 0.58 & \\
\hline Pr & 8.03 & 3.92 & 0.49 & 9.85 & 2.84 & 0.29 & 0.49 & \\
\hline Nd & 37.22 & 17.06 & 0.46 & 46.14 & 13.29 & 0.29 & 0.46 & \\
\hline $\mathrm{Sm}$ & 9.73 & 4.01 & 0.41 & 13.33 & 3.61 & 0.27 & 0.26 & \\
\hline $\mathbf{E u}$ & 2.64 & 0.98 & 0.37 & 3.80 & 1.03 & 0.27 & 0.19 & \\
\hline Gd & 12.39 & 4.92 & 0.40 & 18.66 & 5.22 & 0.28 & 0.16 & \\
\hline $\mathrm{Tb}$ & 1.95 & 0.71 & 0.36 & 3.15 & 0.84 & 0.27 & 0.09 & \\
\hline Dy & 10.57 & 4.28 & 0.40 & 17.06 & 4.83 & 0.28 & 0.12 & \\
\hline Ho & 1.95 & 0.73 & 0.37 & 3.31 & 0.90 & 0.27 & 0.08 & \\
\hline Er & 4.99 & 2.08 & 0.42 & 8.34 & 2.42 & 0.29 & 0.11 & \\
\hline $\mathbf{T m}$ & 0.81 & 0.24 & 0.30 & 1.29 & 0.30 & 0.23 & 0.06 & \\
\hline $\mathbf{Y b}$ & 3.89 & 1.57 & 0.40 & 6.40 & 1.81 & 0.28 & 0.11 & \\
\hline $\mathbf{L u}$ & 0.71 & 0.21 & 0.29 & 1.08 & 0.25 & 0.23 & 0.08 & \\
\hline TREE & 228.14 & & & 304.67 & & & 0.32 & \\
\hline HREE/TREE & $39.5 \%$ & & & $48.2 \%$ & & & & \\
\hline CREE/TREE & $44.7 \%$ & & & $49.6 \%$ & & & & \\
\hline \multicolumn{9}{|c|}{ Major Ions (mg/L) } \\
\hline $\mathrm{Al}$ & 12.99 & 5.18 & 0.40 & 23.14 & 4.86 & 0.21 & 0.02 & yes \\
\hline $\mathbf{C a}$ & 167.95 & 27.18 & 0.16 & 177.47 & 22.77 & 0.13 & 0.64 & \\
\hline $\mathbf{F e}$ & 22.37 & 14.57 & 0.65 & 60.07 & 22.32 & 0.37 & 0.04 & yes \\
\hline $\mathrm{Mg}$ & 123.84 & 26.96 & 0.22 & 75.82 & 10.79 & 0.14 & 0.00 & yes \\
\hline Mn & 10.74 & 3.36 & 0.31 & 9.49 & 2.44 & 0.26 & 0.58 & \\
\hline $\mathrm{Na}$ & 36.72 & 18.74 & 0.51 & 523.52 & 187.96 & 0.36 & 0.00 & yes \\
\hline $\mathrm{Si}$ & 10.98 & 2.25 & 0.21 & 14.28 & 1.66 & 0.12 & 0.03 & yes \\
\hline $\mathrm{Cl}$ & 5.30 & 2.92 & 0.55 & 306.42 & 242.47 & 0.79 & 0.12 & \\
\hline SO4 & 1090.94 & 196.48 & 0.18 & 1717.29 & 340.54 & 0.20 & 0.03 & yes \\
\hline
\end{tabular}

1: $p$ value as determined by two-tailed, equal variance t-test, a value of 0.05 used for significance

The full distribution of TREE data for the NAPP and CAPP raw AMD samples is shown in Figure 2. The significant overlap in the datasets provides graphical confirmation of the t-test results and suggests that the same geochemical processes dictate the REE concentration in AMD in both basins. This outcome is expected as AMD chemistry represents the largescale integration of reactions that occur at small scales, such as the pore water surrounding pyritic versus non-pyritic rock grains, and localized oxidizing versus reducing environments. Integration occurs over the scale of mines ranging from hundreds of acres to 20 square miles or more in the case of large, underground mines. The more interesting component of this plot is the large range of TREE concentrations for both basins. The NAPP basin in particular 


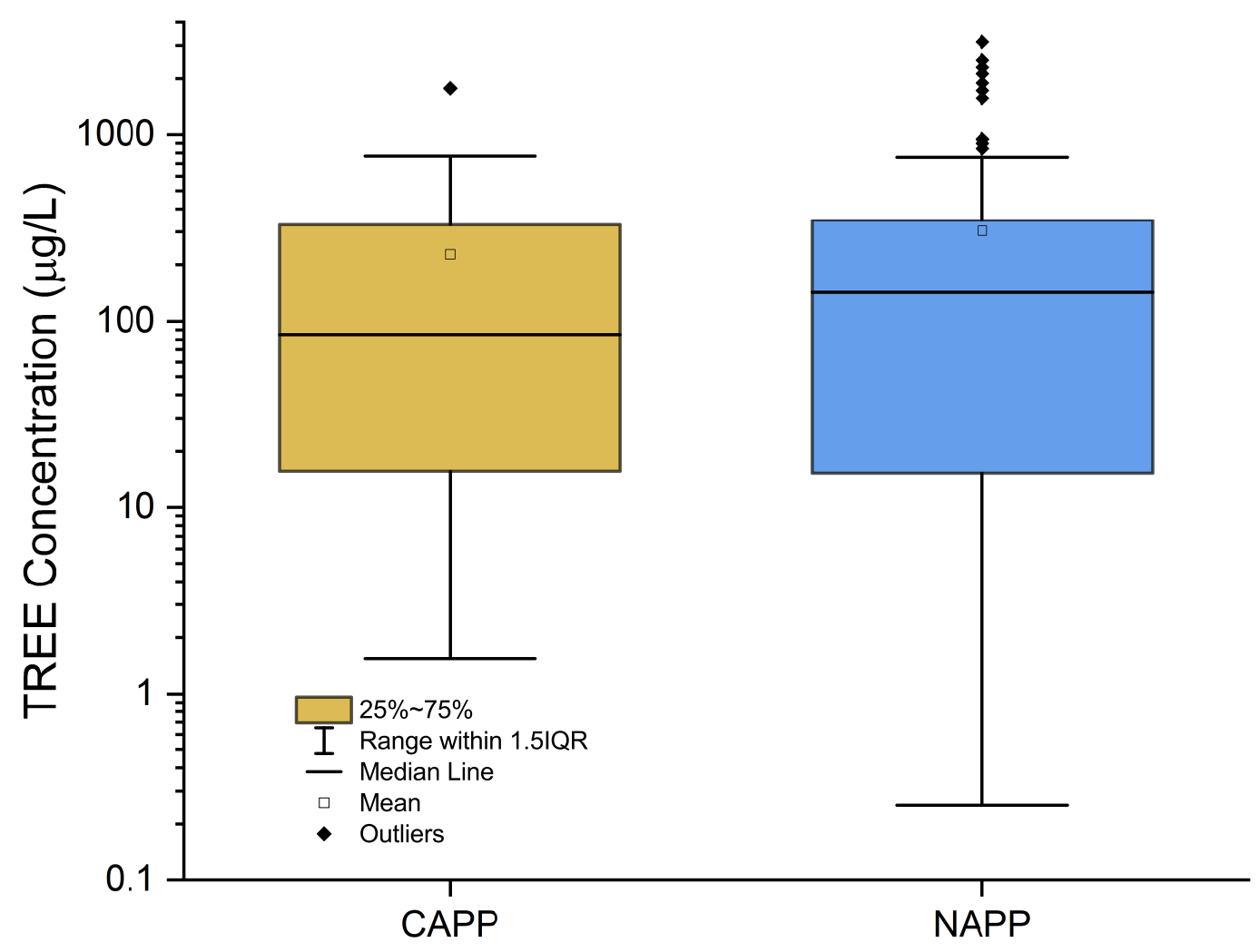

Figure 3.2 - Distribution of total REEs in NAPP and CAPP raw AMD samples

has TREE concentrations that span five orders of magnitude, with a low $0.25 \mu \mathrm{g} / \mathrm{L}$ and a high of $3,100 \mu \mathrm{g} / \mathrm{L}$. Altogether, this result indicates that the processes that control AMD formation also control REE leaching and occurrence in the AMD discharge [40].

To assess the distribution of individual REEs, the data was normalized to the REE content of a standard chondrite sample [41]. Figure 3 shows the average results of this chondrite normalization along with bands for the $95 \%$ confidence interval. Similar to the TREE data, the NAPP and CAPP distributions have significant overlap, further confirming the quantitative results of the t-test. With regard to the general shape of the curve, chondrite normalized REE plots for coal-based materials typically follow a serially decreasing order from La to $\mathrm{Lu}$, with the lone exception being the Eu anomaly [30]. The chondrite normalized AMD plots follow this trend but show some deviation for La and Ce (particularly the NAPP curve, where La and Ce are both less than Pr). This result may indicate that AMD has a slight 


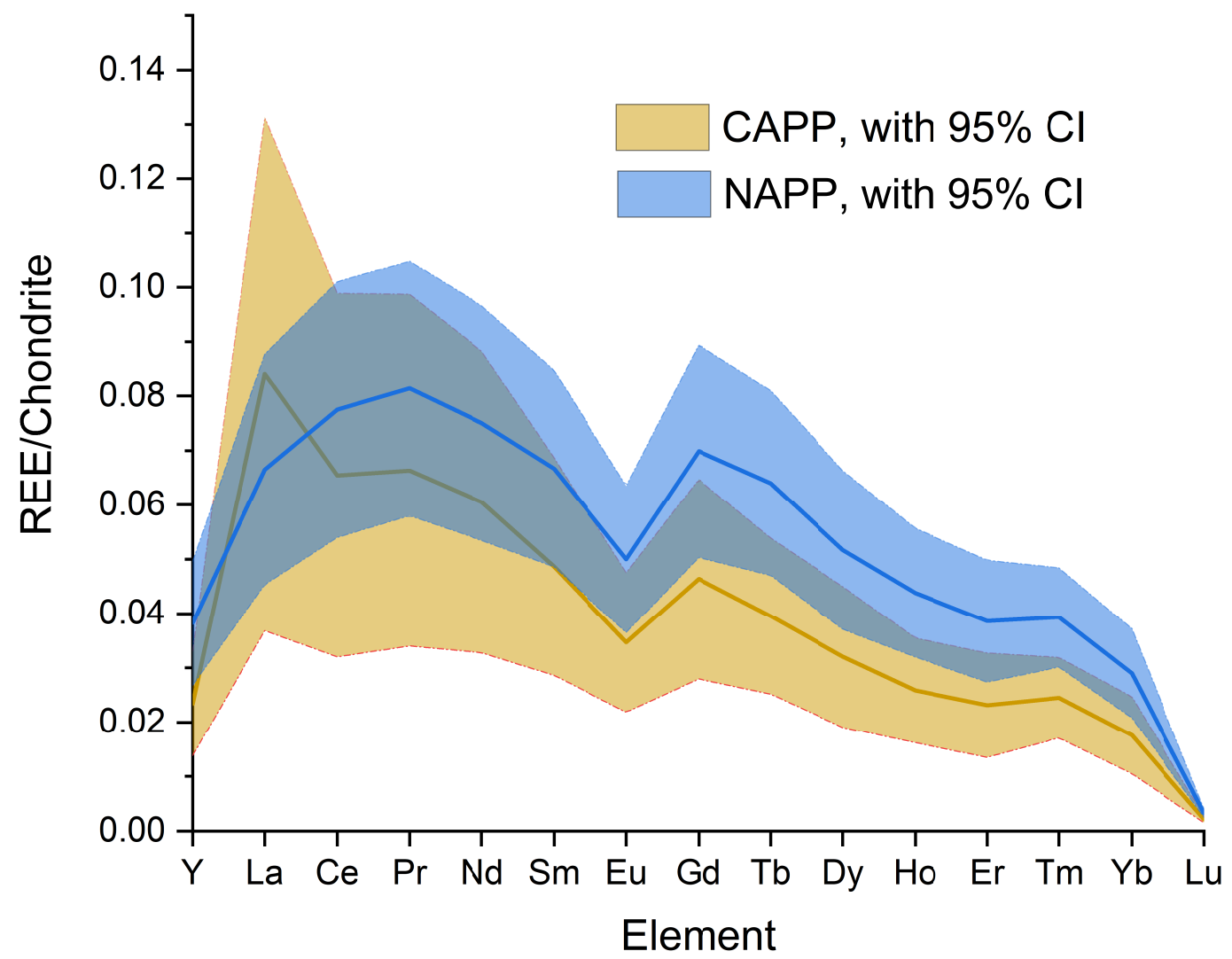

Figure 3.3 - Chondrite normalized REE distribution in raw AMD; with Chondrite normalization after Korotev [41]

tendency to extract middle and heavy REEs from coal strata while extracting La and Ce at a lower rate. This result can be explained geochemically, as the La and Ce in the coal measures are often associated with phosphate mineralization, such as monazite [32]. These rare earth phosphates are extremely resistant to acid attack and are not normally soluble in the $\mathrm{pH}$ ranges present in AMD [42].

\subsubsection{AMD Modeling and Analysis}

As shown in Figure 2, the REE content of raw AMD can vary by several orders of magnitude. REE determination by analytical methods requires specialized equipment and is expensive. As a result, we attempted to develop predictive models to estimate REE content in AMD 


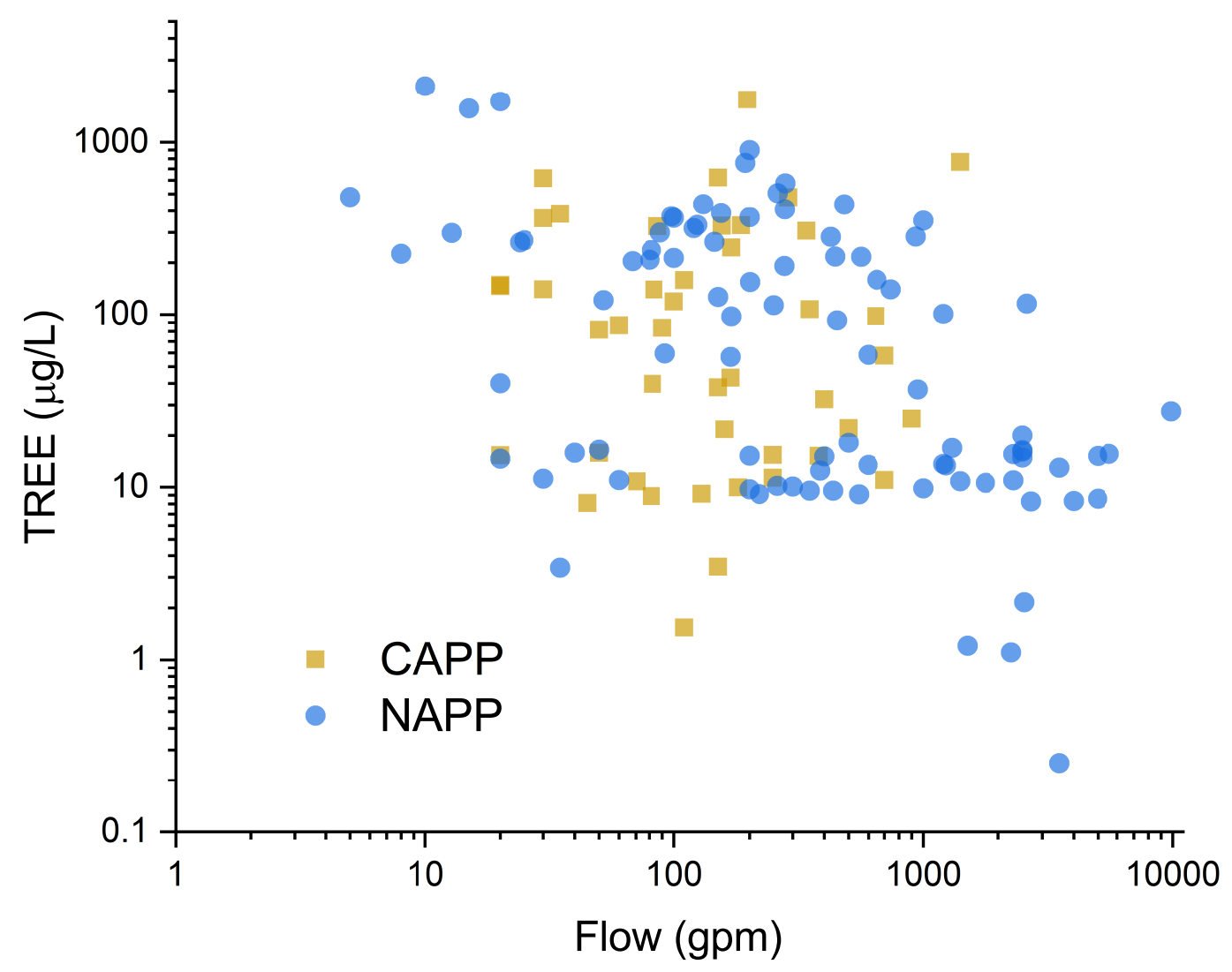

Figure 3.4 - Total REE concentration in AMD as a function of outflow rate

discharges based on readily available site characteristics and field analytical parameters. Initially, graphical analyses were conducted to compare the REE content to: (1) the AMD discharge rate and (2) the outflow pH. Figure 4 shows REE concentration as a function of discharge rate for the NAPP and CAPP datasets. While the plot does show a slight negative correlation (i.e. higher discharges tend to yield lower REE concentrations), the R2 value indicates low precision and poor predictive ability.

With regard to the two basins, the NAPP data tended to have a higher population of high-flow/low-REE outflows, as well as low-flow/high-REE outflows. This reflects the very large, consolidated AMD treatment plants serving flooded underground coal mine complexes. Largely, mines in the Pittsburgh coal seam, tend to be net alkaline. The CAPP data was more centrally distributed in both regards. 
Similarly, Figure 5 shows TREE concentration as a function of $\mathrm{pH}$. This data also shows a strong negative correlation (i.e. lower $\mathrm{pH}$ correlates with higher REE concentrations), but $\mathrm{pH}$ alone is not sufficient to explain all the variance in the data. Moreover, this data confirms the bimodal $\mathrm{pH}$ distribution that was originally proposed in the early prospectivity study [1]. Due to the nature of $\mathrm{Al}$ and Fe buffering in AMD solutions, the region between $\mathrm{pH} 4.5$ and 5.5 is sparsely populated since small changes in acidity result in stability in the 2.5 - 4.5 region where $\mathrm{Fe} 3+$ and $\mathrm{Al} 3+$ precipitate. Likewise, at $\mathrm{pH} 6.0, \mathrm{Fe} 2+$ oxidizes and precipitates resulting in stability in the upper $\mathrm{pH}$ region. These interactions were discussed extensively by Cravotta et al [43].

Due to the bimodal distribution, a boundary between these two populations at $\mathrm{pH}$ five was chosen to delineate the two populations since below five AMD is, by definition, acidic, while above five it becomes increasingly net alkaline. This behavior is indicative of the difference in geochemistry from flooded underground mines and those that are above drainage and produce an acidic discharge [44]. Likewise, this extended exploration study also confirms that the net alkaline discharges typically have lower REE content than acidic AMD discharges.

As neither total flow nor raw water $\mathrm{pH}$ were sufficient to predict the REE content of AMD, a partial least squares analysis was conducted to also include major metal concentrations in the prediction. Generally, $\mathrm{pH}$ and major metals are monitored as part of the National Pollution Discharge Elimination System (NPDES) permit and would be readily available for all AMD outflows. Results from this analysis indicated five factors can explain over $75 \%$ of the variance of concentration of TREEs in the AMD dataset. These factors, in order of importance, include the Mn concentration, $\mathrm{Al}$ concentration, raw water $\mathrm{pH}, \mathrm{Si}$ concentration, and $\mathrm{Mg}$ concentration. Figure 6 shows the results from a multiple linear regression with an r-squared value of 0.63 using these factors. The moderate correlation between $\mathrm{Mn}$ and $\mathrm{Al}$ in $\mathrm{AMD}$ may suggest that the mode of REE occurrence in the host strata is associated with these elements, with specific examples being manganese oxides and alumino-silicates. This result coincides with prior findings from Bryan et al. [45], which shows a strong correlation between $\mathrm{Al}$ concentration and REE concentration for samples in the USGS CoalQual database. 


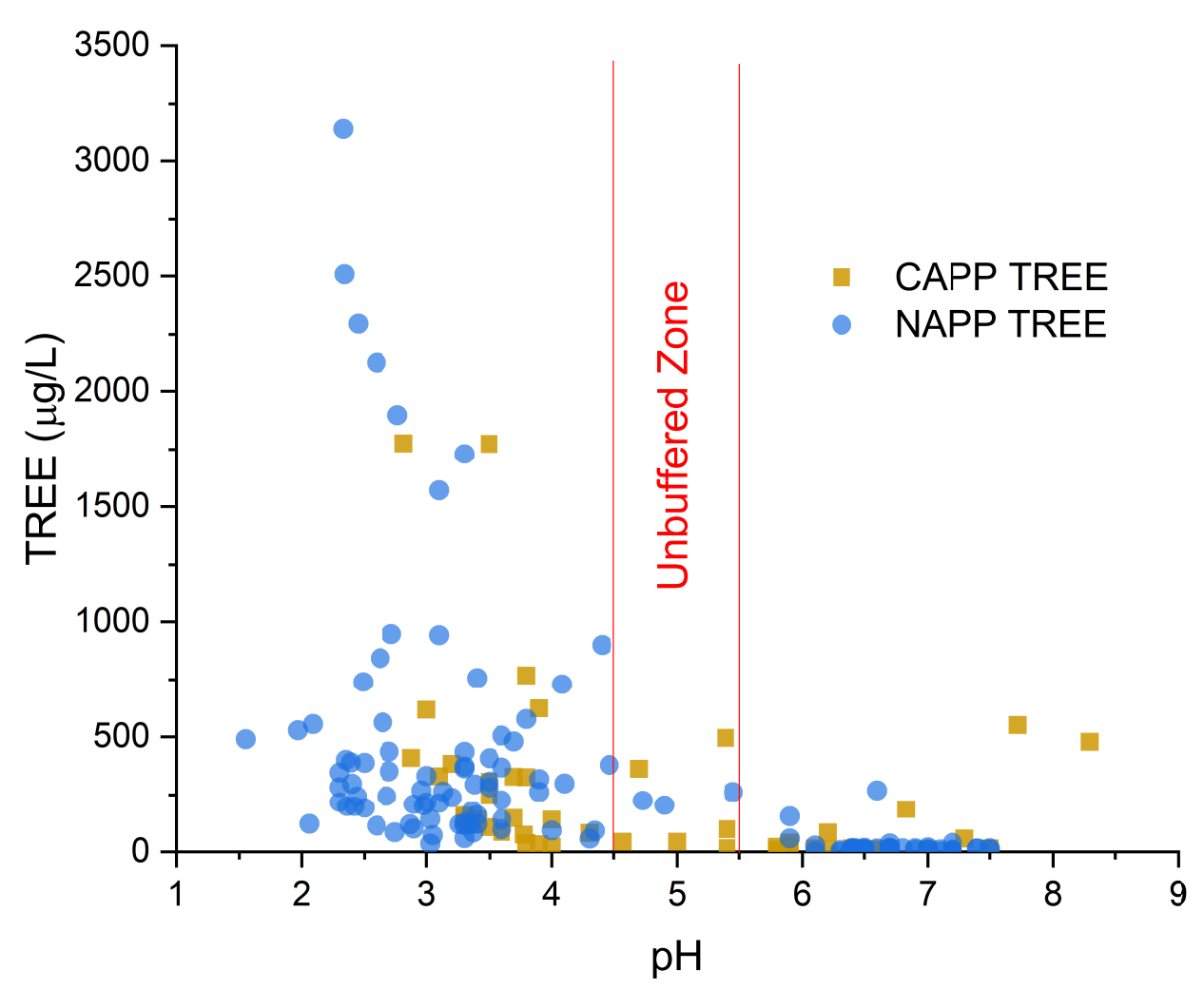

Figure 3.5 - Relationship between $\mathrm{pH}$ of raw AMD and the concentration of TREE in the aqueous phase

\subsubsection{Concentration of REEs in AMDp}

Table 3 shows the average concentrations of REEs and major metals in the AMDp for both CAPP and NAPP samples. TREE concentrations in CAPP averaged $669 \mathrm{~g} / \mathrm{t}$ while those in NAPP averaged $750 \mathrm{~g} / \mathrm{t}$. This result is consistent with the mean raw water TREE concentrations observed for each basin; however, the two-tailed t-test indicates that the differences, in both TREE and individual REEs are normally significant (at $\alpha=0.05$ ) with the primary exceptions being Ce, Pr and Nd. In general, the precision of the AMDp samples is much higher than the AMD samples, which may be attributed to larger sample sizes. In addition to the REEs, the t-tests also confirm that the major metal ions were more prevalent in the AMDp samples from the NAPP versus the CAPP basin. The moisture content between the AMDp was also slightly higher in the NAPP basin likely due to the more prevalent use of clarifiers in AMD treatment where samples were taken at the underflow 


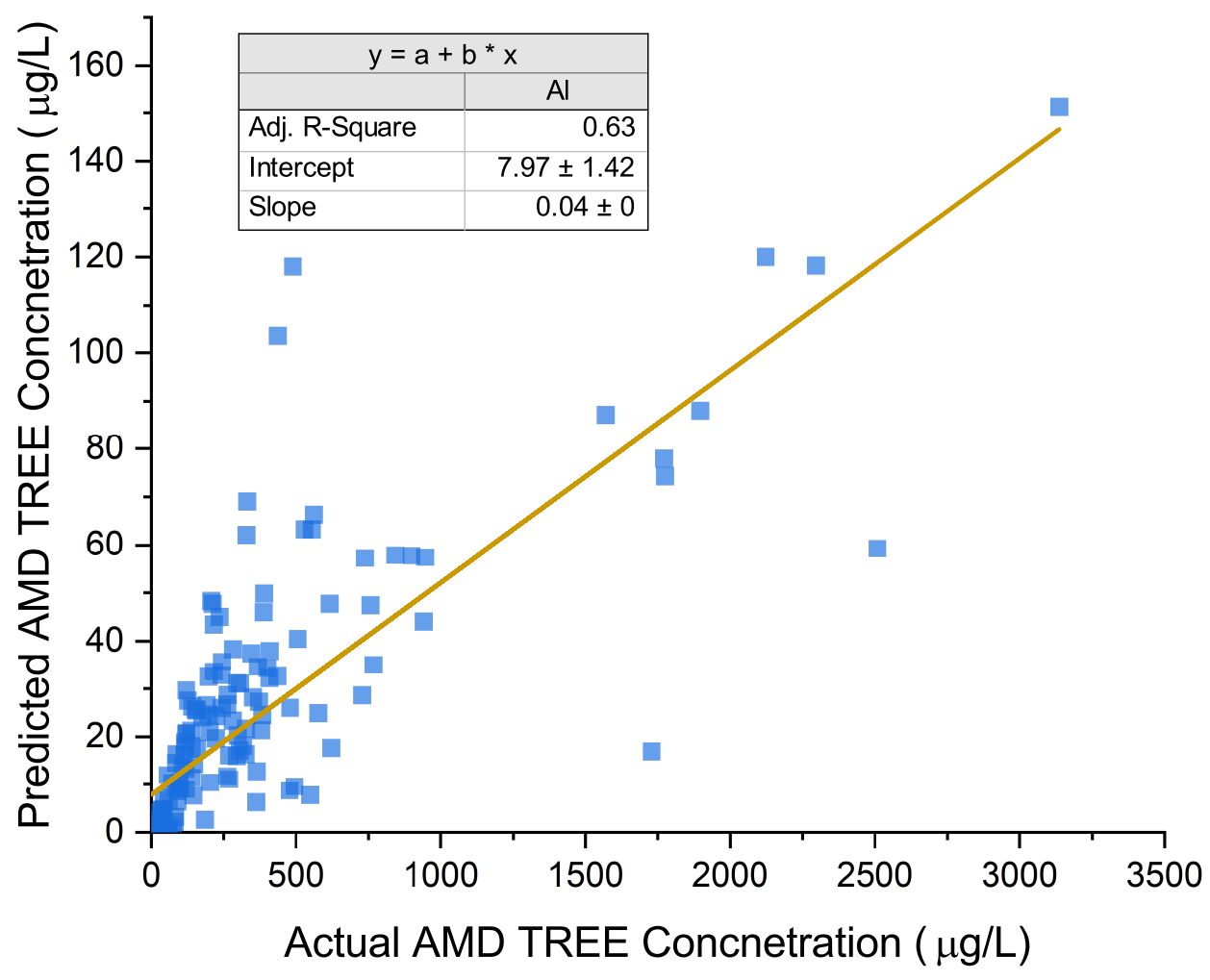

Figure 3.6 - Results of a multiple linear regression predicting TREE concentrations raw AMD using $\mathrm{pH}$ and major metal concentrations

before the AMDp was disposed of via underground injection. Additionally, it is important to note the low concentration of both Th and $\mathrm{U}$ in the AMDp samples as many conventional REE deposits generate significant environmental liabilities during processing. This confirms the observations seen in the preliminary study that indicated Th and U were not mobilized from the parent material at typical $\mathrm{pH}$ values associated with AMD.

The full distribution of TREE data for the NAPP and CAPP AMDp samples is shown in Figure 7. Like the AMD samples (Figure 2), this plot shows large overlap between the distributions from the two basins; however, the NAPP data does have some considerable outliers exceeding $2,000 \mathrm{~g} / \mathrm{t}$. The lower values on this plot $(<50 \mathrm{~g} / \mathrm{t})$ are predominantly from net alkaline AMD outflows with low REE concentrations. 
Table 3.3 - REE concentrations for AMDp at 141 sites across the CAPP and NAPP basins

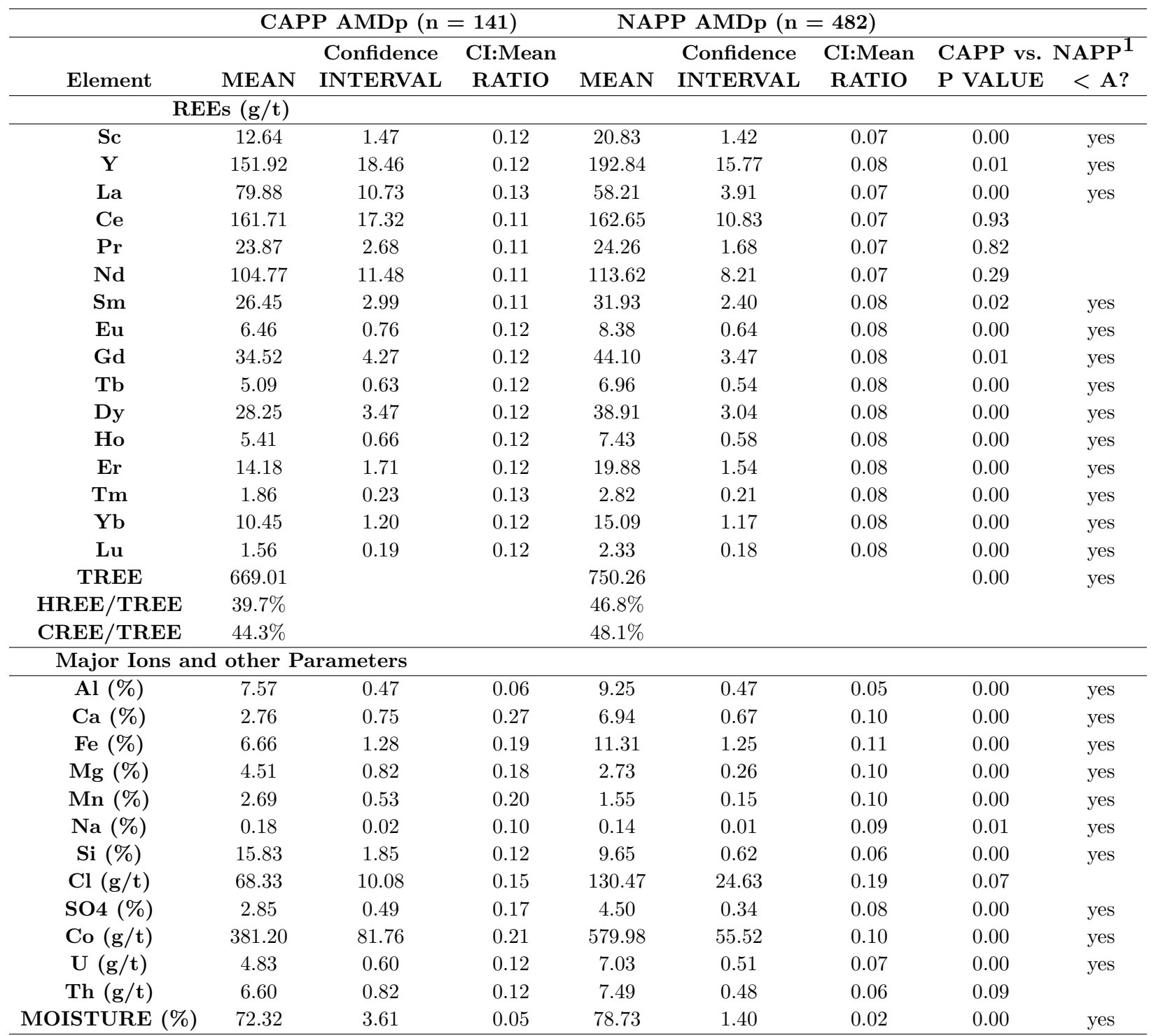

1: $p$ value as determined by two-tailed, equal variance $t$-test, a value of 0.05 used for significance

Like the AMD samples, a chondrite normalized plot was created to assess the distribution of individual REEs in AMDp. The pattern is similar to that of the raw AMD samples with the exception being the scale of the y-axis and the narrower confidence intervals. As mentioned above, these smaller confidence intervals may be dictated by the high number of samples in each distribution. In addition, this chondrite normalized plot largely confirms the t-test results indicating that NAPP AMDp has a higher concentration of many of the REEs, except Ce, $\mathrm{Pr}$, and $\mathrm{Nd}$. 


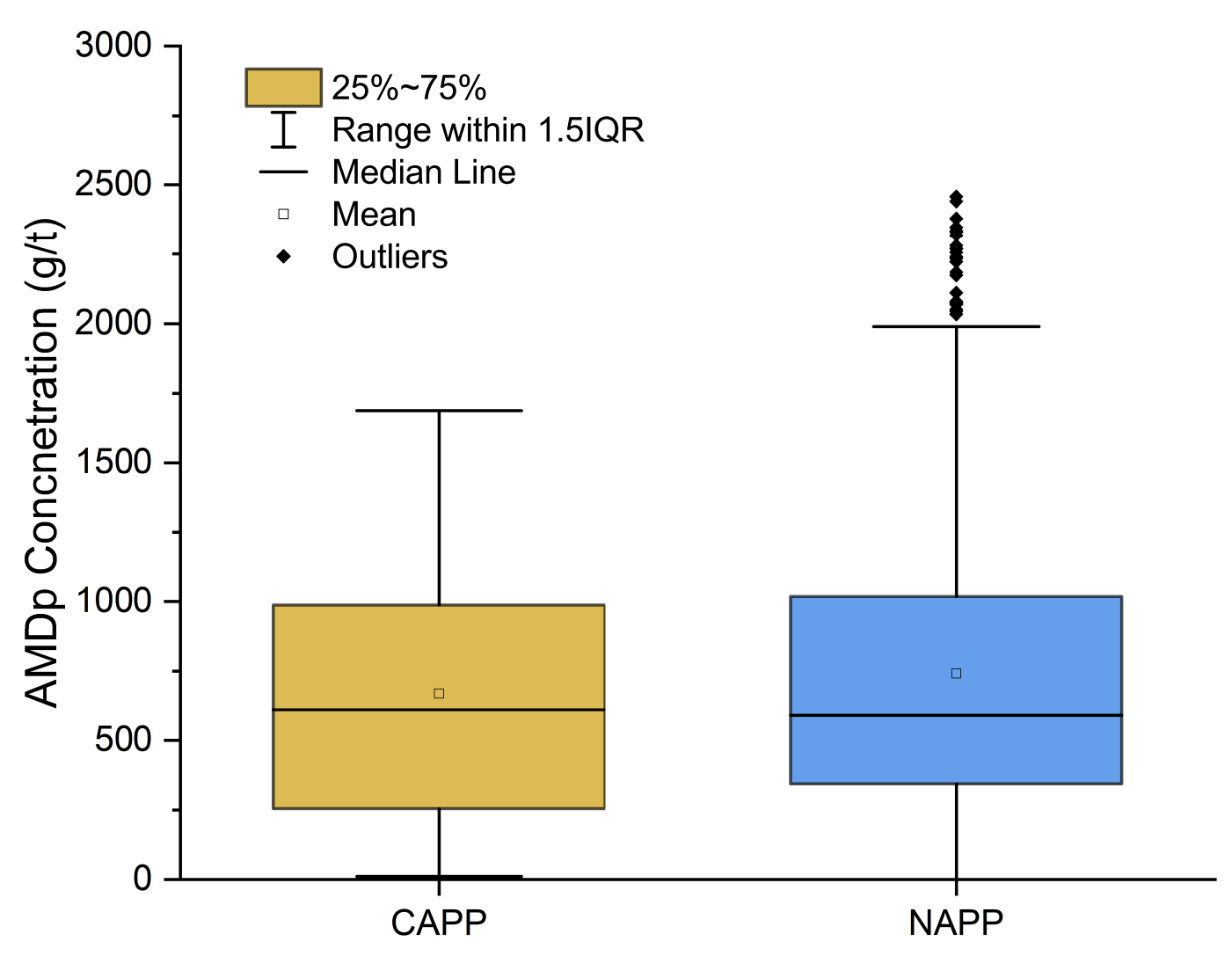

Figure 3.7 - Distribution of total REEs in NAPP and CAPP AMDp samples

In addition to the chondrite normalized distribution, the average raw element-by-element distribution of REEs in AMDp is shown in Figure 9. The distribution between the two basins is relatively similar with minor variations in the elements $\mathrm{Y}$, La, and Ce. Both distributions follow the Oddo-Harkins rule whereby elements with even atomic numbers are more common than their neighboring odd numbered elements [46,47]. Furthermore, two of the three most abundant elements ( $\mathrm{Y}$ and $\mathrm{Nd}$ ) are CREEs that carry significant supply chain risk [6].

\subsubsection{Resource Assessment}

For each site that contained AMDp, the quantity of on-site sludge as well as the steady-state flow of AMD were estimated to assess the resource potential of both in place resource and 


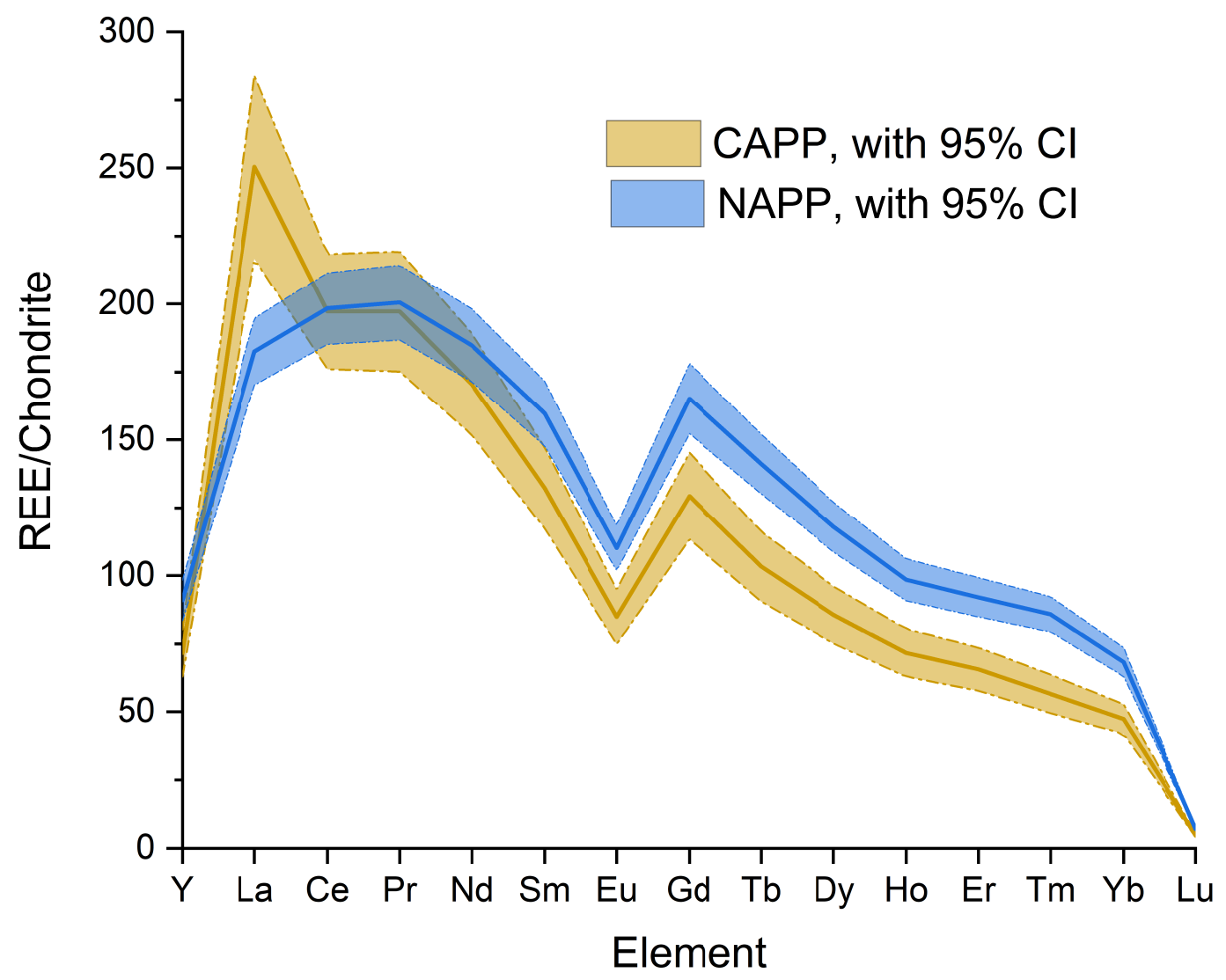

Figure 3.8 - Chondrite normalized REE distribution in AMDp; with Chondrite normalization after Korotev [41]

annual production. For the in-place resource, a total of 1.8MM tons of AMDp was accounted for on a dry basis with a tonne-weighted average grade of $187 \mathrm{~g} / \mathrm{t}$. It is important to note that the majority of AMDp generated at treatment sites is disposed of through underground injection or placed in surface cells and subsequently buried. As a result, this estimate only reflects the tonnage that is currently accessible at the 141 sampled AMD sites. Despite this limitation, the sampled resource was shown to contain approximately 340 tonnes of rare earth elements. Table 4 shows the AMDp tonnage data by basin.

While there was a significantly larger number of samples and mass of AMDp located in the NAPP region, the weighted average grade of this area was significantly lower than the AMDp located in the CAPP region. The difference in grade between the two basins can be 


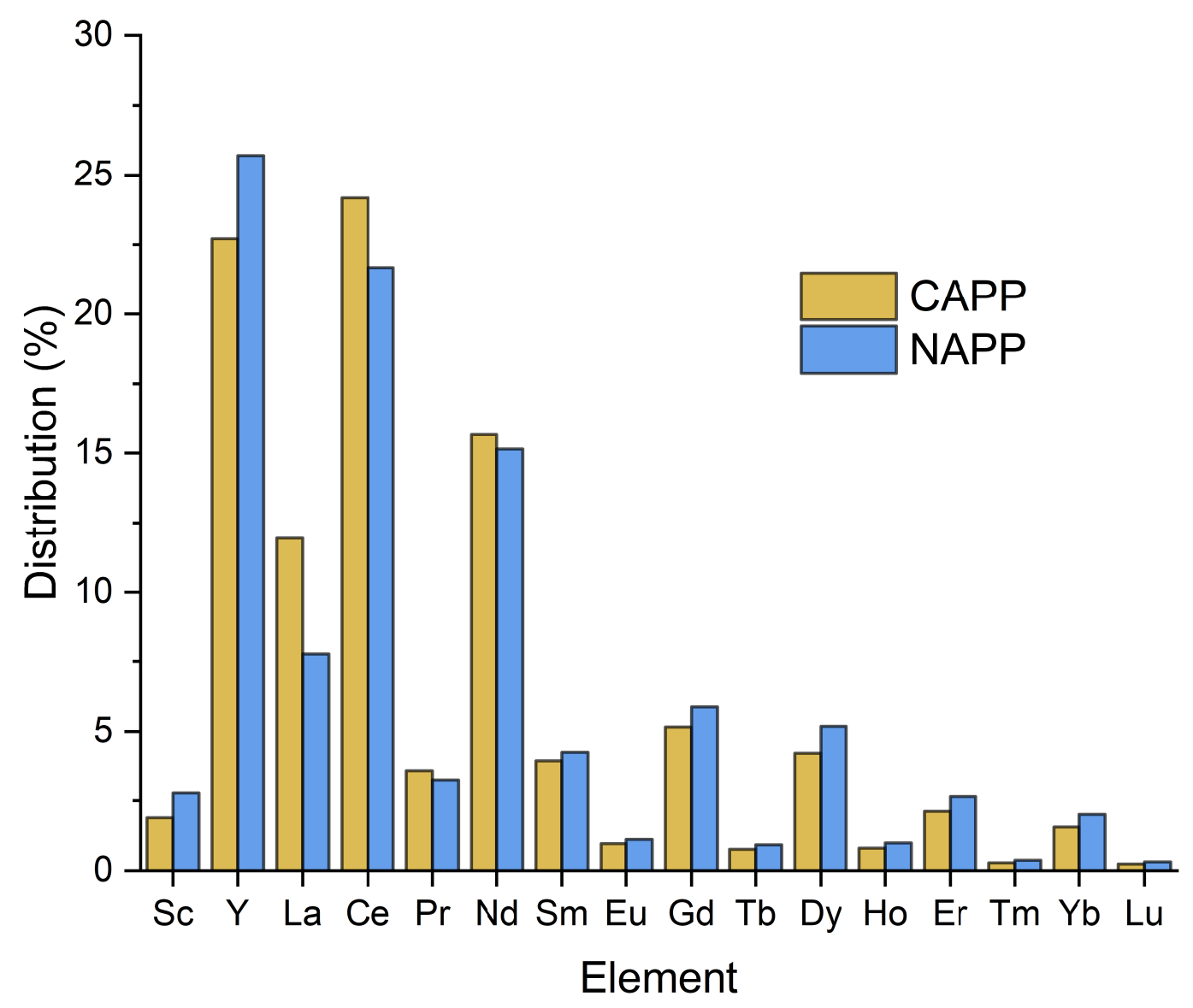

Figure 3.9 - Distribution of REEs between the NAPP and CAPP basins

Table 3.4 - AMDp and TREE resources by coal basin

\begin{tabular}{lcrrr}
\hline Parameter & Units & CAPP & NAPP & TOTAL \\
\hline Count & $(\#)$ & 58 & 95 & 153 \\
Mass Weighted Average Grade & $(\mathrm{g} / \mathrm{t})$ & 338 & 152 & 187 \\
Mass Weighted Average Moisture & $(\%)$ & 55.8 & 43.8 & 46.1 \\
Dry Volume & $(\mathrm{m} 3)$ & $5,495,964$ & $23,681,794$ & $29,177,758$ \\
Dry Mass & $($ tonne) & 342,382 & $1,475,304$ & $1,817,686$ \\
TREE Mass & (tonne) & 116 & 224 & 340 \\
\hline
\end{tabular}

contributed to the higher number of flooded underground mines with high $\mathrm{pH}$ and low TREE values. This result is significant, as low-grade feedstocks may be too costly to transport to a refining process. Furthermore, the overall total tonnage may seem low; however, AMD is often treated in perpetuity resulting in a steady supply of REEs that can supplement other 
Table 3.5 - Implication of cut-off grade on processable AMDp and TREEs

\begin{tabular}{|c|c|c|c|c|c|}
\hline $\begin{array}{l}\text { Cut-off } \\
\text { Grade } \\
(\mathrm{g} / \mathrm{t})\end{array}$ & $\begin{array}{r}\text { AMDp } \\
\text { Mass } \\
\text { (tonnes) }\end{array}$ & $\begin{array}{r}\text { TREE } \\
\text { Mass } \\
\text { (tonnes) }\end{array}$ & $\begin{array}{r}\text { Average Grade } \\
\text { Above Cut-off } \\
(\mathrm{g} / \mathrm{t})\end{array}$ & $\begin{array}{r}\% \text { AMDp } \\
\text { Mass } \\
(\%)\end{array}$ & $\begin{array}{r}\text { \% Tree Mass } \\
\text { Mass } \\
(\%)\end{array}$ \\
\hline 0 & $1,817,686$ & 340 & 128 & 100 & 100 \\
\hline 100 & 599,762 & 309 & 330 & 33 & 91 \\
\hline 150 & 577,048 & 306 & 387 & 32 & 90 \\
\hline 200 & 480,522 & 291 & 446 & 26 & 86 \\
\hline 250 & 466,489 & 288 & 475 & 26 & 85 \\
\hline 300 & 364,463 & 258 & 543 & 20 & 76 \\
\hline 400 & 286,463 & 231 & 659 & 16 & 68 \\
\hline 500 & 203,259 & 194 & 734 & 11 & 57 \\
\hline 750 & 116,508 & 141 & 1,019 & 6 & 42 \\
\hline 1000 & 48,099 & 86 & 1,400 & 3 & 25 \\
\hline
\end{tabular}

feedstocks. For the 141 sites surveyed in this study, the total REE flux passing through AMD treatment systems totaled $13,000 \mathrm{~kg} / \mathrm{yr}$.

In addition to the raw resource data, a supplemental study was conducted to investigate the influence of cut-off grade on the resource availability. Table 5 shows the percentage of TREE tons available given a nominal cut-off grade for all AMDp samples included in this study. This table shows that $67 \%$ of the AMDp mass in the dataset has a TREE concentration well below the grade of $100 \mathrm{~g} / \mathrm{t}$, while the remaining $33 \%$ contains $91 \%$ of the overall TREE mass. Furthermore, by increasing the cut-off grade to $300 \mathrm{~g} / \mathrm{t}$ would result in the exclusion of $80 \%$ of the AMDp mass, while retaining $76 \%$ of the TREE mass.

A compilation of both the assay and tonnage data for AMDp allows for the generation of grade-tonnage curves for each element and the aggregated TREE. As an example, Figure 10 shows the grade-tonnage relationship for REEs. The purpose of this exercise it to show how a minimal cut-off grade could impact the AMDp resource base. For example, if a cut-off grade of $1000 \mathrm{~g} / \mathrm{t}$ is applied to this data, this would leave approximately 86 tonnes of REEs with an overall average grade of approximately $1,400 \mathrm{~g} / \mathrm{t}$.

The grade-tonnage model graphically represents the available resource should a cut-off grade be applied for economic reasons. Figure 10 indicates that a low cut-off grade will be required for AMDp to provide a meaningful mass of REEs. However, the mass of AMDp does not fluctuate linearly with the TREE mass. This analysis indicates that a processing cut-off 


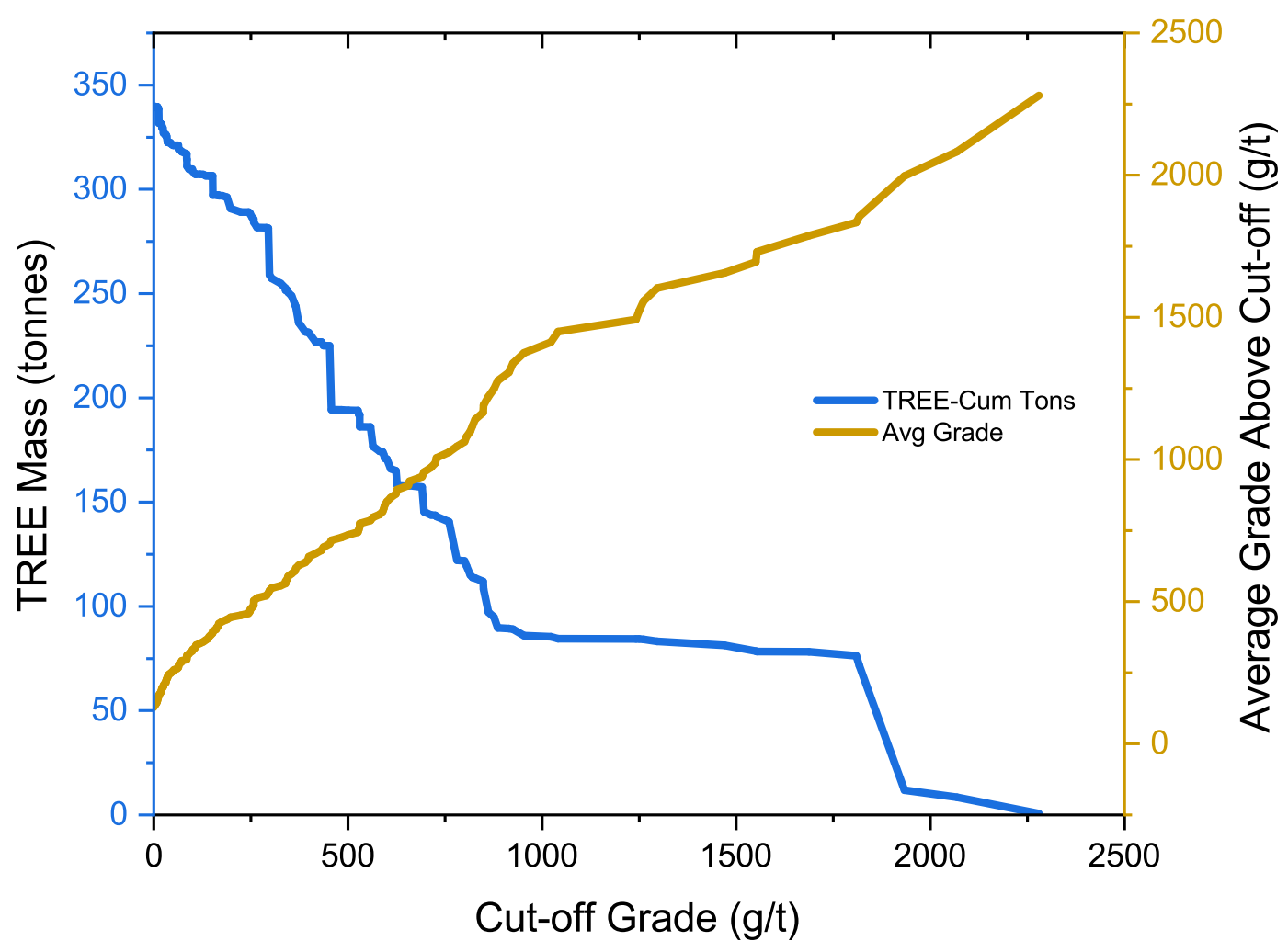

Figure 3.10 - Grade-tonnage curves indicating resource mass and average grade given a processing cut-off level

grade may exclude a significant portion of AMDp currently stockpiled; but at the same time, it will not exclude the majority of REEs contained in the AMDp resource. As a result, not all AMD sites are equal candidates for consideration as a REE feedstock. While this is indicative of the AMDp sampled in the current dataset, the AMD treatment process itself may be changed to produce a more amenable AMDp product for REE beneficiation.

A similar exercise was conducted for the AMD samples and the results are shown in Figure 11. This plot shows both cumulative REE flux (kg/yr) and cumulative AMD flow (gpm) as a function of the individual REE concentration. When organized in this manner, this data indicates the total REE resource available for production and the volume of AMD that must be handled if a suitable recovery technology can produce a nominal REE concentration. For example, if a technology can successfully recover REEs from a raw AMD stream containing $500 \mu \mathrm{g} / \mathrm{L}$, approximately $4,100 \mathrm{~kg} / \mathrm{yr}$ of REEs could be produced, and the total system 


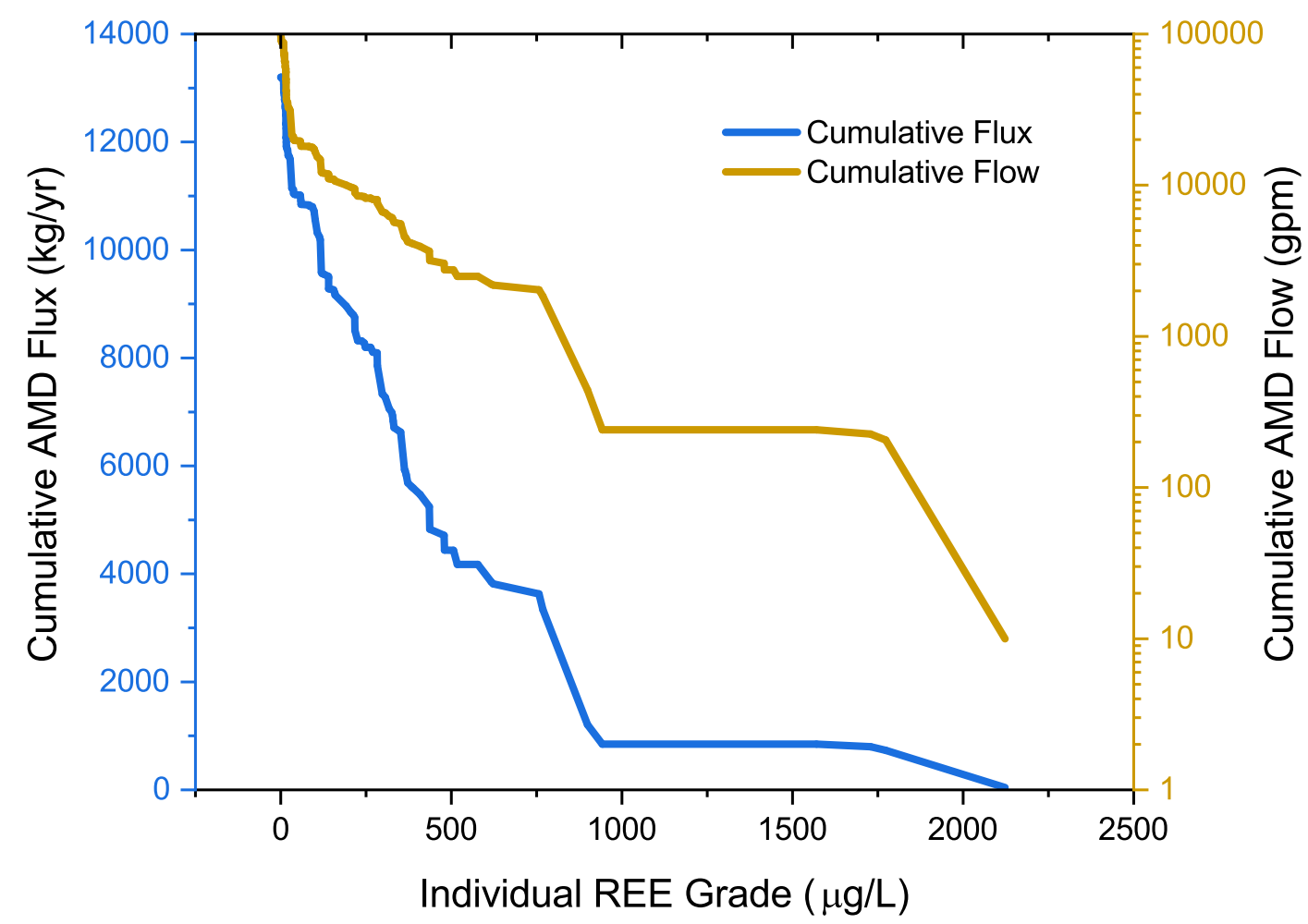

Figure 3.11 - Indication of total REE resource available based on an aqueous REE grade

would need to handle just under 3000 gpm across the best sites included in this study. If the technology can only upgrade REEs from sources containing $1,000 \mu \mathrm{g} / \mathrm{L}$, the total REE production drops to under $900 \mathrm{~kg} / \mathrm{yr}$, and the water handling requirement drops to $200 \mathrm{gpm}$. While the prior assessment estimated a regional production capacity, this data only applies to the limited number of samples evaluated in this study, but the assessment methodology can be easily updated as more sites are evaluated.

\subsubsection{Resource Outlook and Criticality}

Since the REEs typically occur together within a deposit, they are generally lumped into a single category as TREE. Furthermore, they will also be classified as LREE, HREE, or CREE to identify sub-groups of the REEs that occur within the deposit. For economic consideration, these metrics can be misleading as it assumes all of the REEs can be equally 
separated from a given feedstock. Additionally, not all REEs have the same economic value due to varying prices and future demand. For example, La and Ce are relatively abundant and are currently in a state of oversupply within the REE markets [39].

As a result, other criteria are better suited for evaluating REE feedstocks based on current market trends. One such method is the outlook coefficient (C_Outlook) as defined by Seredin and Dai below [7]:

$$
C_{-} \text {Outlook }=\frac{\left(\frac{N d+E u+T b+D y+E r+Y}{\sum R E E}\right)}{\left(\frac{C e+H o+T m+Y b+L u}{\sum R E E}\right)}
$$

In other words, the more valuable critical REEs drive the metric value higher, while the REEs that are oversupplied reduce the value of the metric. This criterion was then applied to the AMDp sites and 58 conventional REE deposits [48]. As shown in Figure 12, the AMDp is generally found to be more favorable from a critical REE content perspective than many of the conventional deposits. This can be attributed to the relative abundance of Y and $\mathrm{Nd}$ in the AMDp. As a result, while the overall resource base may be limited, the REEs in AMD do represent a unique and highly-valued deposit that may support future growth areas.

\subsection{Conclusions}

As part of a regional survey, 141 AMD sites were evaluated for REE content in both raw water and AMDp in two separate campaigns across the CAPP and NAPP basins. This research has shown that REEs concentrate in the byproducts of AMD treatment across both basins with limited variation. The distribution of the REEs in the AMD byproduct was also similar among the two regions. Additionally, the overall inventory of available AMDp and TREEs was calculated for the sites in the dataset. Finally, a grade-tonnage curve was created for the AMDp showing that a significant portion of AMDp contains a low grade of TREEs indicating alternative AMD treatment process may be required to create high-quality AMDp. 


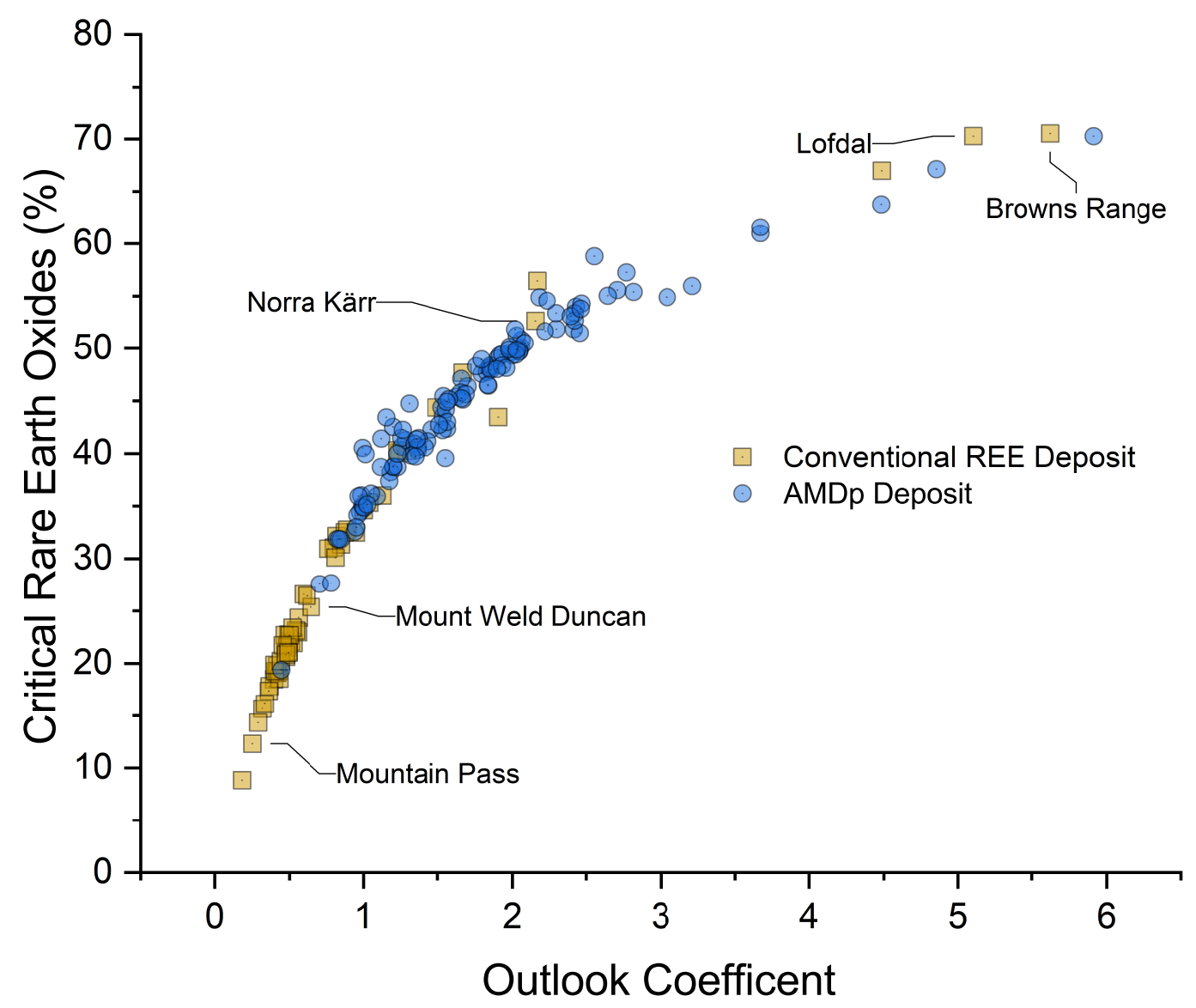

Figure 3.12 - Arrangement of AMDp in relation to conventional REE deposits based on the outlook coefficient after Seredin and Dai [7]

In summary, the following key findings were developed during this research:

- The concentration of REEs in AMD varied from 0.25 to 3,140 $\mu \mathrm{g} / \mathrm{L}$ with an overall number average of $282 \mu \mathrm{g} / \mathrm{L}$. Little variation was observed between the NAPP and CAPP basins.

- Least squares regression analysis showed that the most important factors dictating the REE content in AMD include the raw water $\mathrm{pH}$ as well as the concentrations of Mn, $\mathrm{Al}, \mathrm{Si}$, and $\mathrm{Mg}$. 
- The concentration of REEs in AMDp varied from $<5$ to $2,458 \mathrm{~g} / \mathrm{t}$ with an overall number average of $724 \mathrm{~g} / \mathrm{t}$. A significant difference $(\alpha=0.05)$ was observed between the NAPP and CAPP basins with the NAPP number average being $750 \mathrm{~g} / \mathrm{t}$ and the CAPP average being $669 \mathrm{~g} / \mathrm{t}$.

- The average distribution of REEs in both AMD and AMDp strongly favored Y (25\%), Ce $(22 \%)$, and Nd (15\%). Little deviation was observed between the NAPP and CAPP basins.

- The 141 sites surveyed in this study contain approximately 340 tonnes of REEs in AMDp storage cells and will generate approximately 13,000 kg/yr in AMD. Grade tonnage curves show how these resource bases are influenced by potential process cutoff grades.

- The C_Outlook criterion shows that the distribution of REEs in AMD and AMDp is more favorable than most conventional REE deposits. One site sampled in this study had a C__Outlook value greater than 6.0, representing one of the most promising resources ever identified in the literature.

\section{Acknowledgments:}

This material is based upon work supported by the U.S. Department of Energy under Award Number DE-FE0026444.

\section{Disclaimer:}

This report was prepared as an account of work sponsored by an agency of the United States Government. Neither the United States Government nor any agency thereof, nor any of their employees, makes any warranty, express or implied, or assumes any legal liability or responsibility for the accuracy, completeness, or usefulness of any information, apparatus, product, or process disclosed, or represents that its use would not infringe privately owned rights. Reference herein to any specific commercial product, process, or service by trade 
name, trademark, manufacturer, or otherwise does not necessarily constitute or imply its endorsement, recommendation, or favoring by the United States Government or any agency thereof. The views and opinions of authors expressed herein do not necessarily state or reflect those of the United States Government or any agency thereof.

\section{Conflicts of Interest:}

On behalf of all authors, the corresponding author states that there is no conflict of interest.

\section{References:}

[1] Vass C, Noble A, Ziemkiewicz P. The occurrence and concentration of rare earth elements in acid mine drainage and treatment byproducts. Part 1: Initial survey of the Northern Appalachian coal basin. Mining, Metall Explor 2019;In Press. doi:10.1007/s42461-019-0097$\mathrm{Z}$.

[2] Haque N, Hughes A, Lim S, Vernon C. Rare Earth Elements: Overview of Mining, Mineralogy, Uses, Sustainability and Environmental Impact. Resources 2014;3:614-35. doi:10.3390 /resources3040614.

[3] U.S. Geological Survey. Mineral Commodity Summaries 2018: U.S. Geological Survey. 2018.

[4] Campbell GA. Rare earth metals: a strategic concern. Miner Econ 2014;27:21-31. doi:10.1007/s13563-014-0043-y.

[5] Goodenough KM, Wall F, Merriman D. The Rare Earth Elements: Demand, Global Resources, and Challenges for Resourcing Future Generations. Nat Resour Res 2017:1-16. doi:10.1007/s11053-017-9336-5.

[6] Bauer D, Diamond D, Li J, McKittrick M, Sandalow D, Telleen P. Critical Materials Strategy. 2011.

[7] Seredin V V., Dai S. Coal deposits as potential alternative sources for lanthanides and yttrium. Int J Coal Geol 2012;94:67-93. doi:10.1016/j.coal.2011.11.001. 
[8] Preston JS, Cole PM, Craig WM, Feather AM. The recovery of rare earth oxides from a phosphoric acid by-product. Part 1: Leaching of rare earth values and recovery of a mixed rare earth oxide by solvent extraction. Hydrometallurgy 1996;41:1-19. doi:10.1016/0304386X(95)00051-H.

[9] Preston JS, Cole PM, Du Preez AC, Fox MH, Fleming AM. The recovery of rare earth oxides from a phosphoric acid by-product. Part 2: The preparation of high-purity cerium dioxide and recovery of a heavy rare earth oxide concentrate. Hydrometallurgy 1996;41:2144. doi:10.1016/0304-386X(95)00067-Q.

[10] Preston JS, Du Preez AC, Cole PM, Fox MH. The recovery of rare earth oxides from a phosphoric acid by-product. Part 3. The separation of the middle and light rare earth fractions and the preparation of pure europium oxide. Hydrometallurgy 1996;42:131-49. doi:10.1016/0304-386X(95)00079-V.

[11] Preston JS. The recovery of rare earth oxides from a phosphoric acid byproduct. Part 4. The preparation of magnet-grade neodymium oxide from the light rare earth fraction. Hydrometallurgy 1996;42:151-67. doi:10.1016/0304-386X(95)00082-R.

[12] Binnemans K, Tom P, Blanpain B, Gerven T Van, Yang Y, Walton A, et al. Recycling of rare earths: a critical review. J Clean Prod 2013;51:1-22. doi:10.1016/j.jclepro.2012.12.037. [13] Gambogi J. 2015 Minerals Yearbook. 2018.

[14] Rademaker JH, Kleijn R, Yang Y. Recycling as a Strategy against Rare Earth Element Criticality: A Systemic Evaluation of the Potential Yield of NdFeB Magnet Recycling 2013. [15] Finkelman RB, Stanton RW. Identification and significance of accessory minerals from a bituminous coal. Fuel 1978;57:763-8. doi:10.1016/0016-2361(78)90135-7.

[16] Schofield A, Haskin L. Rare-earth distribution patterns in eight terrestrial materials. Geochim Cosmochim Acta 1964;28:437-46. doi:10.1016/0016-7037(64)90117-6.

[17] Zubovic P, Stadnichenko T, Sheffey NB. Distribution of Minor Elements in Coals of the Appalachian Region. Washington, D.C.: 1966.

[18] United States Department of Energy. Rare Earth Elements from Coal and Coal Byproducts. 2017. 
[19] Hower JC, Granite EJ, Mayfield DB, Lewis AS, Finkelman RB. Notes on Contributions to the Science of Rare Earth Element Enrichment in Coal and Coal Combustion Byproducts 1900. doi:10.3390/min6020032.

[20] Stuckman MY, Lopano CL, Granite EJ. Distribution and speciation of rare earth elements in coal combustion by-products via synchrotron microscopy and spectroscopy. Int J Coal Geol 2018;195:125-38. doi:10.1016/j.coal.2018.06.001.

[21] Honaker RQ, Zhang W, Yang X, Rezaee M. Conception of an integrated flowsheet for rare earth elements recovery from coal coarse refuse. Miner Eng 2018;122:233-40.doi:10.1016/j. mineng.2018.04.005.

[22] Honaker RQ, Groppo J, Yoon R-H, Luttrell GH, Noble A, Herbst JA. Process evaluation and flowsheet development for the recovery of rare earth elements from coal and associated byproducts. Miner Metall Process 2017;34:107-15. doi:10.19150/mmp.7610.

[23] Zhang W, Yang X, Honaker RQ. Association characteristic study and preliminary recovery investigation of rare earth elements from Fire Clay seam coal middlings. Fuel 2018;215:551-60. doi:10.1016/j.fuel.2017.11.075.

[24] Laudal DA, Benson SA, Palo D, Addleman RS. Rare Earth Elements in North Dakota Lignite Coal and Lignite-Related Materials. J Energy Resour Technol 2018;140:062205. doi:10.1115/1.4039738.

[25] Laudal DA. Evaluation of Rare Earth Element Extraction from North Dakota CoalRelated Feed Stocks. University of North Dakota, 2017.

[26] Lin R, Stuckman M, Howard BH, Bank TL, Roth EA, Macala MK, et al. Application of sequential extraction and hydrothermal treatment for characterization and enrichment of rare earth elements from coal fly ash. Fuel 2018;232:124-33. doi:10.1016/j.fuel.2018.05.141.

[27] Lin R, Howard BH, Roth EA, Bank TL, Granite EJ, Soong Y. Enrichment of rare earth elements from coal and coal by-products by physical separations. Fuel 2017;200:506-20. doi:10.1016/j.fuel.2017.03.096. 
[28] Lin R, Bank TL, Roth EA, Granite EJ, Soong Y. Organic and inorganic associations of rare earth elements in central Appalachian coal. Int J Coal Geol 2017;179:295-301. doi:10.1016/j.coal.2017.07.002.

[29] Hower JC, Groppo JG, Joshi P, Dai S, Moecher DP, Johnston MN. Location of Cerium in Coal-Combustion Fly Ashes: Implications for Recovery of Lanthanides. Coal Combust Gasif Prod 2013;5:73-8. doi:10.4177/CCGP-D-13-00007.1.

[30] Kolker A, Scott C, Hower JC, Vazquez JA, Lopano CL, Dai S. Distribution of rare earth elements in coal combustion fly ash, determined by SHRIMP-RG ion microprobe. Int J Coal Geol 2017;184:1-10. doi:10.1016/j.coal.2017.10.002.

[31] Taggart RK, Hower JC, Hsu-Kim H. Effects of roasting additives and leaching parameters on the extraction of rare earth elements from coal fly ash. Int J Coal Geol 2018;196:10614. doi:10.1016/j.coal.2018.06.021.

[32] Hower JC, Berti D, Hochella MF, Mardon SM. Rare earth minerals in a "no tonstein" section of the Dean (Fire Clay) coal, Knox County, Kentucky. Int J Coal Geol 2018;193:7386. doi:10.1016/j.coal.2018.05.001.

[33] Joshi P, Preda D, Skyler DA, Tsinberg A, Green BD, Marinelli WJ. Recovery of Rare Earth Elements and Compounds from Coal Ash. 8969688 B2, 2015.

[34] Huang Q, Noble A, Herbst J, Honaker R. Liberation and release of rare earth minerals from Middle Kittanning, Fire Clay, and West Kentucky No. 13 coal sources. Powder Technol 2018;332:242-52. doi:10.1016/j.powtec.2018.03.063.

[35] Honaker R. Pilot-scale Testing of an Integrated Circuit for the Extraction of Rare Earth Minerals and Elements From Coal and Coal Byproducts Using Advanced Separation Technologies 2017 .

[36] Zhang W, Rezaee M, Bhagavatula A, Li Y, Groppo J, Honaker R. A review of the occurrence and promising recovery methods of rare earth elements from coal and coal byproducts. Int J Coal Prep Util 2015. doi:10.1080/19392699.2015.1033097. 
[37] Seredin V V, Dai S. International Journal of Coal Geology Coal deposits as potential alternative sources for lanthanides and yttrium. Int J Coal Geol 2012;94:67-93. doi:10.1016/ j.coal.2011.11.001.

[38] Cox C, Kynicky J. The rapid evolution of speculative investment in the REE market before, during, and after the rare earth crisis of 2010-2012. Extr Ind Soc 2018;5:8-17. doi:10.1016/j.exis.2017.09.002.

[39] Binnemans K, Jones PT, Muller T, Yurramendi L. Rare Earths and the Balance Problem: How to Deal with Changing Markets? J Sustain Metall 2018;8:126-46. doi:10.1007/s40831018-0162-8.

[40] Skousen JG, Ziemkiewicz PF. Acid Mine Drainage Control and Treatment. Morgantown: West Virginia University; 1995.

[41] Korotev RL. "Rare Earth Plots" and the Concentrations of Rare Earth Elements (REE) in Chondritic Meteorites 2009. http://meteorites.wustl.edu/goodstuff/ree-chon.htm.

[42] Kim E, Osseo-Asare K. Aqueous stability of thorium and rare earth metals in monazite hydrometallurgy: Eh-pH diagrams for the systems Th-, Ce-, La-, Nd- (PO4)-(SO4)-H2O at $25{ }^{\circ} \mathrm{c}$. Hydrometallurgy 2012;113-114:67-78. doi:10.1016/j.hydromet.2011.12.007.

[43] Cravotta CA, Brady KB., Rose AW, Douds JB. Frequency Distribution of the pH of Coal-Mine Drainage in Pennsylvania. US Geol Surv Water-Resources Investig Report 994018A 1999:313-24.

[44] Ziemkiewicz PF, Lovett RJ. Factors Controlling Carbonate Dissolution in Acid-Forming Rock: Implication or Acid Mine Drainage Prevention Strategies. Am. Chem. Soc. Symp. Ser., 1992.

[45] Bryan RC, Richers D, Anderson HT, Gray T. Assessment of Rare Earth Elemental Contents in Select United States Coal Basins. 2015.

[46] Oddo G. Die Molekularstruktur der radioaktiven Atome. Zeitschrift Für Anorg Chemie 1914;87:253-68. doi:10.1002/zaac.19140870118. 
[47] Harkins WD. The evolution of the elements and the stability of complex atoms. I. A new periodic system which shows a relation between the abundance of the elements and the structure of the nuclei of atoms. J Am Chem Soc 1917;39:856-79. doi:10.1021/ja02250a002.

[48] Lifton J, Hatch G. Technology Metals Research 2016. http://www.techmetalsresearch.com /metrics-indices/tmr-advanced-rare-earth-projects-index/. 


\section{Chapter 4}

\section{Bench-Scale System Design}

\subsection{Introduction}

The objective of this research was to develop a bench-scale process that recovers REEs from acid mine drainage precipitates; therefore, demonstrating the feasibility of applying proven processes to a novel feedstock. Extensive laboratory testing provided the basis for the design of a bench scale plant. Included in this research are process design flowsheets, piping and instrumentation diagrams, and a proposed facility layout. Overall, the proposed process utilized standard hydrometallurgical methods to concentrate and extract REEs from the acid mine drainage sludge feedstock. More importantly, this process bypasses energy intensive comminution and physical separation processes that escalate operating costs when compared to traditional REE recovery operations.

This approach was accomplished using a unique feedstock that previously underwent an autogenous leaching process to concentrate the REEs into an amorphous precipitate. During the subsequent processing operations, agitated leaching was first employed to dissolve the REEs to an aqueous phase. Once in solution, the REE's were separated and concentrated via solvent extraction, and finally, the resulting REE stripped concentrate was precipitated and dried. The ultimate goal of this process was to produce a minimum $2 \%$ by mass mixed REO product. After verifying the general processing approach, a detailed system design was conducted to specify the equipment type, size, number, interconnection, and layout 
needed to design a bench-scale process capable of producing several grams per hour of REE concentrate.

The primary processing objective was to demonstrate the technology while assessing key factors affecting cost and performance at a bench-scale. To meet this objective, the resultant design utilized batch-wise leaching following by continuous solvent extraction in a SX minipilot plant with 100 mixer settlers. The final stripped raffinate was then precipitated in batch fashion using neutralizing reagents and oxalic acid. The performance of this process varied slightly with changes in feed moisture and feed REE concentration; however, the system was generally designed to process $190 \mathrm{~g} / \mathrm{hr}$ of AMDp feed, while producing $3 \mathrm{~g} / \mathrm{hr}$ of REE concentrate. The expected REE grade and recovery (based on laboratory-scale tests) differed between feedstocks, but was expected to be as high as $6.50 \%$ and $90.9 \%$ depending on the grade of the initial feedstock.

Throughout this research, several technical terms were used extensively and with a precise definition in mind. Since regional difference and personal preference can occasionally obscure the intended outcome, an abbreviated list of these terms with the precise definition is given below:

- Recovery: a metallurgical accounting term defined as the mass of a particular component that reports to a concentrated product, divided by the mass of that component in the original feed. Recovery is often presented as a percentage.

- Sludge: Also Acid Mine Drainage Precipitates (AMDp). Precipitates created during the treatment of acid mine drainage. This material is usually thickened, flocculated, and permanently stored as waste.

- Yield: a metallurgical accounting term defined as the total mass that reports to a concentrated product, divided by the total mass of the feed. Unlike recovery, yield does not refer to a specific component of the feed.

- Assays: all assays in this research are listed on a whole sample, dry basis unless otherwise noted. 


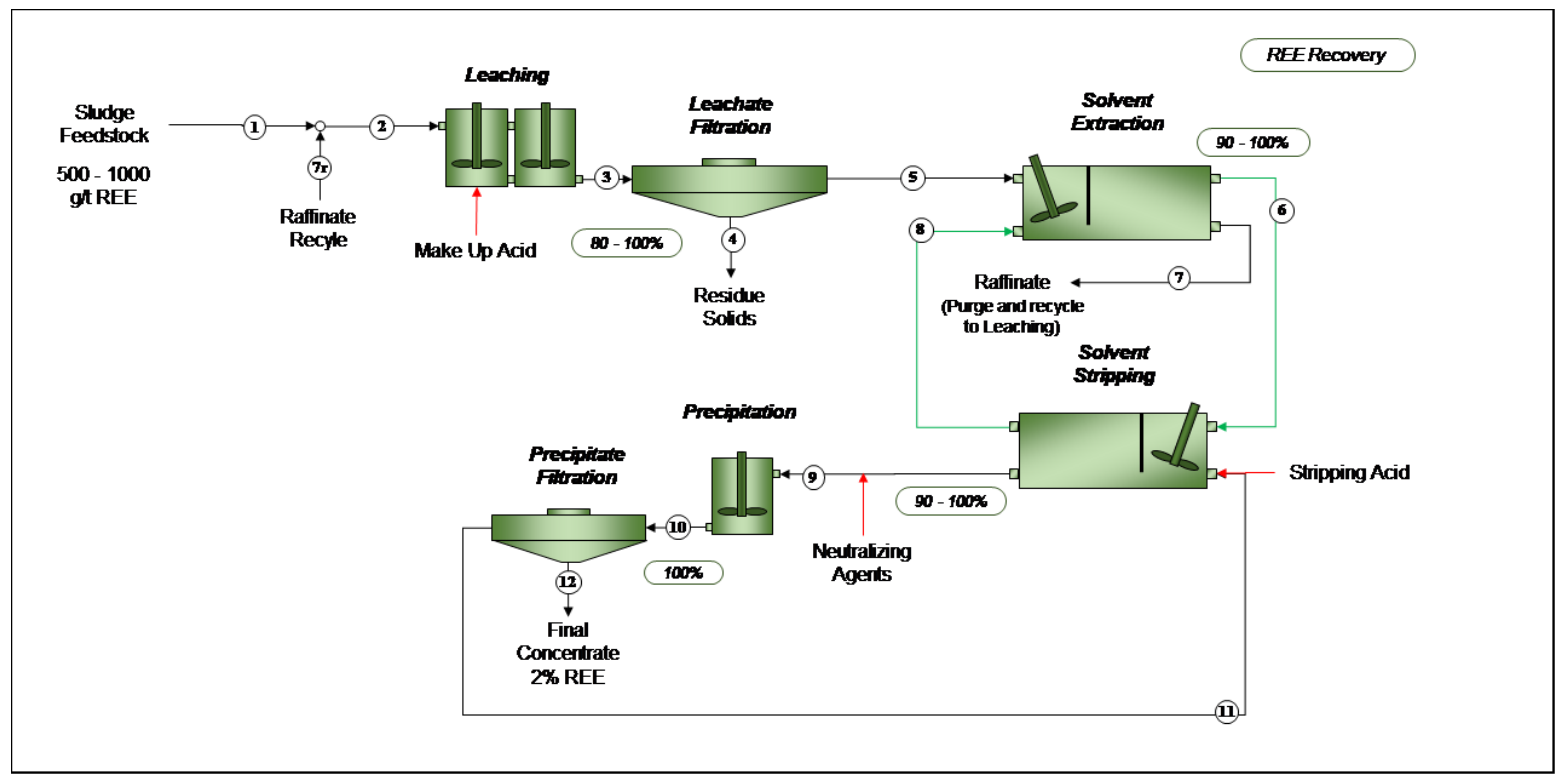

Figure 4.1 - Simplified process flow diagram

\subsection{Process Overview}

Given the favorable feedstock characteristics of AMDp, an extraction and recovery process was developed to specifically exploit AMD sludge as a potential REE resource. AMD sludge has unique chemical and physical properties that make it very amenable to a strict hydrometallurgical processing route. Fundamental considerations and laboratory-scale experimental testing have shown that REEs in AMD sludge are easily extracted into the solution phase with mild acid leaching, and the resultant pregnant leach solution can be separated and concentrated using traditional solvent extraction technologies. Finally, simple $\mathrm{pH}$ adjustment with the addition of oxalic acid can be used to precipitate aqueous REE ions back to a solid phase at purities meeting or exceeding $2 \%$ by mass. A simplified flow diagram depicting these unit operations is shown in Figure 4.1. This straightforward processing route is the basis for the bench-scale system design described in this chapter.

\subsection{Leaching and Precipitation}

Multiple leaching and precipitation tests were conducted throughout the initial stages of this research. These tests were conducted on three AMDp feedstocks from different AMD sites, 
Table 4.1 - ICP-MS analysis of the three AMDp feedstocks.

\begin{tabular}{|c|c|c|c|}
\hline Element & Omega & DLM & Mine-42 \\
\hline \multicolumn{4}{|c|}{ Major Ions (mg/kg) } \\
\hline $\mathrm{Al}$ & 107,000 & 121,000 & 49,000 \\
\hline $\mathrm{Fe}$ & 260,000 & 60,300 & 64,500 \\
\hline $\mathrm{Mg}$ & 2,430 & 81,100 & 112,000 \\
\hline $\mathrm{Mn}$ & 666 & 31,800 & 39,100 \\
\hline $\mathrm{Si}$ & 48,100 & 70,100 & 89,700 \\
\hline Co & 293 & 1,220 & 1,560 \\
\hline \multicolumn{4}{|c|}{ Rare Earth Elements (mg/kg) } \\
\hline $\mathrm{Sc}$ & 61.00 & 12.00 & 11.00 \\
\hline $\mathrm{Y}$ & 111.00 & 388.00 & 192.00 \\
\hline $\mathrm{La}$ & 19.70 & 90.00 & 49.50 \\
\hline $\mathrm{Ce}$ & 72.60 & 266.00 & 132.00 \\
\hline $\operatorname{Pr}$ & 12.00 & 32.60 & 18.60 \\
\hline $\mathrm{Nd}$ & 56.00 & 144.00 & 79.00 \\
\hline $\mathrm{Sm}$ & 17.40 & 38.20 & 23.20 \\
\hline $\mathrm{Eu}$ & 4.40 & 10.10 & 5.50 \\
\hline Gd & 28.10 & 62.60 & 34.60 \\
\hline $\mathrm{Tb}$ & 5.10 & 10.60 & 6.10 \\
\hline Dy & 32.00 & 67.00 & 39.00 \\
\hline Ho & 6.10 & 13.50 & 7.90 \\
\hline Er & 16.50 & 35.60 & 21.50 \\
\hline $\mathrm{Tm}$ & 2.30 & 4.90 & 3.00 \\
\hline $\mathrm{Yb}$ & 12.80 & 26.60 & 17.40 \\
\hline $\mathrm{Lu}$ & 1.80 & 3.60 & 2.30 \\
\hline \multicolumn{4}{|c|}{ Actinides (mg/kg) } \\
\hline $\mathrm{U}$ & 6.10 & 4.20 & 6.40 \\
\hline $\mathrm{Th}$ & 9.70 & 1.90 & 2.70 \\
\hline \multicolumn{4}{|c|}{ Totals $(\mathrm{mg} / \mathrm{kg})$} \\
\hline TREE & 458.80 & $1,205.30$ & 642.60 \\
\hline HREE & 276.70 & 624.40 & 334.80 \\
\hline LREE & 182.10 & 580.90 & 307.80 \\
\hline CREE & 231.50 & 671.70 & 350.10 \\
\hline
\end{tabular}

each having unique characteristics. For the leaching experiments, feedstocks were chosen from the Omega, DLM, and Mine 42 AMD treatment sites. Table 4.1 shows the ICP-OES and ICP-MS results of the AMDp from the three individual sites. The DLM feedstock was chosen due to a high TREE concentration, low Fe content, and high Al concentration. Next, Omega was selected for a high Fe content and relatively low REE content. Finally, Mine-42 was selected due to the high $\mathrm{Mg}$ concentration and moderate TREE content. 


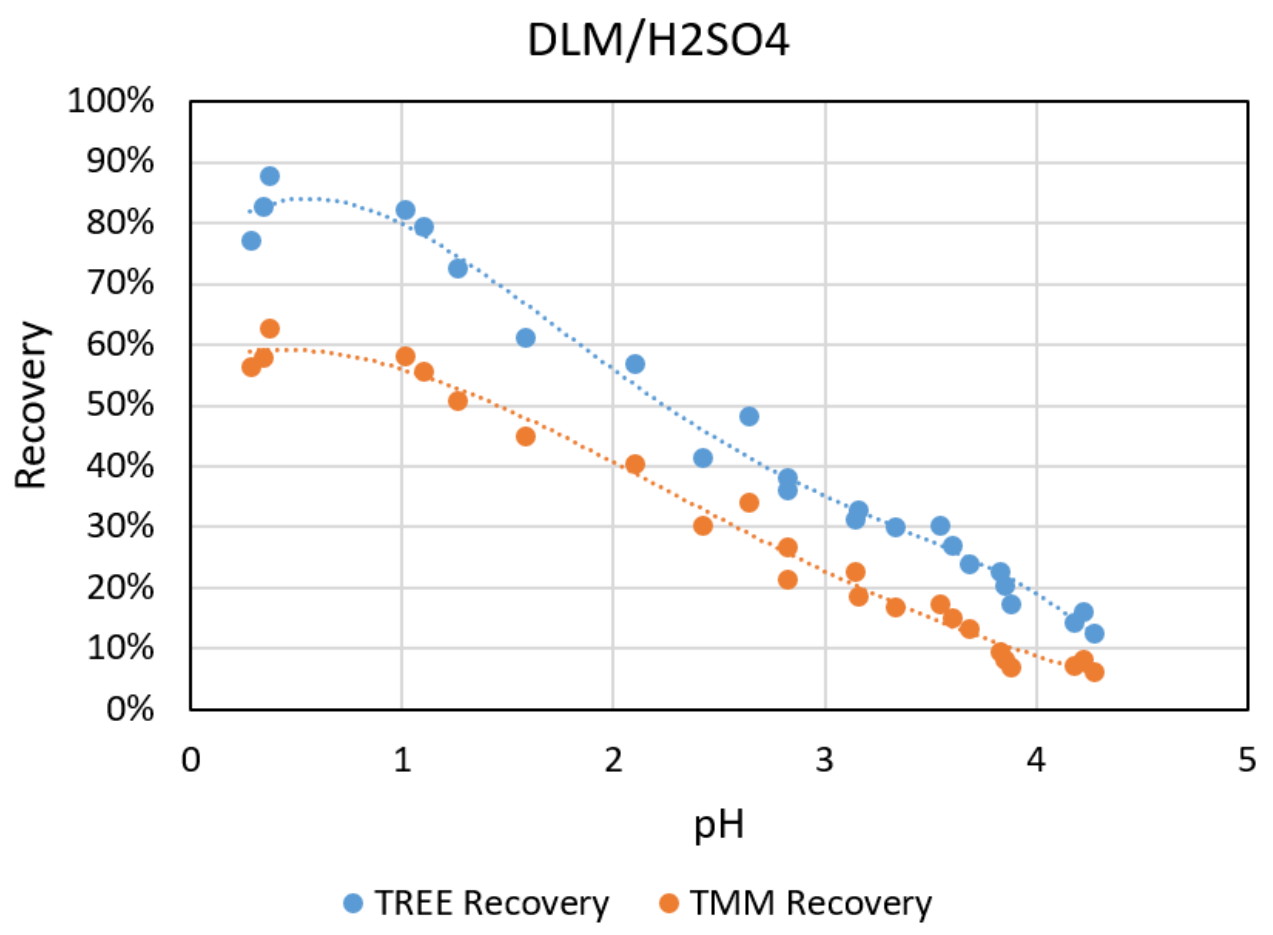

Figure 4.2 - Leaching study results for DLM feedstock subjected to $\mathrm{H}_{2} \mathrm{SO}_{4}$ acid.

Experimental results acquired from the leaching and precipitation studies were used to determine leaching kinetics, optimal leach $\mathrm{pH}$, leaching temperature, and the expected recovery of REEs and major metal ions. As an example, Figure 4.2 shows the results from a parametric leaching study on DLM sludge using sulfuric acid with a leach time of 10 minutes at ambient temperature. This result indicated that leaching at a $\mathrm{pH}$ less than 1 produced high REE recovery and good selectivity between REEs and major metals. All together, these results were used to determine the equipment requirements (leach reactor size) and the baseline operating conditions ( $\mathrm{pH}$, leach time).

\subsubsection{Parametric Leaching Studies}

Parametric leaching tests were conducted on the three distinct sludge feedstocks to validate prior experimental findings (Zhai 2019) and provide a general assessment of the processing variability inherent to sludge material from a single site. In addition, the data collected during this experimental campaign was also used to determine optimal operational conditions 
Table 4.2 - Experimental parameters for parametric leaching tests

\begin{tabular}{lrr}
\hline Parameter & Unit & Value \\
\hline Experimental Parameters & & \\
\hline Leach Time & minutes & $2.5,5,10$ \\
Leaching pH & $\mathrm{pH}$ & $0.5 .1,1.5,2.0,2.5,3,3.5,4$ \\
Samples & -- & Omega, DLM, Mine-42 \\
Acid Type & -- & Nitric, Sulfuric \\
\hline Constant Parameters & & \\
\hline Acid Concentration & $\mathrm{mol} / \mathrm{l}$ & 3 \\
Leach Temperature & ${ }^{\mathrm{C}}$ & Ambient $(\sim 20)$ \\
Solid : Liquid Ratio & -- & $1: 2$ \\
Stirrer Speed & $\mathrm{rpm}$ & 750 \\
Sludge Wet Mass & $\mathrm{grams}$ & 100 \\
Pressure & $\mathrm{psi}$ & Atmospheric \\
\hline Responses & & Measured \\
\hline REE Leach Recovery & $\%$ & Measured \\
Major Metal Leach Recovery & $\%$ & Measured \\
Solids Loss & $\%$ & Calculated \\
Acid Consumption & $\mathrm{mol} / \mathrm{g}$ & \\
\hline
\end{tabular}

and scale-up parameters that were integrated into an experimental design in tests at a larger scale. Specifically, the tests assessed the influence of sludge type (Omega vs. DLM vs. Mine-42), acid type (nitric vs. sulfuric), leach time, and leach pH on REE recovery and major metal recovery. All other variables, including temperature, mixing speed, and solid to liquid ratio, were held constant. Prior exploratory testing revealed optimal values for these parameters, and overall, they were observed to be of a smaller significance with respect to system design and economic assessment.

The full experimental design for the parametric testing campaign is summarized in Table 4.2. All test conditions were conducted in full factorial with individual test runs including a single sample type, a single acid type and a single leach $\mathrm{pH}$. Tests were then conducted as a function of time, with samples taken intermittently per the experimental design. As a result, this campaign included 48 individual test runs (eight pH points, three sample types, two acids).

Individual tests were performed by first splitting several representative samples of the sludge from the sample bucket. Three sub-samples were retained for moisture analysis, one was 


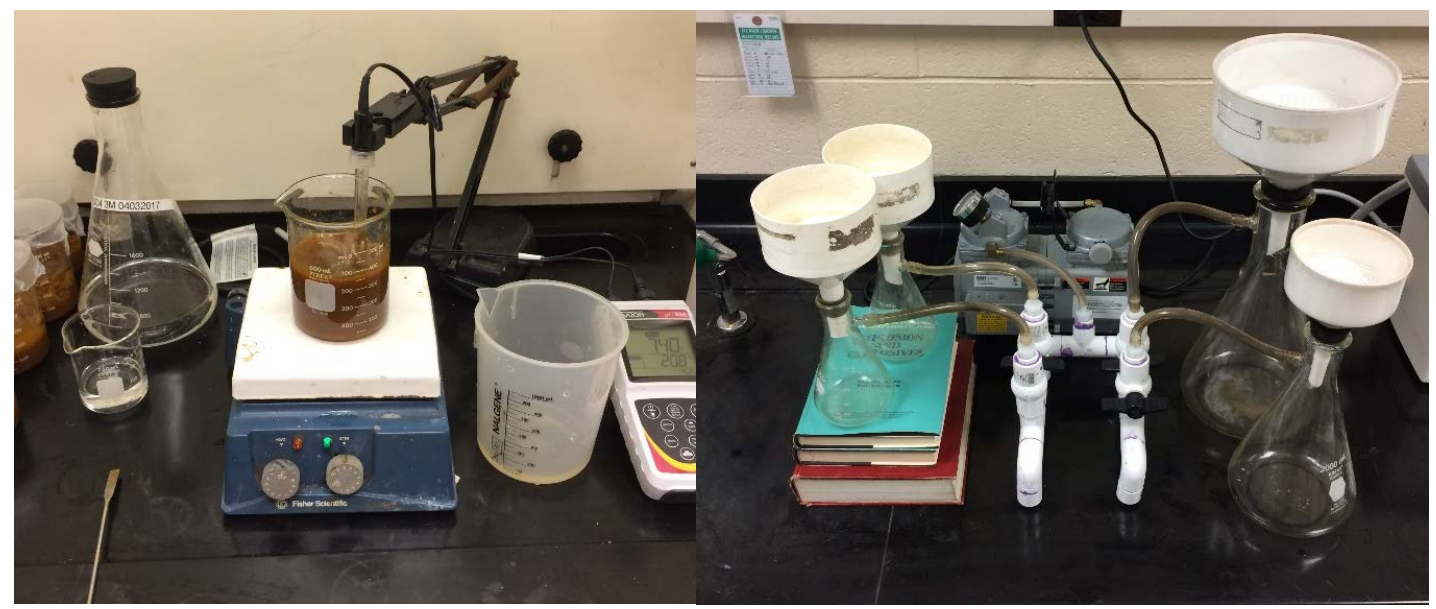

Figure 4.3 - Leaching set up and filtration manifold used for parametric testing.

retained for REE analysis of the feed, and the remaining samples were used in the experiments. During the test runs, 100 grams of wet sludge was placed in a $600 \mathrm{~mL}$ glass beaker with a magnetic stirrer. The sludge sample was mixed with $200 \mathrm{~mL}$ of deionized water, and a $5 \mathrm{~mL}$ pipette was used to slowly add the acid in a drop-wise fashion until the desired test $\mathrm{pH}$ was attained.

At the pre-determined time increments, approximately $35 \mathrm{~mL}$ of leach solution was withdrawn from the reactor using a $100 \mathrm{ml}$ syringe. This solution was then immediately placed into a vacuum filtration apparatus using Whatman \#4 filter paper. The filtrate (i.e., pregnant leach solution) was then split and retained for ICP-MS (REE) and ICP-OES (major ion) analysis. The residual solids were dried in an oven and the mass was recorded to determine overall solids loss. This process was repeated for each time increment, and at the maximum increment, the remaining residue was filtered, dried, and weighed. All tests were performed with the appropriate personal protective equipment under a laboratory fume hood. Pictures of the leaching set up and filtration manifold are shown in Figure 4.3.

\section{Feedstock Characterization}

The three feedstocks (Omega, DLM, and Mine-42) used in this experimental regime were selected as the leading candidates for continued testing at scale, and they represent a diverse mix of physical and chemical properties across all sludge samples assessed to date. As 

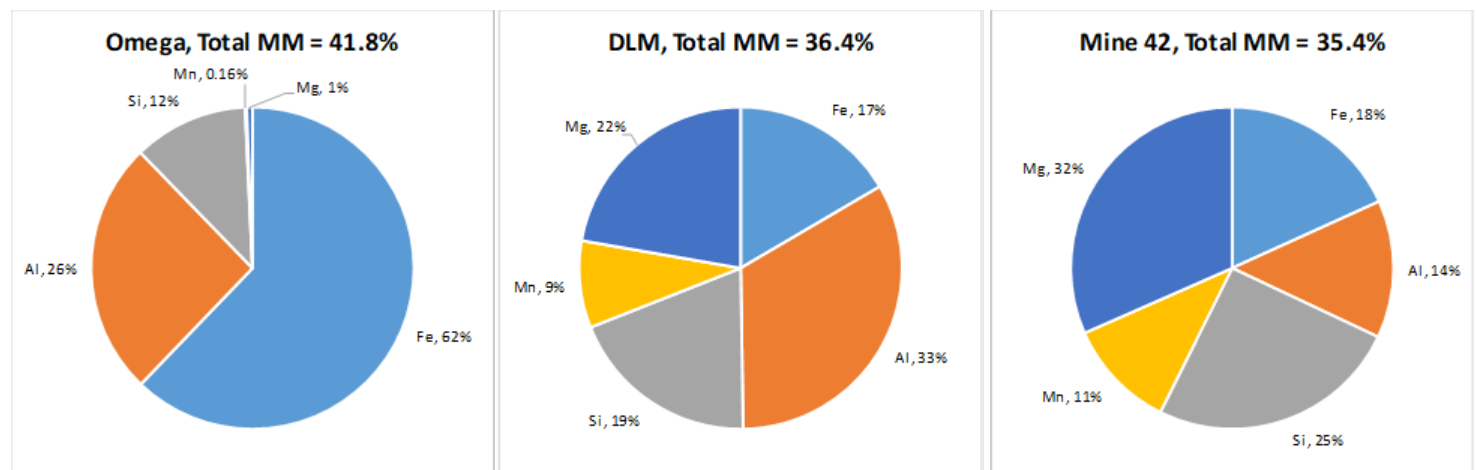

Figure 4.4 - Distribution of major metals within the selected feedstocks.

an example, the most prevalent major metal in the Omega sludge was iron (62\%), while manganese $(0.2 \%)$ and magnesium $(1 \%)$ only occurred in trace amounts within the sludge matrix. In contrast, the predominant major metal in the DLM sludge was aluminum (33\%) with iron (17\%), silica (19\%), magnesium (22\%), and manganese (9\%) comprising the remainder. Finally, the Mine-42 sludge was representative of a precipitate with magnesium $(32 \%)$ as the major component with the remaining major metals varying between eleven and twenty-five percent. For all samples, the REE distribution appeared similar to other sludge material with yttrium, cerium, and neodymium constituting the most abundant REEs. However, lanthanum, gadolinium, and dysprosium also have significant concentrations. Figure 4.4 shows the distributions of major metals within these feedstocks while Figure 4.5 shows the distribution of REEs.

In addition to elemental composition, these three sludge samples varied in physical attributes and morphology. The Omega sludge contained a high moisture content (94\%) when compared to DLM (83\%) and Mine-42 (67\%). The sludge samples varied in color from bright orange to black and, more importantly, in consistency, from a typical amorphous sludge (Omega) to an earthen-like texture with varying hard nodules (Mine-42). These nodules within the Mine-42 sludge matrix increased the difficulty of attaining full dissolution due to the smaller leachable surface area when compared to the unstructured sludge seen from Omega. 


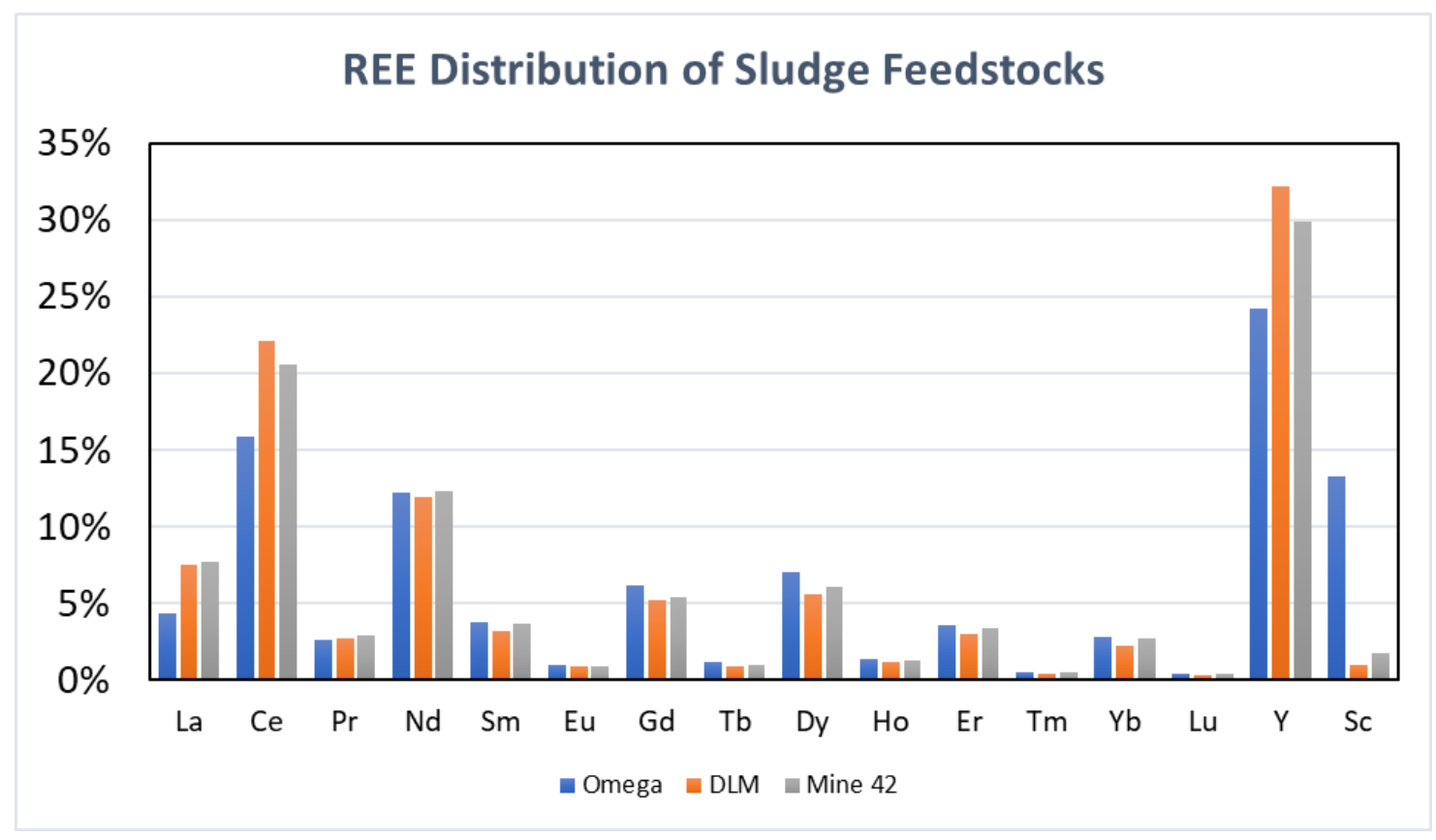

Figure 4.5 - Distribution of REEs between AMD precipitates from tested sites.

\section{Effect of Acid Type}

Two acids, $\mathrm{HNO}_{3}$ and $\mathrm{H}_{2} \mathrm{SO}_{4}$, were used in the test series to obtain a predefined leachate $\mathrm{pH}$. The performance of each acid varied considerably between the three feedstocks. As shown in Figure 4.6, the use of $\mathrm{HNO}_{3}$ generated higher REE recoveries ( $+10 \%$ points) for both the Omega and Mine-42 feedstocks, but only a marginal difference for the DLM material. In contrast, the DLM feedstock exhibited higher leaching efficiencies with $\mathrm{H}_{2} \mathrm{SO}_{4}$, which produced an increase of $15 \%$ points relative to $\mathrm{HNO}_{3}$ for most leach $\mathrm{pH}$ points. While the fundamental mechanism dictating this contrasting behavior between the various feedstocks is not fully understood at this point, the results empirically indicate one acid may not be universally superior. This outcome indicated a unique processing approach may be needed for each sludge or each class of sludges with similar composition. Alternatively, if a centralized acid leaching-solvent extraction (ALSX) facility is implemented commercially, a globally optimum leaching process may be dependent on the blend of feedstocks being fed to the ALSX plant. 

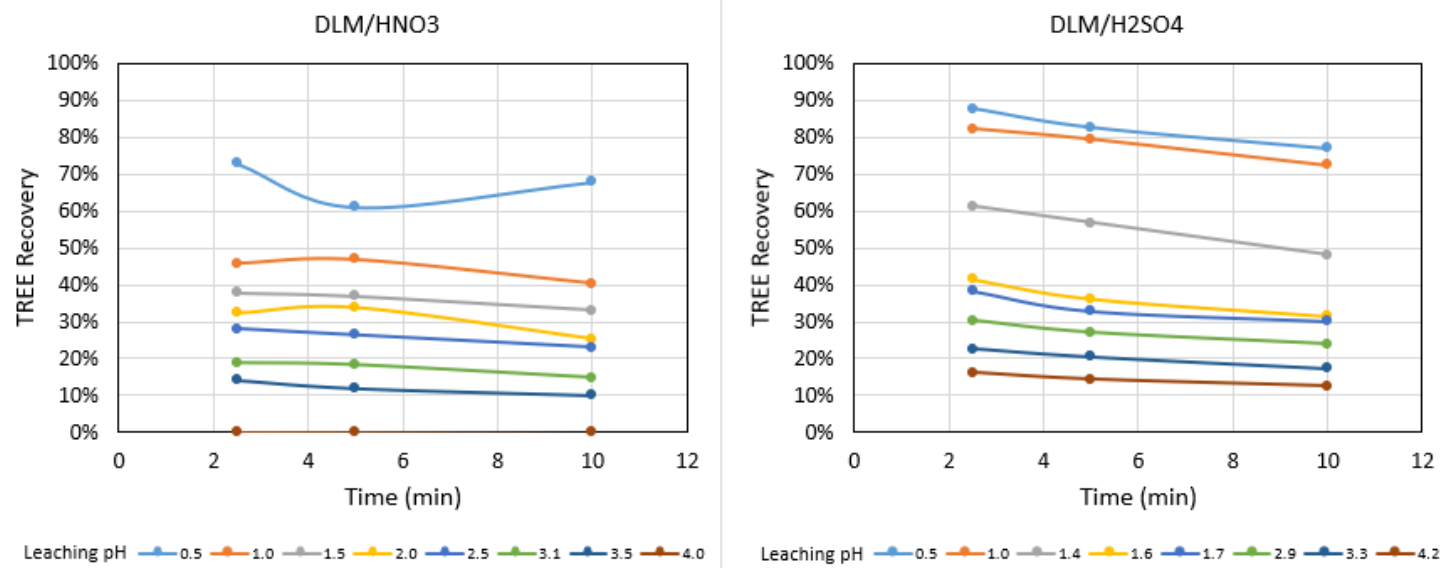

Leaching $\mathrm{pH} \rightarrow 0.5 \rightarrow-1.0-1.4 \rightarrow-1.6 \rightarrow 1.7 \rightarrow 2.9-3.3 \rightarrow 4.2$
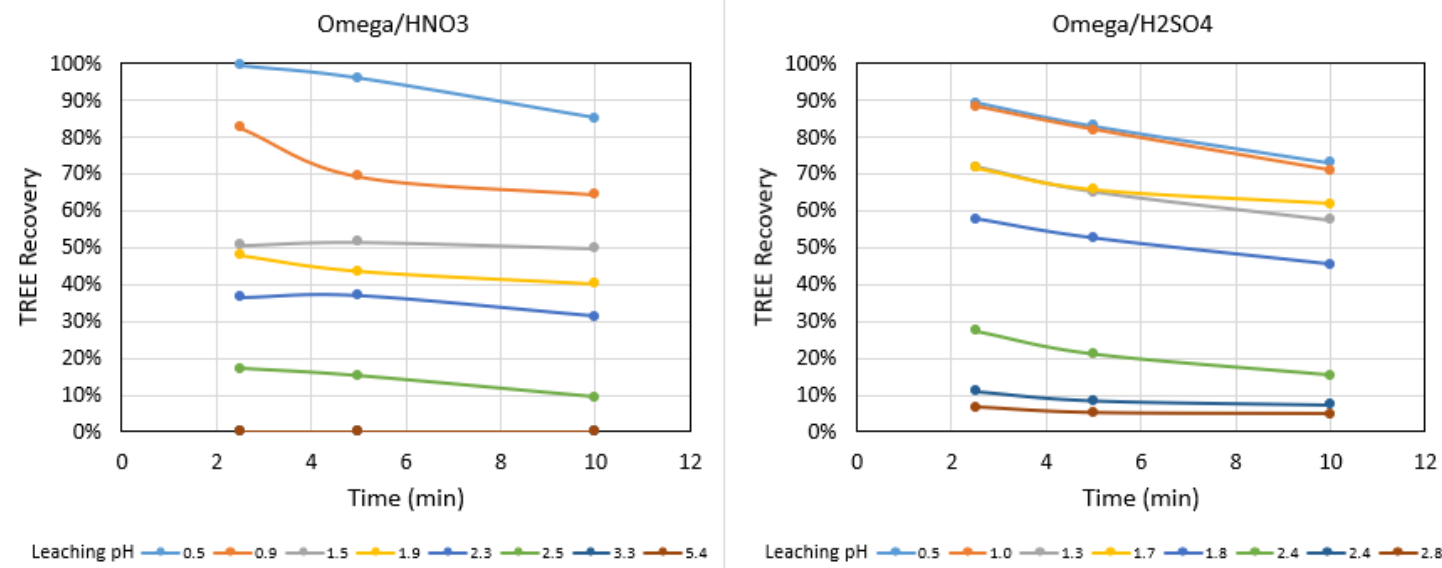

Leaching $\mathrm{pH} \rightarrow 0.5 \rightarrow 1.0 \rightarrow 1.3 \rightarrow 1.7 \rightarrow 1.8 \rightarrow 2.4 \rightarrow 2.4 \rightarrow 2.8$
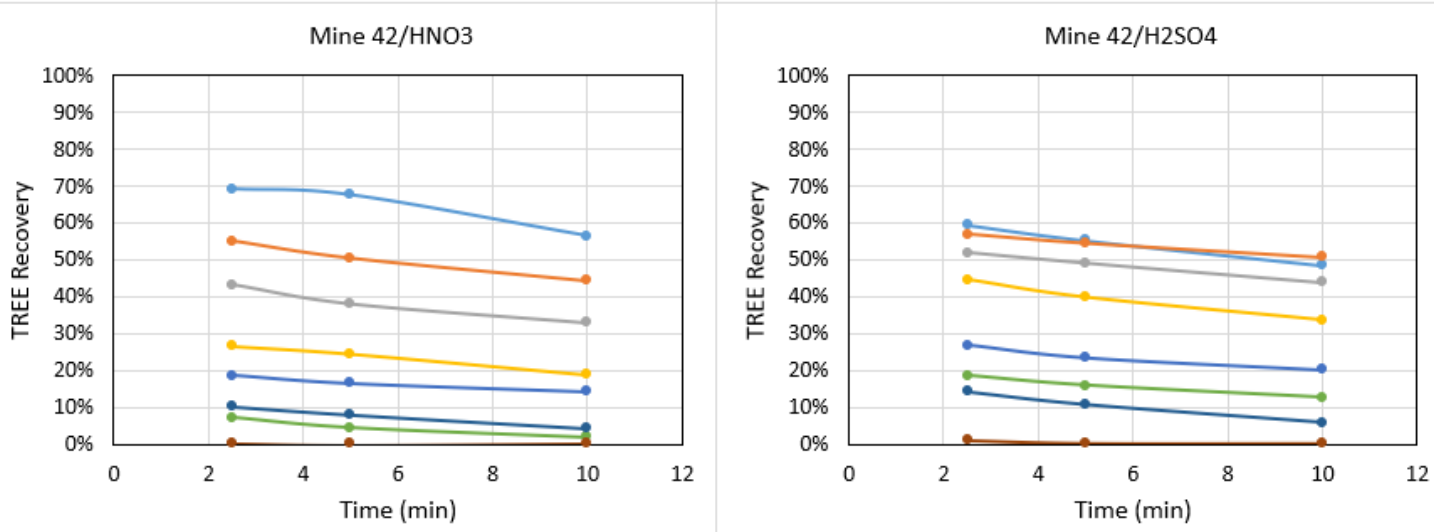

Leaching pH $\rightarrow-0.5 \rightarrow-0.9 \rightarrow-1.4 \rightarrow-2.1 \rightarrow-2.4 \rightarrow-2.8 \rightarrow-2.9 \rightarrow-3.6$

Leaching pH $\rightarrow 0.5 \rightarrow 0.8 \rightarrow-1.1 \rightarrow-1.6 \rightarrow-2.0 \rightarrow 3.0 \rightarrow 3.0 \rightarrow-3.8$

Figure 4.6 - Total REE elemental recovery versus time for parametric leaching experiments.

\section{Kinetic Effects of Leaching}

The duration of the leaching experiment had a nominal effect on the TREE and major metal recoveries. In fact, the overall results indicated the recovery to solution for both major metals and REEs decreased during the ten-minute testing timeframe. For instance, in the test run 
Omega/ $\mathrm{H}_{2} \mathrm{SO}_{4}$ recovery versus time plot, Figure 4.6, the recovery of TREEs decreased by $15 \%$ over the course of the test at a leach $\mathrm{pH}$ value of 0.5 .

This outcome may be explained by one of two phenomena peculiar to the laboratory-scale semi-batch tests. First, the test protocols call for discrete sample removal points at the designated time increments. While the experimental protocol prescribes careful collection of this sample, the sample removal mechanism does permit some degree of bias, as a small portion of undissolved solids are inevitably removed with the liquid. Since these solids are removed from the leaching vessel, they then do not have the opportunity to be recovered into the leachate in future time steps; thus, leading to a potential negative bias in the measured recovery values.

Furthermore, since these semi-batch tests were, by definition, never at steady state, the pH

did gradually rise throughout the test as acid was consumed. In some cases, this $\mathrm{pH}$ rise was quite high, on the order of 1.5 to $2.0 \mathrm{pH}$ points. In these cases, the rise in $\mathrm{pH}$ may have caused some minor re-precipitation that resulted in a slight reduction in measured recovery. Fortunately, both issues were only pertinent to the laboratory-scale batch test, as a continuous leaching vessel can (at least theoretically) be controlled to a fixed $\mathrm{pH}$ point by continual acid addition. This $\mathrm{pH}$ control is notably challenging, given the dynamic and non- linear relationship of $\mathrm{pH}$ to acid addition. However, some advanced control strategies could be implemented to address this effect. Despite the issues with decreasing recovery with time, the tests were successful in confirming the fast reaction kinetics associated with acid leaching of sludge samples.

\section{Effect of Leaching $\mathrm{pH}$ Value}

The acquired results from this laboratory-scale study also indicated higher REE recoveries were obtained at lower leach pH values. For all test runs, every sludge feedstock produced the highest recovery when the leach $\mathrm{pH}$ value was 0.5 , the lowest $\mathrm{pH}$ condition evaluated in this study. Similar recovery results were observed for the major metal fractions of the sludges. Moreover, some selectivity between REEs and major metals may be achieved through varying leach $\mathrm{pH}$ values. As seen in Figure 4.7, several opportunities exist to fractionate REEs from 
the gangue metals. One such trend was noticed at $\mathrm{pH}$ values above 4.5. At these higher $\mathrm{pH}$ values, REE recoveries were at or near zero percent $(0 \%)$, while major metal recoveries were typically in the $10-20 \%$ range. In a like manner, at low $\mathrm{pH}$ values, the REE recoveries tended to be higher than those of major metals. These varying recoveries at certain $\mathrm{pH}$ values may provide a selective processing route to concentrate the REEs in the pregnant leach solution by discarding gangue material throughout the leaching process.

\section{Sensitivity of Results to Moisture Measurement}

The standard testing and analytical protocol used throughout this research provided results on a dry-weight basis; however, the initial feed material always consisted of "fresh" sludge that was not dried and was very high in moisture. To determine the mass of dry sludge used in each test, several independent split samples were recovered from the feed material and subjected to moisture analysis. The wet sludge mass was then multiplied by 100 minus the moisture content to determine the dry sludge mass used in the leach test. Since the moisture content of sludge tended to be very high (often greater than $80 \%$ ), the amount of dry mass in the test (and subsequently the final recovery values, which were based on the initial dry mass) tended to be very sensitive to the initial moisture content. For example, given the results above, a 1\%-point change in the Omega feedstock moisture could result in as much as a $10 \%$ change in leaching REE recovery. During testing, it was noticed the sludge may harden into lumps and trap moisture inside, resulting in inaccurate moisture measurements. Successive drying and comminution of the dried sludge was required to attain a true moisture value.

This potential for error was further compounded since many times the residual mass after leaching was not of sufficient quantity for assay analysis. As a result, a complete mass balance was not formed, and any spurious moisture values were not be identified using the data alone. While this factor does not invalidate the results, it should provide some caution in using the laboratory-scale leach results for predictive models.

To mitigate these concerns in the future, researchers should further validate methods of moisture determination and ensure consistency between measurements. Furthermore, larger 

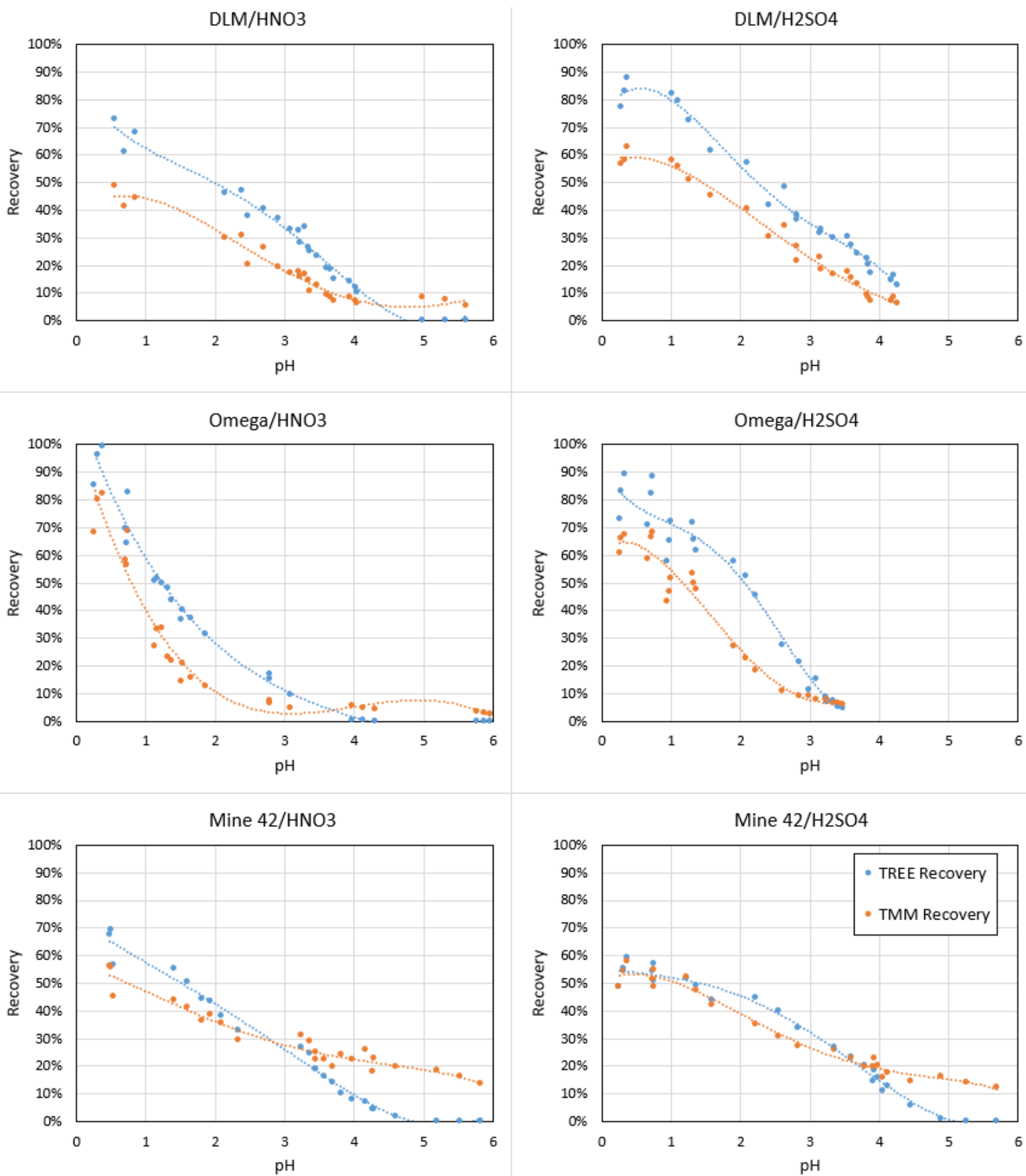

Figure 4.7 - Total REE elemental recovery versus leach pH for parametric leaching experiments.

scale testing should be subjected to redundant assays (i.e. assays of the feed, solution, and residual solids during and after testing), as well as a rigorous data reconciliation/mass balance process to overcome errant data points. 


\section{Results and Discussion}

This testing series highlighted the difference in leaching efficiency when presented with multiple AMD precipitate feedstocks of varying composition. As a result, achieving a globally optimal leaching protocol will require prior knowledge of the quantity and quality of the overall plant feed. The results from these tests indicated the need for further testing to properly determine if selectivity may be increased by using a mixed acid leach solution. Additionally, the results from this parametric testing further emphasized this need, in the event a mixed sludge feedstock would be used as the Technology Readiness Level (TRL) of this technology advances. In other words, AMDp may need to be classified by prevalent compositional characteristics that share common processing amenability.

Furthermore, this parametric testing series validated several results from previous testing. Both leaching kinetics results and the correlation to REE recovery to $\mathrm{pH}$ values were reproduced. As seen in previous tests (Zhai 2019), the amount of time required to leach REEs from the AMD sludge was not a significant factor in maximizing recovery, provided that a minimal leaching time (e.g. 5 minutes) was obtained. Likewise, the parametric testing indicated lower leach $\mathrm{pH}$ values increased the recovery of REEs to solution. This outcome provides critical verification on the leaching vessel size needed for continuous leach operations at a larger scale. More importantly, this testing series validated the differences in REE versus major metal recoveries at multiple $\mathrm{pH}$ values. This result is significant as these differences in recovery may be utilized to concentrate REEs throughout the leaching process. Further leaching experiments should be conducted throughout the shakedown testing process as the bench-scale plant begins operation to exploit these different recovery values.

Finally, the overall body of results seen in this testing contributed to the development of a more thorough experimental design. One issue noted during the data analysis was the sensitivity to recoveries and mass calculations to the measurement of sludge moisture. As a result, future protocols may require lab-scale testing to utilize fully dried sludge feedstock for more accurate results. Additionally, this issue has shown the need to analogue the moisture protocols used by the analyzing laboratory to guarantee reporting reliability. 
Table 4.3 - Results of solvent extraction laboratory-scale tests for the DLM feedstock after (Ren and Liu 2019)

\begin{tabular}{|c|c|c|c|c|c|c|c|c|c|}
\hline Site & Acid & $\mathrm{pH}$ & Stage & $\begin{array}{l}\text { Total } \\
\text { Major } \\
\text { Metals } \\
(\mathrm{mg} / \mathrm{L})\end{array}$ & $\begin{array}{c}\text { Extraction / } \\
\text { Stripping Rate }\end{array}$ & $\begin{array}{l}\text { Total Rare } \\
\text { Earth Ele- } \\
\operatorname{ment}(\mathrm{mg} / \mathrm{L})\end{array}$ & $\begin{array}{l}\text { TREE Extrac- } \\
\text { tion/Stripping } \\
\text { Rate }\end{array}$ & $\begin{array}{c}\text { Estimated } \\
\text { TREE in Solid } \\
\text { Phase }\end{array}$ & $\begin{array}{c}\text { Enrichment } \\
\text { Factor }\end{array}$ \\
\hline \multirow{3}{*}{ DLM } & \multirow{3}{*}{ HNO3 } & \multirow{3}{*}{3.2} & Initial & 803.25 & - & 5.131 & - & $0.63 \%$ & - \\
\hline & & & Extraction & 725.25 & $9.71 \%$ & 0.281 & $94.52 \%$ & $5.85 \%$ & 9.2 \\
\hline & & & Stripping & 17.7 & $11.35 \%$ & 1.672 & $17.24 \%$ & $8.63 \%$ & 13.6 \\
\hline \multirow{3}{*}{ DLM } & \multirow{3}{*}{ HNO3 } & \multirow{3}{*}{3.6} & Initial & 791.5 & - & 5.162 & - & $0.65 \%$ & - \\
\hline & & & Extraction & 735.6 & $7.06 \%$ & 0.174 & $96.63 \%$ & $8.19 \%$ & 12.6 \\
\hline & & & Stripping & 22.7 & $20.30 \%$ & 1.451 & $14.54 \%$ & $6.01 \%$ & 9.3 \\
\hline
\end{tabular}

\subsection{Laboratory-Scale Solvent Extraction}

Throughout this project, batch tests were conducted to evaluate the effectiveness of solvent extraction on the separation and concentration of REEs by Ren and Liu (2019). An example of these test results is shown in Table 4.3. These data indicate that the process is efficient at extracting and concentrating REEs from the pregnant leach solution, and this process is sufficiently selective to meet the $2 \%$ purity requirement. However, this data also indicates that the stripping efficiency is quite low and must be improved to optimize bench-scale operation.

\subsection{Design Approach and Commissioning}

\subsubsection{Design Objectives}

The primary objective of this chapter is to show the development of a bench-scale flowsheet that was used in the construction of an REE solvent extraction bench-scale plant for an AMDp feedstock. To accomplish this, batch testing at the laboratory-scale was conducted and demonstrated this extraction technology at TRL 4. However, the current objective of the overall research is to mature that technology to TRL 5 by operating a continuous-flow benchscale system that integrates the various technology components. To perform this scale-up, these primary objectives were itemized into several technical and economic considerations 
that were answered to properly mature the technology. Detailed descriptions of these items are included in Table 4.4. These considerations guided the system design and dictated many of the constraints and criteria imposed in the design process.

\subsubsection{Design Constraints and Criteria}

The bench-scale system design was limited by several constraints imposed by the funding agency and other restrictions. These constraints limited the scale of the overall system and dictated several design decisions concerning equipment and reagent selection. Constraints considered in this bench-scale plant design included but were not limited to:

- Inherent Safety: The as-built process must pass WVU Environmental Health and Safety approvals. The process must not expose researchers to uncontrollable and unmitigated flammable, health, corrosion, or radioactive hazards.

- Ending TRL: The as-built process must meet or exceed TRL 5.

- Product Purity: The as-built process must be able to produce 5 gram lots of REE concentrate meeting or exceeding $2 \%$ TREE by mass. The system must not produce refined metal.

- Budget: The overall project cost, including the design, construction, operation, and associated analysis of the as-built process must not exceed the budget limits set by the funding agency.

- Procurement and Construction Timeline: The as-built process must have a delivery and testing timeline that does not exceed an 18-month DOE project period.

While design constraints included binary, go/no-go considerations that were met to fulfill project objectives, design criteria represented desired, but not required, elements that were used to evaluate and assess alternatives. The design criteria considered in this development process included but are not limited to: 
Table 4.4 - Technical and economic considerations influencing scale-up of the bench-scale system

\begin{tabular}{|c|c|c|}
\hline Objective & Key Question & Limitations of Current Scale \\
\hline \multicolumn{3}{|c|}{ Primary Objectives } \\
\hline Technology & Can the proposed flowsheet produce a $2 \%$ & Current laboratory testing has only achieved TRL \\
\hline Demonstration & $\begin{array}{l}\text { REE concentrate at a production rate } \\
\text { commensurate with TRL } 5 ?\end{array}$ & 4. \\
\hline $\begin{array}{l}\text { Scale-Factor } \\
\text { Assessment }\end{array}$ & $\begin{array}{l}\text { For each unit operation, how does } \\
\text { performance (REE recovery) vary between } \\
\text { experimental scales? Can this difference be } \\
\text { predicted with simple scale factors? }\end{array}$ & $\begin{array}{l}\text { Only one scale has been tested, so no scale factors } \\
\text { can be derived. }\end{array}$ \\
\hline \multicolumn{3}{|c|}{ Specific Technical Performance Considerations } \\
\hline $\begin{array}{l}\text { Leaching } \\
\text { Kinetics }\end{array}$ & $\begin{array}{l}\text { How does the mixing intensity influence } \\
\text { leaching kinetics? }\end{array}$ & $\begin{array}{l}\text { Small magnetic stirrers only supply a limited } \\
\text { mixing intensity that is not representative of } \\
\text { industrial mixers }\end{array}$ \\
\hline $\begin{array}{l}\text { Dewatering } \\
\text { Kinetics }\end{array}$ & $\begin{array}{l}\text { What are the kinetics of the solid/liquid } \\
\text { separation of the leaching residue and } \\
\text { pregnant leach solution? }\end{array}$ & $\begin{array}{l}\text { This data is needed to size dewatering units; } \\
\text { however, the small laboratory-scale tests do not } \\
\text { produce a sufficient mass of residue for } \\
\text { representative dewatering tests. }\end{array}$ \\
\hline $\begin{array}{l}\text { SX Circuit } \\
\text { Configuration }\end{array}$ & $\begin{array}{l}\text { What is the specific flowsheet arrangement } \\
\text { within the solvent extraction unit? What } \\
\text { number of extraction and stripping stages } \\
\text { are needed to meet quality specifications? }\end{array}$ & $\begin{array}{l}\text { Laboratory batch tests can be used to predict the } \\
\text { general SX performance; however, the flowsheet } \\
\text { arrangement, including number of stages, the } \\
\text { utility of scrubbing and regeneration stages, and } \\
\text { the location of recycle loops, must be specified by } \\
\text { continuous testing. }\end{array}$ \\
\hline $\begin{array}{l}\text { System } \\
\text { Recovery }\end{array}$ & $\begin{array}{l}\text { What is the end-to-end REE system } \\
\text { recovery, when including recycle loops. }\end{array}$ & $\begin{array}{l}\text { Batch, laboratory test has not integrated all } \\
\text { system components in an end-to-end fashion. } \\
\text { Therefore, system recovery can only be estimated. }\end{array}$ \\
\hline Control System & $\begin{array}{l}\text { What is the ideal sensor package and sensor } \\
\text { location within the flowsheet? }\end{array}$ & $\begin{array}{l}\text { Sensor location and control system assessments } \\
\text { require continuous testing. }\end{array}$ \\
\hline \multicolumn{3}{|c|}{ Specific Economic Performance Considerations } \\
\hline $\begin{array}{l}\text { Leaching Acid } \\
\text { Consumption }\end{array}$ & $\begin{array}{l}\text { What is the acid consumption rate during } \\
\text { leaching? How does this value compare with } \\
\text { similar values measured in the laboratory } \\
\text { scale? }\end{array}$ & $\begin{array}{l}\text { Small deviations in sub-sample mass and moisture } \\
\text { content tend to distort results on small samples. } \\
\text { Leaching larger amounts of sample will tend to } \\
\text { average out these variations. }\end{array}$ \\
\hline $\begin{array}{l}\text { SX Reagent } \\
\text { Consumption }\end{array}$ & $\begin{array}{l}\text { What organic/extractant losses are expected } \\
\text { in solvent extraction? }\end{array}$ & $\begin{array}{l}\text { These items are required to accurately estimate } \\
\text { SX consumable costs, but are difficult or } \\
\text { impossible to determine in laboratory batch tests. }\end{array}$ \\
\hline $\begin{array}{l}\text { Other } \\
\text { Consumables }\end{array}$ & $\begin{array}{l}\text { What other reagents and consumables are } \\
\text { needed for ancillary operations? }\end{array}$ & $\begin{array}{l}\text { Laboratory testing usually does not consider } \\
\text { ancillary units, such as solid/liquid separation, so } \\
\text { scaled testing is needed to determine other } \\
\text { consumable materials. }\end{array}$ \\
\hline
\end{tabular}


- Mechanical System Flexibility: A system that can be easily reconfigured will permit novel flowsheet designs and the ability to evaluate multiple parameters simultaneously.

- System Robustness: A system that can handle multiple feedstocks and investigate heavy vs. light REE separation is advantageous.

- Operating Schedule: Given standard university work hours, a system that permits an 8-hour work shift is strongly desired.

- Overall Size/System Location: A system that can fit within the WVU/NRCCE High Bay is strongly desired since this space can be easily acquired and configured for this testing. Furthermore, a system that can be built and operated indoors will alleviate seasonal weather issues.

- Operator requirements: A system that can be easily controlled with one or two operators is strongly desired.

\subsubsection{Design Assumptions}

Several assumptions were included in the this system design. Many of these assumptions were further vetted during the actual bench-scale testing, but the validity was currently supported by fundamental considerations and experimental testing. These assumptions included:

- Recovery values measured at the laboratory scale are suitable for developing a scaled mass balance.

- The feedstock material that was tested will not substantially deviate from prior measured values for the reserve.

- The optimized chemical conditions determined in laboratory-scale testing will adequately scale to the bench-scale system.

Given the constraints, criteria, and assumptions above, the overall flowsheet design was created with use of a master design table. This table identified the specification for each 
unit operation and associated ancillary equipment. Additionally, the values assigned to each parameter in this table reflected the aforementioned constraints and assumptions. In order to provide provide flexibility in the overall development of the flowsheet, an optimal baseline was initially established; however, operational testing dictated that other values or unit operations were required. For example, a specified filtration unit was deemed insufficient, resulting in an additional filtration circuit added to the overall flowsheet based on empirical data.

In addition to a processing flowsheet, additional materials were developed throughout the flowsheet development phase. These materials include a plan-view facility layout and a piping and instrumentation drawing (P\&ID). Like the flowsheet operations, these materials were flexible in design to allow for perturbations that were encountered in the operation of the bench-scale system.

\subsection{System Design}

\subsubsection{Overall Design Approach}

Given the constraints, criteria, and assumptions above, the overall bench-scale design utilized a decoupled, semi-batch process capable of producing several grams per hour of REE concentrate. Each of these items is described and justified in detail below and the flowsheets are provided in Appendix A. "Decoupled" refers to the coordination between the different unit operations and is contrasted to a fully-coupled system where all unit operations operate continuously at the same time, with the product of one operation being immediately fed to the next unit operation. The decision to decouple was largely based on the operational challenges in simultaneously managing multiple unit operations as well as the limited value that fully-coupled testing provides. Even industrial units rarely operate in a fully-coupled manner, as each primary unit operation is usually separated by stockpiles, surge bins, sumps, and other intermediate holding vessels that mitigate process disturbances. 
For the bench-scale system design, the decoupling produced three independent process modules: (1) leaching and dewatering; (2) solvent extraction and stripping; and (3) precipitation and concentrate recovery. Operationally, the solvent extraction module was the driving unit, as these reactors were designed to have a continuous feedstock during the operational period. To accommodate this need, leaching and dewatering were designed perform intermittently, as needed, and the pregnant leach solution was then stored until needed for solvent extraction testing. Likewise, the solvent extraction products were also stored until a sufficient volume was produced, at which time, the REEs were precipitated and recovered in a single batch.

Overall, the decoupling provided the flexibility needed to assess individual process performance parameters for each module while still meeting the testing objectives and DOE requirements. Semi-continuous refers to the operational flow arrangement and is contrasted to batch and continuous flow regimes. In this context, the semi-continuous designation implies that the leaching and dewatering module as well as the precipitation and concentrate recovery module were performed in a batch-wise fashion, while the solvent extraction and stripping units instead were performed in a continuous fashion. While the decision for semibatch flow was independent from other design considerations, it did coordinate well with the decision to decouple the major unit operations. Operating the leaching and precipitation units in a batch-wise fashion had several notable advantages and did not necessarily limit or encumber the ability to meet the testing objectives specific in Table 4.4. On the contrary, batch-wise leaching and dewatering is very common for this experimental scale, as a "weekly batch" of leachate can be generated by simple mixing and overnight dewatering.

\subsubsection{Design Flowsheet}

\section{Flowsheet}

Mass-balanced engineering flowsheets are included in Appendix A and referenced in this section. The three flowsheets included in this appendix depict the expected performance for the three AMDp samples that were proposed for testing during bench-scale operation, including DLM, Omega, and Mine 42. These specific samples were selected to span a wide range of 


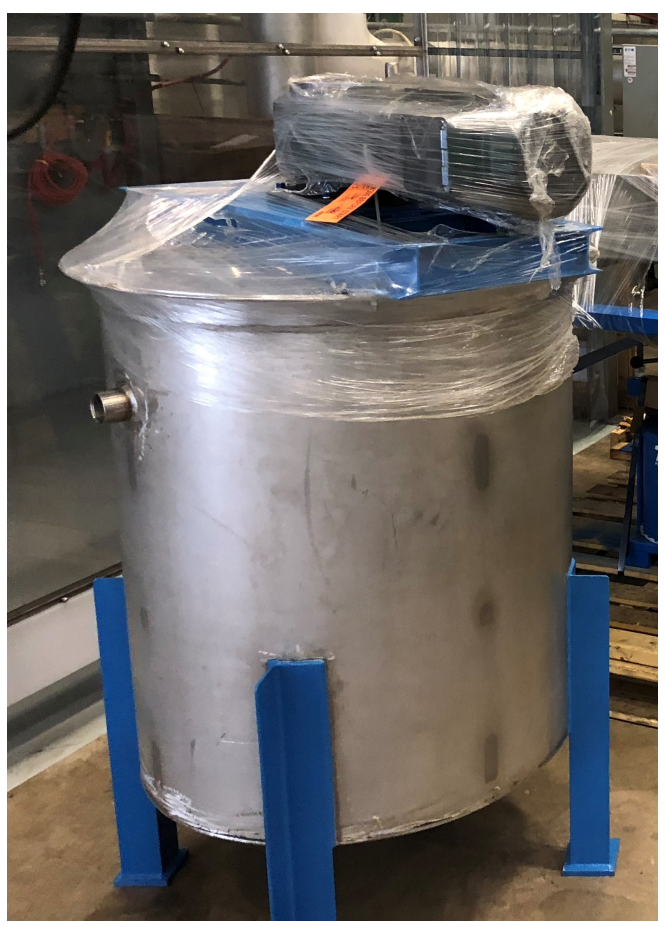

Figure 4.8 - Agitated leach tank

sludge compositions and are typically characterized by either high TREE concentration or high REE mass flux.

Leaching and Dewatering Module The general operating path of this bench-scale system begins with raw AMDp delivered to the plant site. Here, the solids are weighed and loaded into a 70-gallon batch leaching tank at a 1:1 solid to liquid ratio. In this first leaching vessel, recycled raffinate and makeup acid used as the liquid fraction to lower the $\mathrm{pH}$, while potentially reducing downstream acid consumption costs. The leach tank contained wetted parts constructed of Hastelloy, a nickel-chromium alloy which can resist corrosion in the presence of hydrochloric acid (Zhang et al. 2009). The leach tank was equipped with a high-intensity mechanical stirring device (5 to $10 \mathrm{HP} / 1,000$ gallon) to facilitate mixing and reduce process time. The leaching process occurred at atmospheric temperature and pressure. Figure 4.8 shows an example of an agitated leaching tank that was used in testing. Next, an acid-resistant pneumatic diaphragm slurry pump was chosen to transfer the leach slurry to the next batch leaching tank where the $\mathrm{pH}$ was adjusted to a desired value between 0.5 and 3 using strong acids, fresh feed, or a caustic reagent depending upon the experi- 
mental conditions and the required $\mathrm{pH}$ change after the first vessel. The slurry pump was also designed to have the wetted parts comprised of PVFD, a non-reactive thermoplastic. After leaching for the desired retention time ( $<30$ minutes), the mixed leachate-slurry was transported to a pan filter for solid-liquid separation.

A 5' X 5' pan filter was chosen to separate the solid waste residue from the pregnant leach solution (PLS). The residual waste storage vessel was comprised of a plastic bin and ultimately disposed of according the WVU chemical handling procedures. Likewise, the PLS storage containers were designed to accommodate 55-gallons. This surge tank would then feed into the solvent extraction system. Overall, the leaching and dewatering module was operated as fresh leach solution was needed for the solvent extraction module, approximately once every week, depending on test conditions.

Solvent Extraction and Stripping Module The solvent extraction and stripping stage was designed to operate in a continuous fashion with a Masterflex LS series peristaltic pump transferring the pregnant leach solution to the extraction mixer-settler units. These pumps are suitable for corrosive chemical applications, as the pump head does not directly contact the solution. In the solvent extraction stage, organic and the pregnant leach solution flow in a counter-current configuration from unit to unit, throughout the extraction process. The REEs are transferred to the organic solution while the spent aqueous portion is collected as raffinate in a 55-gallon surge tank.

Following the extraction stage, the loaded organic solution was ultimately transferred to the stripping stage, where the solution was mixed with a low $\mathrm{pH}$ strip solution in a countercurrent fashion. Here, the REEs contained in the organic phase were transferred back to an aqueous phase to facilitate precipitation of the metals in the next module. The mixer/settlers used in this phase were identical to the ones used in the extraction stage. A total of 100 mixer-setter units were proposed for use in the bench-scale plant. The standard laboratory units were constructed of borosilicate glass and have a 270-mL active volume in the mixer portion and 1,050-mL active volume in the settler portion. The combined aqueous and organic flow-rate was $150 \mathrm{~mL} / \mathrm{min}$. However, the system permitted variable aqueous to organic flow ratios. 
The mixers within these units perform dual functions as they both form the aqueous/organic emulsion and provide a pumping action that encourages flow through each mixer/settler. While laboratory-scale test results suggested that 8 to 10 mixer-settler units may be sufficient to meet the $2 \%$ product purity requirements, the decision to use 100 mixer-settlers was driven by security, robustness, and testing options. Since the batch results were not verified at scale, over-design (within limits) was advantageous at this stage of technology development to ensure production targets were met. Furthermore, the large number of units could permit the separation of heavy from light REEs in the stripped solution - an alternative process option that may increase product marketability and overall economic feasibility. The large number of units also permitted the addition of impurity scrubbing and other novel flowsheet alternatives, such as the direct enrichment of raw AMD.

Scrubbing often takes place on the loaded organic after the extraction stage. Scrubbing removes residual metal impurities which remain in the organic solution. This process has been well documented by many researchers (Miranda and Zinner 1997; Morais and Ciminelli 2004; Banda, Jeon, and Lee 2012; Xie et al. 2014; Wang et al. 2017). Altogether, the decision to use 100 mixer-settlers supported the design objectives while meeting the criteria and constraints described above. The mixer-settlers mounted to a stainless-steel frame with ten units per frame. These frames rested on laboratory style tables and connected with one of two types of Tygon chemical resistant tubing. Clear tubing transported the aqueous fluids, while yellow Tygon fuel rated tubing was used for the organic. Each mixing-settling unit also had the capability to recycle either the aqueous or the organic phase within the same vessel. This option was essential to maintain the optimum ratio of organic to aqueous within the mixing chamber (Webster 2017). The mixing units were comprised of variable speed agitators coupled with titanium shafts and polypropylene impellers to resist corrosion. An example of a ten-stage mixer- settler unit is shown in Figure 4.9.

Precipitation and Concentrate Recovery Module The final precipitation module of the bench-scale plant was operated in a batch process like the initial leaching stage. After stripping, the collected strip solution was transferred to a 10-gallon mixing vessel by a Masterflex LS peristaltic pump. In this vessel, the $\mathrm{pH}$ of the strip solution had the capacity 


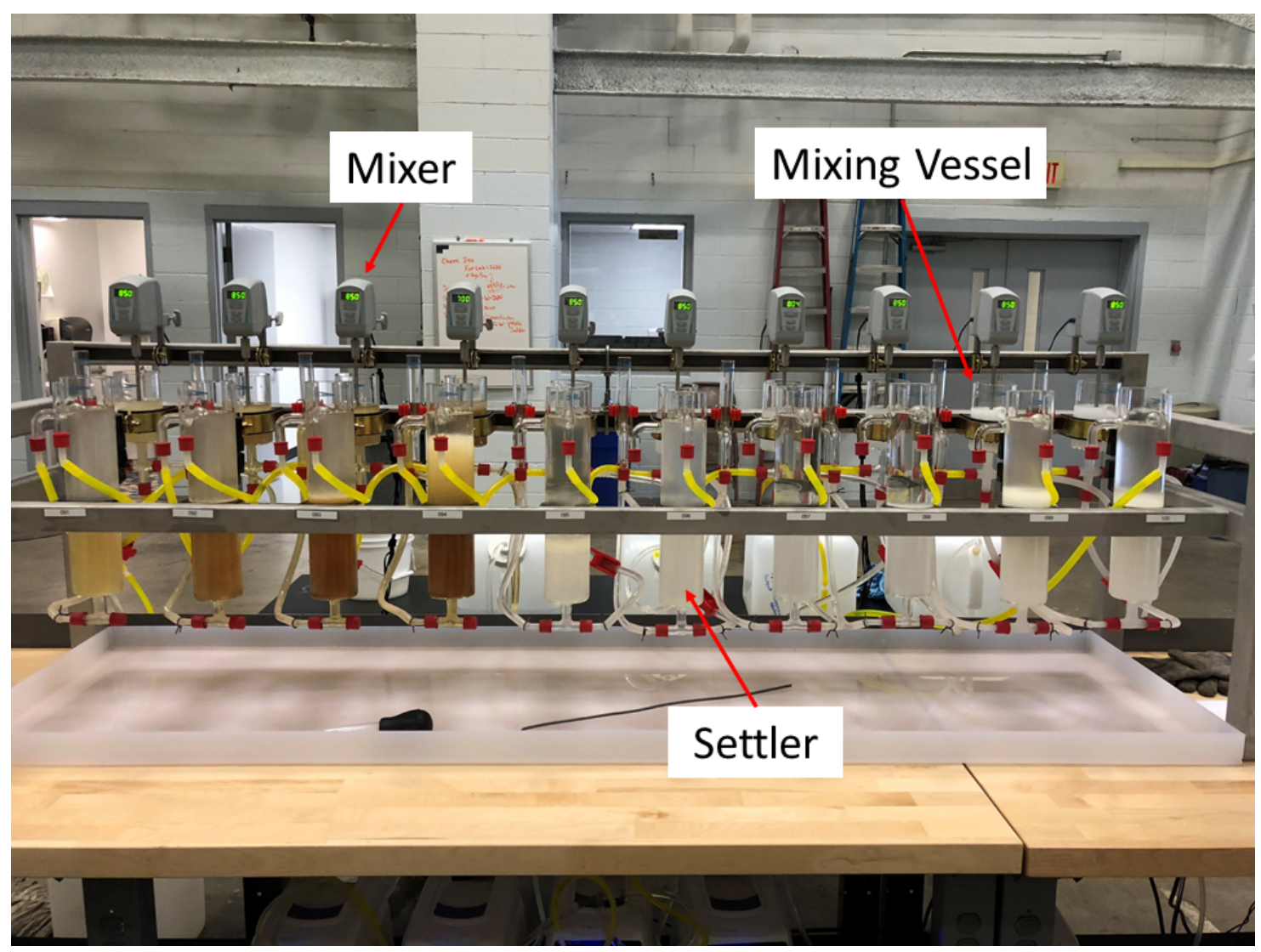

Figure 4.9 - Example of ten stage mixer-settler frame.

to be adjusted through the addition of $\mathrm{NaOH}$ and/or oxalic acid. As the $\mathrm{pH}$ was raised, after the addition of the oxalic acid, metals precipitated from solution in the form of metal oxalate and metal oxides. Next, the precipitate slurry was designed to be transferred to a 10" pressure filter. In this filter, solid REE product was separated from the barren aqueous solution. The barren solution was then transferred from the filter to a 30-gallon storage tank where it could be recycled back into the stripping stage. Finally, the solid REE product was projected to be dried in an oven and stored in a sample container for analysis.

Waste Management During the design phase of this research, laboratory testing had failed to produce a significant quantity of waste product for testing. However, the bench-scale plant generated a sufficient quantity of waste product (both raffinate and leachate residue) to allow for characterization. Additionally, health and environmental effects from the release of REEs into the environment is not well understood, and environmental regulations are 
limited for this industry (Mayfield and Lewis 2013). However, because REE extraction and recovery is a chemically intense process, the use of mineral acids, bases, and organic solvents in REE extraction may result in the generation of multiple waste streams require proper handling.

Proper waste management is an integral part of the REE recovery process design in this study. In the proposed REE recovery process, acids and organic solvents used in leaching and extraction processes are recycled. Key environmental and health issues for the project that require consideration include:

- Safe transport and handling AMD sludge to limit unintended spills or leaching of contaminants.

- In processes that use strong acids or bases, as well as organic solvents, safe handling of chemicals and prevention of accidental release is important to protect workers and the environment.

- Organic solvents used in the extraction process will be recycled to the solvent extraction step.

- The acid leaching process results in an acidified AMD sludge. The Toxicity Characteristics Leaching Procedure (TCLP) test will be conducted for residual solids to determine the leachability of toxic metals/organic compounds in sludge residuals. The results will determine appropriate methods for residuals management.

- If found to be non-toxic residual solids will be re-introduced into the AMD treatment system's lime mixing tank and neutralized prior to disposal per current sludge handling protocols at the treatment facility.

\subsubsection{Design Table}

A master design table (Table 4.5) was used to identify the specifications for each unit operation and ancillary equipment. This table contains design elements for each unit operation, 
Table 4.5 - Master design table

\begin{tabular}{|c|c|c|c|c|c|}
\hline $\begin{array}{l}\text { Unit } \\
\text { Operation }\end{array}$ & Design Element & Decision Type & Required Data & Testing Status & Value \\
\hline & Bin Sizes & PDD & Nominal flow rates & Complete & 55 gallon drums \\
\hline & Slurry Pump Sizes & PDD & Batch flow quantities & Complete & $3 / 4$ " \\
\hline Materials & Slurry Pump Rates & BCOD & Batch flow rates & Complete & $23 \mathrm{gpm}$ \\
\hline Handling and & Pipe/Hose Diameters & PDD & Supplied with off-the-shelf SX unit & $\mathrm{N} / \mathrm{A}$ & $3 / 8$ “ \\
\hline \multirow[t]{3}{*}{ Storage } & Pipe/Hose Materials & PDD & Supplied with off-the-shelf SX unit & $\mathrm{N} / \mathrm{A}$ & Tygon Chemical Resistant \\
\hline & Surge Tank Sizes & PDD & Nominal flow rates & Complete & 55 gallon tanks \\
\hline & Reagent Pump Sizes & PDD & Supplied with off-the-shelf SX unit & $\mathrm{N} / \mathrm{A}$ & $0.3-200 \mathrm{ml} / \mathrm{min}$ \\
\hline \multirow{5}{*}{ Leaching } & Reactor Vessel Number & PDD & Leach Kinetics Tests & Complete & 1 \\
\hline & Reactor Vessel Size & PDD & Leach Kinetics Tests & Complete & 70 gal \\
\hline & Reactor Temperature & BCOD & Leach Kinetics Tests & Complete & Ambient \\
\hline & Acid Type & $\mathrm{BCOD}$ & Acid Consumption Test & Complete & $\mathrm{HNO}_{3}, \mathrm{H}_{2} \mathrm{SO}_{4}$, and $\mathrm{HCl}$ \\
\hline & Target Leach $\mathrm{pH}$ & BCOD & Acid Consumption Test & Complete & $\mathrm{pH}=0.5$ to 2.5 \\
\hline \multirow{4}{*}{ pH Adjustment } & Vessel Number & PDD & Precipitation Kinetics Tests & Complete & 1 \\
\hline & Vessel Size & PDD & Precipitation Kinetics Tests & Complete & $70 \mathrm{gal}$ \\
\hline & Alkaline Type & $\mathrm{BCOD}$ & Alkaline Consumption Test & Complete & $\mathrm{NaOH}, \mathrm{NH}_{3} \mathrm{OH}, \mathrm{MgO}$ \\
\hline & Target precipitation $\mathrm{pH}$ & BCOD & Alkaline Consumption Test & Complete & $\mathrm{pH}=2$ to 3.5 \\
\hline \multirow{3}{*}{$\begin{array}{l}\text { Leachate/Residue } \\
\text { Separation }\end{array}$} & Leachate/Residue Separation Method & PDD & System Design & Complete & Pan filter \\
\hline & Leachate/Residue Separation Vessel Size & PDD & System Design & Complete & 5' X 5' Pan Filter \\
\hline & Leachate/Residue Separation Reagents & BCOD & NA, since batch leaching & $\mathrm{N} / \mathrm{A}$ & Coagulant or Flocculant \\
\hline \multirow{6}{*}{ SX - Extraction } & Number of Extraction Vessels & PDD & McCabe-Thiele Diagrams & $\mathrm{N} / \mathrm{A}$ & 8 to 10 required \\
\hline & Size of Extraction Vessels & PDD & SX Kinetics Test & Complete & $150 \mathrm{ml} / \mathrm{min}$ \\
\hline & Extraction $\mathrm{pH}$ Modifier Rate & BCOD & SX Parametric Test & Complete & Likely $\mathrm{pH}=2-3.5$ \\
\hline & Extractant Type & PDD & SX Parametric Test & Complete & Likely D2EHPA \\
\hline & Extractant Concentration & $\mathrm{BCOD}$ & SX Parametric Test & Complete & Likely $20 \% \mathrm{v} / \mathrm{v}$ \\
\hline & O:A Ratio & BCOD & SX Parametric Test & Complete & Likely $2.5: 1$ \\
\hline \multirow{4}{*}{ SX - Stripping } & Number of Stripping Vessels & PDD & McCabe-Thiele Diagrams & $\mathrm{N} / \mathrm{A}$ & 3 to 4 required \\
\hline & Size of Stripping Vessels & PDD & SX Kinetics Testing & Complete & $150 \mathrm{ml} / \mathrm{min}$ \\
\hline & Stripping $\mathrm{pH}$ modifier rate (Striping $\mathrm{pH}$ ) & BCOD & SX Parametric Testing & Complete & Likely pH $1.5-3.5$ \\
\hline & O:A Ratio & BCOD & SC Parametric Testing & Complete & Likely $0.5: 1$ \\
\hline \multirow{4}{*}{ Precipitation } & Vessel Number & PDD & System Design & Complete & 1 \\
\hline & Vessel Size & PDD & System Design & Complete & $10 \mathrm{gal}$ \\
\hline & Alkaline Type & BCOD & Precipitation Tests & Complete & $\mathrm{NaOH}$ and Oxalic acid \\
\hline & Alkaline Addition Rate/Consumption & BCOD & Precipitation Tests & Complete & $\mathrm{pH}=6$ to 9 \\
\hline \multirow{3}{*}{ Filtration } & Solid/liquid Separation Method & PDD & System Design & Complete & Pressure Filter \\
\hline & Leachate/Residue Separation Vessel Size & PDD & System Design & Complete & $10 "$ \\
\hline & Leachate/Residue Separation Reagents & BCOD & NA, since batch leaching & $\mathrm{N} / \mathrm{A}$ & Coagulant or Flocculant \\
\hline \multirow{4}{*}{$\begin{array}{l}\text { Instrumentation } \\
\text { Package }\end{array}$} & Sensor Type & PDD & Final Flowsheet & $\mathrm{N} / \mathrm{A}$ & $\mathrm{pH}$, Temp., flow rate, metal ion \\
\hline & Sensor Number & PDD & Final Flowsheet & $\mathrm{N} / \mathrm{A}$ & - \\
\hline & Sensor Location & PDD & Final Flowsheet & $\mathrm{N} / \mathrm{A}$ & - \\
\hline & Control System & PDD & Final Flowsheet & $\mathrm{N} / \mathrm{A}$ & -- \\
\hline
\end{tabular}

required data/testing, the current status of the testing, and the expected design value based on information to date. All design decisions were classified as either a "permanent design decision" (PDD) or a "baseline case operational decision" (BCOD). PDD's constitute rigid design elements that cannot be readily changed after the system is constructed. Examples include the type, number, and size of equipment used in each unit operation. Alternatively, BCOD's constitute a large degree of flexibility. For these decisions, an optimal or baseline condition was specified for the initial system design; however, operational testing indicated other values were within a nominal range. Examples include reagent types and addition rates. 


\subsubsection{Piping and Instrumentation}

A Piping and Instrumentation Diagram (P\&ID) document set is attached in Appendix B and referenced in this section. This appendix consists of a total of three drawings, (1) P\&ID Lead Sheet, (2) Overall Plant P\&ID, and (3) Solvent Extraction P\&ID Detail. Drawing 1 contains a master equipment list in addition to specific equipment details. Additionally, an equipment, instrument, and process line legend is included. The P\&ID drawings generally use symbols based on International Society of Automation (ISA) Standard S5.1.

Unlike the process flowsheet, the P\&ID drawing does not differentiate between batch and continuous processes. Here all blue lines represent the primary flow path of material. A green dashed line indicates the flow path of organic and a dashed purple line shows flow paths that require manual (cf. mechanical) effort to transport material. For example, after separation of the final product from the barren strip liquid, the final product was designed to be manually transported on the filter paper to an oven for drying. These stages typically comprise tasks that require manual intervention or analytical analysis (i.e. weighing) and were not feasible to automate in a bench-scale decoupled semi-batch system.

Drawing 2 shows the overall system connections, instruments, flows and sampling points. All equipment is labeled with a unique identifying tag based on the equipment type and number of units. For instance, the pump feeding the solvent extraction system is tagged P-004. This is the fourth of eleven total pumps used in the bench-scale solvent extraction plant. This tag may be cross-referenced on Drawing 1 to identify detailed information about each individual unit. Additionally, Drawing 2 also shows the minimum proposed locations of the system sensors. During the design process, multiple sensor configurations were evaluated to determine the optimal locations to facilitate plant automation. Therefore, the P\&ID drawings show the minimum required sensor arrangement for the bench-scale plant. Flow sensors were placed in the flow-path of the organic, pregnant leach solution, raffinate, stripped solution, and stripping stage feed. Sensors which measure $\mathrm{pH}$ were required in the batch leaching and precipitation vessels, in the extraction stage, and the stripping stage. Finally, the temperature in the drying oven was monitored as a critical process variable. 
A highlighted box is located toward the center of Drawing 2 bounds the stripping and extraction module. This highlighted area denotes that these modules are shown in more detail on Drawing 3. Here, the stripping and extraction modules are represented as individual units showing the combined and individual phases within the mixer-settler units. Additionally, the countercurrent flow of the aqueous and organic fluids is shown in detail. Focusing on the extraction stage, this countercurrent flow becomes apparent as the pregnant leach solution is fed into the last extraction mixer settler in series. In contrast, the organic solution is fed into the first mixer-settler in the series. Each mixer-settler unit is shown as two joined vessels of different sizes. The smaller vessels contain the mixed aqueous and organic solutions. This emulsion then flows to the larger vessel where the organic and aqueous phases settle into two separate fractions based on their density.

\subsection{Facility Layout}

An optimal design for the bench-scale solvent extraction plant is shown in Appendix $\mathrm{C}$ and is titled, SX Bench-Scale Plant Layout. This general layout shows the placement of all major equipment components within the laboratory. The solvent extraction units were located in series in a semi-circular fashion where all units may be visually monitored. A workbench was centrally located to provide a working surface to maintaining the equipment and performing analytical analysis. The area in the south-west corner of the laboratory shows the units required for operating the batch leaching and precipitation stages of the bench-scale solvent extraction unit. Additionally, samples and general storage is located on the south and east walls of the lab, on the proposed layout.

\subsection{Testing Plan for the Bench-Scale System}

System testing was proposed in a total of three phases as follows:

- Shakedown Testing 
- Parametric Testing

- Validation Testing

Each phase of testing builds cumulatively, resulting in an optimized system. Initially, shakedown testing established the fundamental operating parameters of the bench-scale system. As an example, these characteristics may include such parameters as; number of extractant and stripping stages, benefits and location of utilizing a scrubbing stage, optimizing the batch unit processes (leaching, precipitation, etc.), and performance of different reagents. These tests were conducted initially in a laboratory setting and progress to testing on the solvent extraction plant once it was operational. A two-factor experimental design was utilized during the shakedown testing phase. Information gathered in this stage will identify and refine the key parameters necessary for the next stage of testing.

Afterwards, parametric testing was started on the completed bench-scale system. This testing schedule will use a statistical experimental design to evaluate the performance of the system as key operating parameters are varied to identify the optimum values required for the three different sludge feedstocks. Some operating parameters which may be evaluated in this phase of testing include: aqueous to organic ratios in the extraction and stripping stages, stripping $\mathrm{pH}$, extractant concentration, and the quantity of recycled process streams used in the overall process. The parametric testing phase will be conducted on the three AMDp types.

Finally, validation testing will be conducted to confirm experimental results from the parametric testing. Each validation test will be performed a minimum of three times on each sludge feedstock to confirm results of the testing schedule. This testing will ultimately lead to an optimized plant operating procedure where the recovery of the valuable REEs are optimized. Furthermore, results from this testing system will be used to identify the performance of the bench-scale unit based on the technical and economic success factors discussed in the next sections. Lastly, the validation testing stage will be employed in the scale-up of the system to the next TRL.

The overall performance of the solvent-extraction plant was based on several technical and economic success factors related to the design objectives prescribed above. Table 4.6 quan- 
Table 4.6 - Proposed parameters used for technical success factors

\begin{tabular}{ccc}
\hline Parameter & Minimum Target & Optimum Target \\
\hline Product Grade & $2 \%$ & 10\% Light and Heavy Fractions \\
Concentrate Production Rate & $3 \mathrm{~g} / \mathrm{hr}$. & $5 \mathrm{~g} / \mathrm{hr}$. \\
Overall REE Mass Recovery & $50 \%$ & $>80 \%$ \\
Leaching Efficiency & $80 \%$ & Greater than $90 \%$ \\
Major Metal Rejection & $80 \%$ & $>80 \%$ \\
Percent Extraction & $85 \%$ & $>95 \%$ \\
Stripping Recovery & $50 \%$ & $>95 \%$ \\
\hline
\end{tabular}

tifies the technical success factors that will be evaluated in Phase 2. This list is not comprehensive and was refined as the testing plans proceeded.

Each technical success factor was bound by two separate targets, minimum and optimum. The minimum targets were those which represented the threshold acceptable operating performance of the bench-scale system. Additionally, optimum targets were those where the optimization process was expected to exceeded the minimum targets. For example, the product grade of the REE product must meet a minimum of two percent, by mass. As a result, optimum targets contain values that indicate the bench-scale system is operating within an optimum range above and beyond the minimum targets. These success factors will be evaluated during the validation testing phase to show the overall performance of the plant. Additionally, economic success factors will be utilized to gauge the overall performance of the solvent-extraction plant with respect to cost parameters. These factors, when optimized, will directly result in lower operating costs as this project advances to the next TRL. Table 4.7 lists examples of some of the economic success factors which will be calculated at the end of the project. Note that many of these economic factors are normalized to percent of contained value. This approach was preferred over a strict "\$/tonne" limit, as it ensured a consistent profit margin, despite changes in feedstock REE concentration. These calculations will be based on the standard REE price deck, and re-calculated for each feedstock test during parametric testing. This list is not comprehensive and was refined as the testing plans progressed. 
Table 4.7 - Proposed economic success factors for bench-scale SX plant.

\begin{tabular}{cc}
\hline Parameter & Target \\
\hline Leaching Cost & $<30 \%$ of Contained REE Value \\
Direct Process Operating Cost & $<50 \%$ of Contained REE Value \\
Raffinate Recycle & Utilize $>50 \%$ of raffinate in the leaching process \\
Extractant Loss & Minimize loss of extractant to less than $5 \%$ by volume \\
Value-Based Recovery & Recover $80 \%$ of the contained value to the final concentrate \\
\hline
\end{tabular}

\subsection{Summary}

An acid leaching and solvent extraction system was designed to extract REEs from AMD precipitates. Multiple laboratory-scale experiments were conducted based on the standard hydrometallurgical processes of acid leaching and solvent extraction. These experiments assisted in identifying the specifications of the required equipment in regard to size and quantity.

Furthermore, the design constraints defined by the project administrators were identified and applied to the system design, along with the assumptions made during the design process. In all, these parameters led to the constriction of a master design table that was used to identify the specifications of the major components and ancillary equipment required to construct the bench-scale system. From this table, a series of process flowsheets, P\&ID diagrams, and facility layout diagrams were constructed.

This work resulted in a system that was designed to operate in a decoupled, semi-batch fashion capable of producing a minimum of 3 grams per hour of a $2 \%$ mixed rare earth oxide product. Additionally, performance targets for the bench-scale system were established to identify success criteria. Lastly, economic success factors were established to forecast the overall performance. When combined with the optimized system parameters, this wealth of information could be used to model cost of the process as the scale increases. 


\section{Chapter 5}

\section{Bench-Scale Plant Operation}

\section{$5.1 \quad$ Introduction}

An ALSX plant was constructed to recover REEs from AMD precipitates. The plant design was based on extensive acid leaching and solvent extraction laboratory-scale studies. The initially constructed ALSX system closely resembled the proposed system design. Initially, shakedown testing was performed on each module of the plant to identify construction and design oversights of this unproven design. For example, shakedown testing could identify small problems like minor leaks up to major complications such as improper component specification. As a result, modifications to the overall process were required to overcome the observed obstacles. Each of these issues is discussed in greater detail below.

After shakedown testing and plant modification, the ALSX plant was placed into operation by implementing a decoupled, semi-batch process, as designed. The bench-scale system is comprised of three operating units including an acid leaching and filtration module, a solvent extraction module, and a precipitation module. Initially, small batches ( $\sim 60 \mathrm{~L})$ of AMDp were converted to PLS using the acid leaching portion of the plant. As the acid leaching technique was refined, larger batches were produced that could supply a sufficient quantity of feedstock to the SX module for week-long runs. The SX process was scheduled to operate in eight hour shifts for five days per week until the PLS was exhausted. 
Upon completion of each SX plant run, the stripped aqueous product was processed by the precipitation module to convert the REE cations to oxalates. Next, the REE oxalate solids were calcined to transform the oxalates to oxides. After calcination, multiple washing stages were required to separate the REEs from gangue elements; therefore, increasing the grade of the final product. As a result of these procedures, a $61.8 \%$ mixed rare earth oxide material was acquired from the ALSX plant.

\subsection{Feedstock Acquisition and Material Handling}

An outside contractor was employed to collect AMDp from the proposed feedstock sites for processing in the the ALSX bench-scale plant. This contractor provided ten 55-gallon drums of AMDp from each of the three AMD sites evaluated for this research. The contractor used a small excavator to remove the AMDp from on-site storage ponds. Ten 55-gallon drums of AMDp were collected from each site and transported to the WVU ALSX facility. Plastic drum liners were used to isolate the AMDp from the inside of the steel drums. Various photos from the sampling exercise are shown in Figure 5.1. Upon delivery to the facility, the drums were stored in a controlled environment until the material was required for leaching tests.

In regard to the feedstock, there was a change in one of the AMDp sources used for this research. Previously, AMDp from the Mine 42 site was included in the testing regime. However, between the time of sample collection and plant commissioning, several of the Mine 42 AMDp storage ponds were reclaimed resulting in reduced availability of the feedstock. Consequently, AMDp from the Royal Scot site replaced Mine 42 as a feedstock.

Figure 5.2 shows the drums stored at the ALSX facility. Drums were placed on pallets at the time of loading. Once at the ALSX facility, a pallet jack was employed to maneuver the drums into the storage area. When required for leaching, the drums were maneuvered using an overhead crane and tilting drum-lifting device. This configuration was utilized to hoist the drums to the acid leaching module where the AMDp was removed from the lined drum 


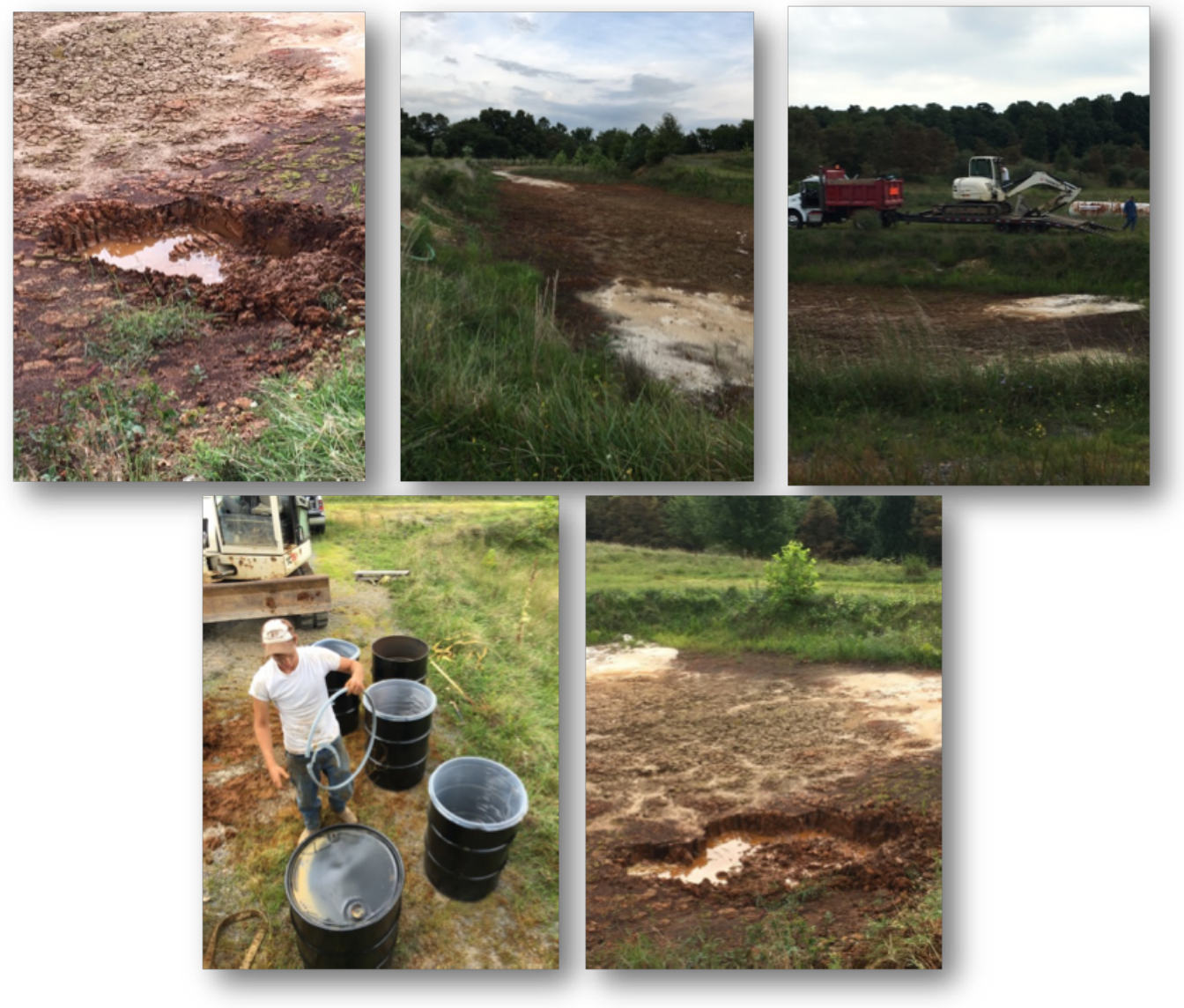

Figure 5.1 - Various pictures from collection of AMDp feedstock.

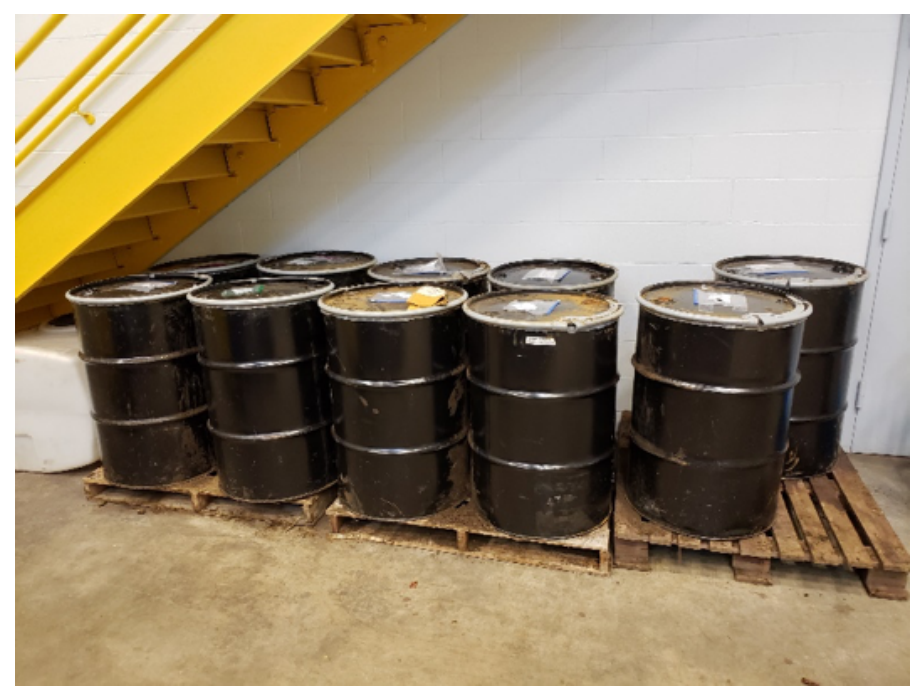

Figure 5.2 - 55-gallon drums stored at the ALSX facility.

and placed into five-gallon buckets. Each of the buckets was individually weighed to record the mass of AMDp before it was used in the acid leaching process. 


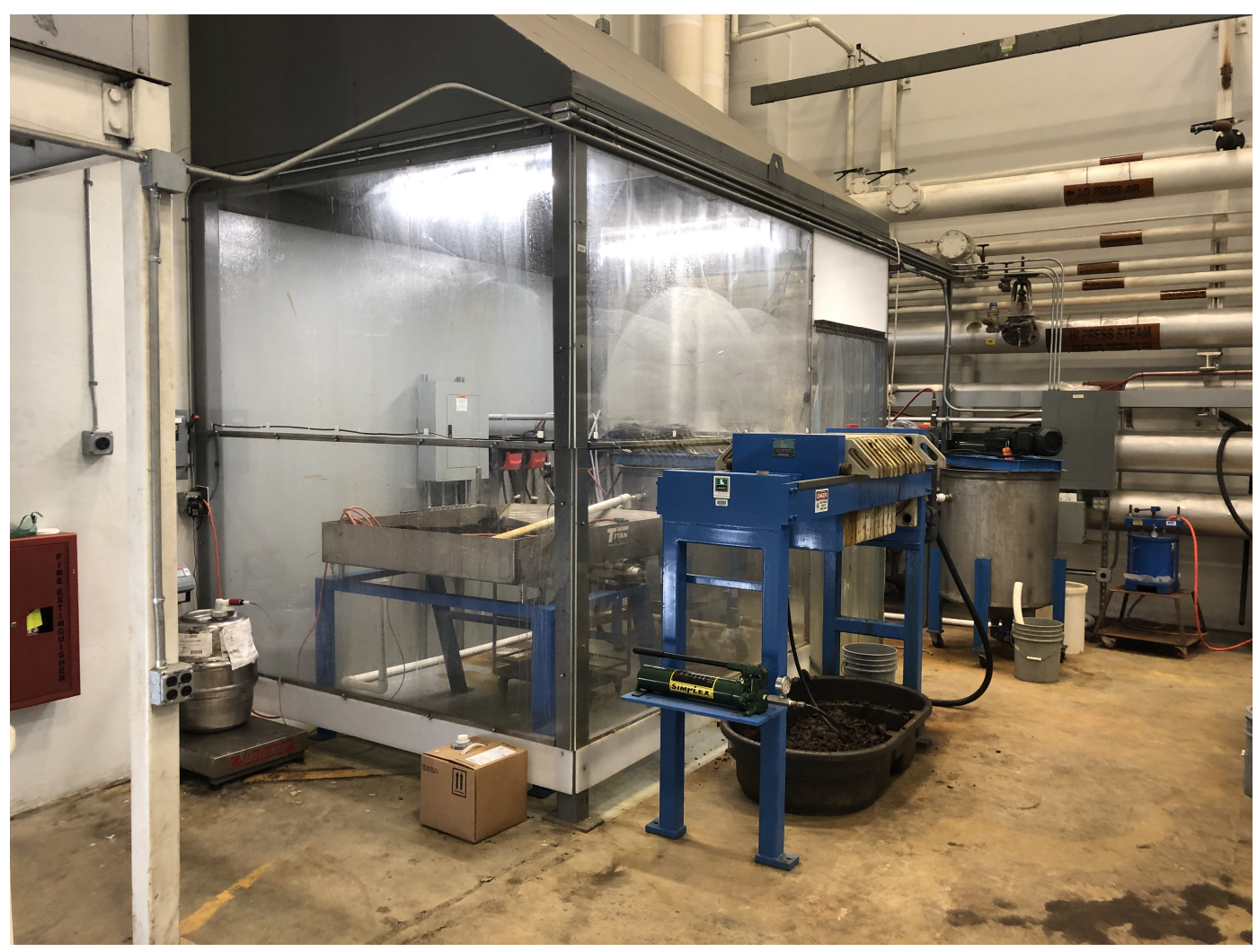

Figure 5.3 - Acid leaching module of bench-scale plant

\subsection{Acid Leaching Module}

The acid leaching module is located adjacent to the solvent extraction bench-scale system. Figure 5.3 shows the as-built acid leaching operating area. The leaching vessels were operated under a full sized fume hood to prevent operator exposure to acidic fumes. The major components of the module include the fume hood, two 75-gallon agitated leaching mixing vessels, a $420 \mathrm{~mm}$ filter press with a 2.0 cubic-foot capacity, air diaphragm pumps, and an acid dosing system. Directly outside the fume hood a scale holds a carboy of $68 \%$ nitric acid. The scale is used to monitor the amount of chemicals and feedstock consumed in the leaching process.

\subsubsection{Acid Leaching Shakedown Testing}

Throughout the shakedown testing of the ALSX system, several operational difficulties were experienced when using the ALSX system as it was initially designed. As a result, modi- 
fications to the acid leaching flowsheet were required to address these issues. This section describes the major operational challenges encountered and the flowsheet modifications implemented to overcome the unforeseen complications.

\section{Gel Formation of PLS}

Initial attempts were made to create PLS during shakedown testing. During the introductory trials, several batches of the PLS would form a gelatinous mixture within the leaching vessel when the $\mathrm{pH}$ was raised above the leaching $\mathrm{pH}$ setpoint. This issue was observed in feedstock from all three AMD sites. Figure 5.4 shows a representative sample of the gelatinous PLS after $\mathrm{pH}$ adjustment. The formation of this gel inhibited pumping of the PLS onto the pan filter. Additionally, the gel prevented filtering of the PLS and therefore, the separation of the solid and aqueous components of the leaching slurry was impractical.

In order to alleviate this issue, multiple lab-scale experiments were conducted to identify the mechanism causing the gel formation by Wang et al (2019). While the exact mechanism controlling the gel formation was not identified, it was discovered that the PLS did not form a gel when an additional filtration step was added to the procedure.

This extra filtration step was introduced directly after the PLS was lowered to the leaching $\mathrm{pH}$ value of 0.7 . When tested on the acid leaching module, the additional filtration step alleviated the congealing of the PLS at $\mathrm{pH}$ values less than 4.0. As a result, this additional filtration step was implemented into the operating procedure to alleviate the material handling complications.

\section{Filtration}

Despite solving the issue with PLS gel formation, the vacuum pan filter was still unable to filter the PLS in an acceptable manner. The pan filter did not have a sufficient filtering area for the amount of solids remaining after acid leaching. This condition was not properly addressed in the design phase because the small-scale filtering apparatus employed during testing did not allow for a proper evaluation of the filtration at the intended scale. For exam-

ple, leaching tests were conducted using vacuum filtration with a Buchner funnel and filter 


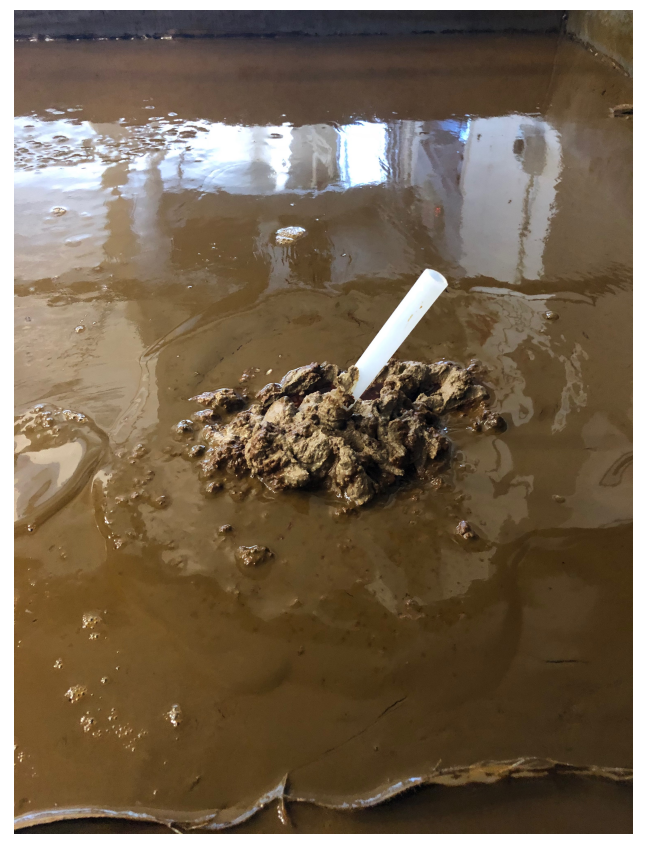

Figure 5.4 - PLS gel formation on pan filter at pH 3.0.

paper. This operating condition did not produce a significant amount of solid precipitate to evaluate the bed depth and therefore the necessary filtration area required to perform an efficient solid-liquid separation.

To mitigate this issue, a plate and frame filter press was proposed to efficiently filter the PLS. Consequently, a $150 \mathrm{~mm}$ Micronics Micro-Test-Press was acquired to test the ability of a plate and frame filter to fully filter the PLS. Multiple batches of PLS were created using the three different feedstocks and were subsequently processed with the laboratory-scale filter. Testing results indicated that the filter press could indeed filter the PLS solutions from all of the feedstocks at multiple $\mathrm{pH}$ values. Results from this experiment were provided to the filter vendor. As a result, a press with $420 \mathrm{~mm}$ plates with a 2 cubic-foot capacity was recommended for the application. As a result a $420 \mathrm{~mm}$ press was acquired to filter PLS from the 75-gallon agitated leach tank and create a clarified PLS. Figure5.5 shows both the $150 \mathrm{~mm}$ lab-scale press used during testing and the $420 \mathrm{~mm}$ filter press that replaced the pan filter.

Full-scale testing with the 2 cubic-foot filter press was successful with all three feedstocks. This was a direct result of the increased filtration area. Originally, the pan filter had a usable 


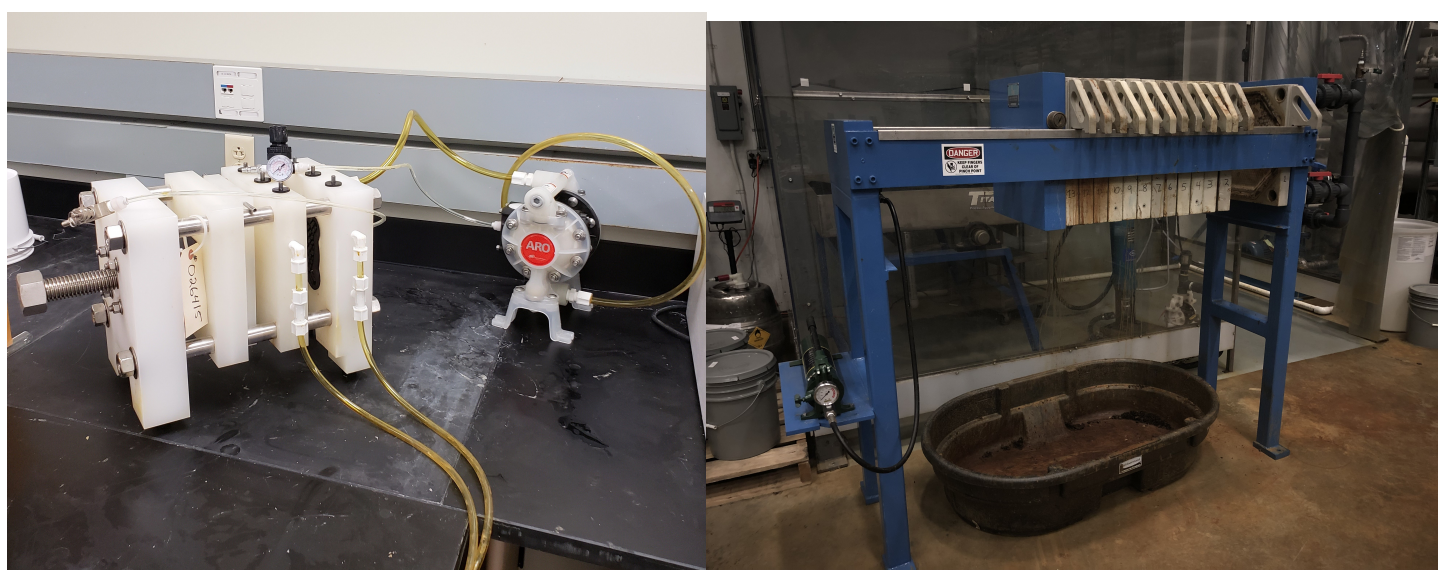

Figure 5.5 - Lab-scale $150 \mathrm{~mm}$ filter press (left) and 420-mm filter press (right).

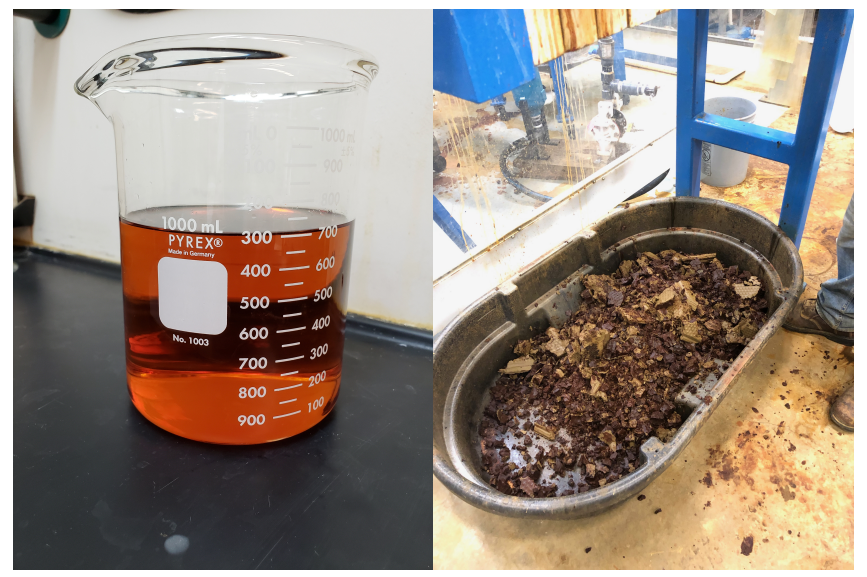

Figure 5.6 - PLS after filtration in the plate and frame filter and filter cake from clean-out of the 2 cubic-foot filter press.

filtration area of 25 square-feet. The new filtration unit increased the filtration area by a factor of almost 1.75 to 43 square-feet.

A Sandpiper S07 air diaphragm pump with a maximum capacity of $23 \mathrm{gpm}$ was utilized to feed the filter press. Additionally, the pump was supplied with PVDF internal components to resist the corrosion when pumping acidic liquids. The filter cake obtained from the filter press achieved moisture values of approximately 60\%, which was substantially better than previous filter cakes acquired using vacuum filtration. Figure 5.6 shows the PLS filtrate and the residual solids that remained after operation of the filter press. 


\subsubsection{Acid Leaching Procedure and Results}

After modifying the acid leaching process and equipment, an updated process flow diagram was created as shown in Figure 5.7. The PLS created for the baseline Royal Scot solvent extraction test was made in two batches. First, AMDp was added to the agitated leaching vessel, bucket-wise, so the mass of the AMDp could be recorded. Additionally, an AMDp sample was collected from each bucket and combined to form an overall representative AMDp sample. The sample was then analyzed using thermogravimetric analysis for moisture, ICPMS for REEs, and inductively coupled plasma - optical emission spectrometry (ICP-OES) for major ion determinations. Second, water was added to the leaching vessel at $0.75 \mathrm{~L}$ per $\mathrm{kg}$ of as-received AMDp. This value was determined empirically during shakedown testing to facilitate mixing, pumping, and filtration of the PLS. Initial trials showed that using only AMDp and acid resulted in a thick slurry that was un-pumpable and therefore unable to undergo the filtering process. Third, under rapid agitation, $68 \%$ nitric acid was pumped into the leaching chamber until the desired leaching $\mathrm{pH}$ set-point of 0.7 was obtained. The

$\mathrm{pH}$ was monitored using a hand-held $\mathrm{pH}$ meter that was calibrated before the start of each batch. This process took several hours for the vessel to achieve $\mathrm{pH}$ equilibrium. Finally, the low pH PLS was filtered using the $420 \mathrm{~mm}$ filter press.

After filtration, the clean PLS was pumped back into a leaching vessel. Next, the pH of the PLS was adjusted upward with $50 \%$ sodium hydroxide, to a $\mathrm{pH}$ value of 3.0 , to remove gangue metals. Once again, this process was performed step-wise over several hours until equilibrium was attained at the desired $\mathrm{pH}$ set-point. Finally, the PLS was again filtered to remove any solids that precipitated during the upward $\mathrm{pH}$ adjustment. The filtrate from this process was sampled then transferred to the SX module as feed for the liquid-liquid extraction process.

Table 5.1 shows the reagents and conditions implemented to create the Royal Scot PLS. Combined, the two batches created a total of 282 liters of PLS for the subsequent SX process. The total acid consumption of the leaching procedure was $1.24 \mathrm{~g}$-acid/g-feed. While the acid consumption of this batch process is high, other processes exist to reduce this metric. For 


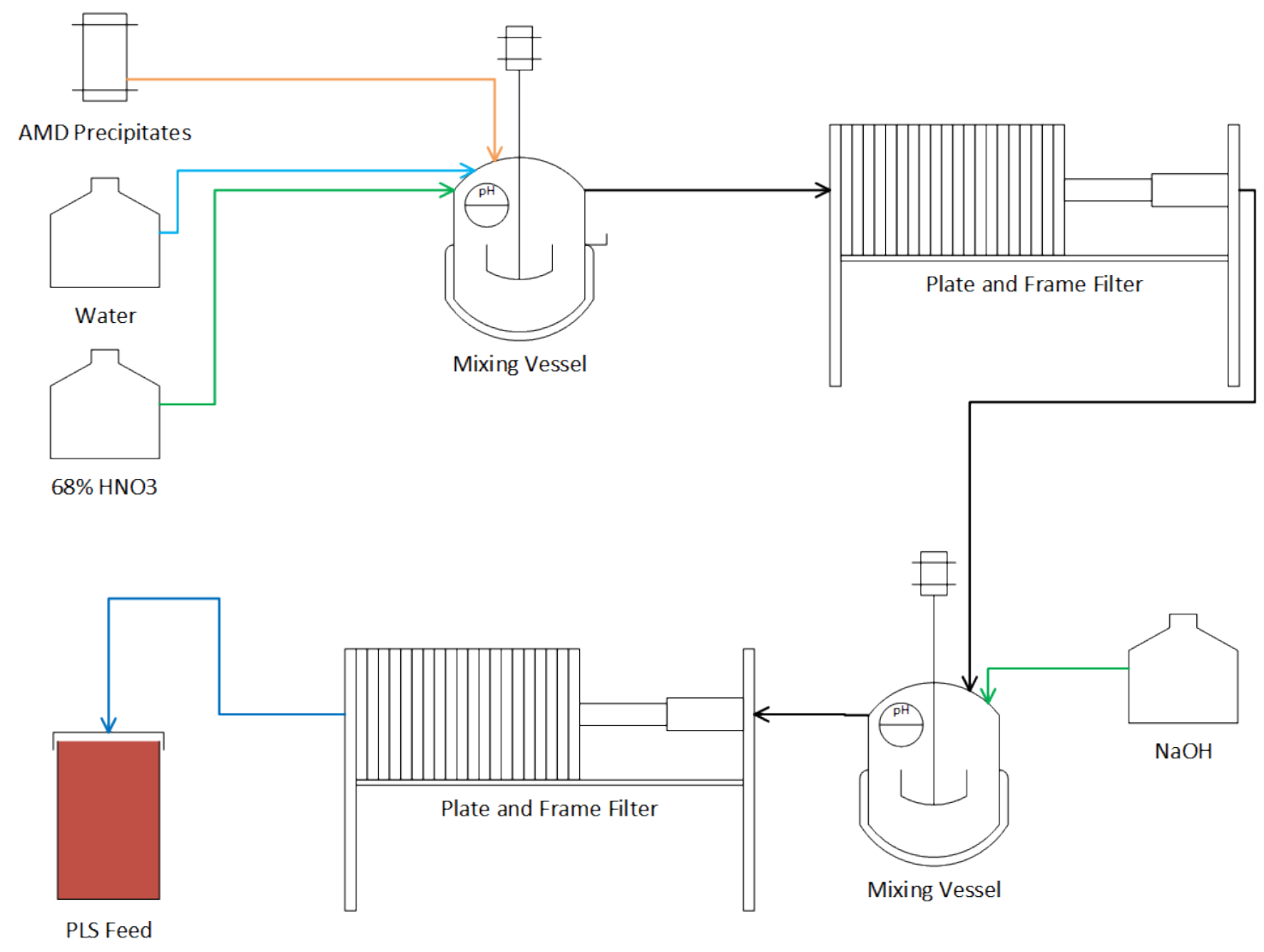

Figure 5.7 - Acid leaching process flow diagram showing PLS generation procedure.

example, the application of countercurrent leaching could provide a more efficient use of the leaching acid.

Analytical testing was performed on the feed, concentrate, and tailings of the comprehensive leaching process. These samples were analyzed using ICP-MS and ICP-OES methods to determine the REE concentrations and major ion concentrations, respectively. Table 5.2 shows the results of the analytical tests as well as the mass balance for both leaching batches. The analytical results revealed several significant developments resulting from the leaching process. Both leaching batches yielded PLS with generally similar concentrations of elements. Overall, approximately $51 \%$ of the REEs were recovered into the PLS solution, while only $27 \%$ of the other major ions were recovered, indicating a significant rejection of gangue material. More noteworthy, the $\mathrm{pH}$ adjustment procedure resulted in the rejection of almost all of the $\mathrm{Fe}(>99.9 \%)$ from the PLS. This is substantial as Fe can interfere with the sub- 
Table 5.1 - Royal Scot acid leaching parameters used to create PLS.

\begin{tabular}{lcrrr}
\hline Parameter & Units & Batch 1 & Batch 2 & Total \\
\hline Feedstock: & $\mathbf{( t x t )}$ & Royal Scot & Royal Scot & Royal Scot \\
AMDp Wet Mass: & $\mathbf{( k g )}$ & 103.51 & 103.96 & 207.47 \\
AMDp Dry Mass & $\mathbf{( k g )}$ & 12.45 & 12.51 & 24.96 \\
Water Volume: & $\mathbf{( L )}$ & 75.60 & 75.60 & 151.20 \\
Initial pH: & $\mathbf{( \# )}$ & 8.57 & 8.37 & 16.94 \\
Acid Type: & $\mathbf{( t x t )}$ & $68 \% \mathrm{HNO}$ & $68 \% \mathrm{HNO}$ & $68 \% \mathrm{HNO}$ \\
Acid Added: & $\mathbf{( k g )}$ & 24.07 & 21.32 & 45.39 \\
Leach pH: & $\mathbf{( \# )}$ & 0.59 & 0.75 & 0.67 \\
Caustic Type: & $\mathbf{( t x t )}$ & $50 \% \mathrm{NaOH}$ & $50 \% \mathrm{NaOH}$ & $50 \%$ NaOH \\
Caustic Added: & $\mathbf{( k g )}$ & 8.71 & 8.44 & 17.15 \\
Final pH & $\mathbf{( \# )}$ & 2.90 & 3.10 & 3.00 \\
Final PLS Volume: & $\mathbf{( L )}$ & 149.31 & 132.30 & 281.61 \\
Filter Cake Wet Mass: & $\mathbf{( k g )}$ & 33.75 & 36.02 & 69.76 \\
Filter Cake Dry Mass: & $\mathbf{( k g )}$ & 10.38 & 10.06 & 20.44 \\
Acid Consumption: & (g-acid/g-ore) & 1.31 & 1.16 & 1.24 \\
\hline
\end{tabular}

Table 5.2 - Royal Scot acid leaching assay and mass balance.

\begin{tabular}{|c|c|c|c|c|c|c|c|c|c|c|c|c|c|c|c|c|c|}
\hline \multicolumn{9}{|c|}{ Batch \#1 } & \multicolumn{9}{|c|}{ Batch \#2 } \\
\hline Analyte & $\begin{array}{r}\text { Sludge } \\
\text { Assay } \\
(\mathrm{mg} / \mathrm{kg})\end{array}$ & $\begin{array}{r}\text { Sludge } \\
\text { Mass } \\
\text { (g) }\end{array}$ & $\begin{array}{r}\text { PLS } \\
\text { Feed } \\
(\mathrm{mg} / \mathrm{L})\end{array}$ & $\begin{array}{r}\text { PLS } \\
\text { Mass } \\
(\mathrm{g})\end{array}$ & Recovery & $\begin{array}{r}\text { Filter } \\
\text { Cake } \\
\text { Assay } \\
(\mathrm{mg} / \mathrm{kg})\end{array}$ & $\begin{array}{r}\text { Filter } \\
\text { Cake } \\
\text { Mass } \\
\text { (g) }\end{array}$ & $\begin{array}{r}\text { Mass } \\
\text { Balance } \\
(\mathrm{g})\end{array}$ & $\begin{array}{l}\text { Analyte } \\
\text { (txt) }\end{array}$ & $\begin{array}{r}\text { Sludge } \\
\text { Assay } \\
(\mathrm{mg} / \mathrm{kg})\end{array}$ & $\begin{array}{r}\text { Sludge } \\
\text { Mass } \\
(\mathrm{g})\end{array}$ & $\begin{array}{r}\text { PLS } \\
\text { Feed } \\
(\mathrm{mg} / \mathrm{L})\end{array}$ & $\begin{array}{r}\text { PLS } \\
\text { Mass } \\
(\mathrm{g})\end{array}$ & Recovery & $\begin{array}{r}\text { Filter } \\
\text { Cake } \\
\text { Assay } \\
(\mathrm{mg} / \mathrm{kg})\end{array}$ & $\begin{array}{r}\text { Filter } \\
\text { Cake } \\
\text { Mass } \\
(\mathrm{g})\end{array}$ & $\begin{array}{r}\text { Mass } \\
\text { Balance } \\
(\mathrm{g})\end{array}$ \\
\hline \multicolumn{18}{|c|}{ Major Ions } \\
\hline $\mathrm{Al}$ & $83,066.8$ & $1,034.4$ & $2,785.7$ & 415.9 & $40 \%$ & $21,406.7$ & 222.1 & 396.3 & $\mathrm{Al}$ & $83,066.8$ & $1,034.4$ & $2,848.4$ & 425.3 & $41 \%$ & $21,145.3$ & 219.4 & 389.6 \\
\hline $\mathrm{Ca}$ & $13,986.9$ & 174.2 & 734.7 & 109.7 & $63 \%$ & $2,004.2$ & 20.8 & 43.7 & $\mathrm{Ca}$ & $13,986.9$ & 174.2 & 777.6 & 116.1 & $67 \%$ & $1,833.8$ & 19.0 & 39.0 \\
\hline Co & 697.2 & 8.7 & 21.1 & 3.2 & $36 \%$ & 87.3 & 0.9 & 4.6 & Co & 697.2 & 8.7 & 24.8 & 3.7 & $43 \%$ & 124.3 & 1.3 & 3.7 \\
\hline $\mathrm{Fe}$ & $124,032.3$ & $1,544.5$ & 4.0 & 0.6 & $0 \%$ & $152,369.3$ & $1,581.2$ & - & $\mathrm{Fe}$ & $124,032.3$ & $1,544.5$ & 2.6 & 0.4 & $0 \%$ & $110,933.2$ & $1,151.2$ & 392.9 \\
\hline $\mathrm{Mg}$ & $57,207.9$ & 712.4 & $2,342.1$ & 349.7 & $49 \%$ & $6,645.2$ & 69.0 & 293.7 & $\mathrm{Mg}$ & $57,207.9$ & 712.4 & $2,387.5$ & 356.5 & $50 \%$ & $5,895.5$ & 61.2 & 294.7 \\
\hline Mn & $19,445.6$ & 242.1 & 707.8 & 105.7 & $44 \%$ & $5,963.3$ & 61.9 & 74.6 & Mn & $19,445.6$ & 242.1 & 862.0 & 128.7 & $53 \%$ & $7,201.1$ & 74.7 & 38.7 \\
\hline $\mathrm{Si}$ & $29,654.3$ & 369.3 & 62.1 & 9.3 & $3 \%$ & $25,952.8$ & 269.3 & 90.7 & $\mathrm{Si}$ & $29,654.3$ & 369.3 & 48.2 & 7.2 & $2 \%$ & $24,190.7$ & 251.0 & 111.0 \\
\hline $\mathrm{SO} 4$ & $8,942.0$ & 111.3 & 940.0 & 140.4 & $100 \%$ & $1,136.0$ & 11.8 & & $\mathrm{SO} 4$ & $8,942.0$ & 111.3 & 875.0 & 130.6 & $100 \%$ & $1,369.6$ & 14.2 & - \\
\hline $\mathrm{Cl}$ & 39.8 & 0.5 & 4.7 & 0.7 & $100 \%$ & 76.4 & 0.8 & - & $\mathrm{Cl}$ & 39.8 & 0.5 & 4.5 & 0.7 & $100 \%$ & 91.9 & 1.0 & - \\
\hline TMM & $337,072.8$ & $4,197.3$ & $7,602.1$ & $1,135.1$ & $27 \%$ & $215,641.2$ & $2,237.8$ & 903.6 & TMM & $337,072.8$ & $4,197.3$ & $7,830.6$ & $1,169.2$ & $28 \%$ & $172,785.3$ & $1,793.0$ & $1,269.7$ \\
\hline \multicolumn{17}{|c|}{ Rare Earth Elements } & (mg) \\
\hline Sc & 13.1 & 163.6 & 143.3 & 21.4 & $13 \%$ & 11.5 & 119.4 & 22.8 & \begin{tabular}{|l} 
Sc \\
\end{tabular} & 13.1 & 163.6 & 212.3 & 31.7 & $19 \%$ & 11.6 & 120.8 & 11.1 \\
\hline $\mathbf{Y}$ & 343.1 & $4,272.2$ & $14,746.1$ & $2,201.7$ & $52 \%$ & 39.3 & 408.3 & $1,662.2$ & Y & 343.1 & $4,272.2$ & $15,472.8$ & $2,310.2$ & $54 \%$ & 42.1 & 437.0 & $1,525.0$ \\
\hline $\mathbf{L a}$ & 67.9 & 845.8 & $3,100.6$ & 462.9 & $55 \%$ & 8.2 & 85.4 & 297.4 & La & 67.9 & 845.8 & $3,293.4$ & 491.7 & $58 \%$ & 8.6 & 89.5 & 264.5 \\
\hline $\mathrm{Ce}$ & 205.6 & $2,560.0$ & $8,849.8$ & $1,321.4$ & $52 \%$ & 26.5 & 274.6 & 964.0 & $\mathrm{Ce}$ & 205.6 & $2,560.0$ & $9,138.1$ & $1,364.4$ & $53 \%$ & 28.0 & 290.5 & 905.1 \\
\hline $\mathrm{Pr}$ & 34.7 & 432.3 & $1,490.2$ & 222.5 & $51 \%$ & 4.4 & 45.9 & 163.9 & $\operatorname{Pr}$ & 34.7 & 432.3 & $1,555.4$ & 232.2 & $54 \%$ & 4.7 & 48.7 & 151.4 \\
\hline $\mathrm{Nd}$ & 170.2 & $2,119.5$ & $7,429.1$ & $1,109.2$ & $52 \%$ & 21.4 & 221.6 & 788.7 & $\mathrm{Nd}$ & 170.2 & $2,119.5$ & $7,766.7$ & $1,159.7$ & $55 \%$ & 23.9 & 248.0 & 711.8 \\
\hline Sm & 58.2 & 725.0 & $2,427.4$ & 362.4 & $50 \%$ & 7.1 & 74.1 & 288.5 & Sm & 58.2 & 725.0 & $2,490.3$ & 371.8 & $51 \%$ & 7.9 & 82.1 & 271.1 \\
\hline Eu & 15.2 & 189.4 & 617.6 & 92.2 & $49 \%$ & 1.9 & 19.3 & 77.9 & $\mathrm{Eu}$ & 15.2 & 189.4 & 639.0 & 95.4 & $50 \%$ & 2.0 & 20.7 & 73.3 \\
\hline Gd & 86.8 & $1,081.0$ & $3,623.2$ & 541.0 & $50 \%$ & 10.2 & 105.9 & 434.1 & Gd & 86.8 & $1,081.0$ & $3,671.1$ & 548.1 & $51 \%$ & 11.0 & 114.1 & 418.8 \\
\hline $\mathrm{Tb}$ & 13.8 & 171.7 & 555.4 & 82.9 & $48 \%$ & 1.7 & 17.5 & 71.3 & $\mathrm{~Tb}$ & 13.8 & 171.7 & 572.7 & 85.5 & $50 \%$ & 1.8 & 19.1 & 67.2 \\
\hline Dy & 75.0 & 933.8 & $3,019.1$ & 450.8 & $48 \%$ & 8.8 & 91.2 & 391.8 & Dy & 75.0 & 933.8 & $2,964.6$ & 442.6 & $47 \%$ & 9.8 & 101.4 & 389.7 \\
\hline Ho & 13.4 & 167.0 & 535.0 & 79.9 & $48 \%$ & 1.6 & 17.0 & 70.1 & Ho & 13.4 & 167.0 & 540.8 & 80.8 & $48 \%$ & 1.8 & 18.6 & 67.7 \\
\hline Er & 35.2 & 438.3 & $1,388.7$ & 207.3 & $47 \%$ & 4.1 & 42.7 & 188.3 & Er & 35.2 & 438.3 & $1,384.5$ & 206.7 & $47 \%$ & 4.7 & 48.6 & 182.9 \\
\hline $\mathrm{Tm}$ & 4.4 & 54.5 & 175.0 & 26.1 & $48 \%$ & 0.6 & 6.0 & 22.4 & $\mathrm{Tm}$ & 4.4 & 54.5 & 173.2 & 25.9 & $47 \%$ & 0.6 & 6.3 & 22.4 \\
\hline $\mathrm{Yb}$ & 23.7 & 294.8 & 949.6 & 141.8 & $48 \%$ & 3.0 & 30.9 & 122.1 & $\mathrm{Yb}$ & 23.7 & 294.8 & 948.2 & 141.6 & $48 \%$ & 3.3 & 34.4 & 118.8 \\
\hline Lu & 3.5 & 43.6 & 140.0 & 20.9 & $48 \%$ & 0.5 & 4.8 & 17.9 & $\mathrm{Lu}$ & 3.5 & 43.6 & 134.8 & 20.1 & $46 \%$ & 0.5 & 5.2 & 18.3 \\
\hline TREE & $1,163.8$ & $14,492.4$ & $49,190.0$ & $7,344.6$ & $51 \%$ & 150.8 & $1,564.5$ & $5,583.4$ & TREE & $1,163.8$ & $14,492.4$ & $50,957.8$ & $7,608.5$ & $52 \%$ & 162.4 & $1,684.9$ & $5,199.0$ \\
\hline \multicolumn{18}{|l|}{ Actinides } \\
\hline Th & 2.8 & 35.0 & 1.0 & 0.1 & $0 \%$ & 3.8 & 39.6 & - & Th & 2.8 & 35.0 & 0.0 & 0.0 & $0 \%$ & 3.1 & 31.9 & 3.2 \\
\hline $\mathrm{U}$ & 11.5 & 143.2 & 267.2 & 39.9 & $28 \%$ & 3.4 & 35.8 & 67.5 & $\mathrm{U}$ & 11.5 & 143.2 & 261.4 & 39.0 & $27 \%$ & 5.1 & 53.4 & 50.7 \\
\hline
\end{tabular}

sequent SX process. Other gangue material was also rejected from the PLS including, Al (40\%), Ca (65\%), Mg (50\%), Mn (49\%), and Si (3\%). 
Additionally, in regard to the REEs, the individual recoveries generally decrease as the atomic number of the REE increases. Once exception to this observation is Sc, which possesses a much lower average recovery of $16 \%$. The low recovery is not readily explained by standard thermodynamic considerations (e.g. Eh-pH diagrams) which indicate that Sc should remain in solution at $\mathrm{pH}$ values less than 6 (Takeno 2005). Additionally, Sc is also readily leached from other feedstocks using mineral acids as described by Wang et al (2013). As a result, the current interpretation of these results indicate that other constituents within the PLS were causing interference with the Sc, resulting in either co-precipitation at the $\mathrm{pH}$ value of less than 3.0 or preventing the Sc from transferring to an aqueous phase with the acid digestion. The overall mass balance of the acid leaching process indicated a large variation between the balance and initial elemental masses of approximately $27 \%$ for the major ions and $37 \%$ for the rare earths. This discrepancy is quite large and indicative of analytical errors resulting from the sampling process, deficiencies in the measurement and recording procedures, or incomplete digestion in the analytical sample preparation process. Furthermore, these types of mass balance errors have be consistent throughout his research when using a saturated AMDp feedstock. To explore these differences, research by Wang et al (2019) used a LECO TGA701 to explore the residual moisture in AMDp material after desiccation. This research studied the dehydration process of AMDp and indicated that some residual moisture may be left in the solid after traditional dehydration methods. Given the high moisture contents of the feedstock (88\%), even a small change in moisture values could have a significant impact on the overall mass balance of the system.

\subsection{Solvent Extraction Module}

A bench-scale solvent extraction system with 100 individual mixer-settlers was acquired for this research. Figure 5.8 shows the layout of the bench-scale system. The constructed system used was identical to the as-designed specifications developed in the planning phase of this research. The overall SX plant consisted of ten individual stainless steel frames, with 


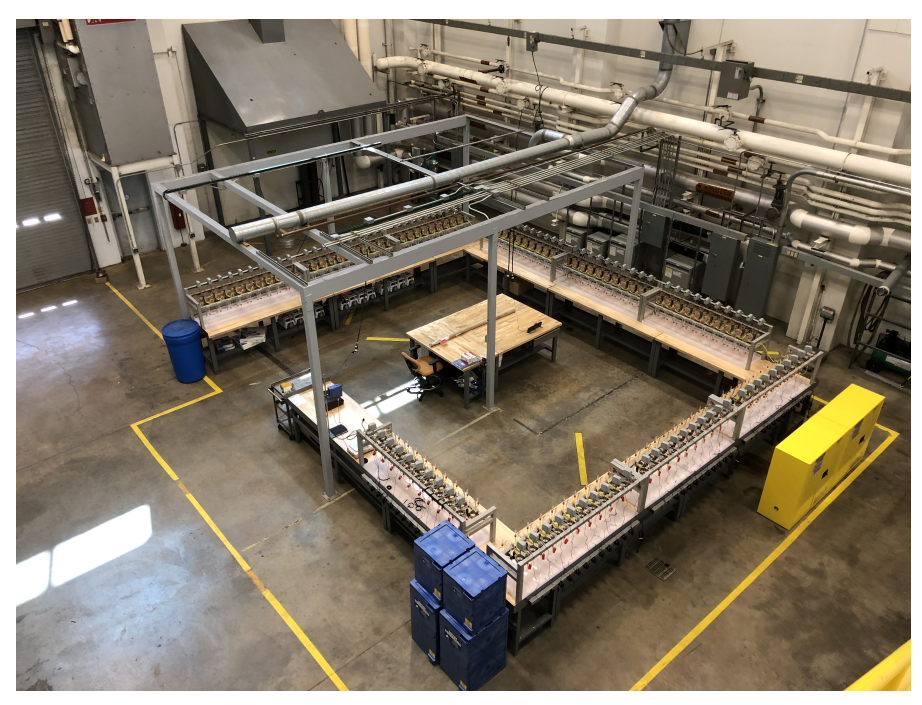

Figure 5.8 - Overview of solvent extraction module

ten mixer-settlers attached to each frame, along with the requisite peristaltic pumps and chemical storage tanks needed for operation.

Multiple shakedown tests were performed on this system to empirically obtain a minimum set of operational parameters required for the system to operate. Initially, a hydrostatic test was completed to identify any leaks in the system. Additionally, each unit operation was evaluated during shakedown testing using multiple parameters to establish the key operating set-points required to perform the necessary process. This was accomplished by using PLS from each feedstock to test the extraction, scrubbing, stripping, and saponification circuits in a batch-wise fashion until analytical testing showed the circuit preformed in a satisfactory manner. After the most promising parameters were identified, each feedstock was then processed using the SX bench-scale plant in a continuous fashion to develop a baseline result from which parametric testing could identify the effect of changing individual SX parameters on the overall performance of the SX plant.

\subsubsection{Solvent Extraction Shakedown Testing}

In the course of shakedown testing, several issues were noted that inhibited the operation of the bench-scale system. As each issue was discovered, modifications to the plant were 
implemented to alleviate the deficiency. Each operational challenge that was observed during this testing regime is described below.

\section{Third-Phase Crud Formation}

During the initial shakedown tests, two of the feedstocks (DLM and Omega) caused considerable third-phase formation as seen in Figure 5.9. This third phase, also called crud, is a stable emulsion that causes significant problems in the SX circuit as noted by Ritcey (1980). The crud encountered during this testing started forming at the organic and aqueous interface and eventually occupied the majority of the volume in the mixer-settler.

This was a significant setback and before a continuous SX process flowsheet using these feedstocks is finalized, a thorough investigation of third phase formation is necessary (Kedari et al. 2006). Some of the issues encountered during the initial testing runs included difficulties in obtaining mass balances, organic loss to the aqueous streams, and complete blockages of the tubing connecting the mixer-settlers. Unfortunately, the generation of large amounts of crud rendered parametric testing with these feedstocks difficult if not impossible to complete.

Characterization of the third phase was conducted by Huang (2019). XRD analysis of the third phase formation indicated that the crud contained Quartz, Nitromagnesite, Sodium Nitrate, and Calcium Carbonate. Furthermore, ICP-OES analysis indicated that the solid fraction of the crud material contained high levels of $\mathrm{Al}$ and $\mathrm{Na}$ while the organic phase contained high a high percentage of Fe. Additionally, multiple exploratory tests were conducted in an attempt to prevent the formation of crud in the mixing chamber. These tests included dilution of the PLS, use of the modifier tributyl phosphate, varying extractant concentrations, changing the extractant O:A ratio, and attempts to recreate the third phase formation using synthetic solutions. Results from this testing suggested that the gangue metals $\mathrm{Al}, \mathrm{Ca}$, Fe and Si are factors in the formation of the third phase. While this testing did not result in a method to eliminate the formation of the crud, it does show that additional gangue removal is necessary in the leaching module. As a result, baseline testing was not successfully completed on these two crud-forming feedstocks. 


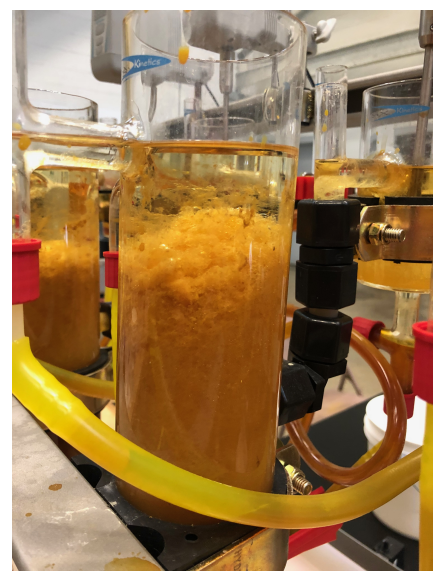

Figure 5.9 - Crud formation in an extraction settler during DLM shakedown testing.

In contrast, the Royal Scot feedstock did not produce a detrimental quantity of crud. When the PLS of the three feedstocks was compared, as shown in Table 5.3, it was evident that the Fe and Ca content in the Royal Scot PLS was considerably lower than in the other two feedstocks. While the fundamental mechanism behind the crud formation was not identified, the crud characterization testing and comparison of PLS feedstocks indicated that that Fe or Ca may have reached a limiting organic concentration (LOC) where the metal ions started to precipitate and created a nucleus that allowed for crud formation as described by Chiarizia and Briand (2007). As a result, the Royal Scott PLS was used to demonstrate the feasibility of recovering REEs from AMDp while DLM and Omega feedstocks were subjected to further leaching tests to remove the excess gangue metals.

\section{Maintaining Mixing O:A}

Another operational difficulty encountered in the operation of the SX plant involved maintaining a consistent O:A ratio in the mixing chamber. This issue was not observed in the SX unit operations using an advance ratio of 1:1. Conversely, unit operations that required high or low O:A ratios often presented challenges in regard to maintaining a consistent mixing $\mathrm{O}: \mathrm{A}$ ratio. This was caused for one of two reasons.

First, over time, the Tygon tubing used to recycle the aqueous phase in the settler back to the mixer would hardened and prevented operation of the roller-clamp that restricts flow in the recycle line. The second issue encountered was inherent to the roller clamp design. Often 
Table 5.3 - Comparison of PLS from the three feedstocks.

\begin{tabular}{|c|c|c|c|c|}
\hline Sample Date & & $1 / 23 / 19$ & $2 / 5 / 19$ & $2 / 27 / 19$ \\
\hline Feedstock & & DLM & Omega & Royal Scot \\
\hline End pH & & 3.05 & 2.94 & 3.01 \\
\hline \multicolumn{5}{|l|}{ Major Ions } \\
\hline $\mathrm{Al}$ & $(\mathrm{mg} / \mathrm{L})$ & $9,480.84$ & $3,133.43$ & $2,982.86$ \\
\hline $\mathrm{Ca}$ & $(\mathrm{mg} / \mathrm{L})$ & $1,401.59$ & $1,372.56$ & 761.02 \\
\hline Co & $(\mathrm{mg} / \mathrm{L})$ & 102.98 & 18.60 & 22.43 \\
\hline $\mathrm{Fe}$ & $(\mathrm{mg} / \mathrm{L})$ & $1,936.00$ & 71.43 & 3.18 \\
\hline $\mathrm{Mg}$ & $(\mathrm{mg} / \mathrm{L})$ & $6,845.59$ & 455.24 & $2,426.65$ \\
\hline $\mathrm{Mn}$ & $(\mathrm{mg} / \mathrm{L})$ & $3,595.23$ & 105.58 & 777.82 \\
\hline $\mathrm{Na}$ & $(\mathrm{mg} / \mathrm{L})$ & 47.55 & $12,699.48$ & $11,493.42$ \\
\hline $\mathrm{Si}$ & $(\mathrm{mg} / \mathrm{L})$ & $1,274.31$ & 59.31 & 53.64 \\
\hline $\mathrm{SO} 4$ & $(\mathrm{mg} / \mathrm{L})$ & 497.79 & 25.39 & 881.37 \\
\hline $\mathrm{Cl}$ & $(\mathrm{mg} / \mathrm{L})$ & 17.92 & 5.65 & 4.67 \\
\hline TMM & $(\mathrm{mg} / \mathrm{L})$ & $25,199.80$ & $17,946.67$ & $19,407.05$ \\
\hline \multicolumn{5}{|c|}{ Rare Earth Elements } \\
\hline $\mathrm{Sc}$ & $(\mu \mathrm{g} / \mathrm{L})$ & $2,118.11$ & 962.45 & $<0.037$ \\
\hline $\mathrm{Y}$ & $(\mu \mathrm{g} / \mathrm{L})$ & $83,061.09$ & $7,151.53$ & $12,504.72$ \\
\hline $\mathrm{La}$ & $(\mu \mathrm{g} / \mathrm{L})$ & $23,908.46$ & $1,477.79$ & $2,646.17$ \\
\hline $\mathrm{Ce}$ & $(\mu \mathrm{g} / \mathrm{L})$ & $64,313.63$ & $4,906.65$ & $7,519.84$ \\
\hline $\operatorname{Pr}$ & $(\mu \mathrm{g} / \mathrm{L})$ & 8,198.92 & 782.96 & $1,248.48$ \\
\hline $\mathrm{Nd}$ & $(\mu \mathrm{g} / \mathrm{L})$ & $34,781.11$ & $3,688.07$ & $6,330.98$ \\
\hline $\mathrm{Sm}$ & $(\mu \mathrm{g} / \mathrm{L})$ & $8,890.67$ & $1,133.53$ & $2,087.38$ \\
\hline $\mathrm{Eu}$ & $(\mu \mathrm{g} / \mathrm{L})$ & $2,325.90$ & 302.10 & 529.65 \\
\hline $\mathrm{Gd}$ & $(\mu \mathrm{g} / \mathrm{L})$ & $13,509.25$ & $1,820.15$ & $3,011.83$ \\
\hline $\mathrm{Tb}$ & $(\mu \mathrm{g} / \mathrm{L})$ & $2,239.51$ & 339.07 & 450.90 \\
\hline Dy & $(\mu \mathrm{g} / \mathrm{L})$ & $13,712.70$ & $2,016.94$ & $2,493.89$ \\
\hline Но & $(\mu g / L)$ & $2,713.13$ & 381.42 & 444.83 \\
\hline Er & $(\mu \mathrm{g} / \mathrm{L})$ & $7,453.57$ & $1,063.41$ & $1,162.19$ \\
\hline $\mathrm{Tm}$ & $(\mu \mathrm{g} / \mathrm{L})$ & 965.45 & 144.99 & 136.08 \\
\hline $\mathrm{Yb}$ & $(\mu \mathrm{g} / \mathrm{L})$ & $5,506.71$ & 824.88 & 801.98 \\
\hline $\mathrm{Lu}$ & $(\mu \mathrm{g} / \mathrm{L})$ & 793.23 & 125.05 & 104.29 \\
\hline $\mathrm{Th}$ & $(\mu \mathrm{g} / \mathrm{L})$ & 163.78 & 11.28 & $<0.007$ \\
\hline $\mathrm{U}$ & $(\mu \mathrm{g} / \mathrm{L})$ & 815.79 & 257.11 & 198.47 \\
\hline TREE & $(\mu \mathrm{g} / \mathrm{L})$ & $274,491.42$ & $27,120.98$ & $41,473.23$ \\
\hline HREE & $(\mu \mathrm{g} / \mathrm{L})$ & $132,072.74$ & $14,829.88$ & $21,110.72$ \\
\hline LREE & $(\mu \mathrm{g} / \mathrm{L})$ & $142,418.68$ & $12,291.10$ & $20,362.51$ \\
\hline CREE & $(\mu \mathrm{g} / \mathrm{L})$ & $136,120.30$ & $13,497.71$ & $22,310.15$ \\
\hline
\end{tabular}


the roller-clamps could not provide the fine adjustment required to properly maintain the preferred mixing O:A range of 1.5:1 to 1:1.5 as recommended by the SX plant manufacturer (Webster 2018). To alleviate this issue, in-line valves were acquired to replace the rollerclamp style valves installed on the recycle lines of the SX processes that required advance O:A ratios greater than the recommended mixing range.

\section{Organic Loss During Saponification}

During initial shakedown testing, four unit operations were utilized including: extraction; scrubbing; stripping; and saponification. During these tests, a large fraction of the organic was reporting to the saponification raffinate and not recycling back to the organic tank. Further research indicated that an additional stage was needed to separate the organic and aqueous phases as indicated by Ritcey et al.(1979). As a result, the Megon Rare Earth Circuit, as presented by Ritcey, showed an additional circuit (acid wash) implemented directly after the saponification stage was required. This addition resolved the misreporting of the organic phase to the aqueous raffinate tank. Furthermore, the concentration of saponification reagent was changed from $2 \mathrm{M}$ sodium hydroxide to $2 \mathrm{M}$ ammonium hydroxide. The combination of reagent substitution and the additional stage greatly improved the recovery of organic to the organic recycle tank.

While the recovery of the organic improved to a level that was acceptable for the operation of the bench-scale plant, further modification to the circuit is required as the scale of the plant increases. Organic loss often constitutes a significant cost to industrial-scale SX operations (Morgan et al. 2011). As a result, the addition of a coalescence device or other chemical modifier warrants evaluation as the TRL of this process increases.

\subsubsection{SX Procedure and Results}

In order to develop a base-line test before parametric testing was started, a batch of PLS was processed in the SX system with an initial set of operating parameters. Table 5.4 shows the parameters used in establishing this baseline test. The extractant, Elixore 205 is a 
highly refined aliphatic diluent, similar to kerosene, with a high flash-point, low viscosity, and ultra-low aromatic content Total (2019). This diluent was chosen for three reasons. First, standard kerosene was used in some initial shakedown testing. However, a strong odor was emitted by the kerosene that permeated the enclosed area. Second, the use of a diluent specifically designed for use in solvent extraction was necessary to minimize further scale-up issues as the TRL of the project increased. Third, phase separation tests conducted by Koermer (2018) showed a slight advantage in phase separation times with Elixore 205 verses other Total diluents.

Next, D2EHPA was chosen as the primary extractant based on the wide acceptance within the REE industry and abundance of literature resources using this extractant in SX processes targeting REEs Ritcey and Ashbrook (1984), Verbaan et al. (2015), and Bourricaudy et al. (2016). The initial extractant concentration was identified by research conducted by Ren and Liu (2019). Additionally, initial shakedown testing indicated third-phase crud formation occurred in the extraction, scrubbing, and stripping circuits. In order to address this issue, TBP was added as a modifier as described by Ritcey and Ashbrook (1984).

The extraction and scrubbing advance O:A ratios were both operated at 1:1 to provide equal transfer of the REEs and gangue metals to the organic phase and scrubbing raffinate respectively. For the stripping circuit, an O:A ratio of 10:1 was utilized to concentrate the REEs into the stripped raffinate, while minimizing the volume of the produced raffinate. This was advantageous for the next process, as a smaller volumes required less material handling. Finally, the saponification and acid wash O:A ratios were of 5:1 and 1:1, respectively, based on previous shakedown testing results. Mixer speeds of $856 \mathrm{rpm}$ were used for every mixer in the SX plant. Lastly, every SX process was conducted using five mixer-settlers, with the exception of the acid-wash stage where only three mixer-settlers were utilized. The use of 5 stages in each process is in excess of the number of stages identified in exploratory testing. However, using extra stages reduced the effects of other system inefficiencies that occurred while conduction the baseline tests. During parametric testing unit-by-unit sampling will later identify the critical number of stages required. 
Table 5.4 - Solvent extraction circuit parameters used during baseline testing.

\begin{tabular}{|c|c|c|}
\hline Parameter & Units & Value \\
\hline \multicolumn{3}{|l|}{ Extraction } \\
\hline Organic & $(\mathrm{txt})$ & Elixore 205 \\
\hline Extractant & (txt) & D2EHPA \\
\hline Extractant Concentration & $(\mathrm{M})$ & $0.5(\mathrm{M})$ \\
\hline Modifier & $(\mathrm{txt})$ & TBP \\
\hline Modifier Concentration & $(\mathrm{v} / \mathrm{v})$ & $20 \%$ \\
\hline Advance O:A & $(\#: \#)$ & $1: 1$ \\
\hline Mixer Speed & $(\mathrm{rpm})$ & 856 \\
\hline Organic Pump & $(\mathrm{ml} / \mathrm{min})$ & 75 \\
\hline Aqueous Pump & $(\mathrm{ml} / \mathrm{min})$ & 75 \\
\hline \multicolumn{3}{|l|}{ Scrubbing } \\
\hline Reagent & $(\mathrm{txt})$ & $\mathrm{H}_{2} \mathrm{O}$ \\
\hline Concentration & $(\mathrm{v} / \mathrm{v})$ & $100 \%$ \\
\hline O:A Ratio & $(\#: \#)$ & $1: 1$ \\
\hline Mixer Speed & (rpm) & 856 \\
\hline Scrub Pump & $(\mathrm{ml} / \mathrm{min})$ & 75 \\
\hline \multicolumn{3}{|l|}{ Stripping } \\
\hline Reagent & $(\mathrm{txt})$ & $\mathrm{HCl}$ \\
\hline Concentration & $(\mathrm{M})$ & 6 \\
\hline O:A Ratio & $(\#: \#)$ & $10: 1$ \\
\hline Mixer Speed & $(\mathrm{rpm})$ & 856 \\
\hline Strip Pump & $(\mathrm{ml} / \mathrm{min})$ & 7.5 \\
\hline \multicolumn{3}{|l|}{ Saponification } \\
\hline Reagent & (txt) & $\mathrm{NH}_{4} \mathrm{OH}$ \\
\hline Concentration & $(\mathrm{M})$ & $2 \mathrm{M}$ \\
\hline O:A Ratio & $(\#: \#)$ & $5: 1$ \\
\hline Mixer Speed & $(\mathrm{rpm})$ & 856 \\
\hline Sap Pump & $(\mathrm{ml} / \mathrm{min})$ & 15 \\
\hline \multicolumn{3}{|l|}{ Acid Wash } \\
\hline Reagent & (txt) & $\mathrm{HNO}_{3}$ \\
\hline Concentration & $(\mathrm{M})$ & 0.75 \\
\hline O:A Ratio & $(\#: \#)$ & $1: 1$ \\
\hline Mixer Speed & $(\mathrm{rpm})$ & 856 \\
\hline Acid Wash Pump & $(\mathrm{ml} / \mathrm{min})$ & 75 \\
\hline
\end{tabular}

The plant was operated over a period of eight days with a total operating time of 58 hours. This equates to roughly 7.2 operating hours per day or $90 \%$ operational availability. During this time, 281 liters of the PLS feedstock was processed through the system and concentrated into 28.3 liters of stripped product. Additionally, the organic phase was constantly 
recycled back to the extraction stage with minimal loss to the aqueous raffinate streams. This demonstrated the ability of the process to run continuously with a fixed quantity of organic and extractant reagents, while showing that no metal ions remained attached to the extractant, which would have reduced the extraction rate in the first circuit. An aqueous sample was obtained at the end of each operating day to evaluate the performance of the system.

Figure 5.10 shows the process flow diagram of the ALSX system at the time of testing. As previously discussed, the aqueous and organic phases were circulated in a counter-current fashion. Additionally, the organic phase advanced through each phase and was recycled for reuse at the end of the processing stream, after regeneration in the saponification and acid wash stages.

In the extraction stage, the PLS and organic phases mix and settle, transferring metal ions into the organic phase. Next, scrubbing removes unwanted elements from the organic while leaving the REEs in the organic phase using water or a mild acid. In the stripping stage, $6 \mathrm{M} \mathrm{HCl}$ acid removed the REEs from the organic phase and concentrated the REEs in the strip raffinate. In this stage a high advance ratio was used to concentrate the REEs into the aqueous strip raffinate. Furthermore, the strip raffinate contained the valuable product from this operation that was used in the next plant module to recover the REEs. The last two stages, saponification and acid wash were used to regenerate the extractant, in essence cleaning the cation exchange sites on each D2EHPA molecule.

Figure 5.11 shows the results of the daily analytical testing performed on the PLS raffinate. While there was not a major change in the concentrations of the gangue material over the length of the test, it did take several days for the system to achieve steady state in regard to consistent extraction of the REEs. This is shown by the low REE concentration in the PLS raffinate. Additionally, during days one thru three, several of the LREEs were not fully extracted from the PLS. This could indicate a relationship to the $\mathrm{pH}$ withing the mixing cell resulting in a low pH value. Furthermore the selectivity order of D2EHPA favors the HREEs at low pH values as shown by Xie et al. (2014). Conversely, the HREEs approached steady-state extraction at Day 2. 


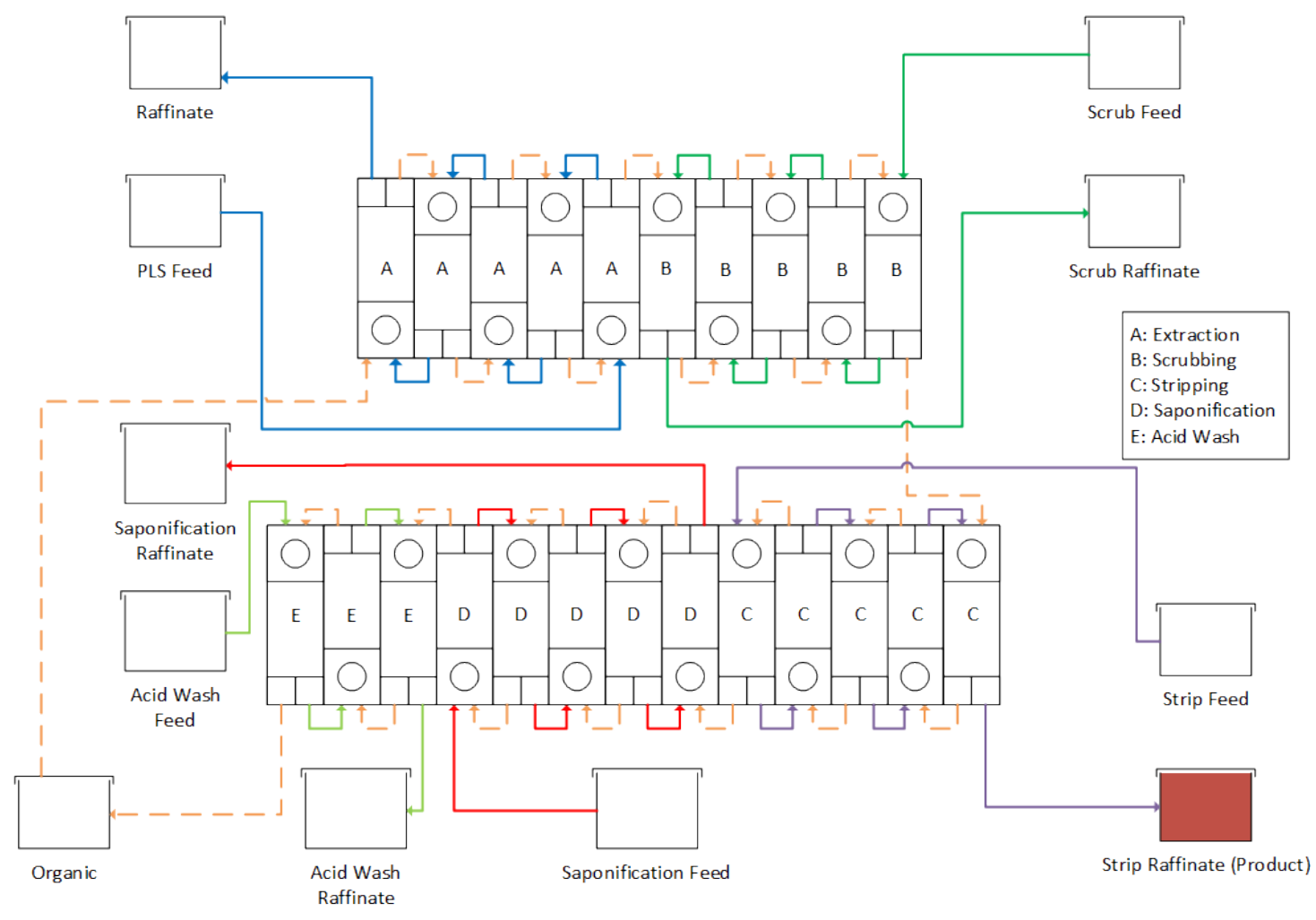

Figure $\mathbf{5 . 1 0}$ - Process flow diagram for the solvent extraction module

Due to the sampling program and analytical limitations, a complete mass balance of this complex system was not feasible, as only aqueous samples were analyzed. Nevertheless, recovery of REEs to the organic phase was high (> 95\%) after the system reached steady state, based on a simple mass balance by subtraction. More detailed sampling and a complete mass balance based on both aqueous and organic streams is recommended for further study. Additionally, the daily analytical testing results for the scrubbing raffinate are shown in Figure 5.12. This data indicated that there was some variation in the removal of chloride and sodium ions from the extractant using water as a scrubbing medium. Moreover, the scrubbing stage did not reach a steady-state condition until after day 4 in regard to the REEs. To further increase the scrubbing potential of the circuit, additional testing using a mild acid should be preformed to optimize the process.

Figure 5.13 shows the concentrations of both the major ions and REEs in the strip raffinate. The data indicated that both $\mathrm{Al}$ and $\mathrm{Ca}$ were both recovered in the stripped raffinate. 

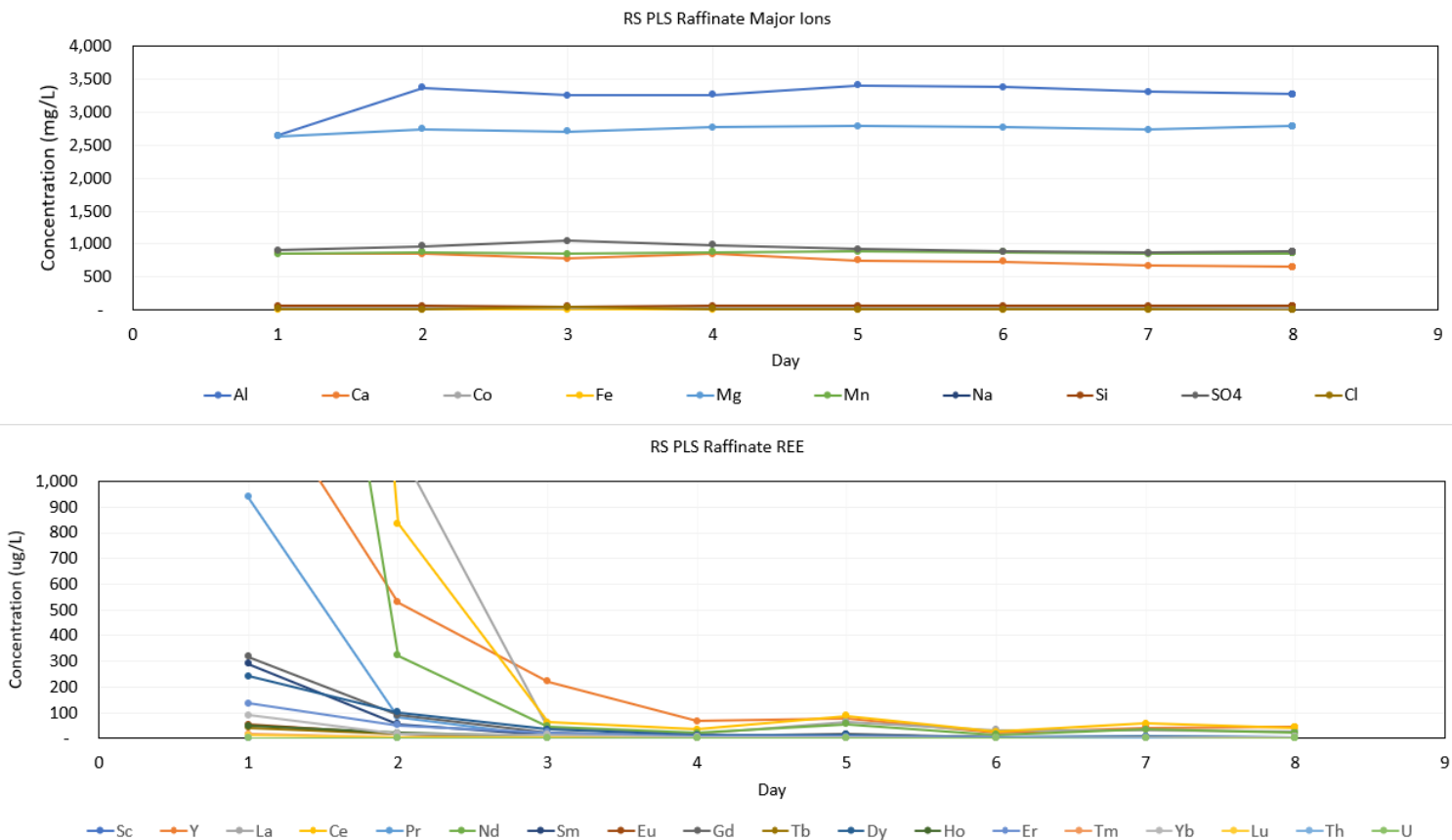

Figure 5.11 - Major lons and REE concentrations in the extractant raffinate.
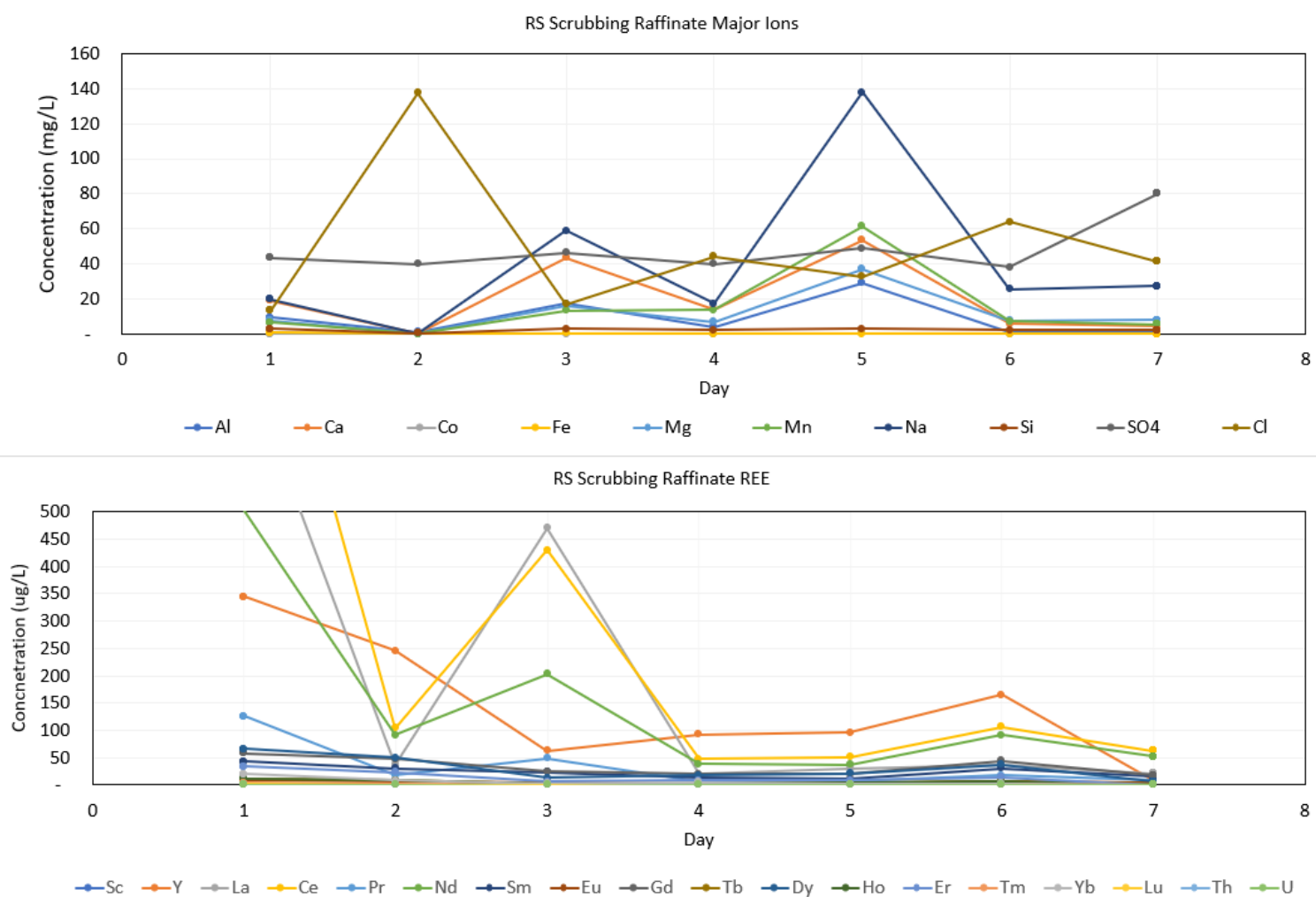

Figure 5.12 - Major lons and REE concentrations in scrubbing raffinate

The presence of these gangue metals in the product stream indicate then need for further separations to increase the grade of the recovered REEs. 
More importantly, the concentration of REEs in the stripped raffinate is significant when compared to the incoming concentration of REEs in the PLS feed. This indicated the REEs are being selectively separated and concentrated into the strip raffinate stream versus the other major ions. Furthermore, the distribution of REEs in the stripped raffinate closely resemble that of the PLS. The most prevalent REE was Y (35\%) followed by Ce (15\%) and $\mathrm{Nd}(13 \%)$. In all, the stripping circuit concentrated the REEs by a factor of 7.7 indicating that the O:A ratio was effective and that the recovery of the REEs was not absolute.

Again, a complete mass balance of this system is beyond the scope of this demonstration. However, initial data indicated the the recovery of REEs to the stripped raffinate exceeds $95 \%$ once the system attained steady state. This is significant because a high unit recovery indicated the stripping process is preforming near optimum conditions.
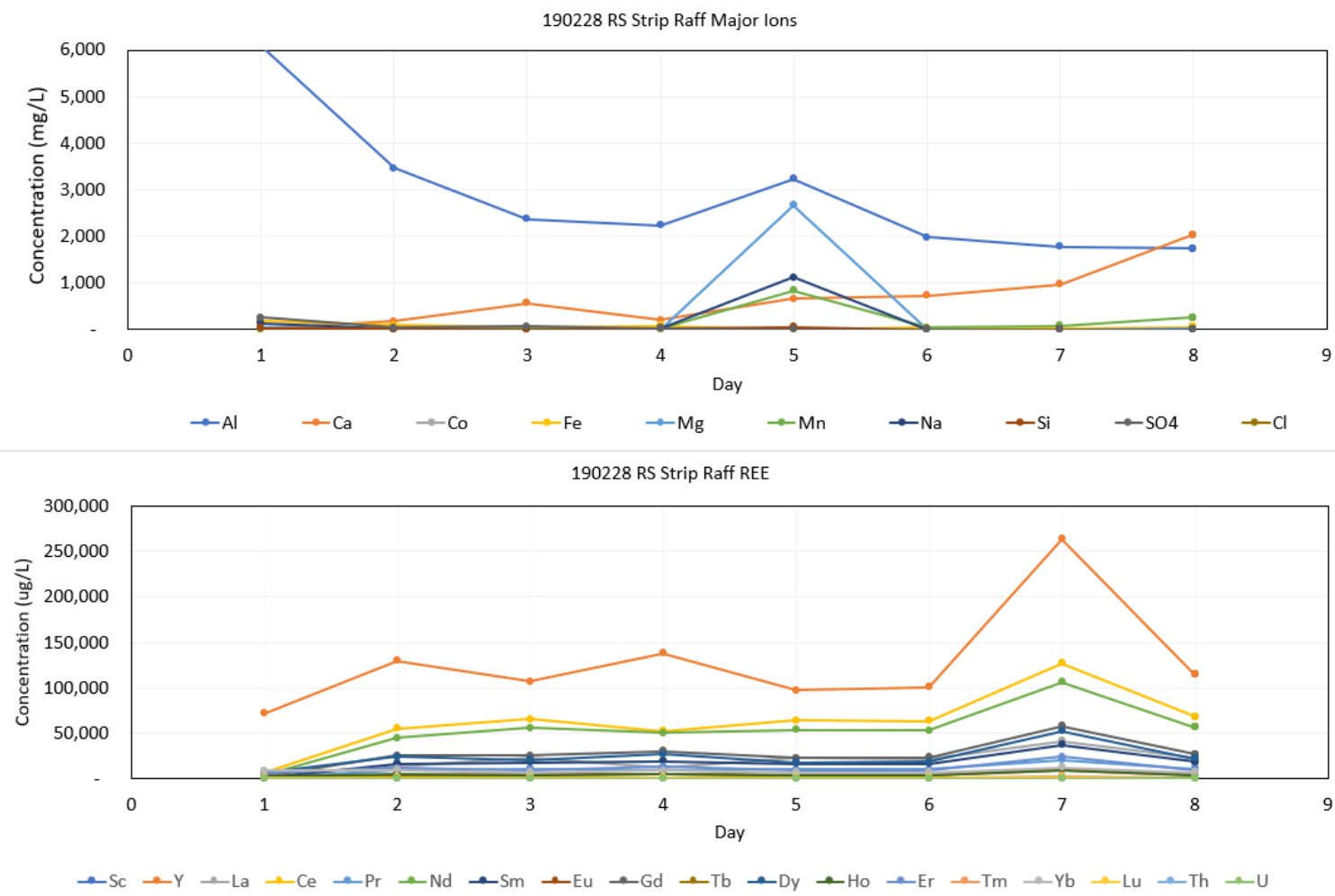

Figure 5.13 - Major ions and REE concentration in stripping raffinate.

Lastly, the results from analytical testing on the saponification raffinate are shown in Figure 5.14. This stage of the SX system showed increased concentrations of both $\mathrm{Al}$ and Fe. Additionally, the $\mathrm{Cl}$ concentration is not shown as the concentration was several orders of 
magnitude higher than the other elements, as a result of using $\mathrm{HCl}$ as the stripping reagent. Additionally, issues with maintaining a consistent mixing O:A can be observed during days five thru eight with REE concentration increasing during this time period. This shows this importance on maintaining the stripping O:A mixing ratio to avoid loss of the REEs in this stage. As a result, further testing will focus on optimizing the mixing ratios in the stripping phase to reduce the loss of REEs to the saponification raffinate.
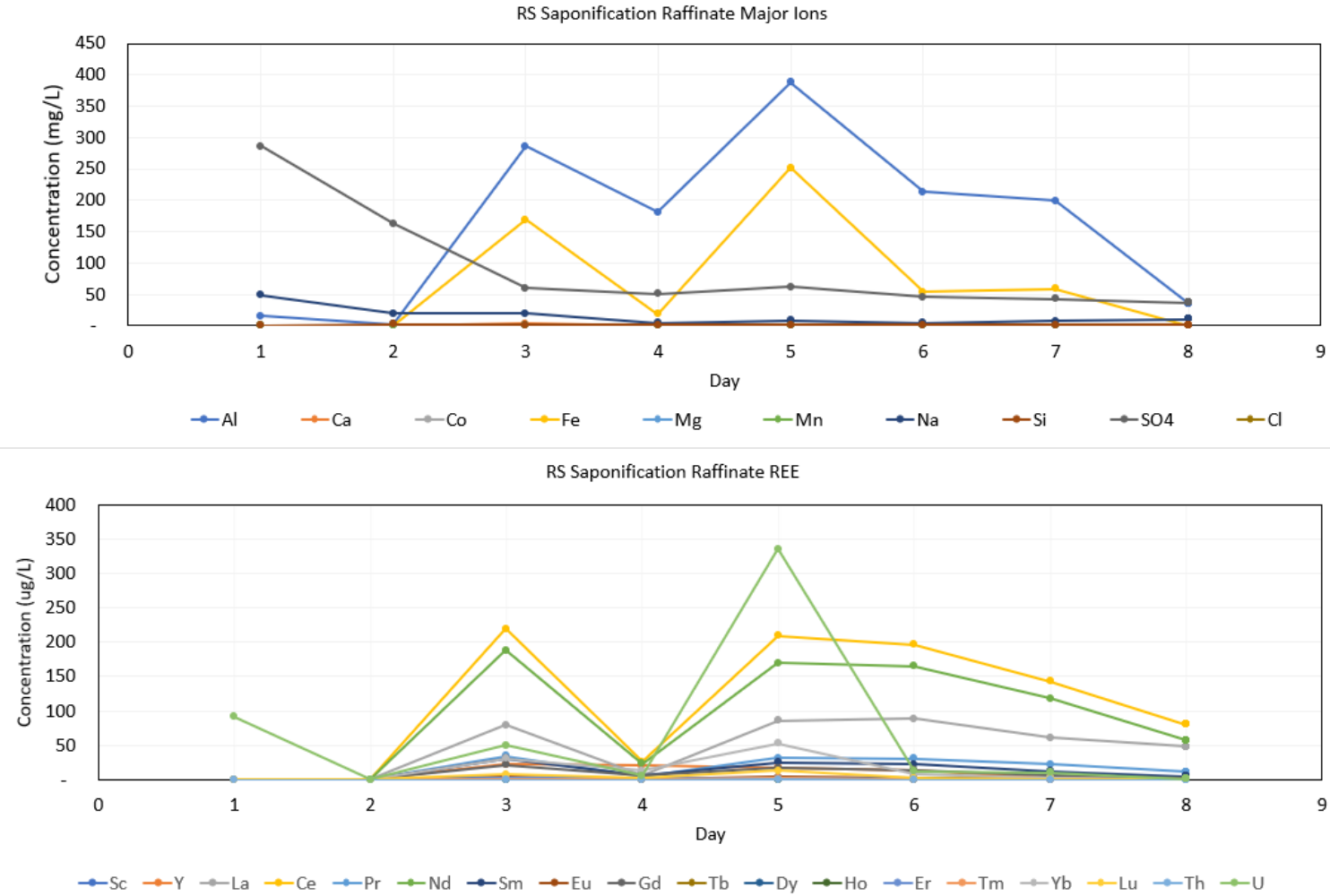

Figure 5.14 - Major ions and REE concentrations in the saponification raffinate.

\subsection{Precipitation Module}

The precipitation module used during testing to recover the REEs from the strip solution is shown in Figure 5.15. This module is smaller in scale than the other ALSX plant equipment. The precipitation module consisted of an overhead mixer used to agitate the stripped raffinate as reagents were added to the solution. After precipitation, the striped raffinate was placed in a ten gallon conical bottom tank allowing the solids to settle at the bottom overnight. The 
use of the conical bottom tank minimized the volume of liquid that required filtration. The last component shown in Figure 5.15 module is a small pressure filter that separated the solid and liquid components of the decanted stripped raffinate. Not shown are the drying oven and furnace used to dry and calcine thee rare earth oxalates that precipitated from solution. This equipment was also utilized for the acid and water washing procedures described below.

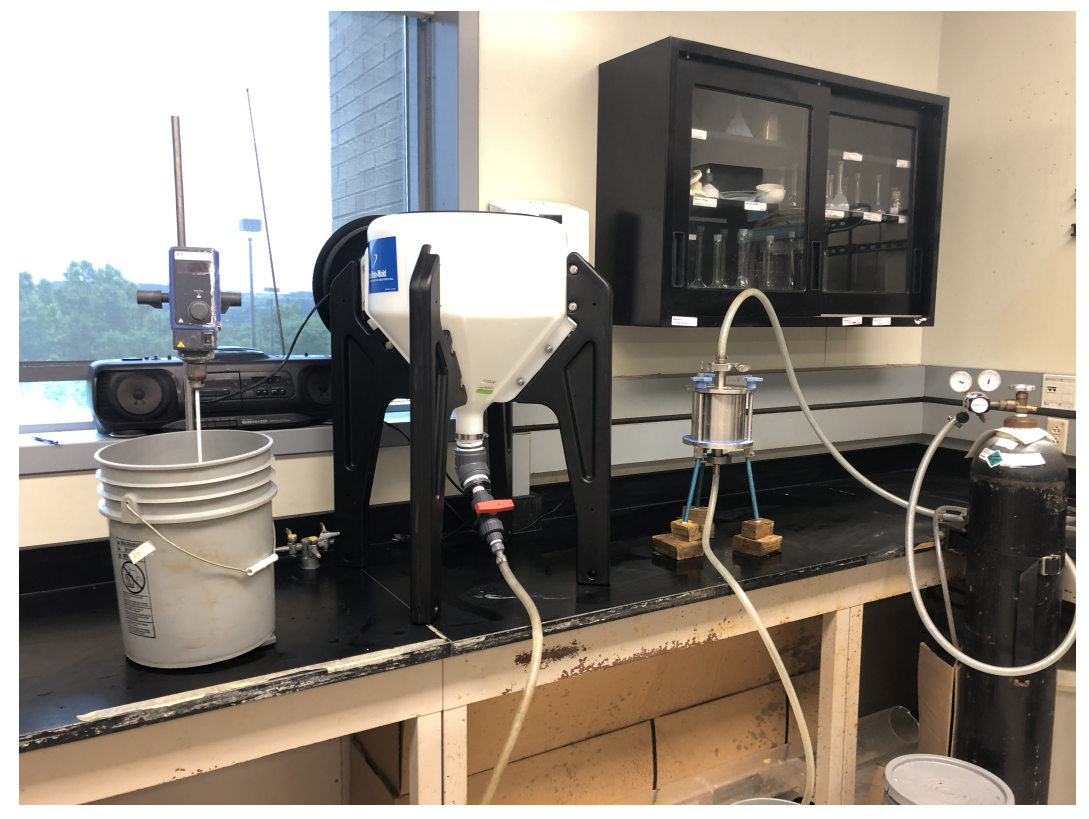

Figure $\mathbf{5 . 1 5}$ - Precipitation module used to recover REEs from stripped raffinate.

\subsubsection{Precipitation Procedure}

After all of the PLS was processed through the solvent extraction plant, the stripping raffinate was collected for processing in the precipitation module. Figure 5.16 shows the process flow diagram that resulted in the separation of a $62 \%$ mixed rare earth oxide product. After acquiring an initial sample of the strip solution, 25 grams per liter of oxalic acid was added to the stripped raffinate, representing approximately 5 times the stochiometric ratio of oxalic acid to REEs. Next, the $\mathrm{pH}$ of the stripped solution was raised with $50 \% \mathrm{NaOH}$ to a value of 1.5. The $\mathrm{pH}$ adjustment was performed in multiple steps over several hours, ensuring the temperature of the solution did not exceed 80 degrees Celsius and $\mathrm{pH}$ equilibrium was accomplished. 


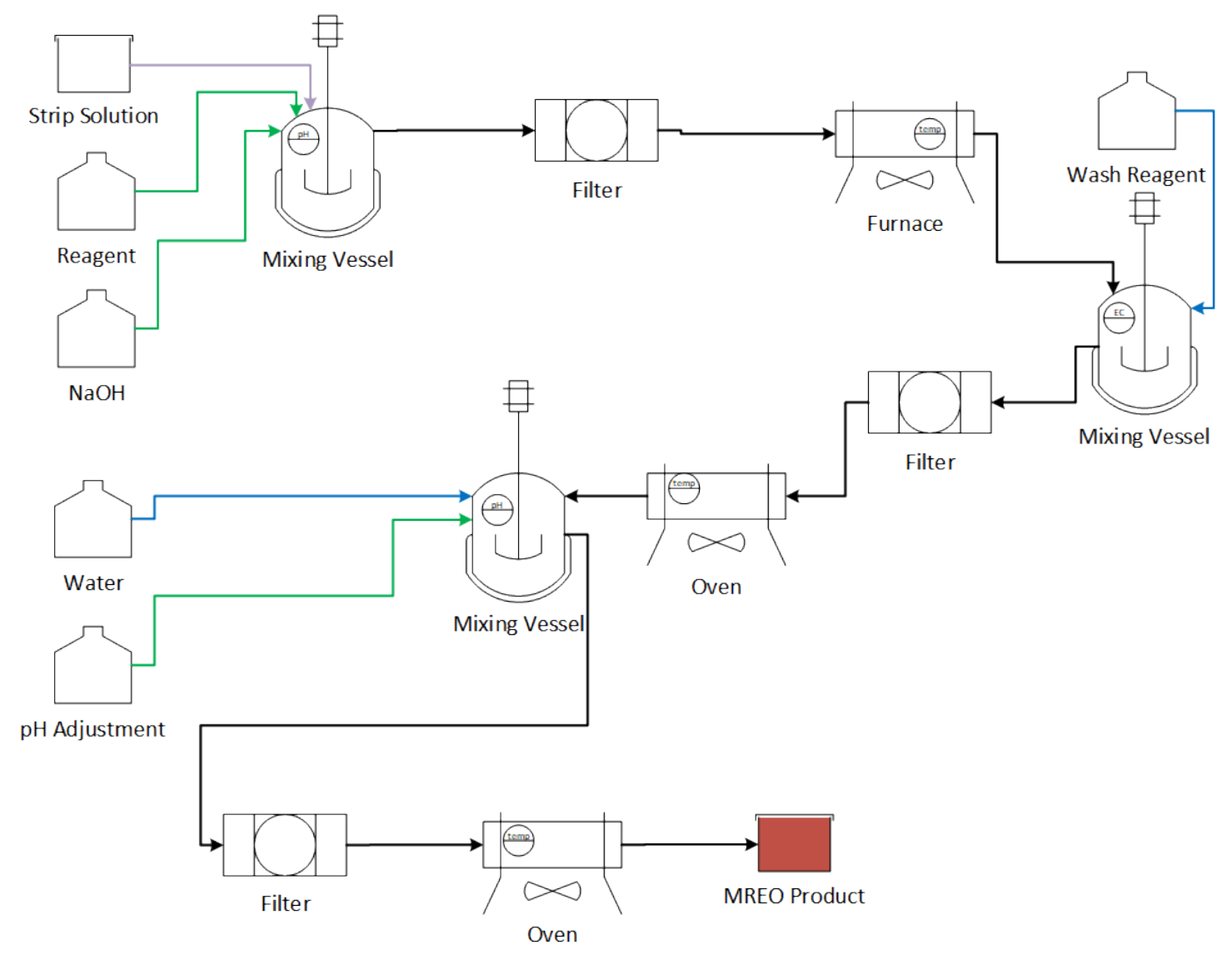

Figure 5.16 - Precipitation process diagram

Once the target $\mathrm{pH}$ was achieved, the solution was allowed to decant overnight where three quarters of the supernatant was left in the decanting vessel and the remaining quarter was separated using a pressure filter with Whatman Grade 40 ash-less filter paper with a nominal particle retention of 8 microns. Next, the precipitate was dried in a Yamato DX602C oven at 105 degrees Celsius. A sample was taken from the precipitate and assayed to determine the REE content, as shown in Table 5.5.

The oxalic acid precipitation process resulted in 190 grams of precipitate containing 11.1 grams of REEs. The represents a TREE recovery of $97 \%$. The majority of the measured major ions were selectively rejected during the precipitation procedure, with the exception of $\mathrm{Ca}$, which entirely co-precipitated with the REEs. Additionally, a mass balance of the process was conducted on the major ions and rare earths. Results of the material balance indicate that little error was observed in the major ions (1.7\%) and REEs $(2.6 \%)$. 
The REE oxalate precipitate was then calcined in a Lindberg muffle furnace at a temperature of 750 degrees Celsius for four hours. A sample of this material indicated the calcination procedure resulted in almost doubling of the concentration of the REO product from $5.8 \%$ to $11 \%$ as shown in Table 5.6. Additionally, $22 \%$ of the dried product consisted of Ca. In order to further concentrate the REO product a series water and acid washing steps were implemented.

Table 5.5 - Initial Royal Scot strip solution, oxalate precipitation, and mass balance steps.

\begin{tabular}{|c|c|c|c|c|c|c|c|}
\hline Analyte & $\begin{array}{r}\text { Strip } \\
\text { Solution } \\
\text { Assay }\end{array}$ & $\begin{array}{r}\text { Strip } \\
\text { Solution } \\
\text { Mass }\end{array}$ & $\begin{array}{r}\text { Oxalic Precip. } \\
\text { Filtrate } \\
\text { Assay }\end{array}$ & $\begin{array}{r}\text { Oxalic Precip. } \\
\text { Filtrate } \\
\text { Mass }\end{array}$ & $\begin{array}{r}\text { Oxalic Precip. } \\
\text { Product } \\
\text { Assay }\end{array}$ & $\begin{array}{r}\text { Oxalic Precip. } \\
\text { Product } \\
\text { Mass }\end{array}$ & $\begin{array}{r}\text { Mass } \\
\text { Balance }\end{array}$ \\
\hline Volume (L) & 28.32 & - & 42.28 & - & - & - & - \\
\hline Mass (g) & - & - & 47.35 & - & 190.27 & - & - \\
\hline Major Ions & $(\mathrm{mg} / \mathrm{L})$ & (g) & $(\mathrm{mg} / \mathrm{L})$ & (g) & $(\mathrm{mg} / \mathrm{kg})$ & (g) & $(g)$ \\
\hline Al & $2,626.16$ & 74.37 & $1,654.35$ & 69.94 & $1,122.60$ & 0.21 & 4.21 \\
\hline $\mathbf{C a}$ & 897.55 & 25.42 & 17.41 & 0.74 & $138,002.05$ & 26.26 & $(1.58)$ \\
\hline Co & 0.04 & 0.00 & 0.01 & 0.00 & - & - & 0.00 \\
\hline $\mathrm{Fe}$ & 80.54 & 2.28 & 68.98 & 2.92 & - & - & (0.64) \\
\hline $\mathrm{Mg}$ & 5.61 & 0.16 & 5.44 & 0.23 & 31.26 & 0.01 & $(0.08)$ \\
\hline Mn & 87.25 & 2.47 & 57.63 & 2.44 & $1,388.97$ & 0.26 & (0.23) \\
\hline Si & 7.75 & 0.22 & 5.89 & 0.25 & 211.41 & 0.04 & $(0.07)$ \\
\hline $\mathrm{SO} 4$ & 8.76 & 0.25 & 0.33 & 0.01 & 450.09 & 0.09 & 0.15 \\
\hline TMM & $3,713.65$ & 105.16 & $1,810.04$ & 76.52 & $141,206.38$ & 26.87 & 1.77 \\
\hline Rare Earth Elements & $(\mu \mathrm{g} / \mathrm{L})$ & (g) & $(\mu \mathrm{g} / \mathrm{L})$ & $(\mathrm{g})$ & $(\mathrm{mg} / \mathrm{kg})$ & $(\mathrm{g})$ & $(g)$ \\
\hline Sc & 0.02 & 0.00 & 0.44 & 0.00 & - & - & - \\
\hline Y & $136,881.10$ & 3.88 & 626.05 & 0.03 & $20,068.41$ & 3.82 & 0.03 \\
\hline La & $21,449.10$ & 0.61 & 43.67 & 0.00 & $3,121.71$ & 0.59 & 0.01 \\
\hline $\mathrm{Ce}$ & $67,127.02$ & 1.90 & 94.28 & 0.00 & $9,686.69$ & 1.84 & 0.05 \\
\hline Pr & $11,125.33$ & 0.32 & 11.66 & 0.00 & $1,620.39$ & 0.31 & 0.01 \\
\hline $\mathrm{Nd}$ & $55,454.65$ & 1.57 & 45.22 & 0.00 & $8,284.33$ & 1.58 & $(0.01)$ \\
\hline Sm & $18,654.50$ & 0.53 & 10.98 & 0.00 & $2,658.68$ & 0.51 & 0.02 \\
\hline Eu & $4,953.41$ & 0.14 & 2.76 & 0.00 & 711.38 & 0.14 & 0.00 \\
\hline Gd & $28,813.05$ & 0.82 & 18.64 & 0.00 & $4,013.41$ & 0.76 & 0.05 \\
\hline $\mathrm{Tb}$ & $4,538.49$ & 0.13 & 4.58 & 0.00 & 621.93 & 0.12 & 0.01 \\
\hline Dy & $25,609.26$ & 0.73 & 43.73 & 0.00 & $3,533.09$ & 0.67 & 0.05 \\
\hline Ho & $4,840.89$ & 0.14 & 15.10 & 0.00 & 648.16 & 0.12 & 0.01 \\
\hline Er & $12,794.07$ & 0.36 & 71.47 & 0.00 & $1,746.58$ & 0.33 & 0.03 \\
\hline Tm & $1,677.06$ & 0.05 & 14.55 & 0.00 & 219.42 & 0.04 & 0.01 \\
\hline $\mathrm{Yb}$ & $9,270.63$ & 0.26 & 104.95 & 0.00 & $1,249.35$ & 0.24 & 0.02 \\
\hline Lu & $1,307.32$ & 0.04 & 19.53 & 0.00 & 170.32 & 0.03 & 0.00 \\
\hline TREE & $404,495.90$ & 11.46 & $1,127.60$ & 0.05 & $58,353.83$ & 11.10 & 0.30 \\
\hline Actinides & $(\mu \mathrm{g} / \mathrm{L})$ & (g) & $(\mu \mathrm{g} / \mathrm{L})$ & (g) & $(\mathrm{mg} / \mathrm{kg})$ & (g) & $(g)$ \\
\hline Th & 9.52 & 0.00 & 5.52 & 0.00 & 0.72 & 0.00 & $(0.00)$ \\
\hline $\mathbf{U}$ & 170.48 & 0.00 & 143.54 & 0.01 & 0.75 & 0.00 & $(0.00)$ \\
\hline
\end{tabular}

The washing procedure consisted of multiple washing cycles. The REO product was agitated in 1 liter of deionized water for thirty minutes, following decanting and filtration. This procedure was repeated until the conductivity of the supernatant was below 50 micro-Siemens per centimeter. In all, ten washing cycles were required to achieve the desired conductivity 
of the wash water. At the end of the washing cycles, a sample of the REO product indicated that only a small portion of the gangue material $\mathrm{Ca}(2 \mathrm{~g})$ and $\mathrm{Cl}(0.7 \mathrm{~g})$ were removed. As a result, a more intense washing procedure was implemented, where the $\mathrm{pH}$ of the wash water was lowered to a $\mathrm{pH}$ of 3.5 to remove the remaining Ca.

Next, the REO product was subjected to an acid wash. This was conducted by placing the REO product in $1 \mathrm{~L}$ of deionized water and the $\mathrm{pH}$ was lowered using $3 \mathrm{M}$ nitric acid until a $\mathrm{pH}$ value of 3.5 was obtained. During this procedure, a notable effervesce occurred as the $\mathrm{pH}$ approached a value of 3.5. After washing and drying of the residual solid material, a noticeable loss of mass was observed as the sample was reduced from 68.g grams to 13.8 grams. ICP_MS analysis confirmed the majority of the Ca was removed.

Finally, Figure 5.17 shows the resulting rare earth oxide product produced by the ALSX plant. The material consisted of a fine powder, that was slightly gray in color. Above all, this material demonstrated that a concentrated REO product was obtained from acid mine drainage precipitates.

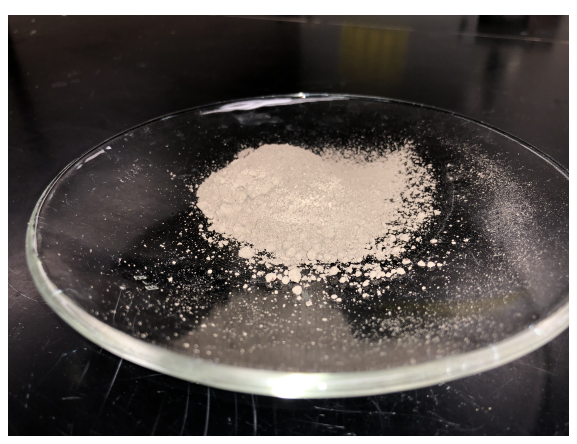

Figure 5.17 - MREO product with $61.8 \%$ grade

\subsection{Solid Waste Stream Characterization}

As with any mining process, waste material is generated from the beneficiation of ores. With respect to REE processing, the generation of harmful waste streams is of particular concern. For example, two of the operating mines outside of China: Mount Weld, Western Australia and Mountain Pass, CA have both experienced difficulties by generating radioactive tailings in the processing of the Monazite and Bastnasite ores (Castor 2008; Haque et al. 2014). While 
Table 5.6 - Assay of precipitation cleaning process

\begin{tabular}{|c|c|c|c|c|c|c|c|}
\hline Analyte & $\begin{array}{r}\text { Calcined } \\
\text { Product } \\
\text { Assay }\end{array}$ & $\begin{array}{r}\text { Calcined } \\
\text { Product } \\
\text { Mass }\end{array}$ & $\begin{array}{r}\text { Washed } \\
\text { Product } \\
\text { Assay }\end{array}$ & $\begin{array}{r}\text { Washed } \\
\text { Product } \\
\text { Mass }\end{array}$ & $\begin{array}{r}\text { Acid-Wash } \\
\text { Product } \\
\text { Assay }\end{array}$ & $\begin{array}{r}\text { Acid-Wash } \\
\text { Product } \\
\text { Mass }\end{array}$ & $\begin{array}{r}\text { Acid-Wash } \\
\text { Oxide } \\
\text { Basis }\end{array}$ \\
\hline Mass (g) & 94.36 & - & 68.5 & - & 13.8 & - & - \\
\hline Major Ions & $(\mathrm{mg} / \mathrm{kg})$ & (g) & $(\mathrm{mg} / \mathrm{kg})$ & (g) & $(\mathrm{mg} / \mathrm{kg})$ & (g) & $(\mathrm{mg} / \mathrm{kg})$ \\
\hline $\mathrm{Al}$ & 2,720 & 0.26 & 2,957 & 0.20 & 12,216 & 0.17 & 19,456 \\
\hline $\mathbf{C a}$ & 222,201 & 20.97 & 277,119 & 18.98 & 76,540 & 1.06 & 91,848 \\
\hline Co & 1 & 0.00 & 2 & 0.00 & 3 & 0.00 & 3 \\
\hline $\mathrm{Fe}$ & 116 & 0.01 & 74 & 0.01 & 748 & 0.01 & 961 \\
\hline $\mathrm{Mg}$ & 232 & 0.02 & 74 & 0.01 & 85 & 0.00 & 113 \\
\hline Mn & 2,433 & 0.23 & 2,734 & 0.19 & 13,947 & 0.19 & 15,975 \\
\hline $\mathrm{Si}$ & 735 & 0.07 & 269 & 0.02 & 673 & 0.01 & 865 \\
\hline $\mathrm{SO} 4$ & 188 & 0.02 & 4 & 0.00 & 183 & 0.00 & 183 \\
\hline $\mathrm{Cl}$ & 7,521 & 0.71 & 4 & 0.00 & 20 & 0.00 & 20 \\
\hline TMM & 228,625 & 21.57 & 283,233 & 19.40 & 104,394 & 1.44 & 129,405 \\
\hline REEs & $(\mathrm{mg} / \mathrm{kg})$ & (g) & $(\mathrm{mg} / \mathrm{kg})$ & (g) & $(\mathrm{mg} / \mathrm{kg})$ & (g) & $(\mathrm{mg} / \mathrm{kg})$ \\
\hline Sc & - & - & - & - & - & - & - \\
\hline $\mathbf{Y}$ & 37,128 & 3.50 & 41,428 & 2.84 & 173,858 & 2.40 & 198,805 \\
\hline La & 5,712 & 0.54 & 6,652 & 0.46 & 24,773 & 0.34 & 29,053 \\
\hline $\mathrm{Ce}$ & 17,251 & 1.63 & 18,798 & 1.29 & 95,650 & 1.32 & 117,494 \\
\hline $\operatorname{Pr}$ & 2,916 & 0.28 & 3,442 & 0.24 & 14,606 & 0.20 & 17,646 \\
\hline Nd & 15,021 & 1.42 & 17,749 & 1.22 & 74,811 & 1.03 & 87,259 \\
\hline $\mathrm{Sm}$ & 5,041 & 0.48 & 5,805 & 0.40 & 25,532 & 0.35 & 29,607 \\
\hline $\mathbf{E u}$ & 1,293 & 0.12 & 1,562 & 0.11 & 6,595 & 0.09 & 7,637 \\
\hline Gd & 7,416 & 0.70 & 9,094 & 0.62 & 36,883 & 0.51 & 42,512 \\
\hline $\mathrm{Tb}$ & 1,149 & 0.11 & 1,429 & 0.10 & 6,019 & 0.08 & 7,079 \\
\hline Dy & 6,546 & 0.62 & 8,035 & 0.55 & 33,201 & 0.46 & 38,104 \\
\hline Ho & 1,218 & 0.11 & 1,559 & 0.11 & 6,099 & 0.08 & 6,986 \\
\hline $\mathbf{E r}$ & 3,254 & 0.31 & 4,064 & 0.28 & 16,236 & 0.22 & 18,566 \\
\hline Tm & 412 & 0.04 & 539 & 0.04 & 2,153 & 0.03 & 2,458 \\
\hline $\mathrm{Yb}$ & 2,301 & 0.22 & 2,890 & 0.20 & 11,867 & 0.16 & 13,512 \\
\hline $\mathbf{L u}$ & 317 & 0.03 & 410 & 0.03 & 1,652 & 0.02 & 1,879 \\
\hline TREE & 106,975 & 10.09 & 123,455 & 8.46 & 529,933 & 7.31 & 618,598 \\
\hline Grade & $11 \%$ & & $12 \%$ & & $53 \%$ & & $62 \%$ \\
\hline Actinides & $(\mathrm{mg} / \mathrm{kg})$ & (g) & $(\mathrm{mg} / \mathrm{kg})$ & (g) & $(\mathrm{mg} / \mathrm{kg})$ & (g) & $(\mathrm{mg} / \mathrm{kg})$ \\
\hline Th & 8 & 0.00 & 8 & 0.00 & 53 & 0.00 & 57 \\
\hline $\mathbf{U}$ & 6 & 0.00 & 6 & 0.00 & 40 & 0.00 & 44 \\
\hline
\end{tabular}

the tables above show that the actinides Th and $\mathrm{U}$ remain near near crustal concentrations indicating this process does not concentrate these detrimental byproducts, additional testing was required to determine if the solid waste of the process was suitable for reintroduction into a typical AMD processing plant (Wedepohl 1995). 
To assess and identify waste disposal options for the leach residue/acidified AMDp, solid leaching residue samples were submitted for EPA 1311 TCLP analysis to determine the leachability of toxic metals/organic compounds in solid residuals(USEPA 2001). The results of this testing series are shown in Table 5.7. Nearly all of the tested parameters resulted in non-detectable (ND) limits. The two parameters that were above detectable limits were Barium and Lead. While detected, they do not exceed the criteria that would classify these materials as hazardous wastes under Resource Conservation and Revocery Act Subtitle C. In fact, they fall below the maximum allowable concentration by at least two orders of magnitude. As a result, this material is suitable for reintroduction to existing AMD storage facilities.the proposed disposal route in a commercial system will be to re-introduce the solids into the AMD treatment system's lime mixing tank to neutralize the material prior to disposal per current AMDp handling protocols at the treatment facility. 
Table 5.7 - TCLP testing on AMDp filter cake after leaching.

Results of Filter Cake TCLP Testing

Parameter
Arsenic
Barium
Cadmium
Chromium
Lead
Selenium
Silver
Mercury
Chlordane (Technical)
Endrin
Heptachlor
Heptachlor epoxide
Methoxychlor
Toxaphene
gamma-BHC (Lindane)
1,1-Dichloroethene
1,2-Dichloroethane
2-Butanone (MEK)
Benzene
Carbon tetrachloride
Chlorobenzene
Chloroform
Tetrachloroethene
Trichloroethene
Vinyl chloride
1,4-Dichlorobenzene
2,4,5-Trichlorophenol
2,4,6-Trichlorophenol
2,4-Dinitrotoluene
2-Methylphenol(o-Cresol)
3\&4-Methylphenol(m\&p Cresol)
Hexachloro-1,3-butadiene
Hexachlorobenzene
Hexachloroethane
Nitrobenzene
Pentachlorophenol
Pyridine

$\mathrm{PQL}=$ Practical Quantitation Limit

$\begin{array}{lrc} & & \text { Organic / } \\ \text { Units } & \text { PQL } & \text { Inorganic } \\ \mathrm{mg} / \mathrm{L} & 0.03 & \mathrm{I} \\ \mathrm{mg} / \mathrm{L} & 0.05 & \mathrm{I} \\ \mathrm{mg} / \mathrm{L} & 0.02 & \mathrm{I} \\ \mathrm{mg} / \mathrm{L} & 0.03 & \mathrm{I} \\ \mathrm{mg} / \mathrm{L} & 0.03 & \mathrm{I} \\ \mathrm{mg} / \mathrm{L} & 0.04 & \mathrm{I} \\ \mathrm{mg} / \mathrm{L} & 0.03 & \mathrm{I} \\ \mu \mathrm{g} / \mathrm{L} & 1.00 & \mathrm{I} \\ \mu \mathrm{g} / \mathrm{L} & 1.00 & \mathrm{O} \\ \mu \mathrm{g} / \mathrm{L} & 0.20 & \mathrm{O} \\ \mu \mathrm{g} / \mathrm{L} & 0.10 & \mathrm{O} \\ \mu \mathrm{g} / \mathrm{L} & 0.10 & \mathrm{O} \\ \mu \mathrm{g} / \mathrm{L} & 1.00 & \mathrm{O} \\ \mu \mathrm{g} / \mathrm{L} & 2.00 & \mathrm{O} \\ \mu \mathrm{g} / \mathrm{L} & 0.10 & \mathrm{O} \\ \mu \mathrm{g} / \mathrm{L} & 50.00 & \mathrm{O} \\ \mu \mathrm{g} / \mathrm{L} & 50.00 & \mathrm{O} \\ \mu \mathrm{g} / \mathrm{L} & 100.00 & \mathrm{O} \\ \mu \mathrm{g} / \mathrm{L} & 50.00 & \mathrm{O} \\ \mu \mathrm{g} / \mathrm{L} & 50.00 & \mathrm{O} \\ \mu \mathrm{g} / \mathrm{L} & 50.00 & \mathrm{O} \\ \mu \mathrm{g} / \mathrm{L} & 50.00 & \mathrm{O} \\ \mu \mathrm{g} / \mathrm{L} & 50.00 & \mathrm{O} \\ \mu \mathrm{g} / \mathrm{L} & 50.00 & \mathrm{O} \\ \mu \mathrm{g} / \mathrm{L} & 50.00 & \mathrm{O} \\ \mu \mathrm{g} / \mathrm{L} & 500.00 & \mathrm{O} \\ \mu \mathrm{g} / \mathrm{L} & 5,000.00 & \mathrm{O} \\ \mu \mathrm{g} / \mathrm{L} & 100.00 & \mathrm{O} \\ \mu \mathrm{g} / \mathrm{L} & 100.00 & \mathrm{O} \\ \mu \mathrm{g} / \mathrm{L} & 2,000.00 & \mathrm{O} \\ \mu \mathrm{g} / \mathrm{L} & 2,000.00 & \mathrm{O} \\ \mu \mathrm{g} / \mathrm{L} & 100.00 & \mathrm{O} \\ \mu \mathrm{g} / \mathrm{L} & 100.00 & \mathrm{O} \\ \mu \mathrm{g} / \mathrm{L} & 200.00 & \mathrm{O} \\ \mu \mathrm{g} / \mathrm{L} & 100.00 & \mathrm{O} \\ \mu \mathrm{g} / \mathrm{L} & 5,000.00 & \mathrm{O} \\ \mu \mathrm{g} / \mathrm{L} & 250.00 & \mathrm{O} \\ \mathrm{g} & & \end{array}$

Ome

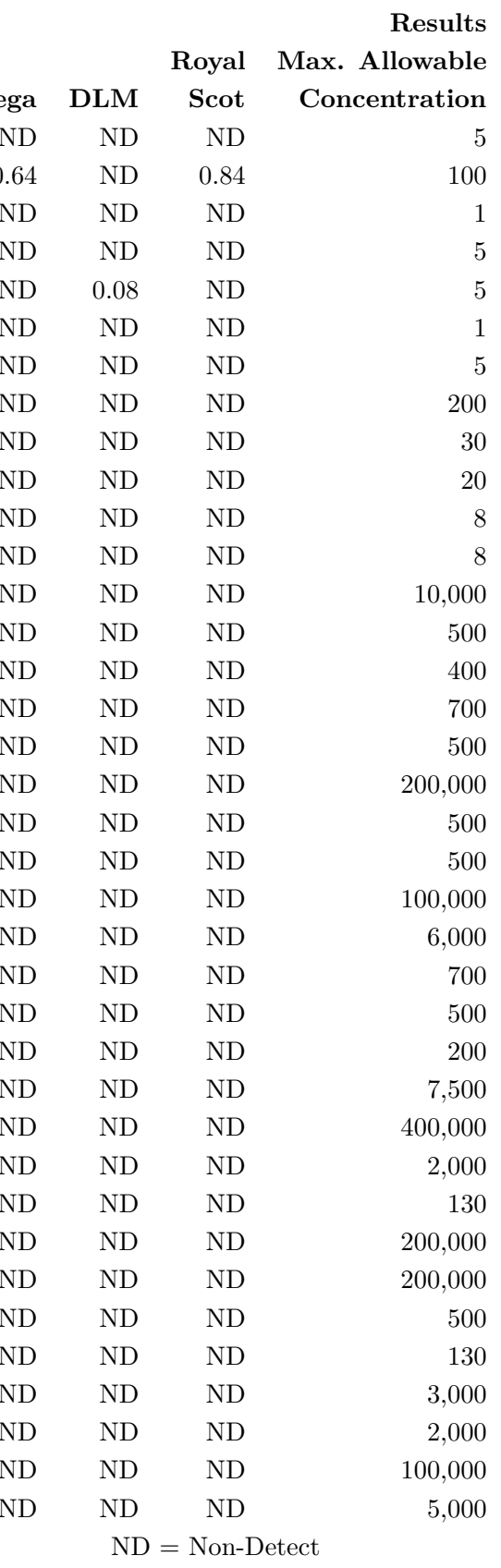


testing, multiple operational impediments were identified that resulted in modification to the designed processing flowsheet.

After shake-down testing, the bench-scale plant was operated for 58 hours to demonstrate the feasibility of producing a concentrated REO product from AMD. As a result of this research, $207 \mathrm{~kg}$ of as-received AMDp was processed utilizing a hydrometallurgical route to generate 13.8 grams of REEs with a grade of $61.8 \%$. This represents the first successful use of an AMDp byproduct to create a concentrated rare earth oxide product.

Additionally, the solid waste stream of the ALSX plant was characterized to identify if any hazardous material were generates as byproducts of this processing route. Results from TCLP testing indicated that the solid waste byproduct did nor result in either radioactive or hazardous material. As a result, the residual material generated in this process was determined to be environmentally benign and could be returned to mine sites for disposal, much like traditional AMD byproducts. 


\section{Chapter 6}

\section{Summary and Conclusions}

\subsection{Summary}

Over the last thirty years, REEs have become increasingly important for manufactured goods utilized on a daily basis. Not only are these elements used in common civilian applications, they are also essential for the production of military products including guidance systems, laser targeting, and detection systems like sonar and radar. Given the increased importance of these materials, the need to develop a domestic supply is essential to prevent the manipulation of REE prices by the predominant exporter, China. The near monopoly on REE production allows China to significantly alter the supply-chain of REEs through regulation. This was seen in the drastically increased prices of REEs in the 2010 to 2011 time-frame when some REE prices increased by up to an order of magnitude. Prevailing reasons for this volatility is attributed to increased demand from the high technology industrial sector coupled with a reduced Chinese export quota, which resulted in a profound disturbance to the end users of REEs.

Furthermore, not only does China control the export of the REEs, they are also becoming one of the largest consumers of REEs. This vertical integration has the capacity to further introduce disorder into the REE supply chain. Due to this potential volatility, many countries have considered bringing REE mines online to help alleviate the monopolistic control of the 
REE market. As such, it is important that the United States once again take a significant role in the research, development, and production of these critical elements.

In reaction to these supply chain vulnerabilities, the United States Department of Energy conducted a criticality assessment of the REEs. The result of which indicated that five of the REEs were critical and many of the others were near critical to existing technologies. Subsequently, other governmental agencies have also identified these elements as critical including the British Geological Survey and the European Commission indicating the need to diversify producers to prevent further supply disruptions.

In evaluating domestic resources of REEs, one novel source of these elements was identified in AMD precipitates. While acid mine drainage may be considered one of the most prevalent water quality issues in the Appalachian region, a beneficial use for AMD and its byproducts may exist; thereby, allowing for the generation of revenue through the beneficiation of REEs from AMD byproducts. Many positive impacts for the coal industry, the environment, and the state regulatory agencies are possible if an additional revenue stream realized through REE production. First, any additional revenue generated from the processing of REEs could supplement or mitigate treatment costs currently incurred by those responsible for the AMD. Second, the necessity of REEs and potential for revenue generation could motivate parties to seek out and treat legacy AMD outflows that are currently untreated. Finally, identifying a profitable extractive technology will provide mine operators with an additional incentive to ensure full environmental compliance at their AMD outfalls.

Given the aforementioned status, this research has identified and characterized the occurrence of REEs in AMD and its byproducts generated by coal mining in the NAPP and CAPP basins. This was accomplished through several extensive sampling programs that encompassed over 140 AMD treatment sites across four states. It was shown that REEs are concentrated in AMD influent by an autogenous leaching process. Additionally, the treated effluent was typically lacking significant REE concentrations. This discovery indicated that once treated through $\mathrm{pH}$ adjustment, the dissolved metal ions in AMD fall out of solution and the residual precipitate contains elevated concentrations of REEs. On average, this treat- 
ment process enriched REEs in the precipitates by a factor of 2000 times when compared to the aqueous influent.

Furthermore, this research has shown REE concentrations are greater in mines with netacidic flows, while flooded underground mines with a net-alkaline chemistry do not possess the same potential for REE concentration. In other words, low $\mathrm{pH}$ mine water is more inclined to contain higher concentration of REEs. Given these findings, a regional flow-rate estimate was conducted to quantify the yearly production of REEs from AMD discharges. Moreover, the regional sampling program provided the necessary data to assess the quantity of REEs stored in AMDp drying cells at the treatment sites. This data showed the distribution of REEs between the CAPP and NAPP basins was similar and an inventory of the TREEs was calculated from the data. Using this inventory, a grade-tonnage curve was applied to the resource, which showed that a relatively small amount of sludge contains the vast majority of REEs within the sampled sites. As such, this indicated treatment methods used at AMD sites have a profound impact on the concentration of REEs in the AMDp.

After characterizing the resource, a flowsheet was developed to establish a processing route capable of extracting REEs from the AMDp using acid leaching and solvent extraction. Multiple laboratory-scale experiments were conducted on the AMDp to identify the specifications required to extract REEs from AMDp. These tests provided the pertinent information to identify the quantity and size of processing equipment required as well as the reagents needed to preform REE separations. Utilizing results from laboratory testing, a bench-scale system was constructed that was capable of generating several grams per hour of a minimum $2 \%$ mixed rare earth oxide product.

After construction, multiple shake-down tests identified operation impediments that were not previously observed in the reduced-scale testing. Modifications to the process were implemented based on results from preliminary testing to overcome the identified process deficiencies. After modification, the bench-scale plant was operated for 58 hours. During that time, $207 \mathrm{~kg}$ of AMDp was refined into 13.8 grams of a $61.8 \%$ mixed rare earth oxide. This result demonstrated the first successful use of AMDp to generate a concentrated rare earth oxide product. 


\subsection{Conclusions}

The following key findings were developed during this research:

- AMD in the CAPP and NAPP coal basins constitutes an autogenous process that liberates REEs from the surrounding geologic strata.

- The concentration of REEs in AMD influent is consistently greater in net-acidic AMD flows with a pH less than 4, while net-alkaline flooded underground mines contained notably reduced concentrations.

- Traditional AMD treatment significantly concentrates REEs in the AMD precipitate by over 2000 times on average.

- Regional flow rate estimates indicate that between 771 and 3400 tonnes of REEs are produced from AMD per year.

- AMDp contains a significantly favorable distribution of REEs when compared to conventional REE deposits.

- Using a strict hydrometallurgical processing route, a concentrated MREO product exceeding $60 \%$ purity was produced from AMDp.

\subsection{Future Work}

While this research demonstrated the feasibility of recovering REEs from AMD, further work is required to significantly advance this technology. The following list details additional work required to develop the technology to an industrial scale.

- Further research is required to demonstrate the potential AMDp holds as a REE reserve. Future studies should expand the geographic area to include other coal basins and include AMD generated by metal/nonmetal sources. 
- Alternative AMD treatment processes should be evaluated to maximize recovery of REEs in the AMD precipitates, while promoting strict environmental compliance.

- Supplementary scale-up work is required to bring the TRL of this technology to a status that supports implementing the processing route at an industrial scale.

- In order for this technology to succeed at an industrial scale, additional research is needed to define a robust downstream processing route for the conversion of rare earth oxides to pure metals. 


\section{Bibliography}

Abreu, Renata D. and Carlos A. Morais (2010). "Purification of rare earth elements from monazite sulphuric acid leach liquor and the production of high-purity ceric oxide". In: Minerals Engineering 23.6, pp. 536-540. ISSN: 08926875. DOI: 10.1016/j .mineng. 2010. 03.010. URL: http://dx.doi.org/10.1016/j.mineng.2010.03.010.

Agency, U. S. Environmental Protection (2000). "Abandoned mine site characterization and cleanup handbook (EPA 910-B-00-001)”. In: August, p. 408.

Akcil, Ata and Soner Koldas (2006). "Acid Mine Drainage (AMD): causes, treatment and case studies". In: Journal of Cleaner Production 14.12-13 SPEC. ISS. Pp. 1139-1145. ISSN: 09596526. DOI: 10.1016/j · jclepro. 2004.09.006. URL: http://linkinghub.elsevier. com/retrieve/pii/S0959652605000600.

Ali, Saleem (2014). "Social and Environmental Impact of the Rare Earth Industries". In: Resources 3.1, pp. 123-134. ISSN: 2079-9276. DOI: 10 . 3390 / resources3010123. URL: http://www . mdpi . com/2079-9276/3/1/123/.

Alonso, Elisa et al. (2012). "Evaluating rare earth element availability: A case with revolutionary demand from clean technologies". In: Environmental Science and Technology 46.6, pp. 3406-3414. ISSN: 0013936X. DOI: 10.1021/es203518d.

Antico, E. et al. (1996). "Solvent extraction of yttrium from chloride media by di(2-ethylhexyl) phosphoric acid in kerosene. Speciation studies and gel formation". In: Analytica Chimica Acta 327.3, pp. 267-276. ISSN: 00032670. DOI: 10 . 1016/0003-2670(96) 00103-1. URL: http : / / www . scopus . com / inward / record . url ? eid=2-s2 . 0-0030578380\{ \& \}partnerID=tZOtx3y 1 . 
Banda, Raju, Ho Seok Jeon, and Man Seung Lee (2012). "Solvent extraction separation of la from chloride solution containing Pr and Nd with Cyanex 272". In: Hydrometallurgy 121-124, pp. 74-80. ISSN: 0304386X. DOI: 10 .1016/j . hydromet . 2012.04 . 003. URL: http://dx.doi.org/10.1016/j.hydromet.2012.04.003.

Belzile, Elzear, Robert Marchand, and Ahmed Bouajila (2015). NI 43-101 Technical Report Montviel Rare Earth Project. Tech. rep. Saint-Lambert, Quebec: GeoMegA Resources, p. 186.

Binnemans, Koen et al. (2018). "Rare Earths and the Balance Problem: How to Deal with Changing Markets?" In: Journal of Sustainable Metallurgy 8, pp. 126-146. ISSN: 21993823. DOI: 10.1007/s40831-018-0162-8. URL: http://link. springer. com/10 .1007/ s40831-018-0162-8.

Birk, D. and J. C. White (1990). "Trace elements in bituminous coals, roof clays, and underclays of the Sydney Basin, Nova Scotia: ash chemistry, element sites, and mineralogy". In: Geological Society of Canada Special Publication, pp. 257-281.

Birk, Dieter and Judy C. White (1991). "Rare earth elements in bituminous coals and underclays of the Sydney Basin, Nova Scotia: Element sites, distribution, mineralogy". In: International Journal of Coal Geology 19.1-4, pp. 219-251. ISSN: 01665162. DOI: 10.1016/01665162 (91) 90022-B.

Bourricaudy, Ernesto et al. (2016). "Commissioning of a Mini SX Pilot Plant at SGS Minerals - Lakefield Site". In: IMPC 2016: XXVIII International Mineral Processing Congress Proceedings. Quebec, pp. 1-16. ISBN: 9781926872292.

Campbell, G. A. (2014). "Rare earth metals: a strategic concern". In: Mineral Economics 27.1, pp. 21-31. ISSN: 21912211. DOI: 10.1007/s13563-014-0043-y.

Capo, Rosemary C et al. (2001). "Hydrogeologic and geochemical evolution of deep mine discharges, Irwin Syncline, Pennsylvania". In: Proceedings - West Virginia Surface Mine Drainage Task Force Symposium. Vol. 22. January, pp. 144-153.

Castor, Stephen B. (2008). "The Mountain Pass rare-earth carbonatite and associated ultrapotassic rocks, California". In: Canadian Mineralogist 46.4, pp. 779-806. ISSN: 00084476. DOI: $10.3749 /$ canmin.46.4.779. 
Cheney, Marcos A and James H Swinehart (1998). "Strategies for Separating Metals from Acid Mine Waters". In: Journal of the American Water Resources Association 34.5, pp. 10511059.

Chi, R and Z Xu (1999). "A Solution Chemistry Approach to the Study of Rare Earth Element Precipitation by Oxalic Acid". In: Metallurgical and Materials Transactions B 30B.April, pp. 189-195.

Chiarizia, Renato and Alexandra Briand (2007). "Third phase formation in the extraction of inorganic acids by TBP in n-Octane". In: Solvent Extraction and Ion Exchange 25.3, pp. 351-371. ISSN: 07366299. DOI: 10.1080/07366290701285397.

Cox, Jason J et al. (2010). TECHNICAL REPORT ON THE THOR LAKE PROJECT. Tech. rep. Toronto, ON: Avalon Rare Metals Inc., p. 313.

Cravotta, Charles A. (2008a). "Dissolved metals and associated constituents in abandoned coal-mine discharges, Pennsylvania, USA. Part 2: Geochemical controls on constituent concentrations". In: Applied Geochemistry 23.2, pp. 203-226. ISSN: 08832927. DOI: 10 . 1016/j . apgeochem. 2007 .10.003. URL: http://dx.doi .org/10.1016/j .apgeochem . 2007.10 .011$.

- (2008b). "Dissolved metals and associated constituents in abandoned coal mine discharges, Pennsylvania, USA; Part 1, Constituent quantities and correlations". In: Applied Geochemistry 23.2, pp. 166-202. ISSN: 0883-2927. DOI: 10.1016/j .apgeochem.2007.10.011. URL: http://dx.doi.org/10.1016/j.apgeochem.2007.10.011.

Dhalberg, Peter S. et al. (2014). Bear Lodge Project Canadian NI 43-101 On the Reserves and Development of the Bull Hill. Tech. rep. Sandy, UT: Rare Element Resources, Ltd, p. 514.

Eskenazy, Greta M. (1987). "Rare earth elements in a sampled coal from the Pirin deposit, Bulgaria”. In: International Journal of Coal Geology 7.3, pp. 301-314. ISSN: 01665162. DOI: $10.1016 / 0166-5162(87) 90041-3$.

Fernandez, Viviana (2017). "Rare-earth elements market: A historical and financial perspective". In: Resources Policy 53.March, pp. 26-45. ISSN: 03014207. DOI: 10 .1016/j . resourpol. 2017.05.010. 
Finkelman, Robert B. (1980). "Modes of occurrence of trace elements in coal". PhD thesis. University of Maryland. ISBN: 81-99. DOI: 10.1016/S0166-5162(00)00043-4.

Finkelman, Robert B. and Ronald W. Stanton (1978). "Identification and significance of accessory minerals from a bituminous coal". In: Fuel 57.12, pp. 763-768. ISSN: 00162361. DOI: $10.1016 / 0016-2361(78) 90135-7$.

Gaba, Jeffery M. (2007). "Generally Illegal: NPDES General Permits under the Clean Water Act". In: Harvard Environmental Law 31.2, pp. 409 -473. ISSN: 02729490. DOI: 10.3868/ s050-004-015-0003-8. arXiv: arXiv:1011.1669v3. URL: https://heinonline .org/ HOL /Page? collection=journals $\{\backslash \&\}$ handle=hein $\cdot$ journals $/$ helr $31\{\backslash \&\} i d=413\{\backslash \&$ \} $\operatorname{men}\left\{\backslash_{-}\right\}$tab $=$srchresults.

Galvez, Edelmira D. et al. (2004). "Design of solvent extraction circuit schemes". In: Hydrometallurgy 74.1-2, pp. 19-38. ISSN: 0304386X. DOI: 10.1016/j .hydromet.2003.10. 005.

Gazea, B., K. Adam, and a. Kontopoulos (1996). "A review of passive systems for the treatment of acid mine drainage". In: Minerals Engineering 9.1, pp. 23-42. ISSN: 08926875. DOI: $10.1016 / 0892-6875(95) 00129-8$.

Gergoric, Marino et al. (2017). "Separation of Heavy Rare-Earth Elements from Light RareEarth Elements Via Solvent Extraction from a Neodymium Magnet Leachate and the Effects of Diluents". In: Journal of Sustainable Metallurgy 3.3, pp. 601-610. ISSN: 21993823. DOI: $10.1007 /$ s40831-017-0117-5. URL: http://link. springer . com/10 .1007/ s40831-017-0117-5.

Goldschmidt, V. M. (1935). "Rare Elements in Coal Ashes". In: Industrial and Engineering Chemistry 27.9, pp. 1100-1102. ISSN: 00197866. DOI: 10.1021/ie50309a032.

Goodenough, Kathryn M., Frances Wall, and David Merriman (2017). "The Rare Earth Elements: Demand, Global Resources, and Challenges for Resourcing Future Generations". In: Natural Resources Research, pp. 1-16. ISSN: 15738981. DOI: 10.1007/s11053-0179336-5.

Grasso, Valerie Bailey (2013). "Rare Earth Elements in National Defense: Background, Oversight Issues, and Options for Congress". In: Congressional Research Service (CRS) Report for Congress, p. 43. URL: http://fas.org/sgp/crs/natsec/R41744.pdf. 
Haque, Nawshad et al. (2014). "Rare Earth Elements: Overview of Mining, Mineralogy, Uses, Sustainability and Environmental Impact". In: Resources 3.4, pp. 614-635. ISSN: 2079-9276. DOI: 10 . 3390 / resources3040614. URL: http : / / www . mdpi . com / 2079$9276 / 3 / 4 / 614 /$.

Haskin, Larry A. et al. (1966). "Meteoritic, solar and terrestrial rare-earth distributions". In: Physics and Chemistry of the Earth 7.C, pp. 167-321. ISSN: 00791946. DOI: 10.1016/00791946 (66) 90004-8. arXiv: arXiv: 1011.1669v3.

Hedin, R. S. (2002). "Recovery of Marketable Iron Oxide From Mine Drainage". In: Journal American Society of Mining and Reclamation 2002.1, pp. 517-526. ISSN: 23288744. DOI: 10 . 21000/JASMR02010517. URL: http: //www . asmr . us /Portals / / Documents / Conference-Proceedings/2002/0517-Hedin.pdf.

Hill, David W. (1969). "Neutralization of Acid Mine Drainage". In: Water Pollution Control Federation 41.10, pp. 1702-1715. ISSN: 0043-1303. URL: http://www. jstor.org/stable/ $25039128\{\backslash \%\}$ Cnhttp://www . jstor.org/stable/pdfplus/25039128.pdf?acceptTC= true.

Hoehn, Robert C and Dallas R Sizemore (1977). "Acid mine drainage (AMD) and its impact on a Virginia stream". In: Water Resources Bulletin 13.1, pp. 153-160. ISSN: 0043-1370. DOI: $10.1111 / j .1752-1688.1977 . t b 02000 . x$.

Honaker, Rick Q. et al. (2017). "Process evaluation and flowsheet development for the recovery of rare earth elements from coal and associated byproducts". In: Minerals $\mathfrak{E}^{3}$ Metallurgical Processing 34.3, pp. 107-115. ISSN: 07479182. DOI: 10 .19150/mmp.7610. URL: http://mmp. smenet. org/abstract. cfm?articleID=7610\{\\&\}page=107.

Huang, Qingqing (2019). "Unpublished Research Characterizing the Formation of Third Phase Emulsions in Solvent Extraction". In:

Huang, Qingqing et al. (2019). "Characterization study of rare earths, yttrium, and scandium from various Colombian coal samples and non-coal lithologies". In: International Journal of Coal Geology 209.April, pp. 14-26. ISSN: 01665162. DOI: 10.1016/j . coal .2019.04.008. URL: https://doi.org/10.1016/j.coal.2019.04.008. 
Huang, Xiao Wei et al. (2015). "Technology development for rare earth cleaner hydrometallurgy in China". In: Rare Metals 34.4, pp. 215-222. ISSN: 18677185. DOI: 10.1007/s12598015-0473-x.

Hulse, Donald E., M. Claiborne Newton, and Deepak Malhotra (2013). NI 43-101 Preliminary Economic Economic Assessment Round Top Project Blanca, Texas. Tech. rep. Texas Rare Earth Resources, p. 196. URL: http://trer.com/\{\_\}resources/reports/ Amended $\left\{\backslash_{-}\right\}$TRER $\left\{\backslash_{-}\right\}$NI43-101\{】_\}PEA $\left\{\backslash_{-}\right\}$FINAL\{\_\}28Apri12014.pdf.

Humphries, Marc (2012). Rare Earth Elements: The Global Supply Chain. Tech. rep. Congressional Research Service, pp. 1-27. URL: http://www.fas .org/sgp/crs/natsec/ R41347.pdf.

Huntsman, B E, J G Solch, and M D Porter (1978). "Utilization of Sphagnum species dominated bog for coal acid mine drainage abatement". In: Proc Geol Soc America, 91st Annual Meeting (Abstracts), Toronto, Ontario, Canada. Vol. 322.

Hurst, Cindy (2010). "China's Rare Earth Elements Industry: What Can the West Learn?" In: Institute for the Analysis of Global Security (IAGS) March, p. 43. URL: http://www . iags.org/rareearth0310hurst.pdf.

Jha, Manis Kumar et al. (2016). "Review on hydrometallurgical recovery of rare earth metals". In: Hydrometallurgy 165, pp. 2-26. ISSN: 0304386X. DOI: 10 . 1016/j . hydromet. 2016.01 .035 .

Jimenez, A. et al. (2009). "Model of behaviour of conductivity versus pH in acid mine drainage water, based on fuzzy logic and data mining techniques". In: Journal of Hydroinformatics 11.2002, p. 147. ISSN: 1464-7141. DOI: 10.2166/hydro.2009.015.

Johnson, D. Barrie and Kevin B. Hallberg (2003). "The microbiology of acidic mine waters". In: Research in Microbiology 154, pp. 466-473. ISSN: 09232508. DOI: 10 .1016/S0923$2508(03) 00114-1$.

Jones, A P, F Wall, and C T Williams (1996). Rare Earth Minerals: chemistry, origin, and ore deposits. Ed. by Chapman and Hall. 1st ed. London; New York: Springer Netherlands, p. 372. ISBN: 978-0-412-61030-1. 
Jordens, Adam, Ying Ping Cheng, and Kristian E. Waters (2013). "A review of the beneficiation of rare earth element bearing minerals". In: Minerals Engineering 41, pp. 97-114. ISSN: 08926875. DOI: 10.1016/j.mineng.2012.10.017.

Kalin, Margarete, Andrew Fyson, and William N. Wheeler (2006). "The chemistry of conventional and alternative treatment systems for the neutralization of acid mine drainage". In: Science of the Total Environment 366.2-3, pp. 395-408. ISSN: 00489697. DOI: 10.1016/ j.scitotenv.2005.11.015.

Kedari, C S et al. (2006). "Third Phase Formation in the Solvent Extraction System Ir (IV)Cyanex 923". In: 6299.Iv. DOI: 10.1081/SEI-200068505.

Kleinmann, Robert L P (2001). "Prediction of Water Quality at Surface Coal Mines". In: The National Mine Land Reclamation Center Located at West Virginia University in Morgantown, West Virginia 239, p. 247.

Koermer, Scott and Aaron Noble (2018). "Unpublished Solvent Extraction Research". PhD thesis. Virginia Polytechnic University.

Laudal, Daniel A et al. (2019). "Rare Earth Elements in North Dakota Lignite Coal and Lignite-Related Materials". In: 140.June 2018, pp. 1-9. DOI: 10.1115/1.4039738.

Li, Wei et al. (2007). "Extraction and separation of yttrium from the rare earths with secoctylphenoxy acetic acid in chloride media". In: Separation and Purification Technology 54.2, pp. 164-169. ISSN: 13835866. DOI: 10.1016/j . seppur.2006.08.029.

Ling, Zhi Li and Xiaosheng Yang (2014). "China's Rare Earth Ore Deposits and Beneficiation Techniques". In: 1st European Rare Earth Resources Conference, pp. 26-36.

Long, Keith R. et al. (2010). A Summary of Domestic Deposits and a Global Perspective. Tech. rep. January 2010. USGS, p. 96.

Mayfield, David B and Ari S Lewis (2013). "Environmental Review of Coal Ash as a Resource for Rare Earth and Strategic Elements". In: 2013 World of Coal Ash (WOCA) Conference, pp. 22-25. URL: https://www.researchgate.net/profile/David\{\_\}Mayfield2/

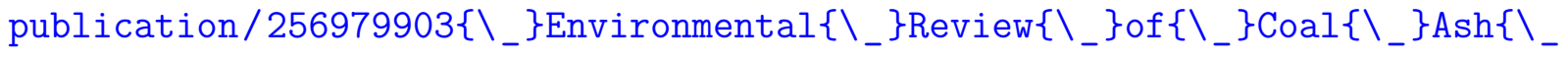
\} as $\left\{\backslash_{-}\right\}$a $\left\{\backslash_{-}\right\}$Resource $\left\{\backslash_{-}\right\}$for $\left\{\backslash_{-}\right\}$Rare $\left\{\backslash_{-}\right\} \operatorname{Earth}\left\{\backslash_{-}\right\}$and $\left\{\backslash_{-}\right\}$Strategic $\left\{\backslash_{-}\right\}$Elements/ links / 00b495241cad856612000000 / Environmental - Review - of - Coal - Ash - as - a Resource-for-Rare-Earth-an. 
Miranda, P. and L. B. Zinner (1997). "Separation of samarium and gadolinium solutions by solvent extraction". In: Journal of Alloys and Compounds 249.1 -2 pt 1, pp. 116-118. ISSN: 09258388. DOI: $10.1016 /$ S0925-8388(96)02754-5.

Moeller, Therald (1963). The Chemistry of Lanthanides. Ed. by Harry H. Sisler and Calvin A. VanderWerf. New York: Reinhold Publishing Corporation, p. 117.

Morais, C. A. and V. S T Ciminelli (2004). "Process development for the recovery of highgrade lanthanum by solvent extraction". In: Hydrometallurgy 73.3-4, pp. 237-244. ISSN: 0304386X. DOI: 10.1016/j.hydromet.2003.10.008.

Morgan, Jason et al. (2011). "Entrainment reduction at Freeport-McMoRan copper \& gold Morenci operations". In: Solvent Extraction and Ion Exchange 29.5-6, pp. 854-867. ISSN: 07366299. DOI: 10.1080/07366299.2011.595642.

Mulller, Maximilian A., Denis Schweizer, and Volker Seiler (2016). "Wealth Effects of Rare Earth Prices and China's Rare Earth Elements Policy". In: Journal of Business Ethics 138.4, pp. 627-648. ISSN: 15730697. DOI: 10.1007/s10551-015-2773-3.

Packey, Daniel J. and Dudley Kingsnorth (2016). "The impact of unregulated ionic clay rare earth mining in China". In: Resources Policy 48, pp. 112-116. ISSN: 03014207. DOI: 10. 1016/j.resourpol . 2016.03.003. URL: http://dx .doi .org/10.1016/j.resourpol . 2016.03 .003$.

Peelman, Sebastiaan et al. (2014). "Leaching of Rare Earth Elements : Past and Present". In: ERES2014: 1st European Rare Earth Resources Conference, pp. 446-456. ISSN: 09596526. DOI: $10.1016 / \mathrm{S} 1002-0721(17) 60971-2$.

Phadke, Roopali (2018). "Green energy futures: Responsible mining on Minnesota's Iron Range". In: Energy Research and Social Science 35.October 2017, pp. 163-173. ISSN: 22146296. DOI: 10 . 1016/ j .erss . 2017 . 10 . 036. URL: https : / / doi .org/10 . 1016 / j.erss. 2017.10.036.

Preston, J. S. et al. (1996). "The recovery of rare earth oxides from a phosphoric acid by-product. Part 1: Leaching of rare earth values and recovery of a mixed rare earth oxide by solvent extraction". In: Hydrometallurgy 41.1, pp. 1-19. ISSN: 0304386X. DOI: 10.1016/0304-386X (95) 00051-H. 
Ren, Panpan and Xingbo Liu (2019). "Unpublished Solvent Extraction Studies". PhD thesis. West Virginia University.

Ritcey, G.M. (1980). "Crud in solvent extraction processing - a review of causes and treatment". In: Hydrometallurgy 5.2-3, pp. 97-107. ISSN: 0304386X. DOI: 10 . $1016 / 0304-$ $386 \mathrm{X}(80) 90031-6$.

Ritcey, G.M. and A. W. Ashbrook (1979). Solvent Extraction Principles and Applications to Process Metallurgy Part II. Volume 2. Amsterdam: Elsevier Scientific Publishing, p. 737. ISBN: 0-444-41751-6.

- (1984). Solvent extraction Principles and Applications to Process Metallurgy Part I. Volume 1, Amsterdam; New York: Elsevier Scientific Pub. Co., p. 361. IsBN: 0444417512.

Sato, Satoshi et al. (2009). "Basic properties of rare earth oxides". In: Applied Catalysis A: General 356.1, pp. 57-63. ISSN: 0926860X. DOI: 10.1016/j.apcata.2008.12.019.

Saucier, Guy et al. (2013). Kipawa Project NI43101. Tech. rep. Quebec, Canada: Matamec Explorations Inc., p. 429.

Schatzel, Steven J. and Brian W. Stewart (2003). "Rare earth element sources and modification in the Lower Kittanning coal bed, Pennsylvania: Implications for the origin of coal mineral matter and rare earth element exposure in underground mines". In: International Journal of Coal Geology 54.3-4, pp. 223-251. ISSN: 01665162. DOI: 10.1016/S0166$5162(03) 00038-7$.

Schofield, Allan and Larry Haskin (1964). "Rare-earth distribution patterns in eight terrestrial materials". In: Geochimica et Cosmochimica Acta 28.4, pp. 437-446. ISSN: 00167037. DOI: $10.1016 / 0016-7037$ (64)90117-6.

Seredin, Vladimir V. and Shifeng Dai (2012). "Coal deposits as potential alternative sources for lanthanides and yttrium". In: International Journal of Coal Geology 94, pp. 67-93. ISSN: 01665162. DOI: 10 .1016/j . coal . 2011 .11 .001. URL: http://dx . doi .org/10 . 1016/j.coal.2011.11.001.

Seredin, V.V. (1996). "Rare earth element-bearing coals from the Russian Far East deposits". In: International Journal of Coal Geology 30.1-2, pp. 101-129. ISSN: 01665162. DOI: 10 . 1016/0166-5162(95) 00039-9. URL: http : / / linkinghub . elsevier . com/retrieve / pii/0166516295000399. 
Skousen, Jeff, Tiff Hilton, and Ben Faulkner (1997). "Overview of acid mine drainage treatment with chemicals". In: Agriculture $\&$ Natural Resources, p. 21. URL: http://anr .ext. wvu. edu/resources/295/1255980588.pdf.

Skousen, J.G. and P.F. Ziemkiewicz (1995). Acid Mine Drainage Control and Treatment. 41. Morgantown: West Virginia University, p. 255.

Sprecher, Benjamin et al. (2015). "Framework for resilience in material supply chains, with a case study from the 2010 rare earth crisis". In: Environmental Science and Technology 49.11, pp. 6740-6750. ISSN: 15205851. DOI: 10.1021/acs .est.5b00206.

Stewart, Brian W. et al. (2016). "Rare earth element resources in coal mine drainage and treatment precipitates in the Appalachian Basin, USA". In: International Journal of Coal Geology 169, pp. 28-39. ISSN: 01665162. DOI: 10 . 1016/ j . coal . 2016 . 11 . 002. URL: http://linkinghub. elsevier.com/retrieve/pii/S0166516216302592.

Swaine, D J (1964). "Scandium in Australian Coals and Related Materials". In: Am. Chem. Soc. Div. Fuel Chem. 8, pp. 172-177.

Takeno, Naoto (2005). Atlas of Eh-pH diagrams - Intercomparison of thermodynamic databases. Tech. rep. 419. Geological Survey of Japan, pp. 1-287. URL: http://scholar.google. com / scholar?hl=en $\{\backslash \&\}$ btnG $=$ Search $\{\backslash \&\} q=$ intitle : Atlas +of +Eh - pH + diagrams + Intercomparison+of+thermodynamic+databases $\{\backslash \#\} 0$.

Taylor, S R (1964). "Abundance of elements in the crust: A new table". In: Geochimica and Cosmochimica Acta 28, pp. 1273-1285. DOI: 10.1016/0016-7037(64)90129-2.

Total (2019). Elixore Aliphatic Diluents for metal extraction. Tech. rep. Total Special Fluids, p. 2 .

Tsakiridis, P. E. and S. Agatzini-Leonardou (2004). "Process for the recovery of cobalt and nickel in the presence of magnesium from sulphate solutions by Cyanex 272 and Cyanex 302". In: Minerals Engineering 17.7-8, pp. 913-923. ISSN: 08926875. DOI: $10.1016 / \mathrm{j}$. mineng. 2004.03 .010$.

U.S. Geological Survey (2017). Critical Mineral Resources of the United States Economic and Environmental Geology and Prospects for Future Supply. Tech. rep. U.S. Geological Survey, p. 797. DOI: 10 . 3133 /pp1802. URL: https : / / pubs . usgs . gov/pp/1802/r / pp1802r.pdfhttps://doi.org/10.3133/pp1802. 
U.S. Geological Survey (2018). Mineral Commodity Summaries 2018: U.S. Geological Survey. Tech. rep., p. 200. URL: https://doi.org/10.3133/70194932.

USEPA (1994). Technical Document: Acid Mine Drainage. Tech. rep. December. Washington DC: U.S. Environmental Protection Agency, p. 48.

- (2001). Toxicity Characteristic Leaching Procedure Method 1311. Tech. rep. July 1992. U. S. Environmental Protection Agency, pp. 1-35. URL: https : //www. epa . gov/sites / production/files/2015-12/documents/1311.pdf.

Van Gosen, Bradley, Philip L. Verplanck, and Poul Emsbo (2019). Rare Earth Element Mineral Deposits in the United States. Tech. rep. April. U. S. Geological Survey, p. 24.

Vass, Christopher (2016). "A Feasibility Study for the Automated Monitoring and Control of Mine Water Discharges". Masters Thesis. West Virginia University, pp. 1-111.

Verbaan, $\mathrm{N}$ et al. (2015). "A review of hydrometallurgical flowsheets considered in current REE projects". In: Symposium on Strategic and Critical Materials Proceedings. Ed. by G.J. Simandl and M. Neetz. Victoria, British Columbia, pp. 147-162.

Wang, Weiwei, Yoko Pranolo, and Chu Yong Cheng (2013). "Recovery of scandium from synthetic red mud leach solutions by solvent extraction with D2EHPA". In: Separation and Purification Technology 108, pp. 96-102. ISSN: 13835866. DOI: 10.1016/ j. seppur . 2013.02.001. URL: http://dx.doi.org/10.1016/j.seppur.2013.02.001.

Wang, Yan and Aaron Noble (2019). "Unpublished Acid Leaching Studies". In:

Wang, Yanliang et al. (2017). "Separation of high-purity yttrium from ion-absorbed rare earth concentrate using (2,6-dimethylheptyl) phenoxy acetic/propanoic acid". In: Separation and Purification Technology 184, pp. 280-287. ISSN: 13835866. DOI: $10.1016 / \mathrm{j}$. seppur . 2017 .04 .049. URL: http : / / linkinghub . elsevier . com/retrieve / pii / S1383586617301442.

Webster, Steve (2017). Solvent Extraction Pilot Plant Quotation No. 1727. Cobourg, ON.

- (2018). Laboratory Solvent Extration Pilot Pland Installation and Operation Manual. Cobourg, $\mathrm{ON}$.

Wedepohl, K Hans (1995). "INGERSON LECTURE The composition of the continental crust". In: Geochimica et Cosmochimica Acta 59.7, pp. 1217-1232. ISSN: 00167037. DOI: 
10.1016/0016-7037 (95)00038-2. URL: http://linkinghub.elsevier.com/retrieve/ pii/0016703795000382.

Wieder, R Kelman and Gerald E Lang (1982). "Modification of acid mine drainage in a freshwater wetland". In: Symposium on wetlands of the unglaciated Appalachian region. West Virginia University Press Morgantown, WV, pp. 43-53.

Wills, B. A. (2006). Wills' Mineral Processing Technology. Ed. by T. J. Napier-Munn. 7th. New York: Elsevier Scientific Pub. Co., p. 444. ISBN: 978-0-7506-4450-1.

Workman, Al, Kurt Breede, and John Goode (2013). Update Report on the Appia Energy Corp. Uranium Rare Earth Property, Elliot Lake District, North0Central Ontario, Canada. Tech. rep. Toronto, ON: Canada Enerco Corporation, p. 394.

Xiao, Yan Fei et al. (2015). "Leaching and mass transfer characteristics of elements from ion-adsorption type rare earth ore". In: Rare Metals 34.5, pp. 357-365. ISSN: 18677185. DOI: $10.1007 /$ s12598-015-0481-x. URL: http://dx . doi .org/10 .1007/s12598-0150481-x.

Xie, Feng et al. (2014). "A critical review on solvent extraction of rare earths from aqueous solutions". In: Minerals Engineering 56, pp. 10-28. ISSN: 08926875. DOI: 10 . 1016 / j . mineng. 2013.10.021. URL: http://dx.doi .org/10.1016/j.mineng. 2013.10.021.

Xing, Peng et al. (2018). "Separation of rubidium from potassium in rubidium ore liquor by solvent extraction with t-BAMBP". In: Minerals Engineering 121.December 2017, pp. 158163. ISSN: 08926875. DOI: 10.1016/j.mineng.2018.03.014. URL: https://doi .org/10. $1016 / j$.mineng . 2018.03.014.

Yang, X. Jin et al. (2013). "China's ion-adsorption rare earth resources, mining consequences and preservation". In: Environmental Development 8.1, pp. 131-136. ISSN: 22114645. DOI: 10.1016/j.envdev.2013.03.006. URL: http://dx.doi.org/10.1016/j.envdev . 2013. 03.006.

Zepf, Volker (2013). Rare Earth Elements A New Approach tto the Nexus of Supply, Demand, and Use of Neodymium in Permenant Magnets. Springer, p. 30. ISBN: 978-3-642-35457-1. DOI: 10 . $1007 / 978-3-642-35458-8$. arXiv: arXiv: 1106 . 3562. URL: http: // link . springer . com/10.1007/978-3-642-35458-8. 
Zhai, Xue (2019). "Unpublished Leaching Exploratory Tests". PhD Dissertation. West Virginia University.

Zhang, Qiang et al. (2009). "Corrosion behavior of Hastelloy C-276 in supercritical water". In: Corrosion Science 51.9, pp. 2092-2097. ISSN: 0010938X. DOI: 10 . 1016 / j . corsci . 2009.05.041. URL: http://dx.doi.org/10.1016/j.corsci .2009.05.041.

Zhang, Zhenyue et al. (2016). "Novel solution injection technology for in-situ leaching of weathered crust elution-deposited rare earth ores". In: Hydrometallurgy 164, pp. 248-256. ISSN: 0304386X. DOI: $10.1016 / \mathrm{j}$.hydromet .2016.06.015.

Zhu, Zhaowu, Yoko Pranolo, and Chu Yong Cheng (2015). "Separation of uranium and thorium from rare earths for rare earth production - A review". In: Minerals Engineering 77, pp. 185-196. ISSN: 08926875. DOI: 10.1016/j .mineng. 2015 .03.012. URL: http : //dx.doi.org/10.1016/j.mineng.2015.03.012.

Ziemkiewicz, P F (1998). "Steel Slag : Applications for AMD Control". In: Proceedings of the 1998 Confrence on Hazardous Waste Research. 304, pp. 44-62. URL: https://www . engg . ksu . edu/HSRC/98Proceed/5Ziemkiewicz/5ziemkiewicz.pdf.

Ziemkiewicz, P.F. et al. (2016). "Recovery of rare earth elements (REEs) from coal mine drainage". In: West Virginia Mine Drainage Task Force Symposium. Morgantown, WV. 


\section{Appendix A}

Appendix A

Bench-Scale Plant Flowsheets 


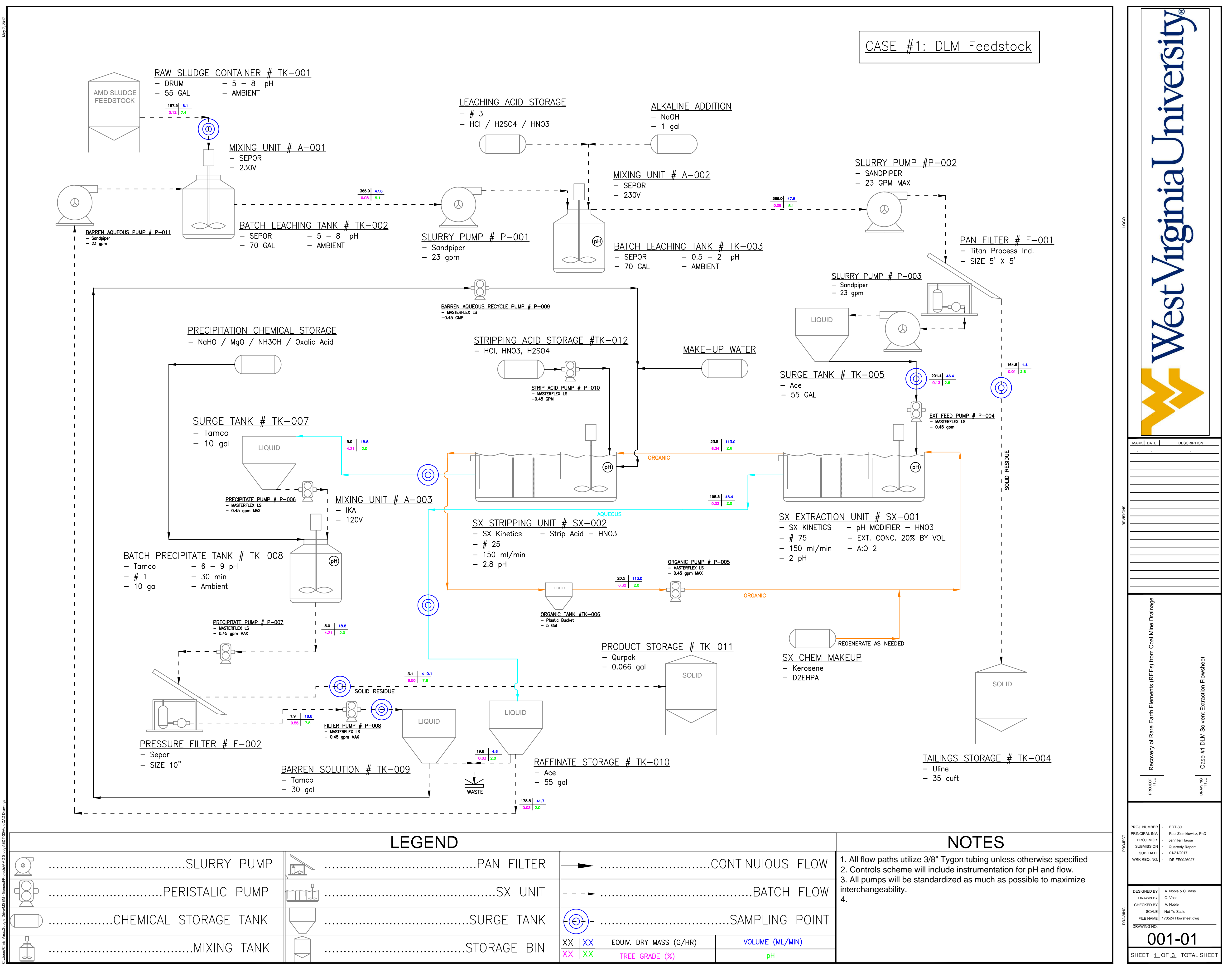




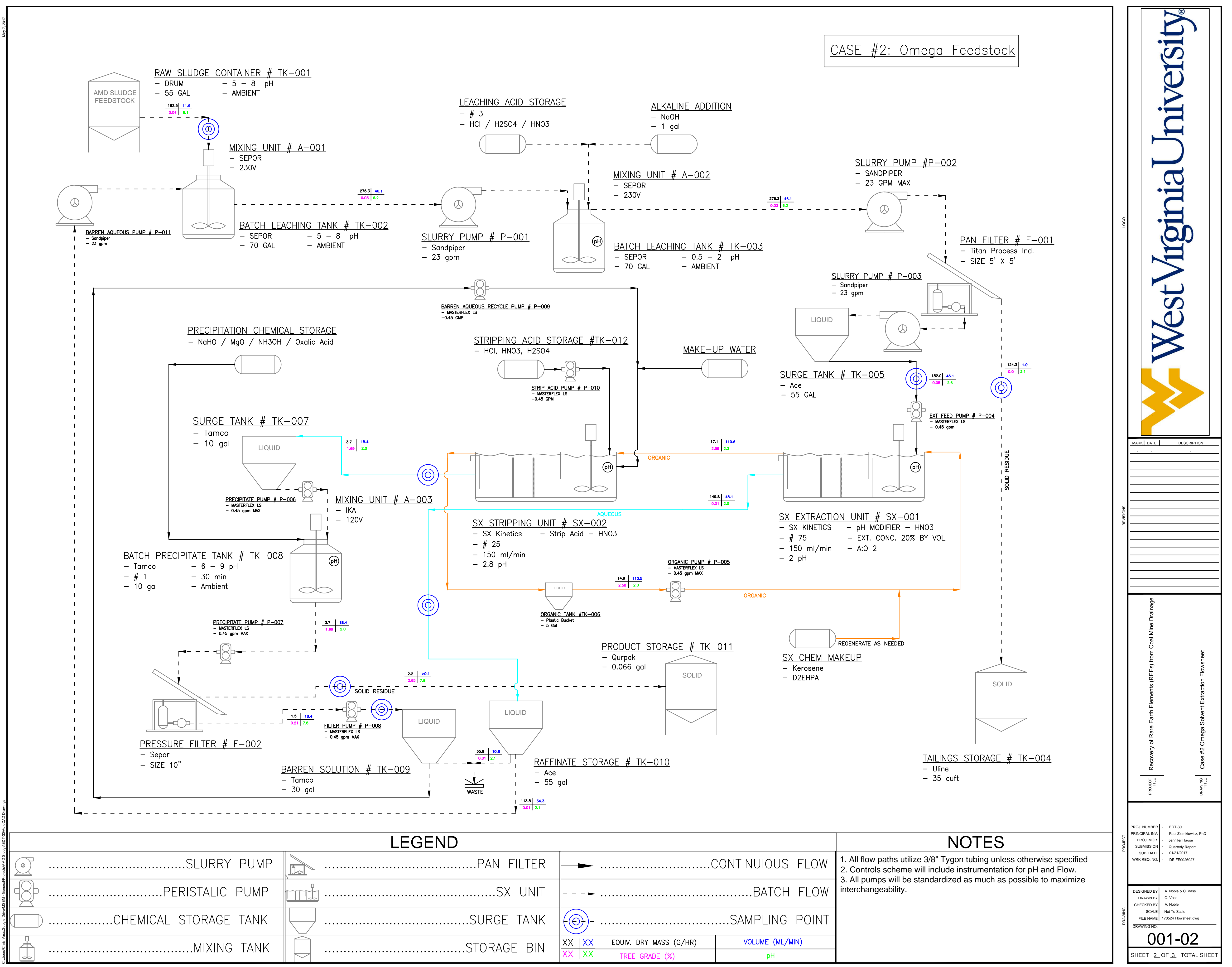




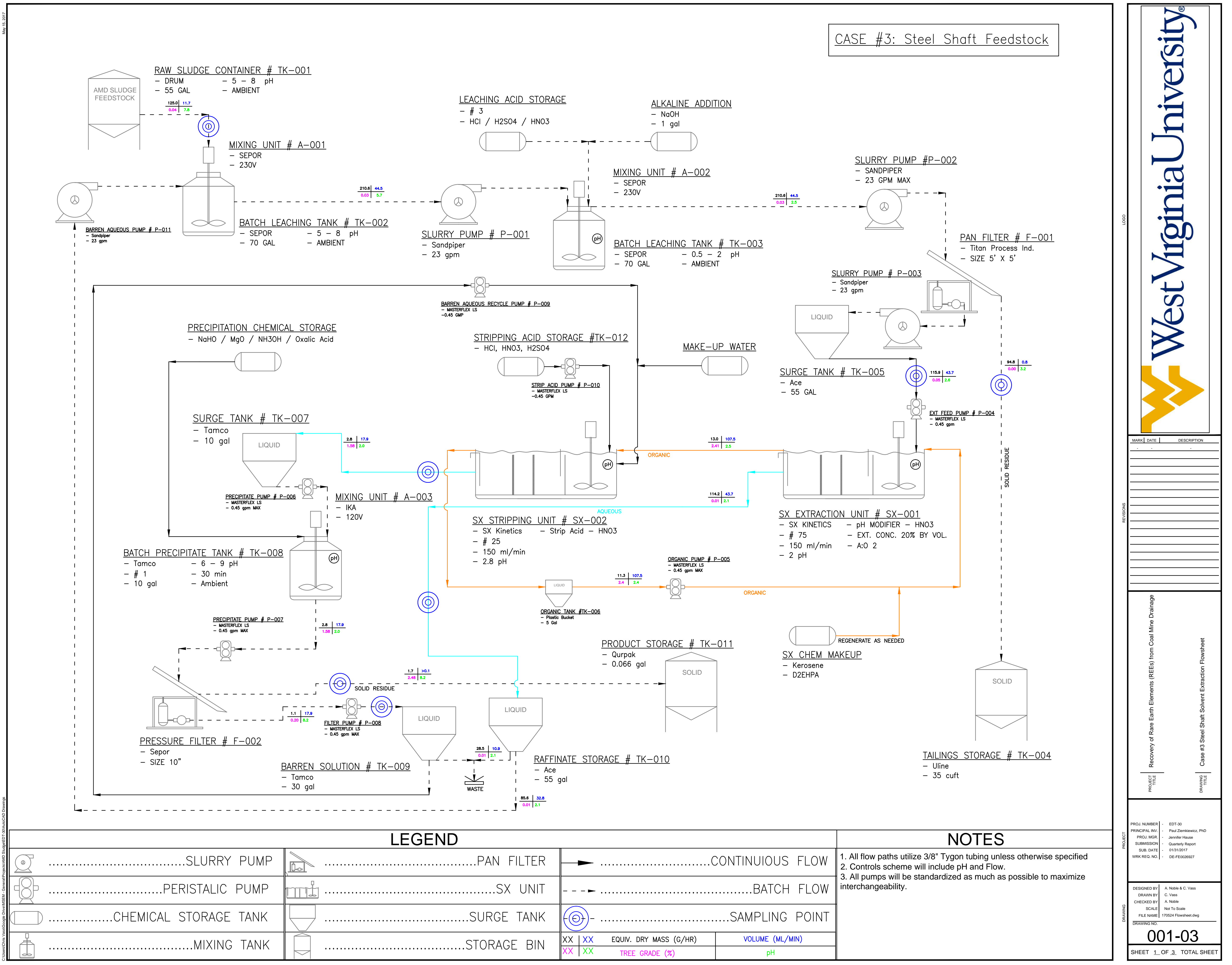




\section{Appendix B}

Appendix B

P\&ID Drawings 
EQUIPMENT INFORMATION

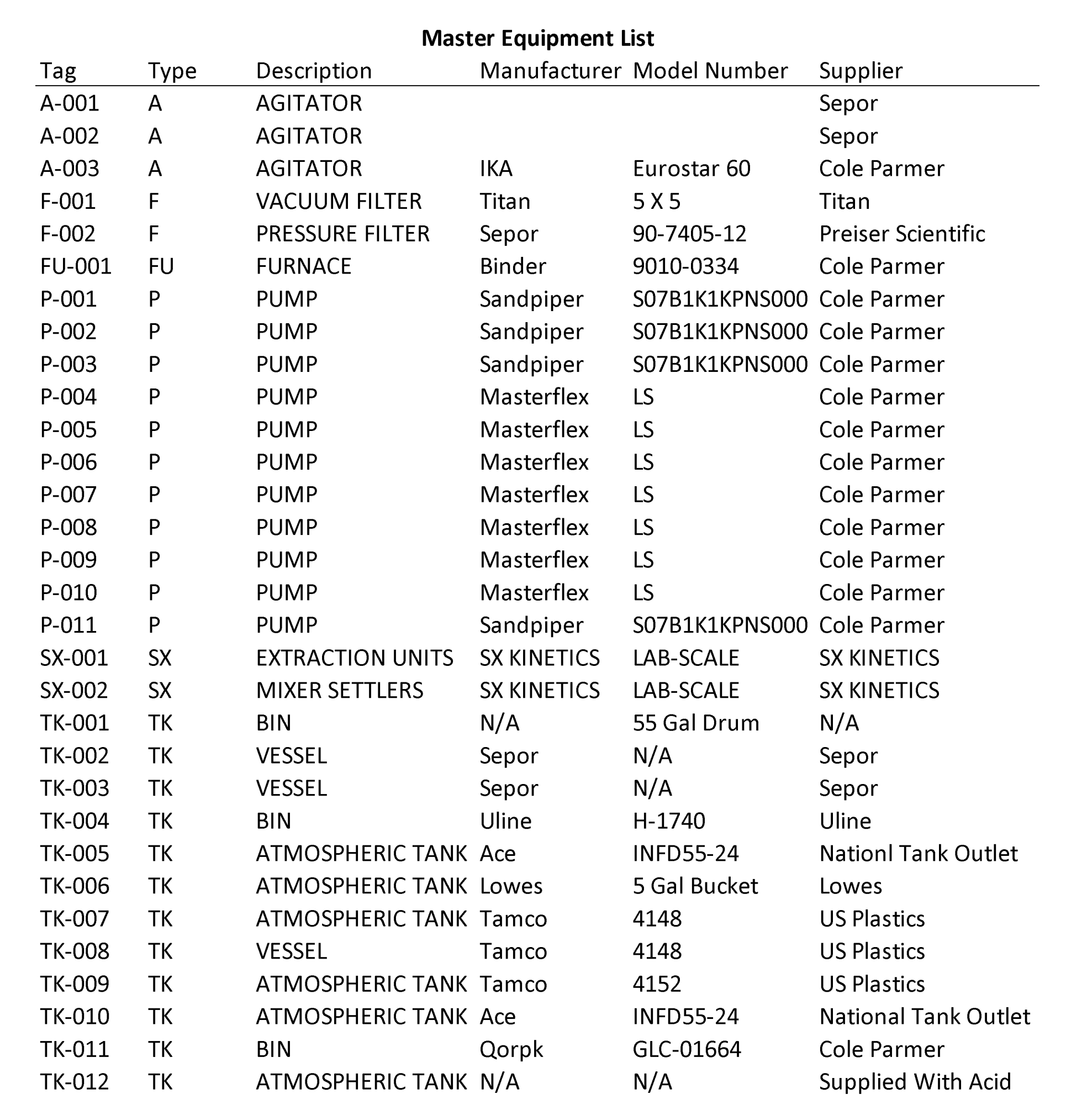

\section{EQUIPMENT SYMBOL LEGEND}

SOLIDS STORAGE BIN

LIQUID STORAGE TANK

AGITATED MIXING VESSEL

VACUUM FILTER

PUMP

DRYING OVEN

SX MIXER/SETTLER UNITS

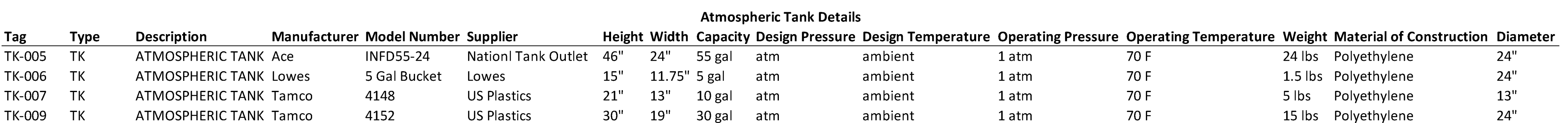

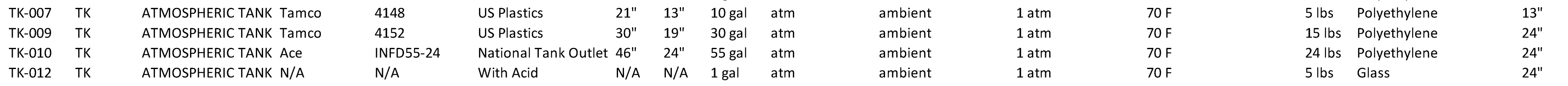

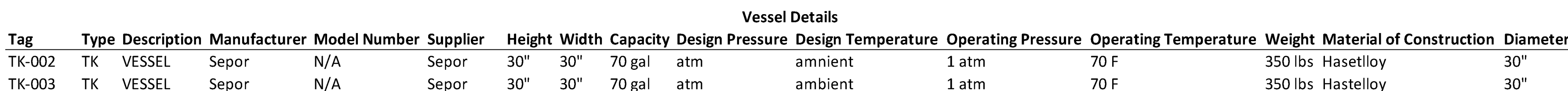

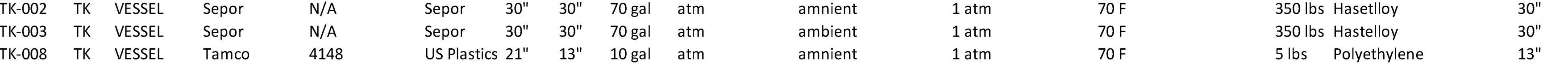

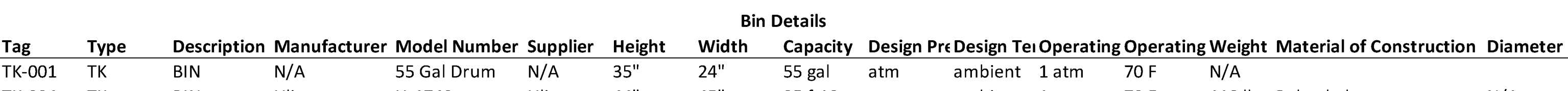

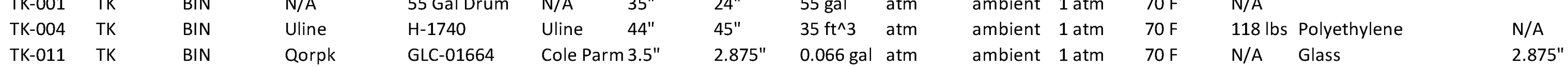

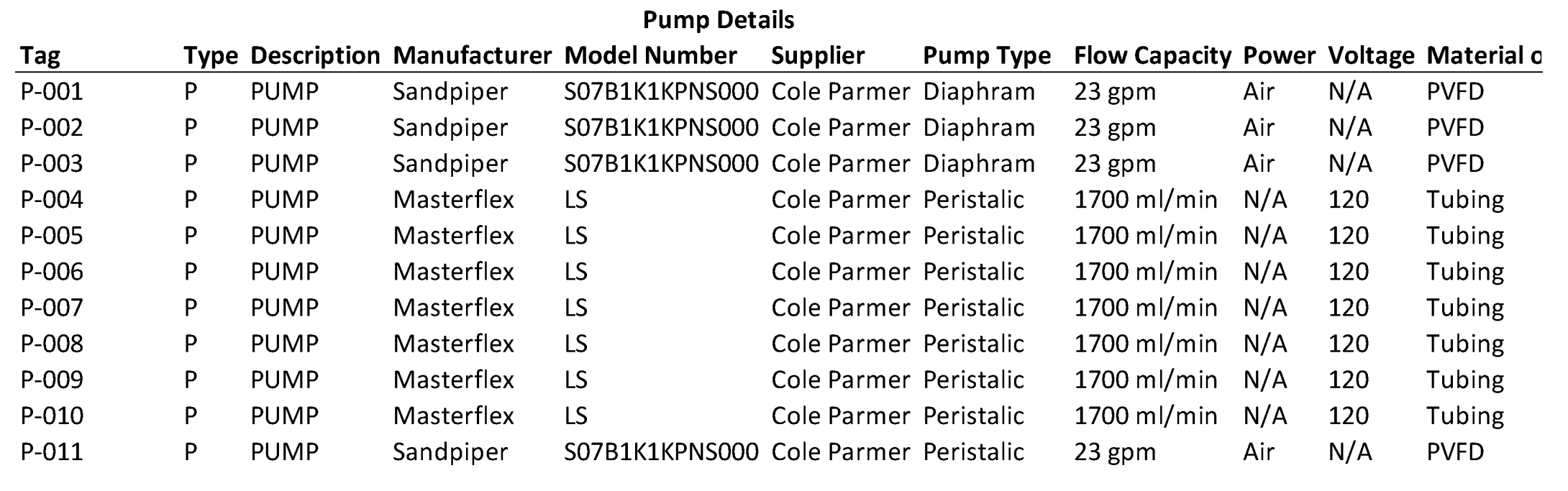

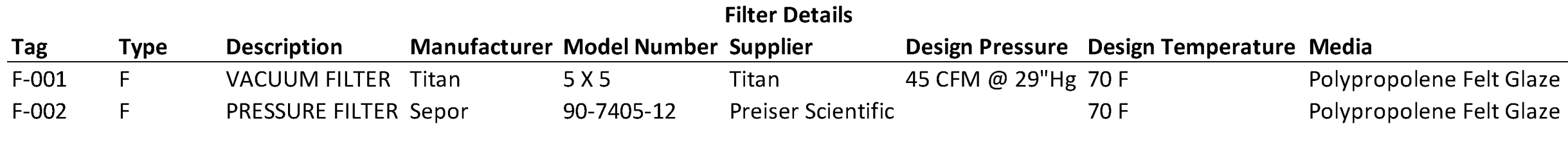

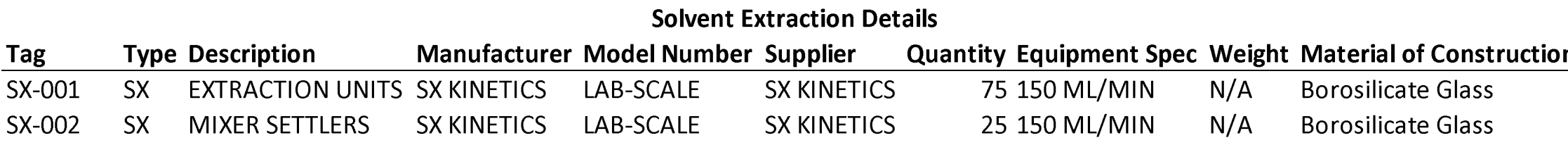

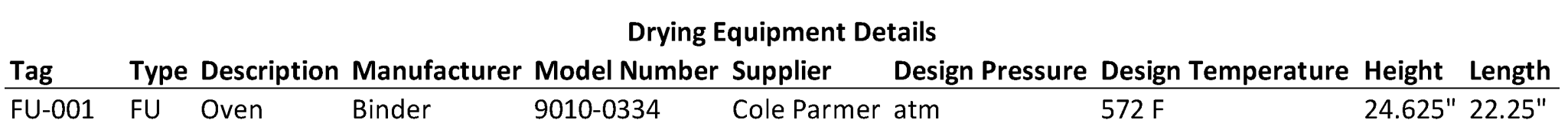

\section{INSTRUMENT SYMBOL LEGEND}

\section{PROCESS LINE LEGEND}

III TEMPERATURE INDICATOR

PH $P H$ MONITORING

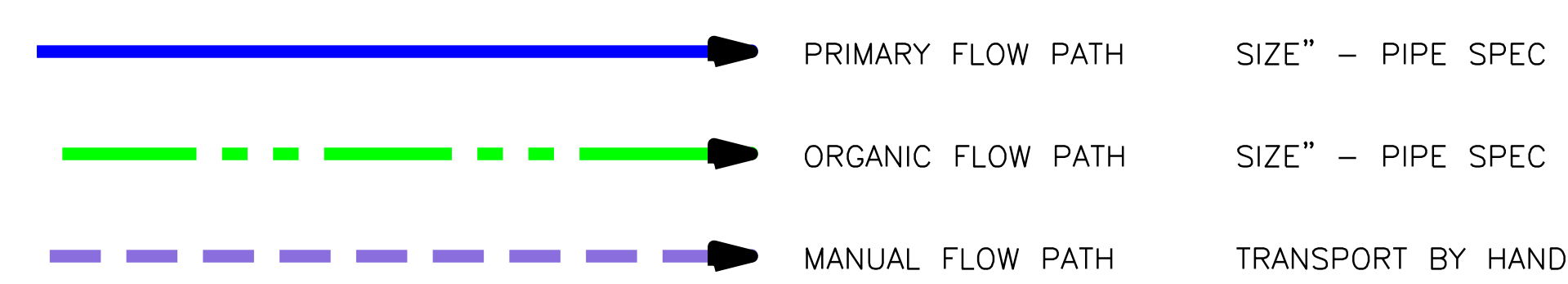

$\underset{\text { HA-120 }}{\bowtie} \quad$ VALVE

$\underset{H A-121}{\searrow} 3$ WAY SAMPLING VALVE

(scs ${ }^{55 / 109}$ SOLIDS SAMPLING LOCATION

હsc AQ/10mI AQUEOUS SAMPLING LOCATION

WLOW METER 


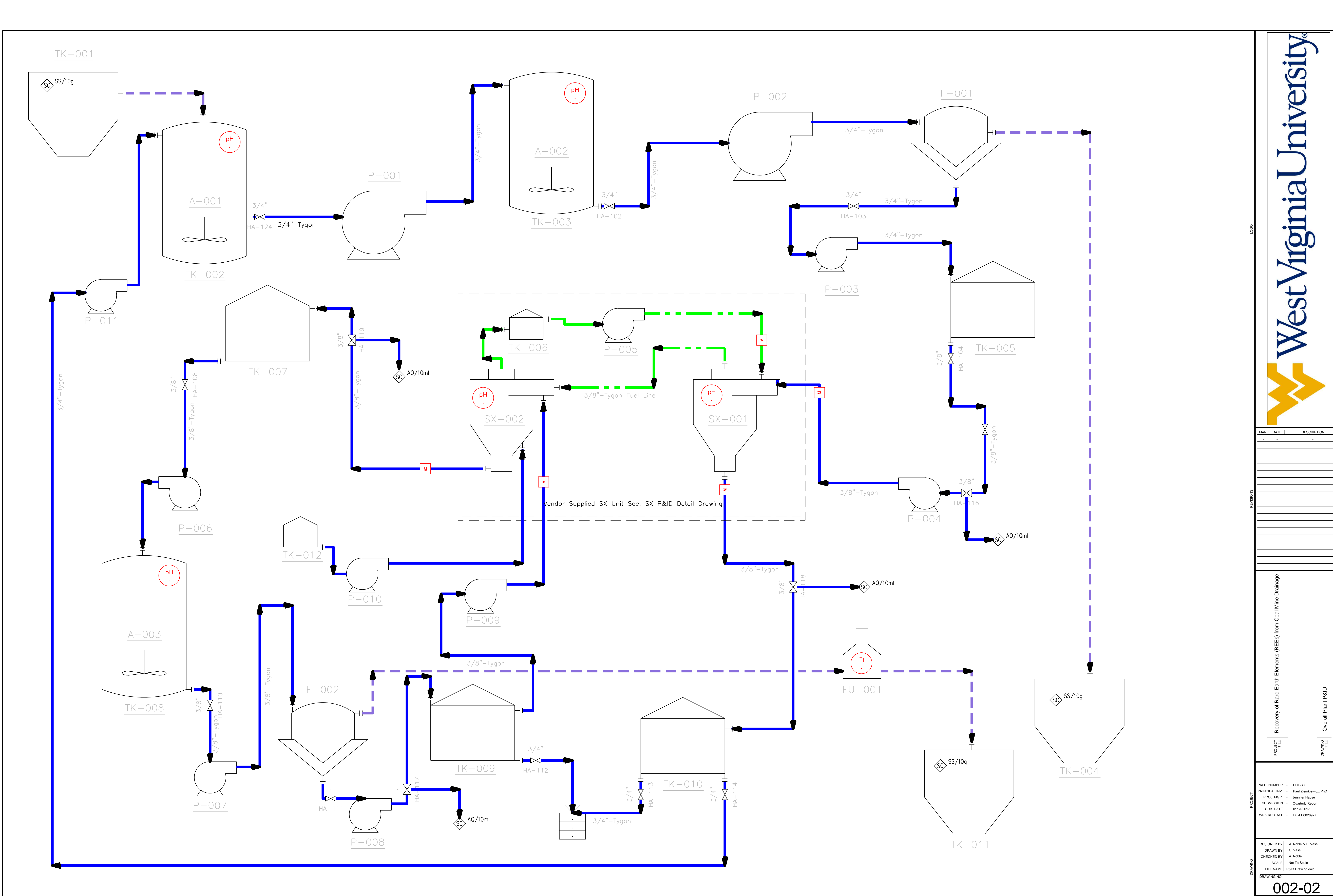




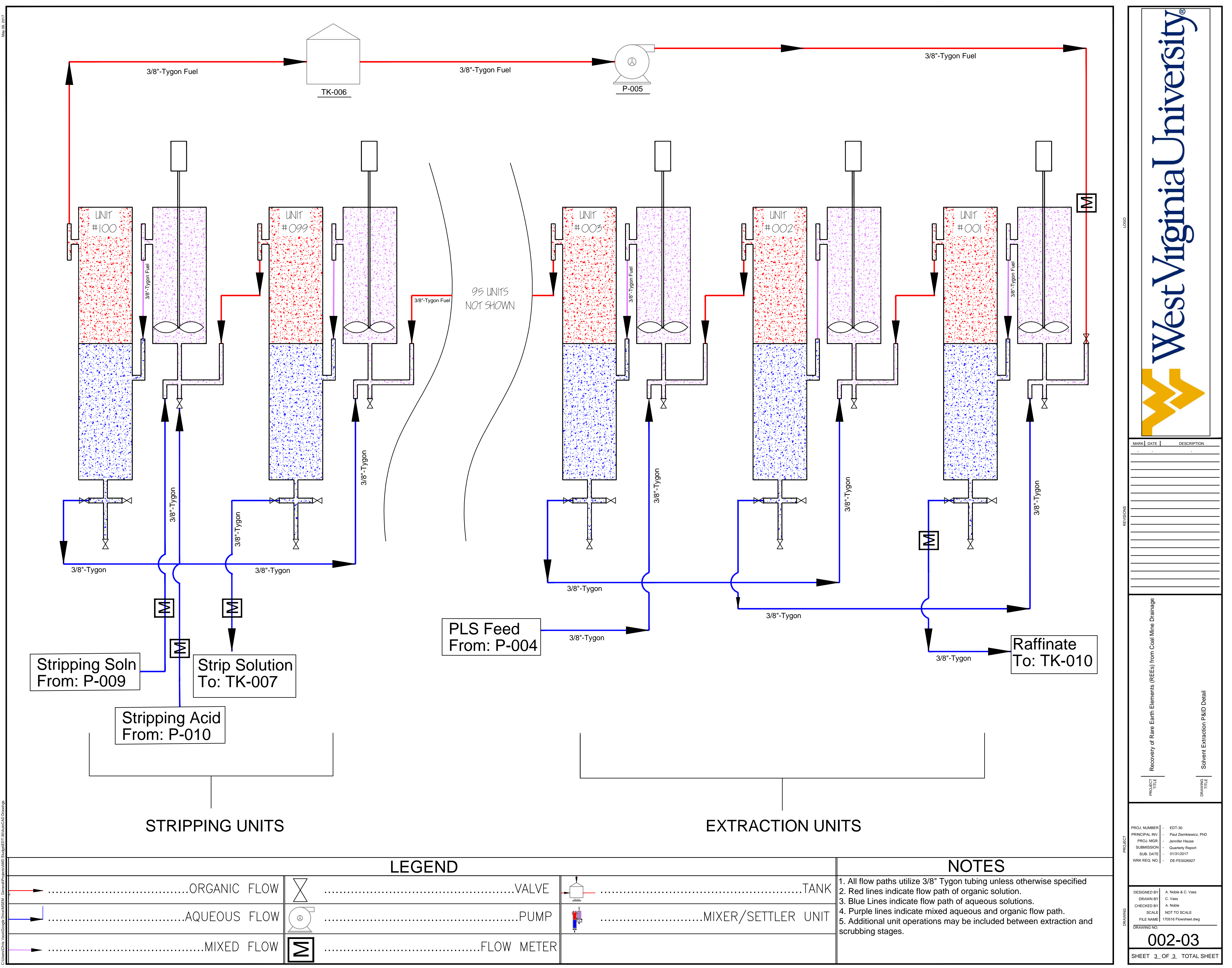




\section{Appendix $\mathrm{C}$}

Appendix C

Solvent Extraction Bench-Scale Plant Layout 


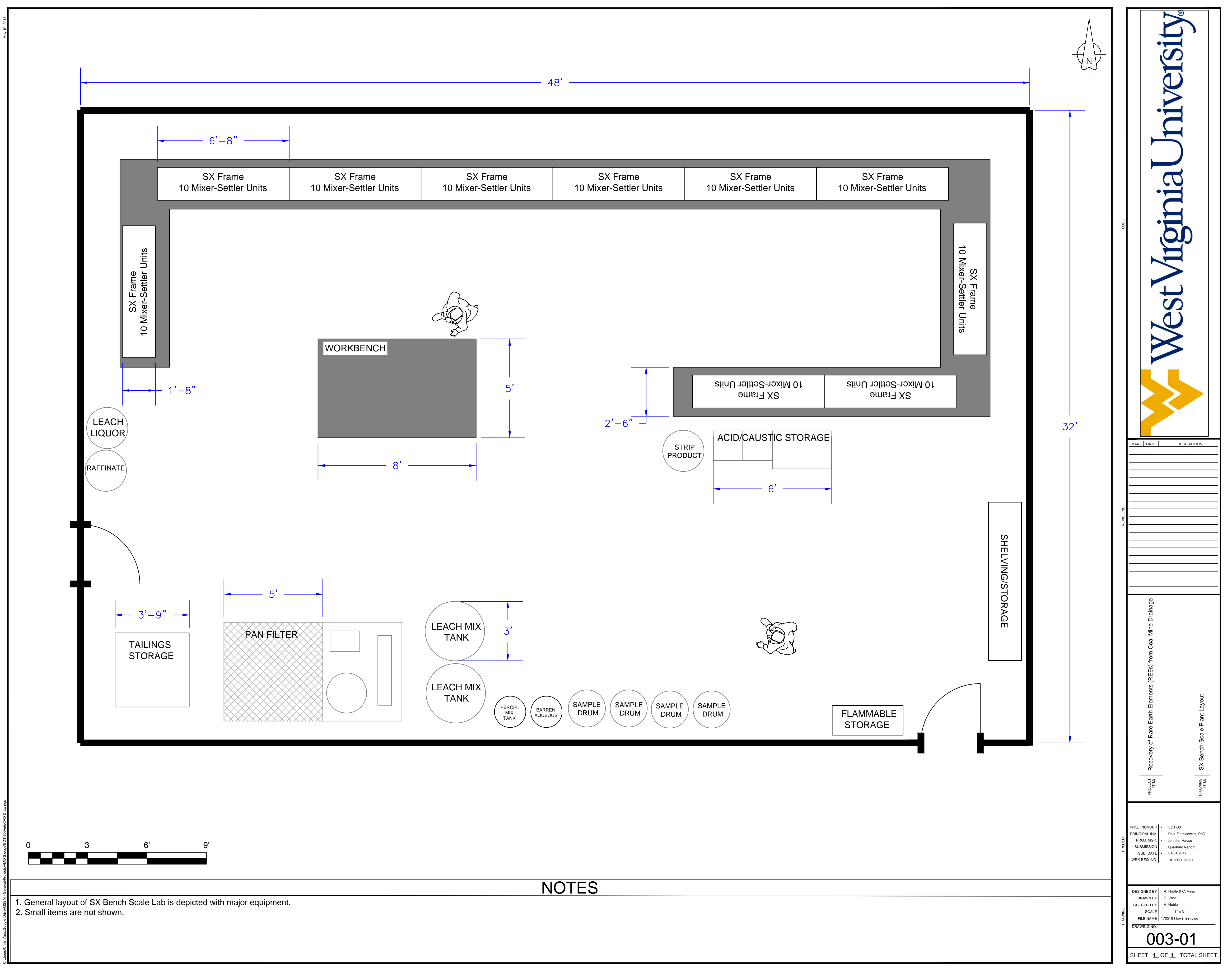

